\title{
Perfluoroalkyl Compounds in Gull Species From Across the Canadian Environment: Tissue Distribution, Maternal Transfer, Sources, and Spatial and Temporal Trends
}

by

Wouter A. Gebbink

A thesis submitted to the Faculty of Graduate and Postdoctoral Affairs in partial fulfillment of the requirements for the degree of

Doctor of Philosophy

in

Chemistry with Specialization in Chemical and Environmental Toxicology

Carleton University
Ottawa, Ontario

(C) 2011, Wouter A. Gebbink 
Library and Archives

Canada

Published Heritage

Branch

395 Wellington Street

Ottawa ON K1A ON4

Canada
Bibliothèque et

Archives Canada

Direction du

Patrimoine de l'édition

395 , rue Wellington

Ottawa ON K1A ON4

Canada
Your file Votre référence

ISBN: 978-0-494-83246-2

Our file Notre référence

ISBN: 978-0-494-83246-2
NOTICE:

The author has granted a nonexclusive license allowing Library and Archives Canada to reproduce, publish, archive, preserve, conserve, communicate to the public by telecommunication or on the Internet, loan, distribute and sell theses worldwide, for commercial or noncommercial purposes, in microform, paper, electronic and/or any other formats.

The author retains copyright ownership and moral rights in this thesis. Neither the thesis nor substantial extracts from it may be printed or otherwise reproduced without the author's permission.
AVIS:

L'auteur a accordé une licence non exclusive permettant à la Bibliothèque et Archives Canada de reproduire, publier, archiver, sauvegarder, conserver, transmettre au public par télécommunication ou par l'Internet, prêter, distribuer et vendre des thèses partout dans le monde, à des fins commerciales ou autres, sur support microforme, papier, électronique et/ou autres formats.

L'auteur conserve la propriété du droit d'auteur et des droits moraux qui protège cette thèse. $\mathrm{Ni}$ la thèse ni des extraits substantiels de celle-ci ne doivent être imprimés ou autrement reproduits sans son autorisation.
In compliance with the Canadian Privacy Act some supporting forms may have been removed from this thesis.

While these forms may be included in the document page count, their removal does not represent any loss of content from the thesis.
Conformément à la loi canadienne sur la protection de la vie privée, quelques formulaires secondaires ont été enlevés de cette thèse.

Bien que ces formulaires aient inclus dans la pagination, il n'y aura aucun contenu manquant.

\section{Canadä}




\section{Abstract}

In this thesis, gull eggs collected from colonies throughout Canada were used to characterize and monitor for perfluoroalkyl compounds (PFCs). The tissue distribution and maternal transfer of PFCs in herring gulls was investigated and using herring gull eggs, spatial and temporal trends of PFCs (including PFOS isomers) were determined among 15 colonies in the Great Lakes. A Pan-Canadian spatial trend of PFCs was determined in glaucous-winged, California, herring and ring-billed gull eggs from 15 colonies spanning Pacific to Atlantic Canada, and sources of exposure to the gulls were investigated. Based on tissue, blood and egg analysis, gulls in Canada were exposed to perfluorosulfonates (PFHxS, PFOS, and PFDS), perfluorocarboxylates $\left(\mathrm{C}_{6}-\mathrm{C}_{15}\right)$ and PFOSA, while FTOHs and FTUCAs were below detection limit. Of all the detected PFCs, PFOS dominated the PFC egg pattern and was comprised of linear and branched isomers. However, the PFOS isomer pattern was highly enriched with L-PFOS compared to T-PFOS. Within the female herring gulls, adipose tissue and brain contained the highest $\sum$ PFSA and $\sum$ PFCA concentrations, respectively. During breeding season, the female gulls were able to transfer a considerable amount of their body burden to the eggs. Although there was a $\mathrm{C}_{6}$ to $\mathrm{C}_{15}$ PFCA chain length dependent distribution among tissues and blood, the combined tissue and blood PFCA pattern reflected the egg PFCA pattern. Therefore, gull eggs are an ideal matrix for environmental PFC monitoring purposes. In both the Great Lakes and Pan-Canadian spatial trend studies of PFCs, eggs that were collected from colonies near urbanized and/or industrialized areas were more contaminated with PFSAs and PFCAs compared to colonies that were located in less urbanized areas. Overall, colonies located in freshwater ecosystems were generally more 
contaminated with PFSAs and PFCAs compared to the colonies located in marine ecosystems. Between 1990 and 2010, ¿PFSA concentrations in gull eggs generally declined at most Great Lakes colonies with the exception of Toronto Harbour, while ¿PFCA concentrations generally increased during this time period. Based on dietary tracers (nitrogen and carbon stable isotopes), gulls throughout Canada were exposed to PFCs via aquatic (marine and freshwater) and terrestrial prey, however, exposure scenarios are colony-specific. 


\section{List of Publications associated with Thesis}

\section{Refereed Journal Publications}

Gebbink, W.A., Letcher, R.J, Hebert, C.E., Weseloh, D.V.C. 2011. Temporal changes over twenty years of perfluoroalkyl sulfonates and carboxylates in herring gull eggs from sites across the Laurentian Great Lakes. J. Environ. Monit. Accepted, Sept 14, 2011 (Chapter 6)

Gebbink, W.A. and Letcher, R.J. 2011. Compartmental accumulation and maternal transfer to eggs of perfluoroalkyl sulfonates and carboxylates in Great Lakes herring gulls. Environ. Pollut. Accepted, Sept 19, 2011 (Chapter 3)

Gebbink, W.A., Letcher, R.J, Burgess, N., Champoux, L., Elliot, J.E., Hebert, C.E., Martin, P., Wayland, M., Weseloh, D.V.C., Wilson, L. 2011. Perfluoroalkyl carboxylates and sulfonates and precursors in relation to dietary source tracers in the eggs of four species of gulls (Larids) from breeding sites spanning Atlantic to Pacific Canada. Environ. Int. 37, 1175-1182 (Chapter 7)

Gebbink, W.A. and Letcher, R.J. 2010. Linear and branched perfluorooctane sulfonate isomer patterns in herring gull eggs from colonial sites across the Laurentian Great Lakes. Environ. Sci Technol. 44, 3739-3745. (Chapter 5)

Gebbink, W.A., Hebert, C.E., Letcher, R.J. 2009. Perfluorinated carboxylates and sulfonates and precursor compounds in herring gull eggs from colonies spanning the Laurentian Great Lakes of North America. Environ. Sci Technol. 43, 7443-7449. (Chapter 4)

\section{Refereed Conference Abstracts and Presentations.}

Platform: Gebbink, W.A., Letcher, R.J., Hebert, C.E., Weseloh, D.V.C. Temporal changes over twenty years of perfluoroalkyl sulfonates and carboxylates in herring gull eggs from sites across the Laurentian Great Lakes. $32^{\text {nd }}$ SETAC North America Congress, November 13-17, 2011, Boston, Massachusetts.

Platform: Gebbink, W.A. and Letcher, R.J. Body compartment accumulation and burden and transfer to eggs of perfluoroalkyl sulfonates and carboxylates in herring gulls as an avian model. $31^{\text {st }}$ International Symposium on Halogenated Environmental Pollutants and POPs (DIOXIN'2011), Aug. 21-25 2011, Brussels, Belgium.

Poster: Gebbink, W.A. and Letcher, R.J. Body compartment accumulation and burden and transfer to eggs of perfluoroalkyl sulfonates and carboxylates in herring gulls as an avian model. OCCI Day, May 27, 2011, University of Ottawa, Ottawa, ON, Canada. 
Platform: Gebbink, W.A. and Letcher, R.J. Linear and branched PFOS isomers in herring gull eggs from colonies across the Laurentian Great Lakes. $20^{\text {th }}$ Annual Meeting of SETAC-Europe, May 23-27, 2010, Seville, Spain.

Platform: Gebbink, W.A., Hebert, C.E., Weseloh, D.V.C. and Letcher, R.J. Spatial trends of perfluorinated carboxylates and sulfonates and precursor compounds in eggs of colonial herring gulls and the influence of dietary and food web sources. $53^{\text {rd }}$ Annual Conference on Great Lakes Research, IAGLR, May 17-21, 2010, Toronto, ON, Canada.

Platform: Gebbink, W.A., Hebert, C.E. and Letcher, R.J. Perfluorinated carboxylates and sulfonates and precursor compounds in herring gull eggs from colonies spanning the Laurentian Great Lakes of North America. 30 ${ }^{\text {th }}$ SETAC North America Congress, November 19-23, 2009, New Orleans, Louisiana.

Poster: Gebbink, W.A., Burgess, N., Champoux, L., Elliot, J.E., Hebert, C.E., Martin, P., Wayland, M., Weseloh, D.V.C., Wilson, L and Letcher, R.J. Perfluoroalkyl compounds in the eggs of four species of gulls (Larids) from breeding sites spanning Atlantic to Pacific Canada. $30^{\text {th }}$ SETAC North America Congress, November 19-23, 2009, New Orleans, Louisiana.

Platform: Gebbink, W.A., Hebert, C.E. and Letcher, R.J. Spatial distribution of bioaccumulative polyfluoroalkyl compounds in herring gull eggs from the Laurentian Great Lakes of North America. $5^{\text {th }}$ SETAC World Congress, August 3-7, 2008, Sydney, Australia.

Poster: Gebbink, W.A., Hebert, C.E. and Letcher, R.J. Recent temporal changes in polyfluoroalkyl contaminants in herring gull eggs from colonial populations in the Laurentian Great Lakes of North America. $5^{\text {th }}$ SETAC World Congress, August 3-7, 2008, Sydney, Australia.

Poster: Gebbink, W.A., Hebert, C.E. and Letcher, R.J. Recent temporal changes in polyfluoroalkyl contaminants in herring gull eggs from colonial populations in the Laurentian Great Lakes of North America. OCCI Day, May 2008, University of Ottawa, Ottawa, ON, Canada

Poster: Gebbink, W.A., Hebert, C.E. and Letcher, R.J. Identification and spatial/temporal trends of polyfluoroalkyl compounds (PFCs) in herring gull eggs from the Great Lakes. Varian Day, April 17, 2008, Carleton University, Ottawa, ON, Canada. 


\section{Acknowledgements}

This thesis would not have been made possible without the help, expertise and involvement of many people. First of all, I would like to thank my supervisor, Robert Letcher. He gave me the opportunity to to do a PhD and fully supported me. During the last four years, Rob`s door was always open and I could count on positive feedback and encouragements. Second, I would like to acknowledge all the contributors who were involved in the separate studies of this thesis: Craig Hebert, Neil Burgess, Louise Champoux, John Elliott, Pamela Martin, Mark Wayland, Chip Weseloh, and Laurie Wilson.

I would like to thank all the people who were involved in the (herring) gull egg collections throughout the past years, and Rob, Craig, Doug Crump, and Kim Williams for collecting the herring gull tissue samples. Guy Savard, Christine McClelland, Lisa Hermsen, and Caroline Robert at the NWRC Specimen bank are thanked for processing all the samples. I would like to thank Chip, Craig, Doug, and Kim for some awesome field work experiences, the helicopter fight over the Niagara Falls and almost being lost in thick fog on Lake Huron are definitely trips to remember.

A big thanks to Shaogang Chu for always being able to fix the LC-MS when it was on the verge of dying. Thanks to the University of Waterloo Environmental Isotopes Laboratory for the egg stable isotope analysis. I thank Glen Fox and Craig Hebert for providing comments on the tissue distribution and maternal transfer chapter.

I would like to thank all the present and past people in the lab group (Lewis, Eric, Melissa, Da, Alana, Shoagang, Luke, Lisa, and Francisco) and many more people at 
NWRC for a great atmosphere and many, many laughs. The lab activities, hockey, and April fools will definitely be missed. Finally, I would like to thank my parents for all their support over the last years.

This study was funded by the Chemicals Management Plan (CMP, Environment Canada) (R. Letcher), Natural Science and Engineering Research Council (NSERC) (R. Letcher), the Ecotoxicology and Wildlife Heath Division (Environment Canada), and Ontario Graduate Scholarship (OGS) (W. Gebbink). 


\section{Table of Contents}

Abstract...................................................................... ii

List of Publications Associated with Thesis................................. iv

Acknowledgements....................................................... vi

List of Tables................................................................ xi

List of Figures.......................................................... xiii

List of Appendices...................................................... xvii

List of Abbreviations.................................................. xviii

Chapter 1: General Introduction........................................... 1

1.1 General Introduction to PFCs........................................ 1

1.2 PFC Production....................................................... 1

1.3 Degradation of Precursors to PFOS and PFCAs........................ 3

1.4 PFCs in Wildlife................................................... 6

1.4 .1 PFC Patterns..................................................... 6

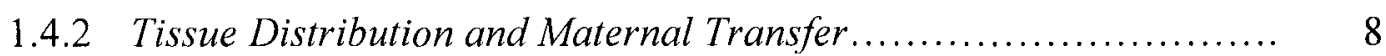

1.4 .3 Foodweb Accumulation............................................. 9

1.4.4 Spatial and Temporal Trends................................. 10

1.4 .5 Avian Toxicity of PFCs ............................................. 12

1.5 Great Lakes Herring Gull Monitoring Program........................... 13

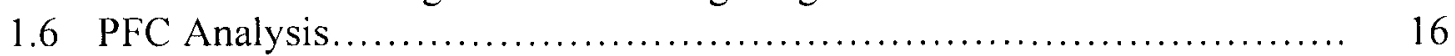

1.6.1 Electrospray Ionization...................................... 16

1.6.2 Atmospheric Pressure Photoionization........................... 17

1.6.3 Triple-Quadrupole Mass Spectrometry.......................... 17

1.7 Thesis Objectives................................................ 18

Chapter 2: Materials and Methods......................................... 23

2.1 Sample Details................................................. 23

2.1.1 Tissue Distribution and Maternal Transfer.................................... 23

2.1.2 Great Lakes Spatial Trend PFCs including PFOS Isomers............ 24

2.1.3 Great Lakes Temporal Trend PFCs................................ 24

2.1.4 Pan-Canadian Spatial Trend PFCs............................... 25

2.2 Contaminant Analysis.................................................. 25

2.2 .1 Standards and Chemicals........................................ 25

2.2.2 Extraction and Clean up........................................ 30

2.2.2.1 PFSAs, PFCAs, FOSAs, FTOHs, FTUCAs.................. 30

2.2.2.2 PFOS Isomers............................................ 31

2.2 .3 Measurements................................................. 31

2.2.3.1 LC-MSMS (PFSAs, PFCAs, FOSAs, FTOHs, FTUCAs)......... 31

2.2.3.2 GC-MS (PFOS Isomers) .............................. 32

2.2.4 Quality Control............................................... 36 
$2.3 \quad$ Stable Isotope Analysis................................................. 37

2.3.1 Extraction ....................................................... 37

2.3.2 Measurements.............................................. 38

2.4 Total Burden Estimates of Perfluorinated Compounds in Herring Gull Tissues and Eggs....................................................... $\quad 40$

2.5 Data Analysis..................................................... 41

2.5.1 Tissue Distribution and Maternal Transfer........................ 41

2.5.2 Great Lakes Spatial Trend PFCS.................................. 42

2.5.3 Great Lakes Spatial Trend PFOS Isomers....................... 42

2.5.4 Great Lakes Temporal Trend PFCs................................. 43

2.5.5 Pan-Canadian Spatial Trend PFCs............................... 44

Chapter 3: Compartmental Accumulation and Maternal Transfer to Eggs of Perfluoroalkyl Sulfonates and Carboxylates in Great Lakes Herring Gulls.... 45

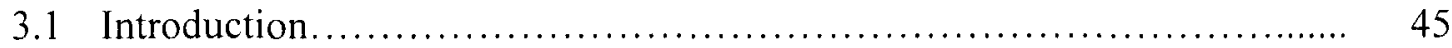

3.2 Results and Discussion........................................... 46

3.2.1 Body Compartment-Specific PFSA and PFCA Patterns and Concentrations.................................................. 46

3.2.2 Tissue Distribution Based on Concentrations and Burdens........... $\quad 52$

3.2.3 Maternal Transfer of PFCAs and PFSAs to Eggs..................... 58

Chapter 4: Perfluorinated Carboxylates and Sulfonates and Precursor Compounds in Herring Gull Eggs from Colonies Spanning the Laurentian Great Lakes of North America.................................................

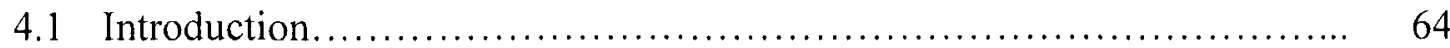

4.2 Results and Discussion........................................... 65

4.2.1 PFSAs and Spatial Distribution.................................... 65

4.2.2 PFOSA in Relation to PFOS...................................... $\quad 70$

4.2.3 PFCAs and Spatial Distribution.................................... $\quad 74$

4.2.4 LPFSA versus IPFCA Accumulation................................ 79

4.2.5 Sources of PFC Exposure in Herring Gulls ......................... 82

Chapter 5: Linear and Branched Perfluorooctane Sulfonate Isomer Patterns in Herring Gull Eggs from Colonial Sites Across the Laurentian Great Lakes.

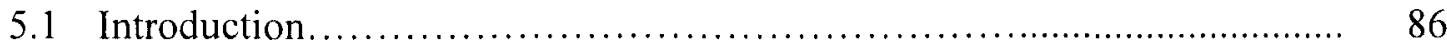

5.2 Results \& Discussion.................................................. 87

5.2.1 Identification of PFOS Isomers in Herring Gulls........................... 87

5.2.2 $\sum$ PFOS Concentrations and Trends.................................... $\quad 89$

5.2.3 Spatial Patterns and Sources of PFOS Isomers........................ 93 
Chapter 6: Twenty Years of Temporal Changes in Perfluoroalkyl Sulfonates and Carboxylates in Herring Gull Eggs from the Laurentian Great Lakes......... 106

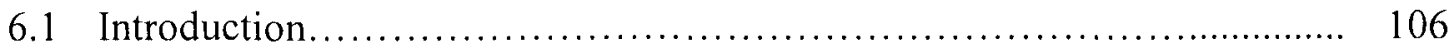

6.2 Results \& Discussion...................................................... 108

6.2.1 Perfluorinated Carboxylate and Sulfonate and Precursor Profiles and Concentrations.......................................................... 108

6.2.2 Temporal Trend of Perfluorinated Sulfonates............................ 111

6.2.3 Temporal Trends of Perfluorinated Carboxylates......................... 117

6.2.4 Dietary Sources of Perfluoroalkyl Acids to Herring Gulls................ 120

Chapter 7: Perfluoroalkyl Carboxylates and Sulfonates and Precursors in Relation to Dietary Source Tracers in the Eggs of Four Species of Gulls (Larids) from Breeding Sites Spanning Atlantic to Pacific Canada.................... 124

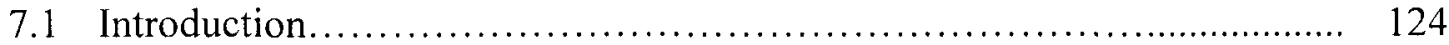

7.2 Results and Discussion............................................... 126

7.2.1 Stable Isotope Dietary Tracers Among Gulls and Regions............ 126

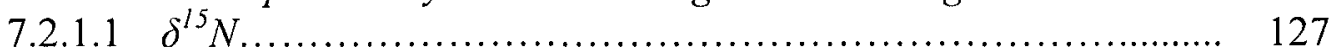

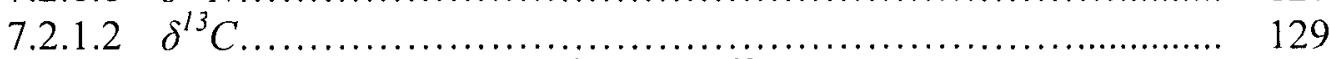

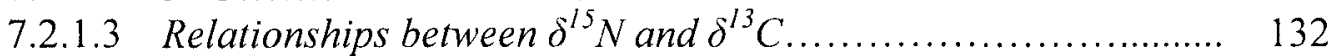

7.2.2 PFCs and Precursors in Gull Eggs.................................. 134

7.2.3 Geographical Distribution of PFSAs and PFCAs................. 141

7.2.4 Stable Isotopes as Dietary Tracers for PFC Exposure................ 144

Chapter 8: Conclusions, Implications and Future Directions................. 148

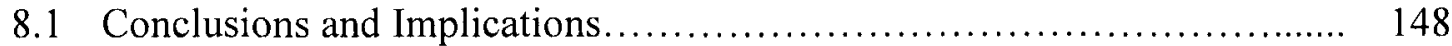

8.2 Future Directions....................................................... 153

References.............................................................. 155 


\section{List of Tables}

Table 2.1 Locations of gull colonies across Canada and gull species of the 2008 egg collection $(\mathrm{n}=10)$

Table 2.2 Chemical names and structures of PFSAs, FOSAs, PFCAs, FTUCAs, and FTOHs and internal standards used

Table 2.3 Chemical names and GC-MS (ECNI) monitoring ions of derivatized PFOS isomers

Table 2.4 Mobile phase gradient for separation of FOSAs, FTOHs (Fraction 1) and PFSAs, PFCAs, and FTUCAs (Fraction 2).

Table 2.5 Source operation parameters and analyzer operation parameters for FTOHs, FOSAs (Fraction 1) and PFSAs, PFCAs and FTUCAs (Fraction 2)

Table 2.6 Transitions and compound dependant operation parameters for FTOHs, FOSAs, PFSAs, PFCAs and FTUCAs determination by LC/MS/MS 35

Table 3.1 Arithmetic mean percentage ( \pm SE) of detectable perfluorosulfonates (PFSAs) and carboxylates (PFCAs) relative to the arithmetic mean $\sum$ PFSA and $\sum$ PFCA concentrations $( \pm \mathrm{SE} \mathrm{ng/g} \mathrm{ww})$, respectively, in female herring gull eggs and tissues collected in 2010 from Chantry Island, Lake Huron.

Table 4.1 Arithmetic mean concentrations of $\Sigma$ PFSA and $\Sigma$ PFCA (ng/g wet weight) in individual herring gull eggs collected from 15 colonies in the Great Lakes in $2007(n=13$ per colony)

Table 4.2 Arithmetic mean concentrations of PFOSA (ng/g wet weight) and PFOS/PFOSA ratio in individual herring gull eggs collected from 15 colonies in the Great Lakes in 2007 ( $n=13$ per colony) 72

Table 4.3 Arithmetic mean concentration ( \pm SE ng/g wet weight) of detectable PFCAs with carbon chain length varying from $\mathrm{C}_{8}$ to $\mathrm{C}_{15}$ in herring gull eggs $(n=13)$ collected from 15 colonies in the Great Lakes in 2007 76

Table 5.1 Arithmetic mean percentage $( \pm \mathrm{SE})$ of detectable perfluorooctane sulfonate (PFOS) isomers and arithmetic mean concentration of $\sum$ PFOS $( \pm$ SE ng/g ww) in herring gull eggs $(n=13)$ collected in 2007 from 15 colonies in the Great Lakes

90

Table 5.2 Correlations between concentrations (ng/g ww) of individual mono(trifluoromethyl) perfluorooctane sulfonate (PFOS) isomers and $\sum$ PFOS in individual herring gull eggs $(n=13)$ from 15 Colonies in the Great Lakes collected in 2007. 
Table 6.1 Average percent (range) of individual PFSAs to $\sum$ PFSA and individual PFCAs to $\sum$ PFCA in herring gull eggs and temporal changes of percent PFSA and PFCA between 1990 and 2010

Table 6.2 Temporal trend of PFSA and PFCA concentrations (ng/g ww) and $\sum$ PFSA/ $\sum$ PFCA correlation in herring gull egg pools collected between 1990 and 2010 at seven colonies.

Table 7.1 Correlations between $\delta^{15} \mathrm{~N}$ and $\delta^{13} \mathrm{C}, \delta^{15} \mathrm{~N}$ and $\sum \mathrm{PFSA}$ and $\sum \mathrm{PFCA}, \delta^{13} \mathrm{C}$ and $\sum$ PFSA and $\sum$ PFCA in Individual Gull Eggs from 15 Colonies across Canada. 133

Table 7.2 Arithmetic mean concentrations of PFOSA (ng/g wet weight) and the PFOS to PFOSA concentration ratio in individual gull eggs from 15 colonies across Canada.....140

Table 7.3 Arithmetic mean concentrations of $\Sigma$ PFSA and PPFCA (ng/g wet weight) in individual gull eggs collected from 15 colonies across Canada in $2008(n=10$ Per Colony)..... 


\section{List of Figures}

Figure 1.1 Chemical structures of perfluorosulfonates, perfluorocarboxylates, perfluorooctanesulfonamides, and fluorotelomer alcohols

Figure 1.2 Chemical structures of linear and branched PFOS isomers. The range of the percentage of each isomer in technical PFOS is given.....

Figure 1.3 Sites of the gull colonies across the Laurentian Great Lakes: (1) Granite Island, (2) Agawa Rocks, (3) Big Sister Island, (4) Gull Island, (5) Channel-Shelter Island, (6) Double Island, (7) Chantry Island, (8) Fighting Island, (9) Middle Island, (10) Port Colborne, (11) Niagara River, (12) Hamilton Harbour, (13) Toronto Harbour, (14) Snake Island, (15) Strachan Island.

Figure 2.1 Sites of the gull colonies across Canada: (1) Florencia Island, (2) Mandarte Island, (3) Dalemead Reservoir, (4) Pipstone Rocks, (5) Silver Islet, (6) Big Chicken Island, (7) Toronto Harbour, (8/9) Ile Deslauriers, (10) Ile Bellechasse, (11) Ile du Corossol, (12) Kent Island, (13) Manawagonish Island, (14) Sable Island, and (15) Gull Island.... .26

Figure 3.1 Proportions of $\mathrm{C}_{6}$ to $\mathrm{C}_{15}$ PFCA to $\Sigma$ PFCA concentrations plotted using the first two principal components (PCs), $\mathrm{PC} 1$ and $\mathrm{PC} 2$. Mean ( $\pm \mathrm{SE}$ ) factor scores (bottom biplot) are shown for the tissues and yolk. The percent variability explained by $\mathrm{PC} 1$ and PC2 is provided.

Figure 3.2 Arithmetic mean percent $\left( \pm \mathrm{SE}\right.$ ) of $\mathrm{C}_{8}$ to $\mathrm{C}_{15} \mathrm{PFCAs}$ to $\sum \mathrm{PFCA}$ in the yolk and combined herring gull tissues and blood.

Figure 3.3 Linear correlations between the plasma and red blood cell concentrations (ng/g ww) for PFOS, PFOA, PFNA and PFUnA. Detection of other individual PFSAs and PFCAs was $<60 \%$ in plasma and/or red blood cells and were not included.

Figure 3.4 Tissue burden amount of $\sum$ PFSA and $\sum$ PFCA $(\mu \mathrm{g})$ in herring gull egg, liver,

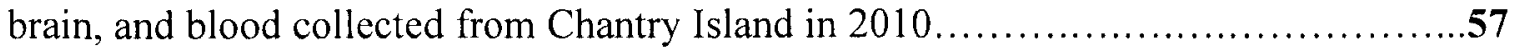

Figure 3.5 Relative percent composition of individual PFCA concentrations in liver versus egg yolk in female herring gulls and eggs, respectively, collected in 2010 from the Chantry Island (Lake Huron) colony site. Detection of PFDoA, PFTrA, and PFTeA in the liver was $<60 \%$ in individual samples and a comparison was not possible. Guillemot and glaucous gull liver and egg data were adapted from Holmström et al. (34) and Verreault et al. (33).

Figure 3.6 Fold change of PFCA to $\sum$ PFCA concentration ratio in herring gull liver, whole blood, and combined tissues and blood compared to the yolk. Only PFCAs with $>60 \%$ detection are included. 
Figure 4.1 Proportions of PFHxS, PFOS and PFDS to EPFSA concentrations plotted using the first two principal components (PCs), PC1 and PC2. Mean ( \pm SE) factor scores (top biplot) are shown for the 15 colonies. The percent variability explained by $\mathrm{PCl}$ and PC2 is provided.

Figure 4.2 Arithmetic mean PFOS concentrations (ng/g ww $\pm \mathrm{SE}$ ) in individual herring gull eggs $(n=13)$ collected in 2007 from 15 colonies in the Laurentian Great Lakes: (1) Granite Island, (2) Agawa Rocks, (3) Big Sister Island, (4) Gull Island, (5) ChannelShelter Island, (6) Double Island, (7) Chantry Island, (8) Fighting Island, (9) Middle Island, (10) Port Colborne, (11) Niagara River, (12) Hamilton Harbour, (13) Toronto Harbour, (14) Snake Island, (15) Strachan Island....

Figure 4.3 Correlation between PFOS and its precursor PFOSA (ng/g wet weight) in individual eggs from all colonies.

Figure 4.4 Proportions of $\mathrm{C}_{8}$ to $\mathrm{C}_{15}$ to $\Sigma$ PFCA concentrations plotted using the first two principal components (PCs), $\mathrm{PCl}$ and $\mathrm{PC} 2$. Mean $( \pm \mathrm{SE}$ ) factor scores (left biplot) are shown for the 15 colonies. The percent variability explained by $\mathrm{PC} 1$ and $\mathrm{PC} 2$ is provided.

Figure 4.5 Plots of $\sum$ PFSA and $\sum$ PFCA concentration ( $\mathrm{ng} / \mathrm{g}$ wet weight) in individual herring gulls eggs from Lakes Superior, Michigan, and Huron, colonies were grouped per lake. The dotted line indicates the $\sum \mathrm{PFSA} / 2 \mathrm{PFCA}$ ratio in lake trout per lake (adapted from Furdui et al.(24)).

Figure 4.6 Plots of $\sum$ PFSA and $\sum$ PFCA concentration ( $\mathrm{ng} / \mathrm{g}$ wet weight) in individual herring gulls eggs from Lakes Erie and Ontario, colonies were grouped per lake. The dotted line indicates the $\sum$ PFSA/ 2 PFCA ratio in lake trout per lake (adapted from Furdui et al.(24)). The Lake Ontario plot includes the $\sum$ PFSA/ $\sum$ PFCA ratio in the alewife and smelt (adapted from Martin et al. (23)) ..........................................81

Figure 4.7 Plots of PPFCA and SPFSA concentrations (ng/g wet weight) versus trophic position based on individual herring gull eggs collected in 2001-2002 from Strachan Island, St. Lawrence River.

Figure 5.1 GC-MS(ECNI) mass chromatogram of linear and branched, geometric perfluorooctane sulfonate (PFOS) isomers in a representative herring gull egg from Strachan Island, Lake Ontario.

Figure 5.2 Plot of arithmetic mean PFOS concentration ( \pm SE ng/g ww) obtained by LCMSMS analysis (Chapter 4) and arithmetic mean $\sum \mathrm{PFOS}$ concentration ( $\pm \mathrm{SE} \mathrm{ng/g} \mathrm{ww)}$ obtained by the present GC-MS analysis of individual herring gull eggs $(n=13)$ from 15 colonies in the Great Lakes. 
Figure 5.3 Proportions of individual perfluorooctane sulfonate (PFOS) isomers (linear PFOS (L-PFOS) and mono(triofluoromethyl)- and di(trifluoromethyl)-PFOS) to $\sum$ PFOS concentrations plotted using the first two principal components (PCs), PC1 and PC2. Mean $( \pm \mathrm{SE})$ factor scores (bottom biplot) are shown for the 15 colonies. The percent variability explained by $\mathrm{PC} 1$ and $\mathrm{PC} 2$ is provided. See Table 2.3 and Figure 1.2 for abbreviations and structures of the linear and branched PFOS isomers

Figure 5.4 Arithmetic mean Ebranched perfluorooctane sulfonate (PFOS) isomer (mono(triofluoromethyl) and di(trifluoromethyl)) to linear PFOS isomer concentration ratios $( \pm \mathrm{SE}$ ) for herring gull eggs ( $\mathrm{n}=13$ eggs per site) collected in 2007 from 15 colonies in the Laurentian Great Lakes: (1) Granite Island, (2) Agawa Rocks, (3) Big Sister Island, (4) Gull Island, (5) Channel-Shelter Island, (6) Double Island, (7) Chantry Island, (8) Fighting Island, (9) Middle Island, (10) Port Colborne, (11) Niagara River, (12) Hamilton Harbour, (13) Toronto Harbour, (14) Snake Island, (15) Strachan Island.

Figure 5.5 Herring gull egg to prey (A) alewife and (B) rainbow smelt ratio of \% individual perfluorooctane sulfonate (PFOS) isomers from Lake Ontario colonies. Alewife and smelt data is taken from Houde et al. (26). See Table 2.1 and Figure 1.2 for abbreviations and structures of the linear and branched PFOS isomers.

Figure 6.1 Temporal trends of $\sum$ PFSA and $\sum$ PFCA (ng/g wet weight) in herring gull egg pools collected between 1990 and 2010 from Agawa Rocks, Gull Island, Channel-Shelter Island, and Chantry Island. See Figure 1.3 for colony locations

Figure 6.2 Temporal trends of $\sum$ PFSA and $\sum$ PFCA (ng/g wet weight) in herring gull egg pools collected between 1990 and 2010 from Fighting Island, Niagara River, and Toronto Harbour. See Figure 1.3 for colony locations.

Figure 6.3 Annual increase or decrease in percent of individual PFCAs to the 2 PFCA based on the slope of linear regression. Only PFCAs are included where significant $(p<0.05)$ temporal changes were observed (see Table 6.1)..... 118

Figure 7.1 Arithmetic mean values of $\delta^{13} \mathrm{C}$ and $\delta^{15} \mathrm{~N}(\% \pm \mathrm{SE})$ in individual eggs $(\mathrm{n}=10)$ collected from 15 gull colonies across Canada collected in 2008. HG - Herring gull, CG California gull, RBG - Ring-billed gull, GWG - Glaucous-winged gull... 128

Figure 7.2 Proportions of $\mathrm{C}_{6}$ to $\mathrm{C}_{15}$ to $2 \mathrm{PFCA}$ concentrations plotted using the first two principal components (PCs), $\mathrm{PCl}$ and $\mathrm{PC} 2$. Mean ( $\pm \mathrm{SE}$ ) factor scores (bottom biplot) are shown for the 15 colonies. The percent variability explained by $\mathrm{PC} 1$ and $\mathrm{PC} 2$ is provided.

Figure 7.3 Arithmetic mean percent ( $\pm \mathrm{SE} \mathrm{ng/g} \mathrm{wet} \mathrm{weight)} \mathrm{of} \mathrm{detectable} \mathrm{PFCAs} \mathrm{to}$ $\sum$ PFCA with carbon chain length varying from $C_{6}$ to $C_{15}$ in gull eggs $(n=10)$ collected from nine colonies across Canada in 2008. ${ }^{*}$ indicates compound being below detection limit. ${ }^{\#}$ indicates compound being detected only at $<60 \%$ in individual eggs...... 
Figure 7.4 Arithmetic mean percent ( \pm SE ng/g wet weight) of detectable PFCAs to $\sum$ PFCA with carbon chain length varying from $\mathrm{C}_{6}$ to $\mathrm{C}_{15}$ in gull eggs $(n=10)$ collected from six colonies across Canada in 2008. ${ }^{*}$ indicates compound being below detection limit. ${ }^{\#}$ indicates compound being detected only at $<60 \%$ in individual eggs...........138 


\section{List of Appendices}

Appendix A: Arithmetic mean concentrations (ng/g ww $\pm \mathrm{SE}$ ), range of concentrations and detection frequency of detectable PFSAs and PFCAs in herring gull tissues, blood and eggs collected in 2010 from Chantry Island, Lake Huron

Appendix B: Arithmetic mean concentrations (ng/g $w w \pm S E$ ), range of concentrations and detection frequency of detectable PFSAs, PFCAs, and PFOSA in herring gull eggs collected in 2007 from 15 colonies in the Great Lakes.

Appendix C: Arithmetic mean concentrations (ng/g ww \pm SE), range of concentrations and detection frequency of detectable linear and branched PFOS isomers in herring gull eggs collected in 2007 from 15 colonies in the Great Lakes...........................169

Appendix D: Concentrations (ng/g ww) of detectable PFSAs, PFCAs and PFOSA in herring gull egg pools collected between 1990 and 2010 from 7 colonies in the Great Lakes

Appendix E: Arithmetic mean concentrations (ng/g ww $\pm \mathrm{SE}$ ), range of concentrations and detection frequency of detectable PFSAs, PFCAs, and PFOSA in herring gull eggs collected in 2008 from 15 colonies across Canada 


\section{List of Abbreviations}

$\delta^{13} \mathrm{C}$

$\delta^{15} \mathrm{~N}$

ANOVA

APPI

BFR

BMF

BTBPE

CG

CWS

DDE

EC-NWSB

ECF

ECNI

EIL.

ESI

FOSA

FOSE

FTCA

FTOH

FTUCA

GC-MS

GLHGMP

GLM

GWG

HBB

HBCD

$\mathrm{HCH}$

$\mathrm{HG}$

HPLC

IS

$\mathrm{KOH}$

L-FABP

L-PFOS

LC-MS

MLOQ

MRM

mRNA

NEtFOSA

NEtFOSE

NMEFOSA

NMeFOSE

$\mathrm{NCP}$

NIST

NWRC carbon stable isotope ratio

nitrogen stable isotope ratio

analysis of variance

atmospheric pressure photoionization

brominated flame retardants

biomagnification factor

1,2-bis(2,4,6-tribromophenoxy)ethane

California gull

Canadian Wildlife Service

dichlorodiphenyldichloroethylene

Environment Canada's National Wildlife Specimen Bank

electrochemical fluorination

electron capture negative ionization

Environmental Isotope Laboratory

electrospray ionization

fluorooctane sulfonamide

fluorooctane sulfonamidoethanol

fluorotelomer acid

fluorotelomer alcohol

fluorotelomer unsaturated acid

gaschromatography mass spectrometry

Great Lakes Herring Gull Monitoring Program

general linear model

glaucous-winged gull

hexabromobenzene

hexabromocyclododecane

hexachlorohexane

herring gull

high performance liquid chromatography

internal standard

potassium hydroxide

liver-fatty acid binding protein

linear-perfluorooctanesulfonate

liquid chromatography mass spectrometry

method limit of quantitation

multiple reaction monitoring

messenger ribonucleic acid

$\mathrm{N}$-ethylfluorooctanesulfonamide

$\mathrm{N}$-ethylfluorooctanesulfonamidoethanol

$\mathrm{N}$-methylfluorooctanesulfonamide

$\mathrm{N}$-methylfluorooctanesulfonamidoethanol

Northern Contaminants Program

National Institute of Standards and Technology

National Wildlife Research Centre 


$\begin{array}{ll}\text { OAT } & \text { organic anion transporter } \\ \text { OCRL } & \text { Organic Contaminants Research Laboratory } \\ \text { P1MHpS } & \text { perfluoro-1-methyl-heptanesulfonate } \\ \text { P2MHpS } & \text { perfluoro-2-methyl-heptanesulfonate } \\ \text { P3MHpS } & \text { perfluoro-3-methyl-heptanesulfonate } \\ \text { P35DMHxS } & \text { perfluoro-3,5-dimethyl-hexanesulfonate } \\ \text { P4MHpS } & \text { perfluoro-4-methyl-heptanesulfonate } \\ \text { P44DMHxS } & \text { perfluoro-4,4-dimethyl-hexanesulfonate } \\ \text { P45DMHxS } & \text { perfluoro-4,5-dimethyl-hexanesulfonate } \\ \text { P5MHpS } & \text { perfluoro-5-methyl-heptanesulfonate } \\ \text { P6MHpS } & \text { perfluoro-6-methyl-heptanesulfonate } \\ \text { P55DMHxS } & \text { perfluoro-5,5-dimethyl-hexanesulfonate } \\ \text { PAPS } & \text { perfluoroalkyl phosphates } \\ \text { PBDE } & \text { polybrominated dipheny ether } \\ \text { PBEB } & \text { pentabromoethylbenzene } \\ \text { PBT } & \text { pentabromotoluene } \\ \text { PCA } & \text { principal components analysis } \\ \text { PFAA } & \text { perfluoroalkyl acids } \\ \text { PFBS } & \text { perfluorobutane sulfonate } \\ \text { PFC } & \text { perfluoroalkyl compounds } \\ \text { PFCA } & \text { perfluoro carboxylates } \\ \text { PFDA } & \text { perfluorodecanoic acid } \\ \text { PFDoA } & \text { perfluorododecanoic acid } \\ \text { PFDS } & \text { perfluorodecane sulfonate } \\ \text { PFHpA } & \text { perfluoroheptanoic acid } \\ \text { PFHxA } & \text { perfluorohexanoic acid } \\ \text { PFHxS } & \text { perfluorohexane sulfonate } \\ \text { PFNA } & \text { perfluorononanoic acid } \\ \text { PFOA } & \text { perfluorooctanoic acid } \\ \text { PFOS } & \text { perfluorooctane sulfonate } \\ \text { PFOSA } & \text { perfluorooctane sulfonamide } \\ \text { PFPA } & \text { perfluoropentanoic acid } \\ \text { PFSA } & \text { perfluoro sulfonates } \\ \text { PFTeA } & \text { perfluorotetradecanoic acid } \\ \text { PFTriA } & \text { perfluoropentadecanoic acid } \\ \text { PFUnA } & \text { perfluoroundecanoic acid } \\ \text { POP } & \text { persistent organic pollutant } \\ \text { POSF } & \text { perfluorooctanesulfonyl fluoride } \\ \text { PPAR } & \text { peroxisome proliferator-activated receptor } \\ \text { PreFOS } & \text { precursors of PFOS } \\ \text { QA/QC } & \text { quality assurance / quality control } \\ \text { RBC } & \text { red blood cells } \\ \text { RBG } & \text { ring-billed gull } \\ \text { RSD } & \\ \text { SE } & \text { stative standard error deviation } \\ \text { SI } & \end{array}$


SIM

SPE

SRM

T-PFOS

TBAH

TH

VLDL

WW selected ion monitoring

solid phase extraction

standard reference material

technical PFOS

tetrabutylammonium hydroxide

thyroid hormone

very low density lipoproteins

wet weight 


\section{Chapter 1: General Introduction}

\subsection{General Introduction to PFCs}

Perfluorinated and their precursor compounds (PFCs) have been industrially manufactured since the 1950s with global production in the order of thousands of tons per year. PFCs are used in various industrial and consumer products such as fluorinated polymers, surfactants, insecticides, and aqueous fire-fighting foams ( $I$ ). Major classes of PFCs in environmental samples are perfluorosulfonates (PFSAs) and perfluorocarboxylates (PFCAs), which are characterized by a fully fluorinated carbon chain with a functional group (sulfonate of carboxylate) (see Figure 1.1 for structures). Of environmental concern are PFSAs and PFCAs with carbon chain length varying from four to fifteen carbons. Other major produced fluorinated compounds are perfluorooctanesulfonamides (PFOSAs) and fluorotelomer alcohols (FTOHs), which are precursors of PFSAs and PFCAs, respectively (Figure 1.1).

\subsection{PFC Production}

Perfluorosulfonates (PFSAs) and perfluorocarboxylates (PFCAs) are produced via electrochemical fluorination (ECF) and/or telomerization process (2). For example, during the ECF process all the hydrogens on octanesulfonate are replaced by fluorine to produce perfluorooctanesulfonyl fluoride (POSF). This intermediate was used to produce $\mathrm{C}_{8}$ chain length PFCs such as PFOS, PFOA, and PFOSA. During this ECF process, fragmentation and rearrangement of the carbon chain results in the formation of branched 
<smiles>CC(CCS(=O)(=O)[O-])(C(F)(F)F)C(F)(F)F</smiles>

Perfluorosulfonates

[PFSA, $n=5,7,9]$<smiles>O=C([O-])N(C(F)(F)F)C(F)(F)F</smiles>

Perfluorocarboxylates [PFCA, $n=2-13$ ]<smiles>[R]N([R2])S(=O)(=O)[Y7](F)(F)C(F)(F)F</smiles>

Perfluorosulfonamides [PFOSA, $\mathrm{R}=\mathrm{H}, \mathrm{CH}_{3}, \mathrm{CH}_{2} \mathrm{CH}_{3}$ ]

\section{$\mathrm{CF}_{3}\left(\mathrm{CF}_{2}\right)_{n} \mathrm{CF}_{2} \mathrm{CH}_{2} \mathrm{CH}_{2} \mathrm{OH}$}

Fluorotelomer alcohols

[FTOH, $n=4,6,8]$

Figure 1.1 Chemical structures of perfluorosulfonates, perfluorocarboxylates, perfluorooctanesulfonamides, and fluorotelomer alcohols of environmental concern. 
PFOS isomers in addition to linear PFOS (L-PFOS). Typically, technical PFOS (TPFOS) contains between 2-20\% of non-PFOS impurities, and of the remaining portion about $65-79 \%$ is L-PFOS and $21-35 \%$ is branched PFOS isomers $(3,4)$. Theoretically there are 89 geometric PFOS isomers that are branched (5), however, only eleven isomers have been identified in technical PFOS products and/or environmental samples by either LC-MS or GC-MS-based methods (see Figure 1.2 for PFOS isomer structures) $(3,4,6)$. The telomerization process produces linear products and is used to produce PFCAs, FTOHs and perfluoroalkyl phosphates (PAPS). These compounds are produced by a polymerization reaction between a perfluoroalkyl iodide and tetrafluoroethylene and this reactions produces chain with even numbered carbons (7).

In 2002, the 3M Company (the main producer of PFCs in North America) phased-out the production of the $\mathrm{C}_{8}$ PFCs (PFOS and precursors), however, other countries continue to produce PFOS (8). The production of fluorinated compounds via telomerization, however, is still increasing to date and is a continues source of PFC into the environment (9).

\subsection{Degradation of Precursors to PFOS and PFCAs}

PFSAs and PFCAs are chemically stable and thus highly persistent in the environment as there is no environment degradation of these compounds. There are, however, numerous fluorinated compounds that can undergo biodegradation/biotransformation to form PFOS and PFCAs. These precursors include alkyl- and non-alkyl-substituted perfluorooctanesulfonamides (FOSAs) and perfluorooctanesulfonamidoethanols (FOSEs), perfluoroalkyl phosphates (PAPS), and fluorotelomer alcohols. Both in vivo 
<smiles>O=S(=O)([O-])C(F)CC(F)C(F)CC(F)C(F)(F)F</smiles>

L-PFOS [67.0 - 78.9\%]<smiles>FC(F)CC(F)C(F)C(F)C(F)(F)C(F)F</smiles>

P1MHpS [0.88-3.18\%]<smiles>O=S(=O)(O)CC(F)C(F)(F)C(F)C(F)C(F)F</smiles>

P3MHpS [2.03-7.43\%]<smiles>FC(C(F)(F)C(F)(F)F)C(F)(F)C(F)(F)F</smiles>

P5MHpS [4.47-7.16\%]<smiles>O=S(=O)(O)CC(F)C(F)(F)C(F)C(F)(F)C(F)(F)F</smiles>

P35DMHXS $[0.46-1.01 \%]$<smiles>O=S(=O)(O)CC(F)CC(F)(C(F)(F)F)C(F)(F)C(F)(F)F</smiles>

P44DMHXS [0.07-0.45\%]<smiles>O=S(=O)(O)CC(F)C(F)C(F)C(F)C(F)C(F)(F)F</smiles>

P2MHpS $[0.61-1.57 \%]$<smiles>O=S(=O)(O)C(F)[C]C(F)C(F)(CC(F)F)C(F)(F)F</smiles>

P4MHpS [2.24-4.75\%]

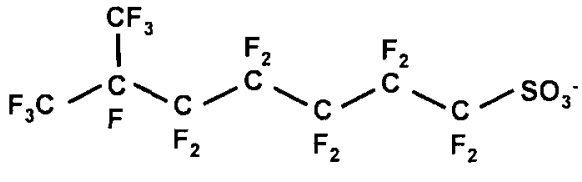

\section{P6MHpS [8.99-11.68\%]}<smiles>O=S(=O)(O)CC(F)CC(F)C(C(F)(F)F)C(F)(F)F</smiles>

P45DMHXS $[0-0.71 \%]$

P55DMHXS $[0.20-0.53 \%]$

Figure 1.2 Chemical structures of linear and branched PFOS isomers. The range of the percentage of each isomer in technical PFOS is given. 
and in vitro degradation of perfluorooctanesulfonamides (PFOSA, NEtFOSA) and perfluorooctaneamidoethanols (NEtFOSE) has been shown to be a source for PFOS. For example, in an in vitro study using rainbow trout (Onchorhynchus mykiss) liver microsomes, Tomy et al. (10) investigated the biotransformation of NEtFOSA. With incubations at various time points, a decrease in NEtFOSA concentrations was observed while the PFOSA and PFOS concentrations increased. The biotransformation of NEtFOSE has, to our knowledge, only been studied in vitro using Sprague-Dawley rat microsomes, cytosol, and liver slices $(l l)$. Multi-step degradation of NEtFOSE, with intermediates such as NEtFOSA and PFOSA, lead to the formation of PFOS.

Biodegradation/biotransformation of e.g., PAPS and FTOH has been shown to be a source of PFCAs. As commercial PAPS and FTOHs formulations contain a mixture of fluorinated chain lengths, the degradation products can vary in chain length as well. The atmospheric degradation of the 4:2,6:2, and 8:2 FTOH results in the formation of PFCAs (PFOA, PFNA) and fluorotelomer acids (4:2, 6:2 and 8:2 FTCA), amongst other fluorinated compounds (12). The aerobic biotransformation of 8:2 FTOH in sludge and a microbial system resulted in the formation of three compounds: 8:2 FTCA, 8:2 FTUCA and PFOA $(13,14)$. The in vivo, multi-step, metabolism of various chain length PAPS and FTOH by rats was shown to produce PFCAs $(15,9)$. Among the identified intermediates were fluorotelomer acids.

As the FOSA and FOSE precursors are produced by ECF, linear as well as branched isomers are produced. Isomer-specific degradation of PFOS precursors could potentially be a secondary source of PFOS isomers. Very recently there has been a report showing that the model PFOS-precursor, NEtFOSA, can be degraded isomer-specifically. Benskin 
et al. (16) used human microsomes and recombinant human cytochrome P450s (CYPs) 2C9 and 2C19 to show that branched isomers were transformed more rapidly to PFOSA isomers than linear NEtFOSA. They concluded that PFOS isomer patterns in biota exposed predominantly to precursors could be much different than expected from the isomer pattern of the precursor.

Many of these precursors are more volatile than PFOS or PFCAs, and have been detected in air samples, e.g., NMeFOSE, NEtFOSE, and FTOH (17). Atmospheric transport and deposition of these precursors in remote locations and subsequent degradation could potentially lead to increasing concentrations of PFOS and PFCAs in those environments.

\subsection{PFCs in Wildlife}

\subsubsection{PFC Patterns}

In 2001, Giesy and Kannan (18) first reported on the global distribution of PFOS in fish, birds, and marine mammals, however, archived samples showed the presence of PFOS in wildlife dating back to $1968(19)$. Numerous studies have reported on the presence of various PFCs in wildlife in different ecosystems around the world $(20,21,22)$. PFSAs (PFHxS, PFOS, and PFDS), PFCAs $\left(\mathrm{C}_{8}\right.$ to $\left.\mathrm{C}_{15}\right)$ were routinely reported in fish, birds, and mammals, whereas reports on the presence of precursors, such as PFOSA, are more limited.

In Canada, the presence of PFCs in wildlife species has primarily been reported in the Great Lakes or Arctic regions. In the Great Lakes, reports on the various PFCs in wildlife and fish are limited. Martin et al. (23) reported on the presence of PFOS, PFOSA and the 
$\mathrm{C}_{8}-\mathrm{C}_{15}$ PFCAs in invertebrates (Mysis and Diporeia), prey fish [alewife (Alosa pseudoharengus), rainbow smelt (Osmerus mordax), and slimy sculpin (Cottus cognatus)] and predator fish [lake trout (Salvelinus namaycush)] from Lake Ontario, while Furdui et al $(24,7)$ reported all these PFCs, as well as PFHxS, PFDS, PFHpA, 8:2 FTUCA, and 10:2 FTUCA in lake trout collected from all five Great Lakes. PFOS was the dominant PFC in all those species with the exception of Mysis, where PFOSA was found at the highest concentrations. The PFCA pattern in the invertebrates was mostly dominated by the shorter chain length PFCAs (PFOA, PFNA, and PFDA), while higher in the food web, the patterns shift towards longer chain length PFCAs in the prey fish and lake trout. In wild birds from the Great Lakes, information on PFC patterns is extremely limited, and only PFOS has been reported. These species included herring gull (Larus argentatus) (in blood/plasma), double crested cormorant (Phalacrocorax auritus) (in blood/plasma), and ring-billed gull (Larus delawarensis) (in egg yolk) (25). Recent studies identified PFOS isomers in aquatic and avian species in the Great Lakes. Along with L-PFOS, P1MHpS, P3/4/5MHpS (reported as coelution), P6MHpS, and unidentified dimethyl-PFOS isomers were detected in zooplankton, invertebrates, prey and predator fish collected from Lake Ontario (26). In herring gull and double crested cormorant eggs from the Great Lakes, the PFOS pattern was dominated by L-PFOS ( $95 \%$ of $\sum$ PFOS concentrations) while the proportion of $\mathrm{P} 6 \mathrm{MHpS}>\mathrm{P} 5 \mathrm{MHpS}>\mathrm{P} 3 \mathrm{MHpS}=\mathrm{P} 4 \mathrm{MHpS}>$ P1MHpS > P2MHpS (3). PFUnA and PFTrA branched isomers were also identified in lake Ontario lake trout, however, no quantitations were made due to lack of standards at the time (7). In the Canadian Arctic, PFCs were reported in (mainly liver) marine mammals [including polar bears (Ursus maritimus), ringed seals (Pusa hispida), and 
beluga whales (Delphinapterus leucas)], seabirds (liver and eggs) and several fish species ((22) and references therein). However, to our knowledge, the presence and/or concentrations and patterns of PFSAs, PFCAs and precursors have not been reported in any wildlife species in other regions across Canada, e.g., Atlantic and Pacific Canada.

\subsubsection{Tissue Distribution and Maternal Transfer}

Limited studies have shown that there are associations between PFSAs and PFCAs (mainly PFOS) and proteins. For example, Luebker et al. (27) reported on the binding of PFOS and PFOA to the liver fatty acid binding protein (L-FABP) isolated from rats. Also, PFSAs and PFCAs have been found to bind to proteins such as albumin and sexhormone binding globulins in birds, fish and humans $(28,29)$. Therefore, often liver and blood samples were used to measure PFCs. However, the distribution of PFCs among several tissues within a whole animal has only been studied sporadically, for example in harbour seals (Phoca vitulina) and harbour porpoises (Phocoaena phocoena relicta) from Europe $(30,31,32)$. In birds, such tissue distribution studies of PFSAs and PFCAs has been limited to Norwegian glaucous gulls (Larus hyperboreus) and Swedish common guillemots (Uria aalge) $(33,34)$, while Olivero-Verbel et al. (35) reported on the tissue distribution of just PFOS and PFOSA in Columbian pelicans (Pelecanus occidentalis). In these limited body compartment comparisons, the highest concentrations of either $\sum$ PFSA or $\sum$ PFCA were found in plasma, liver or eggs compared to tissues such as brain, muscle and heart. The PFSA and PFCA patterns in glaucous gull and guillemot tissues were dominated by PFOS, and $\mathrm{C}_{11}$ (PFUnA) and $\mathrm{C}_{13}$ (PFTrA) PFCAs $(33,34)$. To our knowledge, tissue or whole body burdens, rather than concentrations, of bioaccumulative 
PFAAs have only been reported for harbour seals from Germany Bight (30), where blood and liver were shown to contain a combined total of $74 \%$ of the overall PFAA burden in the whole animal.

The maternal transfer of PFCs from female birds to their eggs has only been reported in Swedish guillemots and Norwegian glaucous gulls $(34,33)$. PFOS has been found to accumulate in the yolk and specifically in the isolated fractions containing very low density lipoprotein (VLDL), phosvitin, and lipovitellin in mallard (Anas platyrhynchos) and bobwhite quail (Colinus virginianus) eggs (Newsted et al., 2007). Yolk proteins, such as VLDL, are formed in the liver of a female bird and subsequently transported to the ovaries. PFOS has been associated with VLDL (36), and as Holmström et al. (34) reported for guillemots, this protein-PFOS complex is transferred to the egg. In comparing the PFCA pattern in the guillemot liver and eggs, there was an enrichment of the longer chain length PFCAs in the egg relative to the liver; however, this was not observed in glaucous gulls. To our knowledge, it is not known whether there is chain length dependant binding of PFCAs to yolk proteins.

\subsubsection{Foodweb Accumulation}

Although studies reporting on PFCs mostly use top-predator species (whether aquatic or avian), food web studies for PFCs are limited. In an Arctic marine food web PFOS was shown to biomagnify as a significant relationship was seen between PFOS concentrations and trophic levels of various species (37). For avian top predators in that food web, PFOS biomagnification factors (BMFs) of 5 and 9 were reported for black-legged kittiwakes (Rissa tridactyla) and glaucous gulls, respectively, using Arctic cod 
(Arctogadus glacialis) as prey. In the Lake Ontario food web, positive relationships were seen between the trophic level of invertebrates, prey fish and predator fish and the PFOS, PFDA, PFUnA, and PFTrA concentrations, indicating biomagnification of these PFAAs (23). Declining PFOSA and PFOA concentrations were seen with increasing trophic level. BMFs from prey fish to lake trout ranged from 1.4 (PFOSA) to 3.4 (PFUnA), only PFOA had a BMF $<1$. The PFOS isomer pattern determined in the Lake Ontario food web as well as water and sediment varied considerable. While in water there was almost an equal amount of L-PFOS and $\sum$-branched isomers, in the sediment and food web species, the isomer pattern was highly enriched with L-PFOS ( $>88 \%$ of $\sum$ PFOS) (26). Greater sorption of L-PFOS to the sediment and invertebrates resulted in this pattern and was transferred to species higher in the food web.

\subsubsection{Spatial and Temporal Trends}

As PFCs are man-made chemicals and have industrial and consumer product applications, studies have investigated the influence of sampling location, e.g., samples collected in remote areas versus industrialized/urbanized areas. For example, bottlenose dolphin (Tursuops truncates) blood samples collected near highly industrialized and urban areas were more contaminated with PFCs (PFOS, PFOA, PFNA, PFDA, PFUnA) compared to samples collected near more residential areas (38). Skipjack tuna (Katsuwonus pelamis) livers collected off-shore Japan contained higher concentrations of $\sum$ PFCs (PFOS, PFOSA, PFNA, PFDA, PFUnA, and PFDoA) compared to tuna collected in open ocean (39). In the Great Lakes, spatial tends of PFCs have only been determined in lake trout collected from all five Great Lakes (24). Generally the highest 
concentrations of PFSAs and PFCAs were found in the trout collected from the more urbanized lakes (Lakes Erie, Ontario, and Huron), compared to the more remote lakes (Lakes Superior and Michigan). Infrequent detection of 8:2 and 10:2 FTUCA at low concentrations were found in the trout from all the lakes, however, only 8:2 FTUCA was detected in $>60 \%$ of the trout collected from Lake Michigan. These studies show the influence of sampling location on concentrations in wildlife. Samples collected close to urban and/or industrialized areas are closer to sources of PFCs and more contaminated compared to samples collected in remote areas.

In biota, temporal trends of PFSAs and PFCAs (including precursors) have been determined in birds, fish and mammals in various parts of the world $(21,20)$, and the earliest reporting of PFOS in archived wildlife samples (guillemot eggs from Sweden) dating back to 1968 (19). In North America, and particularly in the Arctic, increasing concentrations of PFSAs and PFCAs were seen in polar bears, ringed seals, thick-billed murres (Uria lomvia), and northern fulmars (Fulmarus glacialis) between 1972 and 2005 (21). Butt et al. (40) reported on doubling times ranging from 2.3 to 11.7 years for PFOS and $\mathrm{C}_{10}$ to $\mathrm{C}_{15}$ PFCAs in thick-billed murres and northern fulmars collected from the Canadian Arctic between 1975 and 2004. Doubling times of $\mathrm{C}_{9}$ to $\mathrm{C}_{15}$ PFCAs and PFOS and PFDS in Swedish peregrine falcon (Falco peregrines) eggs ranged from 5.6 to 12 years based on samples collected between 1974 and 2007 (41). In Norwegian tawny owl (Strix aluco) eggs, PFOS concentrations declined with a half-life of 40 years, while $\mathrm{C}_{10}$ to $\mathrm{C}_{13}$ PFCA concentrations doubled every 6 to 18 years (42). In the Great Lakes, the temporal trend studies of PFSAs and PFCAs are limited to lake trout collected from Lake Ontario (23,7). While Martin et al. (23) only determined the temporal trend of PFOS, and 
found an four-fold increase in the concentrations between 1980 and 2001; Furdui et al. (7) determined the temporal trends of a range of PFCs. Between 1979 and 2004, overall increasing trends in lake trout were seen for PFOS, PFDS and $\mathrm{C}_{9}$ to $\mathrm{C}_{15}$ PFCAs, while no temporal changes were seen for PFOSA and PFOA. Based on linear and branched isomer analysis, Furdui et al. (7) implied that the source of PFCAs (PFUnA and PFTrA) in recent years was almost exclusively from linear products manufactured using the telomerization process.

\subsubsection{Avian Toxicity of PFCs}

Information on the toxicity of PFCs to (wild) birds is limited and often single compounds are tested. In many cases PFOS toxicity was investigated, however, in recent years other PFCs, such as individual PFCAs, are included in toxicity studies. Acute and chronic exposure to PFOS caused decreased body weight, increased liver mass and mortality in mallards and quails; although liver and serum concentrations associated with mortality and other adverse toxic effects were much greater than what has been reported in avian wildlife $(43,36)$. Chicken (Gallus gallus domesticus) eggs that were injected with PFOS, PFDS, PFOA, or PFUnA only showed reduced success in hatchability when exposed to PFOS at concentrations two orders of magnitude higher compared to environmental concetrations $(44,45,46)$. In chicken embryo hepatocytes O'Brien et al. $(45,46)$ reported that PPAR $\alpha$-regulated genes were not affected after PFOS exposure; however, PFUnA increased cytochrome P450 1A4 and liver fatty acid binding protein mRNA expression only at high dose exposure $(10 \mu \mathrm{g} / \mathrm{g})$. Chicken embryonic neuronal cells exposed to PFSAs and PFCAs of variable chain length showed a greater change in the expression of 
thyroid hormone responsive genes when exposed to shorter chain PFSAs and PFCAs $(<8$ carbons) compared to longer chained ( $>8$ carbons) (47). However, herring gull embryonic neuronal cells exposed to short chain PFSAs and PFCAs $(<8$ carbons $)$ showed variable transcription changes to mRNA expression. When comparing the effects of L-PFOS and T-PFOS on the transcription profiles of cultured chicken embryo hepatocytes, O'Brien et al. (48) found that T-PFOS resulted in a greater transcriptional response than L-PFOS alone. The authors suggested that the branched isomers may account for a larger proportion of the toxicological effects of PFOS. Toxicity of PFC mixtures, reflecting environmental exposure to birds has yet not been studied.

\subsection{Great Lakes Herring Gull Monitoring Program}

Since the early 1970s, the Canadian Wildlife Service (CWS) has been collecting herring gull eggs from 15 colonies around the Great Lakes (Figure 1.3) as part of the Great Lakes Herring Gull Monitoring Program (GLHGMP). The GLHGMP provides annual information on the levels of environmental contaminants in herring gull eggs. The program was initiated in response to observations of poor reproductive success in colonial waterbirds on the Great Lakes caused by environmental pollutants. The herring gull was chosen as the primary monitoring species for several reasons: it was assumed to primarily consume fish, thereby occupying a high aquatic trophic position; the adults are year-round Great Lakes residents; and it nests in colonies facilitating population assessments (49). Female herring gulls lay a clutch of three eggs in April-May. Since the 


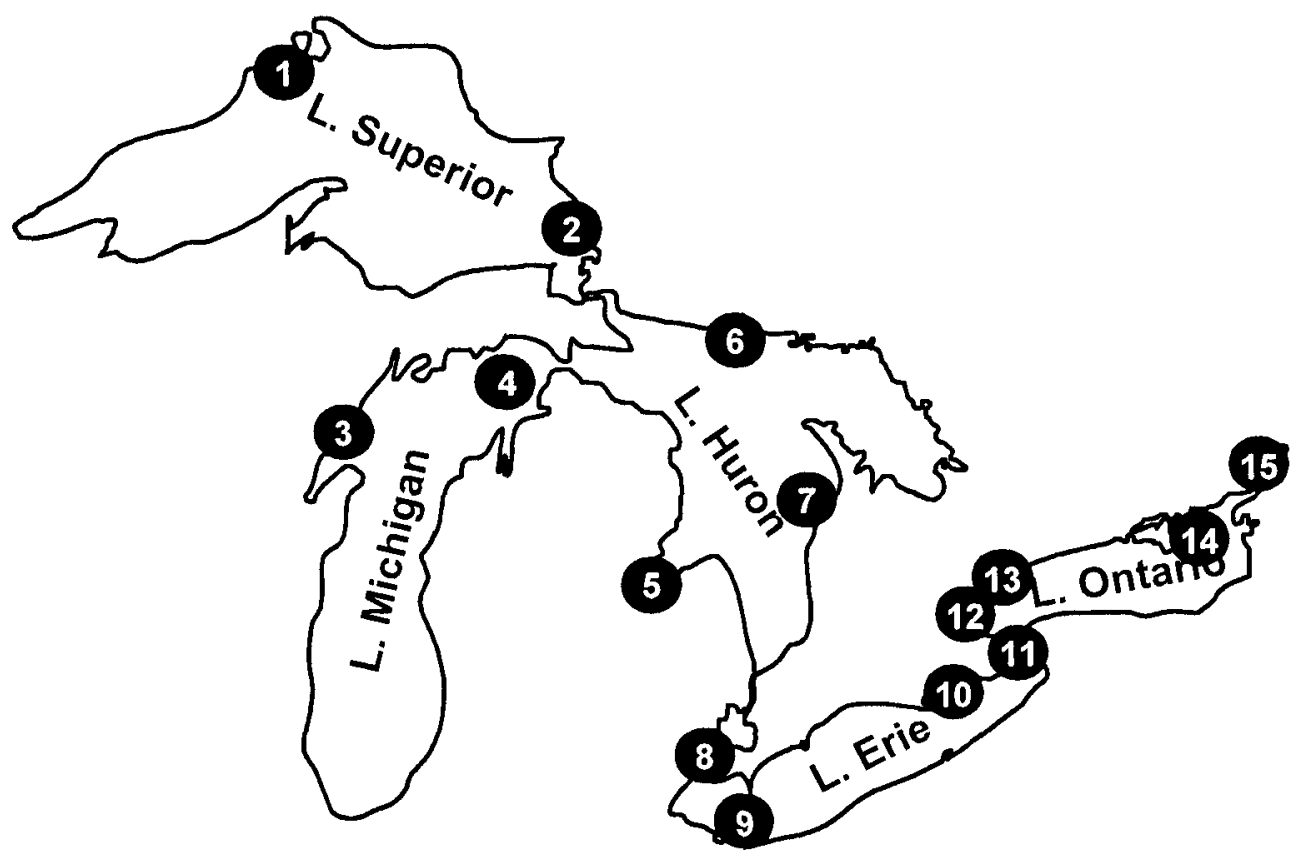

Figure 1.3 Sites of the gull colonies across the Laurentian Great Lakes: (1) Granite Island, (2) Agawa Rocks, (3) Big Sister Island, (4) Gull Island, (5) Channel-Shelter Island, (6) Double Island, (7) Chantry Island, (8) Fighting Island, (9) Middle Island, (10) Port Colborne, (11) Niagara River, (12) Hamilton Harbour, (13) Toronto Harbour, (14) Snake Island, (15) Strachan Island. 
beginning of the monitoring of contaminants in herring gull eggs, numerous persistent organic pollutants (POPs) have been detected. Spatial and or temporal trends have been determined for organochlorine pesticides (DDE, dieldrin, oxychlordane, $\mathrm{HCH}$, heptachlor epoxide, mirex $(50,5 I))$, but also recently the emerging brominated flame retardants (BFRs) polybrominated diphenyl ethers (PBDEs), hexabromobenzene (HBB), pentabromoethylbenzene (PBEB), pentabromotoluene (PBT), 1,2-bis(2,4,6tribromophenoxy)ethane (BTBPE) and hexabromocyclododecane (HBCD) isomers $(52,53,54,55)$. Other than a single report on PFOS detected in herring gull blood from Lake Huron (25), there is no information on other perfluorinated compounds in herring gull tissues or eggs from colonial populations in the Great Lakes or across Canada.

Herring gulls are exposed to environmental contaminants through their diet. Herring gulls are opportunistic feeders, and Fox et al. (56) and Ewins et al. (57) made an attempt to determine the diet composition of the herring gulls on the Great Lakes. Based on regurgitations, herring gulls feed on fish [alewife and rainbow smelt, sunfish, yellow perch (Perca flavescens)], amphibians (mudpuppies), birds (migrating birds, young of ducks, gulls and terns), small mammals (meadow voles), and insects (coleopteran, beetles) (50). As these observations were based on regurgitations, it only provides a snapshot of the gull's diet, whereas there could be colony-specific or year-to-year variation in the diet. Dietary tracers, such as stable isotopes (SI) $\left(\delta^{15} \mathrm{~N}\right.$ and $\left.\delta^{13} \mathrm{C}\right)$ and fatty acids, however, have become a useful tool for estimating trophic position and sources of carbon (freshwater versus marine and aquatic versus terrestrial feeding) and thus provide information on feeding patterns. The main sources of nitrogen for most animals are amino acids derived from digested protein from the diet. As ${ }^{14} \mathrm{~N}$ is preferentially excreted 
in the digestive system $\left({ }^{15} \mathrm{~N} /{ }^{14} \mathrm{~N}\right.$ value is higher in the diet compared to feces), the ${ }^{15} \mathrm{~N} /{ }^{14} \mathrm{~N}$ value $\left(\delta^{15} \mathrm{~N}\right)$ will be higher in a predator compared to their prey with an enrichenment of $4 \%$ at each trophic level $(58)$. The $\delta^{13} \mathrm{C}\left({ }^{13} \mathrm{C} /{ }^{12} \mathrm{C}\right)$ values are mostly used to determine the carbon source. $\mathrm{CO}_{2}$ is a carbon source for $\mathrm{C}_{3}$ and $\mathrm{C}_{4}$ plants, and while there is a discrimination against ${ }^{13} \mathrm{C}$ isotope by $\mathrm{CO}_{2}$ fixing enzymes of the $\mathrm{C}_{3}$ plants, this discrimination against ${ }^{13} \mathrm{C}$ is not as strong for $\mathrm{C}_{4}$ plants. In the marine environment, bicarbonate is a carbon source and the $\delta^{13} \mathrm{C}$ signature is enriched compared to the terrestrial $\mathrm{C}_{3}$ plants $(58,59)$. Using these dietary tracers, Hebert et al. $(60,61)$ reported on an overall trend where in recent years herring gulls throughout the Great Lakes were consuming more terrestrial prey in their diet due to declines in prey fish abundance. This temporal change and variation in the gull's diet impacts the interpretation of temporal trend data of environmental contaminants using the herring gull eggs (62).

\subsection{PFC Analysis}

Liquid chromatography-mass spectrometry (LC-MS) is a well used analytical technique for measuring PFCs in wildlife samples. Taniyasu et al. (63) and Chu and Letcher (64) reported on the use of LC-MS/MS for the determination of PFSAs, PFCAs, FOSAs, FTOHs and FTUCAs in various sample matrices. In those studies, electrospray ionization (ESI) was used for the ionization of PFSAs, PFCAs, and FTUCAs, while atmospheric pressure photoionization (APPI) was used for ionization of FOSAs and FTOHs. For all target PFCs, mass analysis was via a tandem quadrupole mass spectrometer. 


\subsubsection{Electrospray Ionization}

After analyte separation on a given LC column, the eluant passes through a small capillary, which results in the nebulisation of the mobile phase into a fine droplet spray. The metal capillary is also subject to high voltage, and thus all applicable components, including the target analytes, are ionized either positively or negatively depending on the polarity of the capillary. Thus, thus this process is called electrospray ionization (ESI). The ESI droplets undergo a process of evaporation of the solvent by a drying gas or by the heated chamber. As the droplets diminish in size, any ions (which are involatile) are concentrated. Due to repulsion of ions of like charge, any ions eventually desorb from as a consequence of drop size reduction, All evaporated solvent, or neutral mobile phase vapour is removed, and the desorbed ions are drawn to the mass analyzer by acceleration via accelerating plates of increasing potential.

\subsubsection{Atmospheric Pressure Photoionization}

The process of atmospheric pressure photoionization (APPI), like ESI and atmospheric pressure chemical ionization (APCI), required the nebulization of the LC mobile phase, analyte ionization by high voltage application, and subsequent analyte ion desorption from the evaporating solvent from the nebulized droplet. However, for APPI, in the ionization region, dopant molecules (e.g., toluene or acetone) are ionized by UV radiation to form photo ions. These dopant photoions initiate a cascade of ion-molecule reactions leading to the formation of the ionized analytes in the form $[\mathrm{MH}]+$ (by proton transfer) or $[\mathrm{M}]+\bullet$ (by charge transfer). 


\subsubsection{Triple-Quadrupole Mass Spectrometry}

After ionization, either by ESI or APPI, the analyte ions undergo mass separation using mass analyzers such as low mass resolution analyzers such as quadrupoles, or higher resolution mass analyzers such as time-of flight. For PFC quantification, the common mass analyzers used are quadrupoles, and often triple quadrupole mass analyzer systems are used. In such systems, the first and the third quadrupoles are mass-selective analyzers, while the second quadrupole serves as a collision cell. The first quadrupole serves as a mass-selective analyzer for molecular, or parent, ions of the target analytes. The molecular ions are accelerated and collide with neutral molecules (argon) in the collision cell, causing fragmentation of the molecular ions to produce daughter ions. These daughter ions are subsequently analyzed in the third mass selective quadrupole. For each of the target compounds unique parent-daughter ion MRM channels can be generated in order to identify and quantify the target analytes. For example, for perfluorosulfonates, after molecular ions are fragmented, the $\mathrm{SO}_{3}{ }^{-}$daughter ion is an abundant fragment and molecular-to- $\mathrm{SO}_{3}{ }^{-}$transition channels are used. For perfluorocarboxylates, the $\left[\mathrm{M}-\mathrm{CO}_{2}\right]^{-}$ ions are the most abundant fragment after molecular ions are fragmented.

\subsection{Thesis Objectives}

As mentioned, there is limited information on the presence of PFCs in avian species in the Canadian environment. Therefore, the main objective of this thesis was to determine whether gull eggs could be used to monitor (spatial and temporal trends) PFCs in the Great Lakes environment, as well as Canada wide. The separate sub-objectives investigated in the five individual chapters are described below. 
Objective 1. As eggs are often used for monitoring purposes and to determine to what environmental contaminants wild birds are exposed to, the main question is whether egg contaminant patterns reflect the patterns in the female birds. The limited examples in the literature investigating the tissue distribution and maternal transfer of PFCs in wild birds (guillemots and glaucous gulls) have shown that the patterns among the analyzed tissues are comparable; however, one study reported on a selective transfer of the longer chain length PFCAs to the (guillemot) eggs, while this was not seen for glaucous gulls. To better understand how PFCs are distributed and accumulatively compartmentalized in the body of Great Lakes female herring gulls, in Chapter 3, PFSAs and PFCAs and several PFOSA, FTUCA and FTOH precursors were determined in a comprehensive suite of tissues as well as blood components. Furthermore, the maternal transfer of these same PFCs was examined from the female gulls to her entire clutch of eggs, and the albumen and yolk compartments. The hypothesis was tested that the PFC pattern in the analyzed tissues and blood will be comparable; however, chain length dependant selective transfer occurs from the female gulls to their eggs.

Objective 2. PFCs are man-made chemicals and are used in consumer and industrial products. Studies have shown the influence of sampling location when spatial trends of PFCs were determined; generally, samples located near urbanized and/or industrialized areas were more contaminated compared to remote areas (24,39). In Chapter 4, spatial trends of PFSAs, PFCAs, and their precursors were determined in herring gull eggs collected from 15 colonies across the Great Lakes collected in 2007 (Figure 1.3). These colonies were located in remote (Lakes Superior, Michigan, and Huron) as well as urbanized areas (Lakes Erie and Ontario). In Chapter 4, the hypothesis was tested that the 
herring gull eggs collected from colonies near urbanized areas were more contaminated with PFSAs, PFCAs, and precursors compared to colonies near remote areas. Secondly, dietary sources of PFCs to gulls were examined by using nitrogen and carbon stable isotopes using eggs from Strachan Island as a representative colony.

Objective 3. Studies that reported on the PFC pattern in wildlife samples showed that PFOS was by far the most dominant compound (2l). Recently, it has been shown that the PFOS detected in wildlife samples is made up of linear and branched isomers. In the Lake Ontario food web, linear PFOS dominated the $\sum$ PFOS concentration $(>88 \%)$ in invertebrates, prey fish (including herring gull prey species) and predator fish (26). Several monomethyl-branched isomers were detected consistently and dimethyl-branched isomers were only detected in high trophic species. Similar PFOS isomer pattern were seen in very limited herring gull and double-crested cormorant eggs from the Great Lakes. In these rare examples, an enrichment of L-PFOS was observed compared to TPFOS, which contains $60-70 \%$ L-PFOS. There are no reports on the spatial patterns of PFOS isomers among populations of a given wildlife species. In Chapter 5, the hypothesis was tested that the PFOS isomer pattern in herring gull egg was comprised of L-PFOS and several monomethyl and dimethyl branched isomers regardless of colony location. As the PFOS isomer pattern in the herring gull prey fish was enriched with LPFOS compared to T-PFOS, it was also hypothesized that this enrichment occurs in the herring gull eggs. Factors that could influence the site-specific concentrations and spatial patterns among 15 colonies throughout the Great Lakes were also investigated.

Objective 4. PFCs have been produced since the 1950s and PFOS has been detected in archived samples dating from 1968 (19). In 2002, the production of the $\mathrm{C}_{8}$ PFCs 
(PFOS) was phased out in North America, however, fluorotelomer based compounds (a source for PFCAs) are still being produced. In recent years, numerous studies have investigated the temporal trend of PFSAs and PFCAs in fish, birds, and marine mammals $(20,21)$. For example, increasing PFOS concentrations were seen in Arctic birds and marine mammals; however, declining concentrations in Arctic ringed seals collected in recent years were linked to the phase out of the $\mathrm{C}_{8} \mathrm{PFC}$ in 2002. Generally increasing PFCA concentrations in wildlife were seen in temporal trend studies, still produced fluorotelomer based compounds are sources for PFCAs. In the only Great Lakes temporal trend study, increasing concentrations of PFOS, PFDS, and $\mathrm{C}_{9}$ to $\mathrm{C}_{15}$ PFCAs were seen in Lake Ontario lake trout collected between 1974 and 2004 (7). In Chapter 6, temporal trends of PFSAs, PFCAs, and their precursors were examined in herring gull egg pools collected between 1990 and 2010 from seven colonies in the Great Lakes. The hypothesis was tested that the egg PFSA concentrations decreased in recent years as a result from the 2002 phase-out, while PFCA concentrations increased during the examined time period. Whether dietary changes of the gulls during this time period will affect the temporal trends of PFCs will be examined.

Objective 5. In Canada, the Great Lakes region and the Arctic have been studied when it comes to PFCs in wildlife $(24,22)$, information on PFCs in wildlife in other regions, such as Pacific or Atlantic Canada, to our knowledge, do not exist. As was explained for Objective 2, sampling location could have an influence of the concentrations found in wildlife samples. In Chapter 7, spatial trends of PFSAs and PFCAs, and precursor compounds were examined in individual eggs of four different gull species [glaucous-winged (Larus glaucescens), California (Larus californicus), ring- 
billed (L. delawarensis) and herring (L. argentatus)] collected in 2008 from 15 colony sites across Canada (Figure 2.1). The hypothesis was tested that the gull eggs collected near urbanized areas are more contaminated by these compounds compared to colonies in remote areas. As for many of these colonies the diet of the gulls is not known, the nitrogen and carbon stable isotope values in the individual eggs will be determined in order gain insights into the gull's diet and thus how they are exposed to PFCs. 


\section{Chapter 2: Materials and Methods}

\subsection{Sample Details}

\subsubsection{Tissue Distribution and Maternal Transfer (Chapter 3)}

Samples of organs and tissues, i.e., liver, blood, the whole brain, muscle and adipose, were collected from female herring gulls $(n=8)$ from Chantry Island, Lake Huron in April 2010 (See Figure 1.3 for colony location). This site was chosen as a representative colony for herring gulls in the Great Lakes. As there are thousands of breeding herring gulls on this island, the sacrifice of eight female herring gulls had little impact on the herring gull population at this colony. The blood samples were centrifuged on site to separate the plasma from the red blood cells (RBCs). All of these samples were directly frozen in liquid nitrogen on site (within one hour of death). Also, complete clutches of eggs ( $n=17)$ from the eight nests were collected (seven nests with two eggs, one nest with three eggs). The eggs were keept warm, but not incubated, by placing them in a foam padded case. All of the frozen tissues and eggs were transported to Environment Canada's National Wildlife Specimen Bank (EC-NWSB) in Ottawa, Canada within 36 hours of collection. Frozen samples were stored in the EC-NWSB at $-40^{\circ} \mathrm{C}$ prior to chemical analysis. Shortly after arrival at the EC-NWSB, the eggs were processed by separating and homogenizing the yolk and albumen and storing them also at $-40^{\circ} \mathrm{C}$ until chemical analysis. Animal capturing, handling and euthanization was approved by the Animal Care Committee for NWRC and Ontario region of the Canadian Wildlife Service (Environment Canada). 


\subsubsection{Great Lakes Spatial Trend PFCs including PFOS Isomers (Chapters 4 \& 5)}

Individual herring gull eggs were collected in late April to early May 2007 at fifteen colonies in the Laurentian Great Lakes: Granite Island, Agawa Rocks, Big Sister Island, Gull Island, Channel-Shelter Island, Double Island, Chantry Island, Fighting Island, Middle Island, Port Colborne, Niagara River, Hamilton Harbour, Toronto Harbour, Snake Island, and Strachan Island (Figure 1.3). For each site, $\mathrm{n}=13$ individual eggs were homogenized and stored at $-40^{\circ} \mathrm{C}$ at Environment Canada's National Wildlife Specimen Bank (EC-NWSB) prior to chemical analysis.

\subsubsection{Great Lakes Temporal Trend PFCs (Chapter 6)}

Herring gull eggs $(n=13)$ were collected from seven colonies on the Laurentian Great Lakes (Agawa Rocks, Gull Island, Channel-Shelter Island, Chantry Island, Fighting Island, Niagara River, and Toronto Harbour). Eggs were analyzed from 1990 and 19972010 with the exception of Fighting Island for which no eggs were available in 2009 (Figure 1.3). These years were chosen to determine the influence of the 2002 North American phase-out of the ECF-related $\mathrm{C}_{8}$ chemistry PFCs on concentrations in wildlife. Egg pools were analyzed from five years (1997 to 2001) prior to and eight years following (2003 to 2010) the phase-out. Egg pools from 1990 were analyzed to determine concentrations $>10$ years prior to the phase-out concentrations. For each year at each colony, the individual eggs were pooled on an equal weight basis and stored at $-40^{\circ} \mathrm{C}$ at Environment Canada's National Wildlife Specimen Bank (EC-NWSB) prior to chemical analysis. 


\subsubsection{Pan-Canadian Spatial Trend PFCs (Chapter 7)}

Individual eggs $(\mathrm{n}=10)$ from glaucous-winged, California, ring-billed, and herring gulls were collected in early May to early July 2008 from 15 selected colony sites in provinces across Canada: Florencia Island, Mandarte Island, Dalemead Reservoir, Pipstone Rocks, Silver Islet, Big Chicken Island, Toronto Harbour, Ile Deslauriers, Ile Bellechasse, Ile du Corossol, Kent Island, Manawagonish Island, Sable Island, and Gull Island. (Table 2.1, Figure 2.1). The collected eggs (embryo development was observed in several eggs from six colonies) were transported to Environment Canada's National Wildlife Specimen Bank (EC-NWSB) and subsequently homogenized and stored at $-40^{\circ} \mathrm{C}$ prior to chemical analysis.

\subsection{Contaminant Analysis}

\subsubsection{Standards and Chemicals}

Perfluorosulfonate, perfluorocarboxylate, perfluorosulfonamide, fluorotelomer alcohol, and fluorotelomer unsaturated acids as well as sixteen labelled internal standards (IS) were obtained from Wellington Laboratories (Guelph, ON, Canada). A technical PFOS solution containing six mono(trifluoromethyl) isomers (P1MHpS, P2MHpS, P3MHpS, P4MHpS, P5MHpS, P6MHpS), four di(trifluoromethyl) isomers (P35DMHxS, P44DMHxS, P45DMHxS, P55DMHxS) and linear PFOS (L-PFOS) isomers were purchased from Wellington Laboratories (Guelph, ON, Canada). The full chemical names and structures of all PFCs are detailed in Tables 2.2 and 2.3. All chemicals were 


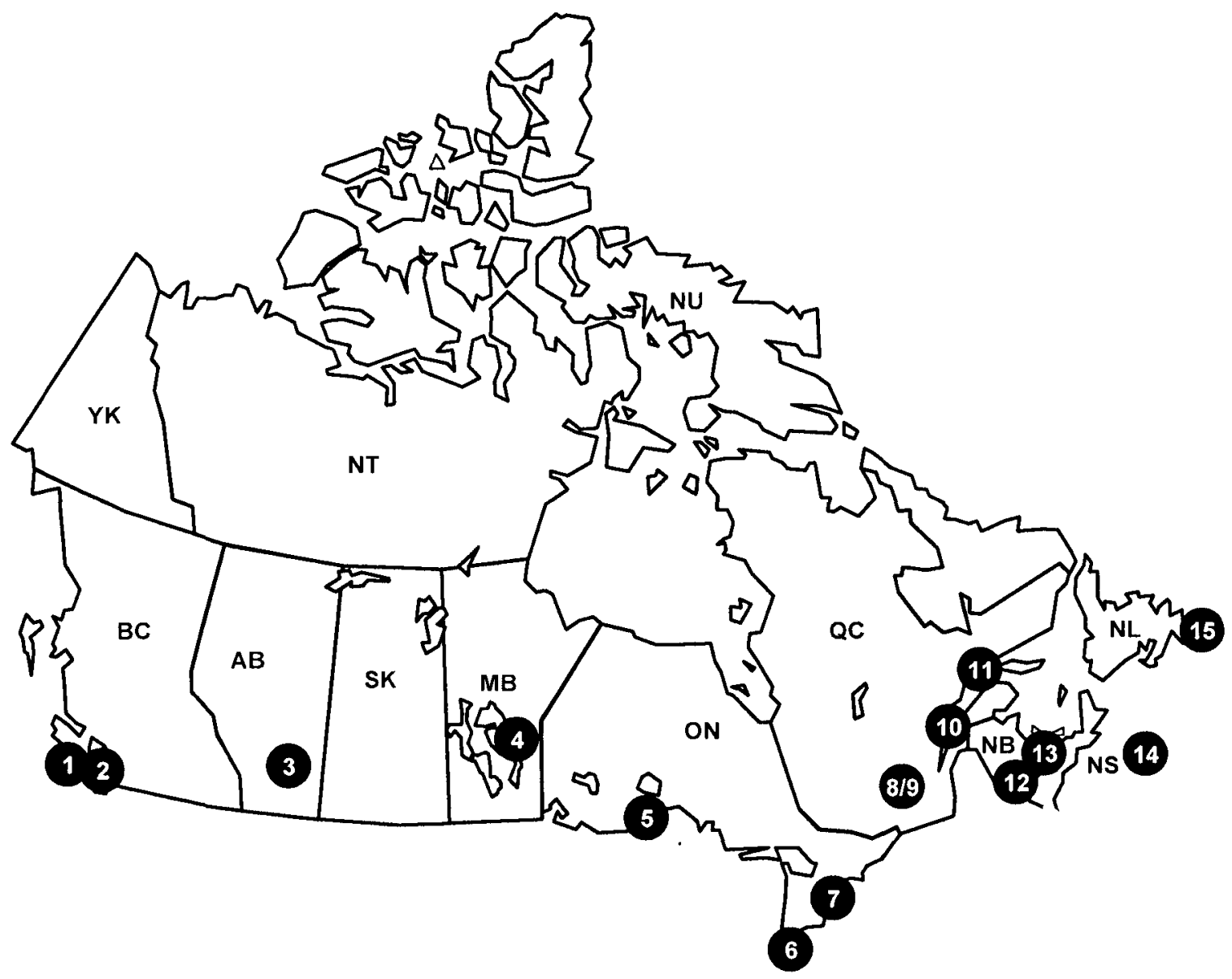

Figure 2.1 Sites of the gull colonies across Canada: (1) Florencia Island, (2) Mandarte Island, (3) Dalemead Reservoir, (4) Pipstone Rocks, (5) Silver Islet, (6) Big Chicken Island, (7) Toronto Harbour, (8/9) Ile Deslauriers, (10) Ile Bellechasse, (11) Ile du Corossol, (12) Kent Island, (13) Manawagonish Island, (14) Sable Island, and (15) Gull Island. 
Table 2.1 Locations of gull colonies across Canada and gull species of the 2008 egg collection $(n=10)$

\begin{tabular}{|c|c|c|c|c|c|c|c|}
\hline Colony $\#^{\text {a }}$ & Location & Province & Water body & Ecosystem & Species & Latıtude & Longitude \\
\hline 1 & Florencia Is & Britısh Columbıa & Pacific Ocean & Marıne & Glaucous-winged Gull & $4858 \mathrm{~N}$ & $12538^{\prime} \mathrm{W}$ \\
\hline 2 & Mandarte Is & Britısh Columbıa & Strait of Georgia & Marine & Glaucous-wınged Gull & $4840^{\prime} \mathrm{N}$ & $12318^{\prime} \mathrm{W}$ \\
\hline 3 & Dalemead Reservoir & Alberta & Bow River system & Freshwater & Calıfornıa Gull & $5055^{\prime} \mathrm{N}$ & $11337^{\prime} \mathrm{W}$ \\
\hline 4 & Pipestone Rocks & Manitoba & Lake Winnıpeg & Freshwater & Herring Gull & $5123^{\prime} \mathrm{N}$ & $9633^{\prime} \mathrm{W}$ \\
\hline 5 & Silver Islet & Ontario & Lake Superior & Freshwater & Herrıng Gull & $4829^{\prime} \mathrm{N}$ & $8842^{\prime} \mathrm{W}$ \\
\hline 6 & Big Chicken Is & Ontario & Lake Erie & Freshwater & Herring Gull & $4154^{\prime} \mathrm{N}$ & $8248^{\prime} \mathrm{W}$ \\
\hline 7 & Toronto Harbour & Ontario & Lake Ontarıo & Freshwater & Herrıng Gull & $4338^{\prime} \mathrm{N}$ & $7922^{\prime} \mathrm{W}$ \\
\hline 8 & Ile Deslaurıers & Quebec & St Lawrence River & Freshwater & Herrıng Gull & $4542^{\prime} \mathrm{N}$ & $7326^{\prime} \mathrm{W}$ \\
\hline 9 & Ile Deslauriers & Quebec & St Lawrence River & Freshwater & Ring-billed Gull & $4542 \mathrm{~N}$ & $7326^{\prime} \mathrm{W}$ \\
\hline 10 & Ile Bellechasse & Quebec & St Lawrence River & Mixed & Herrıng Gull & $4655^{\prime} \mathrm{N}$ & $7046^{\prime} \mathrm{W}$ \\
\hline 11 & Ile du Corossol & Quebec & Gulf of St Lawrence & Marıne & Herrıng Gull & $505 \mathrm{~N}$ & $6623^{\prime} \mathrm{W}$ \\
\hline 12 & Kent Is & New Brunswick & Bay of Fundy & Marıne & Herring Gull & $4434 \mathrm{~N}$ & $6645^{\prime} \mathrm{W}$ \\
\hline 13 & Manawagonısh Is & New Brunswick & Bay of Fundy & Marıne & Herrıng Gull & $4512^{\prime} \mathrm{N}$ & $666^{\prime} \mathrm{W}$ \\
\hline 14 & Sable Is & Nova Scotıa & Atlantıc Ocean & Marıne & Herrıng Gull & $4357 \mathrm{~N}$ & $5955^{\prime} \mathrm{W}$ \\
\hline 15 & Gull Is & Newfoundland & Atlantic Ocean & Marıne & Herring Gull & $4715^{\prime} \mathrm{N}$ & $5245^{\prime} \mathrm{W}$ \\
\hline
\end{tabular}

${ }^{a}$ See Figure 2.1 map for colony location. 
Table 2.2 Chemical names and structures of PFSAs, FOSAs, PFCAs, FTUCAs, and FTOHs and internal standards used

\begin{tabular}{|c|c|c|c|}
\hline \multicolumn{2}{|c|}{ Target Compound } & \multirow{2}{*}{$\begin{array}{l}\text { Chemical Structure } \\
\mathrm{CF}_{3}\left(\mathrm{CF}_{2}\right)_{3} \mathrm{SO}_{3}{ }^{-}\end{array}$} & \multirow{2}{*}{$\begin{array}{l}\text { Internal Standard } \\
\mathrm{PFH} \times \mathrm{A}^{-13} \mathrm{C}_{2}\end{array}$} \\
\hline PFSAs & PFBS & & \\
\hline & PFHxS & $\mathrm{CF}_{3}\left(\mathrm{CF}_{2}\right)_{5} \mathrm{SO}_{3}^{-}$ & PFHxS- ${ }^{18} \mathrm{O}_{2}$ \\
\hline & PFOS & $\mathrm{CF}_{3}\left(\mathrm{CF}_{2}\right)_{7} \mathrm{SO}_{3}^{-}$ & PFOS $-{ }^{13} \mathrm{C}_{4}$ \\
\hline & PFDS & $\mathrm{CF}_{3}\left(\mathrm{CF}_{2}\right)_{9} \mathrm{SO}_{3}^{-}$ & PFUnA- ${ }^{13} \mathrm{C}_{2}$ \\
\hline \multirow[t]{2}{*}{ FOSAs } & PFOSA & $\mathrm{CF}_{3}\left(\mathrm{CF}_{2}\right)_{7} \mathrm{SO}_{2} \mathrm{NH}_{2}$ & PFOSA $-{ }^{3} \mathrm{C}_{8}$ \\
\hline & N-Me-FOSA & $\mathrm{CF}_{3}\left(\mathrm{CF}_{2}\right)_{7} \mathrm{SO}_{2} \mathrm{NCH}_{3} \mathrm{H}$ & d-N-Me-FOSA \\
\hline \multirow[t]{10}{*}{ PFCAs } & PFHxA & $\mathrm{CF}_{3}\left(\mathrm{CF}_{2}\right)_{4} \mathrm{COOH}$ & $\mathrm{PFHxA}-{ }^{13} \mathrm{C}_{2}$ \\
\hline & PFHpA & $\mathrm{CF}_{3}\left(\mathrm{CF}_{2}\right)_{5} \mathrm{COOH}$ & PFHxS- ${ }^{18} \mathrm{O}_{2}$ \\
\hline & PFOA & $\mathrm{CF}_{3}\left(\mathrm{CF}_{2}\right)_{6} \mathrm{COOH}$ & $\mathrm{PFOA}-{ }^{13} \mathrm{C}_{4}$ \\
\hline & PFNA & $\mathrm{CF}_{3}\left(\mathrm{CF}_{2}\right)_{7} \mathrm{COOH}$ & PFNA $-{ }^{13} \mathrm{C}_{5}$ \\
\hline & PFDA & $\mathrm{CF}_{3}\left(\mathrm{CF}_{2}\right)_{8} \mathrm{COOH}$ & PFDA $-{ }^{13} \mathrm{C}_{2}$ \\
\hline & PFUnA & $\mathrm{CF}_{3}\left(\mathrm{CF}_{2}\right)_{9} \mathrm{COOH}$ & PFUnA- $-{ }^{13} \mathrm{C}_{2}$ \\
\hline & PFDoA & $\mathrm{CF}_{3}\left(\mathrm{CF}_{2}\right)_{10} \mathrm{COOH}$ & PFDoA $-{ }^{13} \mathrm{C}_{2}$ \\
\hline & PFTriA & $\mathrm{CF}_{3}\left(\mathrm{CF}_{2}\right)_{11} \mathrm{COOH}$ & PFDoA- $-{ }^{13} \mathrm{C}_{2}$ \\
\hline & PFTeA & $\mathrm{CF}_{3}\left(\mathrm{CF}_{2}\right)_{12} \mathrm{COOH}$ & PFDoA $-{ }^{13} \mathrm{C}_{2}$ \\
\hline & PFPA & $\mathrm{CF}_{3}\left(\mathrm{CF}_{2}\right)_{{ }_{3}} \mathrm{COOH}$ & PFDoA- ${ }^{13} \mathrm{C}_{2}$ \\
\hline \multirow[t]{3}{*}{ FTUCAs } & 62 FTUCA & $\mathrm{CF}_{3}\left(\mathrm{CF}_{2}\right)_{4} \mathrm{CFCHCOOH}$ & 6:2 FTUCA- ${ }^{13} \mathrm{C}_{2}$ \\
\hline & $8: 2$ FTUCA & $\mathrm{CF}_{3}\left(\mathrm{CF}_{2}\right)_{6} \mathrm{CFCHCOOH}$ & $8: 2$ FTUCA- ${ }^{13} \mathrm{C}_{2}$ \\
\hline & $10 \cdot 2$ FTUCA & $\mathrm{CF}_{3}\left(\mathrm{CF}_{2}\right)_{8} \mathrm{CFCHCOOH}$ & 10:2 FTUCA- ${ }^{13} \mathrm{C}_{2}$ \\
\hline \multirow[t]{3}{*}{ FTOHs } & $6: 2 \mathrm{FTOH}$ & $\mathrm{CF}_{3}\left(\mathrm{CF}_{2}\right)_{5}\left(\mathrm{CH}_{2}\right)_{2} \mathrm{OH}$ & $6: 2 \mathrm{FTOH}-{ }^{13} \mathrm{C}_{2}$ \\
\hline & $8: 2$ FTOH & $\mathrm{CF}_{3}\left(\mathrm{CF}_{2}\right)_{7}\left(\mathrm{CH}_{2}\right)_{2} \mathrm{OH}$ & $8: 2 \mathrm{FTOH}_{-}{ }^{13} \mathrm{C}_{2}$ \\
\hline & $10: 2 \mathrm{FTOH}$ & $\mathrm{CF}_{3}\left(\mathrm{CF}_{2}\right)_{8}\left(\mathrm{CH}_{2}\right)_{2} \mathrm{OH}$ & 10:2 FTOH $-{ }^{13} \mathrm{C}_{2}$ \\
\hline
\end{tabular}


Table 2.3 Chemical names and GC-MS (ECNI) monitoring ions of derivatized PFOS isomers

\begin{tabular}{llll}
\hline No. & Compound & Chemical Name & Ions \\
\hline 1 & L-PFOS & n-perfluoro-1-octanesulfonate & 499 \\
2 & P1MHpS & perfluoro-1-methyl-heptanesulfonate & 137 \\
3 & P2MHpS & perfluoro-2-methyl-heptanesulfonate & 137 \\
4 & P3MHpS & perfluoro-3-methyl-heptanesulfonate & 480 \\
5 & P4MHpS & perfluoro-4-methyl-heptanesulfonate & 480 \\
6 & P5MHpS & perfluoro-5-methyl-heptanesulfonate & 480 \\
7 & P6MHpS & perfluor-6-methyl-heptanesulfonate & 480 \\
8 & P35DMHxS & perfluoro-3,5-dimethyl-hexanesulfonate & 480 \\
9 & P44DMHxS & perfluoro-4,4-dimethyl-hexanesulfonate & 137 \\
10 & P45DMHxS & perfluoro-4,5-dimethyl-hexanesulfonate & 480 \\
11 & P55DMHxS & perfluoro-5,5-dimethyl-hexanesulfonate & 137 \\
& & & \\
IS & L-PFOS- ${ }^{13} \mathrm{C}_{4}$ & $n$-perfluoro-1-[1,2,3,4- $\left.{ }^{13} \mathrm{C}_{4}\right]$ octanesulfonate & 503 \\
\hline
\end{tabular}


analytical grade purity and solvents used were HPLC grade and purchased from Fisher Scientific (Ottawa, Canada).

\subsubsection{Extraction and Clean up}

\subsubsection{PFSAs, PFCAs, FOSAs, FTOHs, FTUCAs}

The PFC extraction and cleanup for all tissues, plasma, RBCs, and egg albumen and yolk were the same, and described in Taniyasu et al. (63) and Chu and Letcher (64). Samples (0.2 - $2 \mathrm{~g}$ depending on the tissue) were spiked with labelled internal standards and extracted three times with $3 \mathrm{ml} 10 \mathrm{mM}$ potassium hydroxide $(\mathrm{KOH})$ acetonitrile/water $(80 / 20 \mathrm{v} / \mathrm{v})$. A volume of $2 \mathrm{ml}$ of the combined extract was diluted with $8 \mathrm{ml}$ water and adjusted to $\mathrm{pH} 4$ with $2 \%$ aqueous formic acid $(\sim 100 \mu \mathrm{l})$. The cleanup and fractionation of the overall PFC extract was performed using Waters Oasis WAX solid phase extraction (SPE) cartridges. The cartridges were preconditioned with $3 \mathrm{ml}$ methanol followed by 3 $\mathrm{ml}$ of water. The fraction from the $\mathrm{KOH}$ acetonitrile/water sample extraction was loaded onto the SPE cartridge, washed with $1 \mathrm{ml} 2 \%$ aqueous formic acid and then with two times $1 \mathrm{ml}$ water. The first fraction was collected by using $1 \mathrm{ml}$ methanol; this fraction contained the neutral FTOHs and FOSAs. The SPE cartridge was then washed with $1 \mathrm{ml}$ methanol before the second fraction was eluted using two times $1 \mathrm{ml}$ of $1 \%$ ammonium hydroxide in methanol. This fraction contained the acidic PFSAs, PFCAs and FTUCAs. A volume of $0.5 \mathrm{ml}$ of fraction 1 was mixed with $20 \mathrm{mg}$ of active carbon. Fraction 2 was dried using a stream of nitrogen and dissolved in $200 \mu \mathrm{l}$ of methanol. Prior to LC-MS/MS analysis, both fractions were filtered using centrifugal filters (modified nylon $0.2 \mu \mathrm{m}, 500$ $\mu \mathrm{l})$. 


\subsubsection{PFOS Isomers}

The PFOS isomer extraction and cleanup from herring gull eggs was based on Chu and Letcher (3). The methanol LC-MS/MS Fraction 2 extracts (which already contained the

${ }^{13}$ C-labeled PFOS as internal standard) were evaporated to dryness and dissolved in 100 $\mu \mathrm{l}$ water. A volume of $100 \mu \mathrm{l}$ tetrabutylammonium hydroxide (TBAH) solution $(0.5 \mathrm{~g}$ of TBAH in $5 \mathrm{ml}$ diethyl ether) was added to each sample. The tubes were capped and the solution was vortexed, subsequently $100 \mu \mathrm{l}$ of diethyl ether was added and mixed again. The samples were centrifuged and frozen at $-20^{\circ} \mathrm{C}$. The diethyl ether phase was separated from the aqueous layer (ice) and transferred into another tube. The samples were evaporated to dryness, redissolved in $100 \mu \mathrm{l}$ of diethyl ether and transferred to a vial with $100 \mu \mathrm{l}$ insert for GC-MS analysis.

\subsubsection{Measurements}

\subsubsection{LC-MS/MS (PFSAs, PFCAs, FOSAs, FTOHs, FTUCAs)}

The LC-MS/MS methods were based on Taniyasu et al. (63) and Chu and Letcher (64). The separation of the target compounds in both fractions was carried out on a Waters 2695 HPLC equipped with an ACE $3 \mathrm{C}_{18}$ analytical column (50 $\mathrm{mm} \times 2.1 \mathrm{~mm}$ I.D., $3 \mu \mathrm{m}$ particle size $)$ and an $\mathrm{ACE} 3 \mathrm{C}_{18}$ guard column (10 mm x $2.1 \mathrm{~mm}$ I.D., $3 \mu \mathrm{m}$ particle size, Advanced Chromatography Technologies, Aberdeen, UK). The mobile phases for Fraction 1 were water and methanol; for Fraction 2, $2 \mathrm{mM}$ ammonium acetate in water and methanol were used. The flow rate was $0.2 \mathrm{ml} / \mathrm{min}$, details on the mobile phase gradients are provided in Table 2.4 , and the LC column was kept at $40^{\circ} \mathrm{C}$. Coupled to the HPLC was a Waters Quattro Ultima triple quadrupole mass spectrometer (Waters, 
Milford, MA, USA). Nitrogen was used as nebulizing gas and desolvantion gas, argon was used as collision gas when multiple reaction monitoring (MRM) mode was used. For neutral PFCs in fraction 1, atmospheric pressure photoionization (APPI) was used in negative mode with a krypton UV lamp. Toluene was used as dopant and introduced to the APPI source at $2 \%$ of the flow rate of the mobile phase. The source temperature was $150^{\circ} \mathrm{C}$, the probe temperature $250^{\circ} \mathrm{C}$. An electrospray ionization (ESI) source in negative mode was used for acidic PFCs in fraction 2, with a source temperature of $120^{\circ} \mathrm{C}$ and a desolvation temperature of $350^{\circ} \mathrm{C}$. Further details on the source and analyzer operation parameters and compound dependant operation parameters are provided in Tables 2.5 and 2.6 .

\subsubsection{GC-MS (PFOS Isomers)}

The in-port derivatization and gas chromatography-mass spectrometric analysis, based on Chu and Letcher (3) were performed using an Agilent 6890 gas chromatograph (GC) coupled to an Agilent-5973N quadrupole mass spectrometer (MS) detector (Mississauga, ON, Canada). The GC was equipped with a $30 \mathrm{~m} \times 0.25 \mathrm{~mm}$ i.d. DB-5 capillary column with a film thickness of $0.25 \mu \mathrm{m}$. Helium was used as carrier gas at a constant flow of 1 $\mathrm{mL} / \mathrm{min}$. Five microliters of sample solution were injected with splitless mode, and a double taper deactivated splitless inlet liner was used. The injector temperature was $300^{\circ} \mathrm{C}$; the oven temperature was programmed as follows: $50^{\circ} \mathrm{C}$, hold for $2 \mathrm{~min}$, then at $5^{\circ} \mathrm{C} /$ min to $120^{\circ} \mathrm{C}$. Ionization was performed in electron capture negative ionization (ECNI) mode using methane as reagent gas. The transfer line, source, and quadrupole temperatures were 280,180 , and $150^{\circ} \mathrm{C}$, respectively. Selected ion-monitoring mode 
Table 2.4 Mobile phase gradient for separation of FOSAs, FTOHs (Fraction 1) and PFSAs, PFCAs, and FTUCAs (Fraction 2).

\begin{tabular}{|c|c|c|c|c|}
\hline & Time (min) & $\mathrm{A} \%$ & $\mathrm{~B} \%$ & Flow $(\mathrm{ml} / \mathrm{min})$ \\
\hline \multirow[t]{6}{*}{ Fraction 1} & 0 & 95 & 5 & 0.200 \\
\hline & 10 & 0 & 100 & 0.200 \\
\hline & 20 & 0 & 100 & 0.200 \\
\hline & 21 & 95 & 5 & 0.200 \\
\hline & 35 & 95 & 5 & 0.200 \\
\hline & \multicolumn{3}{|c|}{$\begin{array}{l}\mathrm{A}=\text { Milli-Q water } \\
\mathrm{B}=\text { HPLC Grade methanol }\end{array}$} & \\
\hline \multirow[t]{7}{*}{ Fraction 2} & 0 & 95 & 5 & 0.200 \\
\hline & 10 & 20 & 80 & 0.200 \\
\hline & 20 & 0 & 100 & 0.200 \\
\hline & 25 & 0 & 100 & 0.200 \\
\hline & 26 & 95 & 5 & 0.200 \\
\hline & 40 & 95 & 5 & 0.200 \\
\hline & \multicolumn{4}{|c|}{$\begin{array}{l}\mathrm{A}=2 \mathrm{mM} \text { Ammonium Acetate in Milli-Q water } \\
\mathrm{B}=2 \mathrm{mM} \text { Ammonium Acetate in HPLC Grade methanol }\end{array}$} \\
\hline
\end{tabular}


Table 2.5 Source operation parameters and analyzer operation parameters for FTOHs, FOSAs (Fraction 1) and PFSAs, PFCAs and FTUCAs (Fraction 2).

Fraction 1

Source Operation Parameters

Source

Corona

Capillary voltage

Cone voltage

RF Lens l voltage

Aperture voltage

RF Lens 2 voltage

Source temperature

Probe temperature

Cone Gas flow

Desolvation gas flow
APPI-

$15.00 \mu \mathrm{A}$

See Table 2.6

$5 \mathrm{~V}$

$0 \mathrm{~V}$

$0.5 \mathrm{~V}$

$150^{\circ} \mathrm{C}$

$250^{\circ} \mathrm{C}$

$100 \mathrm{~L} / \mathrm{h}$

$700 \mathrm{~L} / \mathrm{h}$
Fraction 2

ESI-

$1.0 \mathrm{kV}$

See Table 2.6

10

0

$0.2 \mathrm{~V}$

$120^{\circ} \mathrm{C}$

$350^{\circ} \mathrm{C}$

$100 \mathrm{~L} / \mathrm{h}$

$600 \mathrm{~L} / \mathrm{h}$

\section{Analyzer Operation Parameters}

LM Resolution

13.0

13.0

13.0

HM Resolution

1.0

Ion Energy 1

Entrance

$-2$

1.0

Collision energy

Exit

LM Resolution 2

HM Resolution 2

Ion Energy 2

Multiplier

See Table 2.6

$$
-2
$$

1.0

13.0

See Table 2.6

13.0

1.0

13.0

1.0

13.0

650 
Table 2.6 Transitions and compound dependant operation parameters for FTOHs, FOSAs, PFSAs, PFCAs and FTUCAs determination by LC/MS/MS.

\begin{tabular}{|c|c|c|c|c|c|c|}
\hline & $\begin{array}{c}\text { Target } \\
\text { Compound }\end{array}$ & $\begin{array}{c}\text { Parent } \\
\text { ion (Da) }\end{array}$ & $\begin{array}{l}\text { Daughter } \\
\text { ion (Da) }\end{array}$ & $\begin{array}{c}\text { Cone } \\
\text { Voltage (V) }\end{array}$ & $\begin{array}{c}\text { Collısion } \\
\text { Energy }(\mathrm{eV})\end{array}$ & $\begin{array}{c}\text { Dwell } \\
\text { Tıme (sec) }\end{array}$ \\
\hline \multirow[t]{10}{*}{$\overline{F l}$} & $62 \mathrm{FTOH}$ & 3629 & 3029 & 35 & 10 & 02 \\
\hline & $82 \mathrm{FTOH}$ & 4628 & 4028 & 40 & 10 & 02 \\
\hline & $102 \mathrm{FTOH}$ & 5628 & 5028 & 40 & 10 & 02 \\
\hline & $62 \mathrm{FTOH}-{ }^{13} \mathrm{C}_{2}$ & 3669 & 3059 & 50 & 10 & 02 \\
\hline & $82 \mathrm{FTOH}^{-13} \mathrm{C}_{2}$ & 4668 & 4059 & 35 & 8 & 02 \\
\hline & $102 \mathrm{FTOH}_{-}{ }^{13} \mathrm{C}_{2}$ & 5668 & 5058 & 45 & 8 & 02 \\
\hline & PFOSA & 4977 & 781 & 70 & 40 & 02 \\
\hline & N-Me-FOSA & 5118 & 1689 & 60 & 30 & 02 \\
\hline & PFOSA $-{ }^{13} \mathrm{C}_{8}$ & 5059 & 780 & 70 & 40 & 02 \\
\hline & d-N-Me-FOSA & 5148 & 1689 & 60 & 30 & 02 \\
\hline \multirow[t]{28}{*}{ F2 } & PFBS & 2988 & 803 & 45 & 35 & 050 \\
\hline & PFHxS & 3988 & 799 & 50 & 40 & 020 \\
\hline & PFOS & 4988 & 799 & 35 & 40 & 020 \\
\hline & PFDS & 5988 & 800 & 35 & 55 & 020 \\
\hline & $\mathrm{PFHxS}-{ }^{18} \mathrm{O}_{2}$ & 4028 & 839 & 50 & 40 & 020 \\
\hline & PFOS- ${ }^{13} \mathrm{C}_{4}$ & 5028 & 800 & 35 & 40 & 020 \\
\hline & PFHxA & 3128 & 2689 & 40 & 10 & 030 \\
\hline & PFHpA & 3629 & 3189 & 40 & 8 & 020 \\
\hline & PFOA & 4128 & 3689 & 35 & 8 & 025 \\
\hline & PFNA & 4628 & 4189 & 45 & 10 & 020 \\
\hline & PFDA & 5128 & 4689 & 45 & 10 & 030 \\
\hline & PFUnA & 5628 & 5189 & 35 & 10 & 020 \\
\hline & PFDoA & 6129 & 5689 & 35 & 10 & 020 \\
\hline & PFTrıA & 6629 & 6190 & 35 & 10 & 050 \\
\hline & PFTeA & 7128 & 6690 & 35 & 15 & 030 \\
\hline & PFPA & 7628 & 7190 & 35 & 10 & 030 \\
\hline & PFHxA $-{ }^{13} \mathrm{C}_{2}$ & 3148 & 2699 & 40 & 10 & 030 \\
\hline & PFOA $-{ }^{13} \mathrm{C}_{4}$ & 4169 & 3719 & 35 & 8 & 025 \\
\hline & PFNA $-{ }^{13} \mathrm{C}_{5}$ & 4679 & 4230 & 45 & 10 & 020 \\
\hline & PFDA $-{ }^{13} \mathrm{C}_{2}$ & 5148 & 4699 & 45 & 10 & 030 \\
\hline & PFUnA $-{ }^{13} \mathrm{C}_{2}$ & 5649 & 5199 & 35 & 10 & 020 \\
\hline & PFDoA $-{ }^{13} \mathrm{C}_{2}$ & 6149 & 5700 & 35 & 10 & 030 \\
\hline & 62 FTUCA & 3569 & 2930 & 35 & 10 & 020 \\
\hline & 82 FTUCA & 4569 & 3930 & 35 & 10 & 020 \\
\hline & 102 FTUCA & 5569 & 4930 & 35 & 10 & 020 \\
\hline & 62 FTUCA $-{ }^{13} \mathrm{C}_{2}$ & 3589 & 2940 & 35 & 10 & 020 \\
\hline & $82 \mathrm{FTUCA}^{13} \mathrm{C}_{2}$ & 4589 & 3940 & 35 & 10 & 020 \\
\hline & $102 \mathrm{FTUCA}^{-13} \mathrm{C}_{2}$ & 5589 & 4940 & 35 & 10 & 020 \\
\hline
\end{tabular}


(SIM) was used for quantitative analysis of the derivatized PFOS isomers (see Table 2.3 for ions monitored of derivatized PFOS isomers). After each sample, an $12.5 \mu \mathrm{L}$ solution of TBAH in diethyl ether was injected (with oven temperature held at $300^{\circ} \mathrm{C}$ for $10 \mathrm{~min}$ ) to elute residual matrix compounds and reduce sample-to-sample carry-over. During the in-port derivatization GC-MS method, the acid forms of PFOS isomers are deprotonated by strongly basic TBAH:

$$
\mathrm{C}_{8} \mathrm{~F}_{17} \mathrm{SO}_{3} \mathrm{H}+\left(\mathrm{C}_{4} \mathrm{H}_{9}\right)_{4} \mathrm{~N}^{+} \mathrm{OH}^{-} \rightarrow \mathrm{C}_{8} \mathrm{~F}_{17} \mathrm{SO}_{3}^{-}\left(\mathrm{C}_{4} \mathrm{H}_{9}\right)_{4} \mathrm{~N}^{+}+\mathrm{H}_{2} \mathrm{O}
$$

In the GC injection port the quaternary ammonium salts of the PFOS isomers conjugate bases are thermally decomposed to give tertiary amine and butyl derivatives of PFOS isomers:

$$
\mathrm{C}_{8} \mathrm{~F}_{17} \mathrm{SO}_{3} \cdot\left(\mathrm{C}_{4} \mathrm{H}_{9}\right)_{4} \mathrm{~N}^{+} \rightarrow \mathrm{C}_{8} \mathrm{~F}_{17} \mathrm{SO}_{3} \mathrm{C}_{4} \mathrm{H}_{9}+\mathrm{N}\left(\mathrm{C}_{4} \mathrm{H}_{9}\right)_{3}
$$

\subsubsection{Quality Control}

Quantification of all the PFC, including the PFOS isomers, was performed using an internal standard approach. The calibration curve of PFTeA was used for PFPA quantification since PFPA standard was unavailable at the time of this study. Where no labeled standards were available, labeled ISs with the closest retention time were used. For the tissue distribution and maternal transfer dataset the recovery of the individual PFSA and PFCA IS ranged from $79 \pm 3 \%$ to $89 \pm 3 \%$. For the Great Lakes spatial trend dataset the recovery of the individual PFSA and PFCA IS ranged from $69 \pm 2 \%$ to $105 \pm$ $7 \%$. For the temporal tend dataset the recovery of the individual PFSA and PFCA IS ranged from $72 \pm 2 \%$ to $94 \pm 3 \%$. For the Pan-Canadian spatial trend dataset, the recovery of the individual PFSA and PFCA IS ranged from $70 \pm 2 \%$ to $80 \pm 2 \%$. Since an 
isotope dilution quantification approach was used, the concentrations were inherently recovery-corrected. For every block of samples, an NWRC in-house reference material of double-crested cormorant egg pool (based on eggs collected in 2003) was analyzed to assess reproducibility of the method. For both $\Sigma$ PFSA $\left(\mathrm{C}_{6}, \mathrm{C}_{8}, \mathrm{C}_{10}\right)$ and $\Sigma \mathrm{PFCA}\left(\mathrm{C}_{8}-\mathrm{C}_{15}\right)$, good reproducibility was obtained with a RSD of $13 \% \Sigma \mathrm{PFSA}$ and $10 \%$ for $\Sigma \mathrm{PFCA}$ $(n=60)$. For each batch of samples method blanks were included, and low background levels were subtracted on a batch-by-batch basis. At NWRC, the Organic Contaminants Research Laboratory (OCRL) regularly participates in inter-laboratory QA/QC exercises for PFC analysis. Since 2007 and up until and including this year, the OCRL: participated in two PFC QA/QC exercises. For several PFCAs, PFSAs, and PFOSA, NIST SRM 1945 analysis results were within $10 \%$ of the interlab mean values, and reported in the e.g. 2007 NIST/NOAA Interlaboratory Comparison Exercise Program for Organic Contaminants in Marine Mammal Tissues. Similar results were achieved on a ringed seal liver SRM as part of an interlab QA/QC exercise in the 2007, 2008, 2009 and recently 2010, as part of the Northern Contaminants Program (NCP, Department of Indian and Northern Affairs Canada).

\subsection{Stable Isotope Analysis}

\subsubsection{Extraction}

For the Pan-Canadian spatial trend dataset, gull egg homogenates were analyzed for $\delta^{15} \mathrm{~N}$ and $\delta^{13} \mathrm{C}$ stable isotopes based on Hebert et al. (65). Approximately 1 gram of homogenized egg was dried overnight at $\sim 80^{\circ} \mathrm{C}$. The dried samples were ground to a powder and $20 \mathrm{ml}$ chloroform/methanol $(2: 1)$ was added. The samples were vortexed and 
sonicated and allowed to stand overnight. Subsequently the samples were centrifuged at $3000 \mathrm{rpm}$ for $20 \mathrm{~min}$, the supernatant was discarded. $20 \mathrm{ml}$ water was added and the samples were vortexed, sonicated and centrifuged. The supernatant (containing lipids) was discarded and the lipid-extracted samples were dried overnight at $\sim 80^{\circ} \mathrm{C}$. Samples $(\sim 0.2-0.3 \mathrm{mg})$ were accurately weighed into $5 \times 3.5 \mathrm{~mm}$ tin capsules.

\subsubsection{Measurements}

The samples were analyzed for nitrogen $\left({ }^{15} \mathrm{~N}^{114} \mathrm{~N}\right)$ and carbon $\left({ }^{13} \mathrm{C}^{/ 12} \mathrm{C}\right.$ ) isotopes (from this point on referred to as $\delta^{15} \mathrm{~N}$ and $\delta^{13} \mathrm{C}$ ) by the Environmental Isotope Laboratory (EIL) at the University of Waterloo, Ontario, Canada. $\delta^{15} \mathrm{~N}$ and $\delta^{13} \mathrm{C}$ SI data represent the difference in the SI ratio in the samples relative to the ratio in a standard. For example, the nitrogen SI ratio is reported in per mil $(\%)$ as:

$$
\delta^{15} \mathrm{~N}=\left[\left(\frac{{ }^{15} \mathrm{~N} /{ }^{14} \mathrm{~N}_{\text {sample }}}{{ }^{15} \mathrm{~N} /{ }^{14} \mathrm{~N}_{\text {standard }}}\right)-1\right] \times 1000 \% 0
$$

Replicates of NIST or EIL carbon and nitrogen standards were analyzed for QA/QC purposes. Analytical details from EIL were as follows. At EIL, solid samples are run for nitrogen and carbon SI analysis on one of 2 systems, 1) a Delta Plus Continuous Flow Stable Isotope Ratio Mass Spectrometer (Thermo Finnigan / Bremen-Germany) coupled to a Carlo Erba Elemental Analyzer (CHNS-O EA1108 - Italy), or 2) an Isochrom Continuous Flow Stable Isotope Ratio Mass Spectrometer (GVInstruments / MicromassUK) coupled to a Carlo Erba Elemental Analyzer (CHNS-O EA1108 - Italy). The Micromass Isochrom EA-IRMS system was checked each day before analyzing samples 
by running the peak shape program. With the standard gas flowing, the mass spectrometer scanned from peak 43 to 47 . The operator checked to make sure the peak shape was correct and that the collectors were set in the center of the peaks. The standard was then introduced 10 times to check stability and reproducibility. If the reproducibility was less than 0.01 , the peak shape was adjusted and the standard check was repeated. The mass spectrometer sample run program performed an analysis on the gas standard with each sample to confirm stability. The performance of the complete sample run was checked by the reproducibility of this analysis.

$\delta^{15} \mathrm{~N}$ and $\delta^{13} \mathrm{C}$ analysis results were generally corrected to nitrogen standards IAEA$\mathrm{N} 1$ and IAEA-N2 (both ammonium sulphate) and carbon standards IAEA-CH6 (sugar), EIL-72 (cellulose) and EIL-32 (graphite). The error for clean ball-milled standard material is $+/-0.2 \%$ for carbon and $+/-0.3 \%$ for nitrogen. This error can be expected to increase depending on the homogeneity, type and amount of sample used in analysis. A truer representation of sample reproducibility can be gained through sample repeats. Standards are placed throughout each run at a range of weights to allow for an additional linearity correction, when necessary, due to machine fluctuations or samples of varying signal peak areas. Nitrogen and carbon compositions are calculated based on Carlo Erba Elemental Standards B2005, B2035 and B2036 with an error of $+/-1 \%$. Other NIST organic materials have been run at EIL and cross-checked with other labs in hopes of producing a collection of Organic Reference materials for use in stable isotope research. At present these materials are not used in correction but rather as monitoring material. For each group of 100 samples, at EIL standards were run to check and allow for bias and linearity corrections. Four replicates of different weights were placed at the beginning 
and end of each run. This set allowed for linearity corrections. Two sets of three or four replicates of NIST or EIL carbon and nitrogen standards were analyzed in each group. Two sets of replicates of element standards were also run in each group. EIL has accumulated a set of data on a number of NIST elemental standards with respect to their isotope content. This set of control standards was used to confirm that the EA is combusting and transporting gases with the correct isotope ratio to the mass spectrometer. A sample replicate was run at least every eight samples and duplicates were run from previous groups. The overall average number of repeats was about one every eight samples. A few sample replicates of different weights were analyzed to check linearity of the sample matrix. EIL recommends that each client establish a statistical population of 30 or more analysis of one sample to confirm the error associated with the natural variation of that sample type.

\subsection{Total Burden Estimates of Perfluorinated Compounds in Herring Gull Tissues and}

\section{Eggs (Chapter 3)}

To determine the extent of maternal transfer of PFCs and chemical burdens in tissues, total amounts of $\sum$ PFSA and $\sum$ PFCA were estimated in the eggs, liver, blood, and brain. Mass of the whole body, eggs, and brain were $946 \pm 15 \mathrm{~g}, 82 \pm 2 \mathrm{~g}$ (29\% yolk, $71 \%$ albumen), and $5.7 \pm 0.1 \mathrm{~g}$, respectively. Liver mass was not recorded; however, a significant relationship $(\mathrm{n}=109, \mathrm{r}=0.478, \mathrm{p}<0.0001)$ has been shown between body mass and liver mass for female herring gulls (Mr. Glen A. Fox, NWRC, Environment Canada, personal communication). This relationship was used to estimate liver mass ( $25.3 \pm 0.5 \mathrm{~g}, 2.7 \%$ of body mass) for the eight female herring gulls. Blood samples were 
separated into plasma $(\sim 60 \% \mathrm{v} / \mathrm{v})$ and red blood cells $(\sim 40 \% \mathrm{v} / \mathrm{v})$. Herring gull whole blood volume was estimated at $60 \mathrm{~mL} / \mathrm{kg}$ body mass $(66,67)$, resulting in a blood volume estimate of $56.8 \pm 0.9 \mathrm{ml}$ for the present herring gulls. The total burdens of PFAAs in eggs, liver, blood and brain were calculated by multiplying the tissue specific concentrations (ng/g wet wt) multiplied by the estimated weight of the tissue ( $\mathrm{g}$ ).

\subsection{Data Analysis}

All tests were two-tailed and considered significantly different at $p<0.05$. Statistical tests were performed using Statistica (StatSoft, Tulsa, OK, USA). In all cases, arithmetic mean concentrations of individual PFCs or sum concentrations were only generated when detection was $>60 \%$ in individual samples. For samples with PFC concentrations < method limits of quantitation (MLOQs), a randomly generated value was assigned between zero and MLOQ for statistical purposes. MLOQs for PFSAs and PFCAs were generally $<0.1$ and $<0.05 \mathrm{ng} / \mathrm{g} \mathrm{ww}$, respectively.

\subsubsection{Tissue Distribution and Maternal Transfer (Chapter 3)}

Differences in the pattern of PFCAs in the tissues, plasma, RBCs and yolk were investigated using principal components (PC) analysis using correlation matrices. PC analysis was conducted on percent composition data. For example, percent composition data for individual PFCAs $\left(\mathrm{C}_{6}\right.$ to $\left.\mathrm{C}_{15}\right)$ were calculated relative to $\Sigma \mathrm{PFCA}$ concentrations. The differences in patterns and sum concentrations ( $\log _{10}$ transformed) in the tissues and eggs were analyzed using a single factor analysis of variance (ANOVA), followed by a Tukey's Honestly Significantly Different post hoc test. A general linear model (GLM) 
was used to determine the significance and Pearson's correlation coefficient of the PFOS, PFOA, PFNA and PFUnA correlations in the plasma and RBCs.

\subsubsection{Great Lakes Spatial Trend PFCs (Chapter 4)}

Differences in the pattern of PFCAs and PFSAs in the eggs collected from the 15 colonies were investigated using principal components (PC) analysis using correlation matrices. PC analysis was conducted on percent composition data for the concentration of individual PFCAs $\left(\mathrm{C}_{8}\right.$ to $\left.\mathrm{C}_{15}\right)$ relative to the $\mathrm{PFCA}$ concentrations, and individual PFSAs $\left(\mathrm{C}_{6}, \mathrm{C}_{8}, \mathrm{C}_{10}\right)$ relative to $\Sigma$ PFSA concentrations. Concentrations that did not approximate the normal distribution using the Shapiro-Wilk's $W$ test required $\log _{10^{-}}$ transformation. Thus, all PFCA and PFSA concentrations were $\log _{10}$-transformed to meet the assumptions of the statistical tests. The differences in patterns and sum concentrations $\left(\log _{10}\right.$ transformed) in the eggs from the 15 colonies were analyzed using a single factor analysis of variance (ANOVA), followed by a Tukey's post hoc test. A general linear model (GLM) was used to determine the significance and Pearson's correlation coefficient of the $\Sigma \mathrm{PFSA} / \Sigma \mathrm{PFCA}$ ratio.

\subsubsection{Great Lakes Spatial Trend PFOS Isomers (Chapter 5)}

A Shapiro-Wilk's $W$ test indicated a normal distribution of the arithmetic mean concentrations and subsequent arithmetic mean percent as a function of the sum for the majority of individual isomers. Differences in the pattern of PFOS isomers in the eggs collected from the 15 colonies were investigated using principal components (PC) analysis using correlation matrices. PC analysis was conducted on percent composition 
data for the concentration of individual isomer relative to the $\Sigma$ PFOS concentrations. The differences in patterns and sum concentrations ( $\log _{10}$ transformed) in the eggs from the 15 colonies were analyzed using a single factor analysis of variance (ANOVA), followed by a Tukey's post hoc test. A general linear model (GLM) was used to determine the significance and Pearson's correlation coefficient of the mono(trifluoromethyl) isomer/ $\mathrm{SPFOS}$ concentration ratio.

\subsubsection{Great Lakes Temporal Trend PFCs (Chapter 6)}

A general linear model (GLM) was used to determine the significance and Pearson's correlation coefficient of the temporal trends of individual and sum PFCs concentrations ( $\log _{10}$ transformed). Temporal trends were determined only when detection of individual PFCs was $>60 \%$ in the analyzed years at a given colony. Relationships between $\sum$ PFSA and $\sum$ PFCA, PFC concentrations and $\delta^{15} \mathrm{~N}$ and $\delta^{13} \mathrm{C}$ were assessed by GLM. Temporal changes in the PFCA pattern in the egg pools from the seven colonies was investigated using principal components (PC) analysis as well GLM. PC analysis and GLM were conducted on the percent composition for the concentration of individual PFCAs $\left(\mathrm{C}_{8}-\mathrm{C}_{15}\right)$ relative to the $\sum$ PFCA concentrations. Doubling-times and half-lives of individual PFSAs and PFCAs were estimated with $t_{1 / 2}=\ln (2) / m$, where $m$ represents the slope of the $\ln$ transformed egg concetation versus time. Doubling-times and half-lives were only estimated when strong and significant temporal trends $(r>0.5$ and $p<0.05)$ were observed between 1990 and 2010. 


\subsubsection{Pan-Canadian Spatial Trend PFCs (Chapter 7)}

Shapiro-Wilk's $W$ test indicated a normal distribution for the majority of individual PFCAs and PFSAs. Differences in the pattern of PFCAs and PFSAs in the eggs collected from the 15 colonies were investigated using principal components (PC) analysis using correlation matrices. PC analysis was conducted on percent composition data for the concentration of individual PFCAs $\left(\mathrm{C}_{6}\right.$ to $\left.\mathrm{C}_{15}\right)$ relative to the $\Sigma$ PFCA concentrations. The differences in sum concentrations ( $\log _{10}$ transformed) in the eggs from the 15 colonies were analyzed using a single factor analysis of variance (ANOVA), followed by a Tukey's post hoc test. Pearson's correlation coefficients were used to examine the relationship between egg $\Sigma$ PFSA and $\Sigma$ PFCA concentrations, and $\delta^{15} \mathrm{~N}$ and $\delta^{13} \mathrm{C}$ values at each of the 15 colonies. 


\section{Chapter 3: Compartmental Accumulation and Maternal Transfer to Eggs of Perfluoroalkyl Sulfonates and Carboxylates in Great Lakes Herring Gulls*}

\subsection{Introduction}

Information on PFCs in herring gulls from the Great Lakes or throughout Canada is extremely limited. PFOS was detected in herring gulls (blood) from Lake Huron, while PFOS was also found in ring-billed gull egg yolks from Lake Huron (25). Whether other PFCs, such as PFCAs, accumulate in herring gulls, how they are distributed through the body and/or transferred to the eggs has not been studied. In other avian species, however, the PFSA and PFCA were detected in guillemot and glaucous gull tissues, and patterns have been shown to be consistent among the analyzed tissues, however, there were differences in the tissue concentrations $(34,33)$. Liver and plasma were among the highest contaminated tissues, as PFCs were thought to be associated with proteins in these tissues. The maternal transfer of PFCs has been studied for guillemots and glaucous gulls $(33,34)$. When comparing the guillemot egg PFCA pattern to the liver pattern, a chain length dependant transfer of PFCAs to the eggs was observed (34). There was a preferential accumulation of longer chain length PFCA in the egg compared to the liver. This selective transfer of PFCAs to eggs was not seen for glaucous gulls (33). From a monitoring perspective, selective maternal transfer of individual PFCs to eggs could be important when relating the egg PFC pattern to what the female gull is exposed to.

* Gebbink, W.A. and Letcher, R.J., Environ. Pollut., Accepted, Sept 19, 2011. 
To better understand how PFCs are distributed and accumulatively compartmentalized in the body of Great Lakes female herring gulls, we determined PFSAs and PFCAs and several PFOSA, FTUCA and FTOH precursors in a comprehensive suite of tissues as well as blood components. Furthermore, we examined the maternal transfer of these same PFCs from the female gulls to her entire clutch of eggs, and the albumen and yolk compartments. The hypothesis was tested that the PFC pattern in the analyzed tissues and blood are comparable; however, chain length dependant selective transfer occurs from the female gulls to their eggs.

\subsection{Results and Discussion}

\subsubsection{Body Compartment-Specific PFSA and PFCA Patterns and Concentrations}

The highest mean $\sum$ PFSA concentrations (PFHxS, PFOS, PFDS) were detected in adipose tissue at $171 \pm 83 \mathrm{ng} / \mathrm{g}$ wet weight, followed by liver $>$ plasma $>$ muscle $>$ RBCs $>$ brain (Table 3.1). See Appendix A for individual PFSA concetrations in the tissues and blood. In studies that reported on other breeding seabirds, in Swedish guillemots, a similar $\sum$ PFSA distribution was found where concentrations in the liver $>$ muscle (34); however, in Norwegian glaucous gulls the concentration in plasma $>$ liver $>$ brain (33). In Columbian brown pelicans, Olivero-Verbel et al. (35) reported PFOS concentrations in the liver $>$ brain $>$ muscle. In the adipose tissue of the present herring gulls, ¿PFSA concentrations ranged from 3 to $577 \mathrm{ng} / \mathrm{g}$ ww. No previous studies have reported PFSAs in adipose tissue from a bird species; however, van de Vijver et al. (31) measured PFOS in the blubber of harbor seal and found similar concentrations compared to the liver. 
Table 3.1 Arithmetic mean percentage $( \pm \mathrm{SE})$ of detectable perfluorosulfonates (PFSAs) and carboxylates (PFCAs) relative to the arithmetic mean $\sum$ PFSA and $\sum$ PFCA concentrations ( \pm SE ng/g ww), respectively, in female herring gull eggs and tissues collected in 2010 from Chantry Island, Lake Huron.

\begin{tabular}{|c|c|c|c|c|c|c|c|c|}
\hline \multirow[b]{2}{*}{ PFAA } & \multicolumn{8}{|c|}{ Egg Compartments $(n=17)$ or Tissues and Blood (each $n=8)$} \\
\hline & Yolk & Albumen & Liver & Plasma & $\mathrm{RBC}$ & Brain & Muscle & Adipose \\
\hline$\%$ PFHxS & $0.8 \pm 0.2$ & $0^{\mathrm{a}}$ & $0.8 \pm 0.3$ & $7.9 \pm 3.1$ & $0-7.9^{b}$ & $0-1.5$ & $0-2.1$ & $0-0.2$ \\
\hline$\%$ PFOS & $96.8 \pm 0.4$ & 0 & $98.8 \pm 0.3$ & $91.7 \pm 3.1$ & $98.9 \pm 1.0$ & $88.4 \pm 1.7$ & $99.3 \pm 0.4$ & $99.9 \pm 0.1$ \\
\hline$\%$ PFDS & $2.4 \pm 0.2$ & 0 & $0.5 \pm 0.1$ & $0.4 \pm 0.2$ & $0-0.4$ & $11.4 \pm 1.5$ & $0-1.7$ & 0 \\
\hline $\begin{array}{l}\sum \text { PFSA } \\
(n g / g ~ w w)\end{array}$ & $258 \pm 39$ & $<0.1$ & $85 \pm 16$ & $29 \pm 8$ & $6.2 \pm 1.8$ & $5.0 \pm 0.9$ & $9.2 \pm 4.2$ & $171 \pm 83$ \\
\hline$\%$ PFHxA & $0-0.3$ & 0 & 0 & $0-1.3$ & 0 & 0 & 0 & 0 \\
\hline$\%$ PFHpA & $0-0.3$ & 0 & 0 & $3.7 \pm 1.2$ & 0 & 0 & 0 & 0 \\
\hline$\%$ PFOA & $2.1 \pm 0.2$ & 0 & $14.2 \pm 4.5$ & $22.1 \pm 3.4$ & $50.0 \pm 7.5$ & $0-0.3$ & $0-100$ & 0 \\
\hline$\%$ PFNA & $5.1 \pm 0.2$ & 0 & $28.3 \pm 4.5$ & $15.5 \pm 1.8$ & $7.9 \pm 4.8$ & 0 & $0-31.3$ & $0-23.2$ \\
\hline$\%$ PFDA & $11.2 \pm 1.0$ & 0 & $28.4 \pm 2.7$ & $12.5 \pm 2.3$ & $0-17.4$ & $1.4 \pm 0.3$ & $0-41.0$ & 0 \\
\hline$\%$ PFUnA & $13.3 \pm 0.8$ & 0 & $23.9 \pm 2.4$ & $16.1 \pm 2.5$ & $36.9 \pm 8.9$ & $3.7 \pm 0.8$ & $0-90.6$ & $0-100$ \\
\hline$\%$ PFDoA & $17.1 \pm 0.7$ & 0 & $0-1.0$ & $6.5 \pm 1.8$ & 0 & $7.2 \pm 0.9$ & 0 & 0 \\
\hline$\%$ PFTrA & $29.8 \pm 1.0$ & 0 & $0-10.9$ & $18.7 \pm 3.4$ & 0 & $37.1 \pm 1.6$ & 0 & 0 \\
\hline$\%$ PFTeA & $15.9 \pm 0.7$ & 0 & $0-15.3$ & $4.5 \pm 1.4$ & $0-24.5$ & $26.8 \pm 1.4$ & 0 & 0 \\
\hline$\%$ PFPA & $5.4 \pm 0.3$ & 0 & 0 & 0 & 0 & $23.8 \pm 1.7$ & 0 & 0 \\
\hline $\begin{array}{l}\sum \mathrm{PFCA} \\
(\mathrm{ng} / \mathrm{g} w \mathrm{w})\end{array}$ & $88 \pm 9$ & $<0.05$ & $5.2 \pm 3.8$ & $8.8 \pm 2.0$ & $0.7 \pm 0.3$ & $22 \pm 2$ & $0.2 \pm 0.1$ & $0.3 \pm 0.1$ \\
\hline
\end{tabular}

${ }^{a}$ Zero percent means that the calculation was not possible since the individual PFSAs or PFCAs were below the method limit of quantitaion.

${ }^{b}$ Where detection of the individual PFSAs or PFCAs was $<60 \%$ in individual eggs or tissues, a min.-max. percent range is given 
The PFSA pattern was dominated by PFOS in all tissues, ranging from $88.4 \%$ (brain) to $99.9 \%$ (adipose) of the $\sum$ PFSA concentration (Table 3.1). Shorter chain PFHxS was detected in all the tissues, although in RBC, brain, muscle, and adipose detection was $<60 \%$. $\sum$ PFSA concentrations in the plasma contained the highest proportion of PFHxS among tissues (8\%), which was significantly higher relative to tissues with the next highest being in the liver $(0.8 \%)$. PFDS was detected in all tissues with the exception of adipose. In plasma, RBCs, and muscle, PFDS detection was $<60 \%$. Brain contained the highest proportion of PFDS in the $\sum$ PFSA concentration, $11.4 \%$, followed by the liver $(0.5 \%)$. The proportion of PFHxS to $\sum$ PFSA in the plasma and PFDS to $\sum$ PFSA in the brain was not reported to be greater in harbor seal (30).

The highest mean $\sum$ PFCA concentrations $\left(\mathrm{C}_{6}-\mathrm{C}_{15}\right)$ were detected in the brain at $22 \pm$ $2 \mathrm{ng} / \mathrm{g}$ wet weight, followed by the plasma $>$ liver $>\mathrm{RBC}>$ adipose $>$ muscle (Table 3.1). See Appendix A for individual PFCA concetrations in the tissues and blood. In Swedish guillemot, $\sum$ PFCA concentrations were reported to be highest in the liver followed by muscle (34), and Verreault et al. (33) reported on the highest ¿PFCA concentrations in plasma followed by the liver and brain in Norwegian glaucous gulls. None of the existing tissue distribution studies of PFAAs in any species have reported such high $\sum$ PFCA concentrations in the brain compared to other tissues as was found in the present herring gulls. Ahrens et al. (30) reported that $\sum$ PFCA concentrations in the brain of harbor seals collected in German Bight (North Sea) to be higher compared to the muscle and blubber, which was consistent with the present results.

The PFCA pattern was highly variable among the present herring gull tissues (Table 3.1, Figure 3.1). The PFCA patterns in liver, RBC, muscle, and adipose were dominated by 

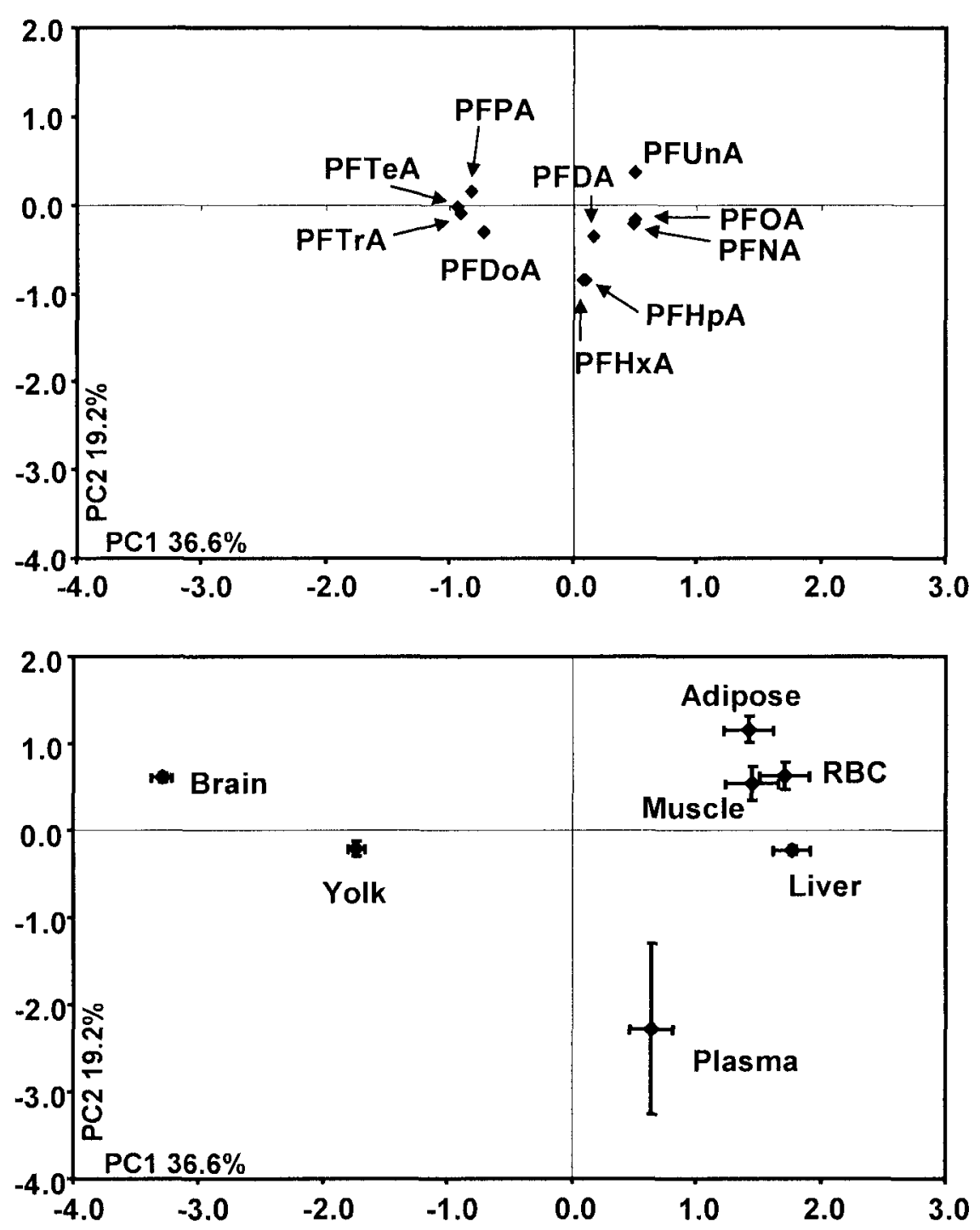

Figure 3.1 Proportions of $\mathrm{C}_{6}$ to $\mathrm{C}_{15}$ PFCA to $\Sigma$ PFCA concentrations plotted using the first two principal components (PCs), PC1 and PC2. Mean ( \pm SE) factor scores (bottom biplot) are shown for the tissues and yolk. The percent variability explained by $\mathrm{PC} 1$ and PC2 is provided. 
the $\mathrm{C}_{8}$ to $\mathrm{C}_{11}$ PFCAs, although in muscle and adipose the detection of these compounds was infrequent. The liver also contained PFDoA, PFTrA, and PFTeA, although detection was $<60 \%$ in individual samples. In plasma, the $\mathrm{C}_{6}$ to $\mathrm{C}_{14}$ PFCAs were present; however, the pattern was dominated by $\mathrm{C}_{8}$ to $\mathrm{C}_{11}$ PFCAs and PFTrA (83\% of $\sum$ PFCA). In brain, the PFCA pattern consisted of $\mathrm{C}_{10}$ to $\mathrm{C}_{15}$ PFCAs but was dominated by PFTrA, PFTeA, and PFPA (88\% of $\sum$ PFCA). To our knowledge, tissue-specific accumulation of PFCAs as a function of chain length has not as yet been reported in birds. In both Swedish guillemots and Norwegian glaucous gulls, the PFCA pattern in liver, kidney, muscle, and plasma was reported to be dominated by PFUnA and PFTrA, while individual PFCAs in the glaucous gull brain were not reported (33). PFCAs with chain length $<\mathrm{C}_{11}$ dominated patterns in harbor seal (German Bight) liver and plasma (30), which is consistent with the patterns in the present herring gull liver and plasma. However, the shorter PFCAs also dominated the pattern in the harbor seal brain, unlike the herring gull brain pattern. When combining the PFCA pattern in all the present herring gull tissues and blood, the pattern was dominated by PFTrA, PFTeA, and PFPA (64\% of $\sum$ PFCA) which was mainly driven by the abundance of these longer chain length PFCAs in the brain (Figure 3.2). The PFCA pattern to which the present gulls are exposed to remains unknown, although in another study the $\mathrm{C}_{8}$ to $\mathrm{C}_{14}$ PFCAs were detected in prey fish from Lake Ontario (alewife and rainbow smelt) (23), which suggests that prey fish are in part a source for PFCAs for the herring gulls from Chantry Island.

Although all the tissues, blood, and the egg compartments were analyzed for PFOS and PFCA precursors [PFOSA, NMeFOSA, FTOHs $(6: 2,8: 2,10: 2)$, and FTUCAs $(6: 2$, 


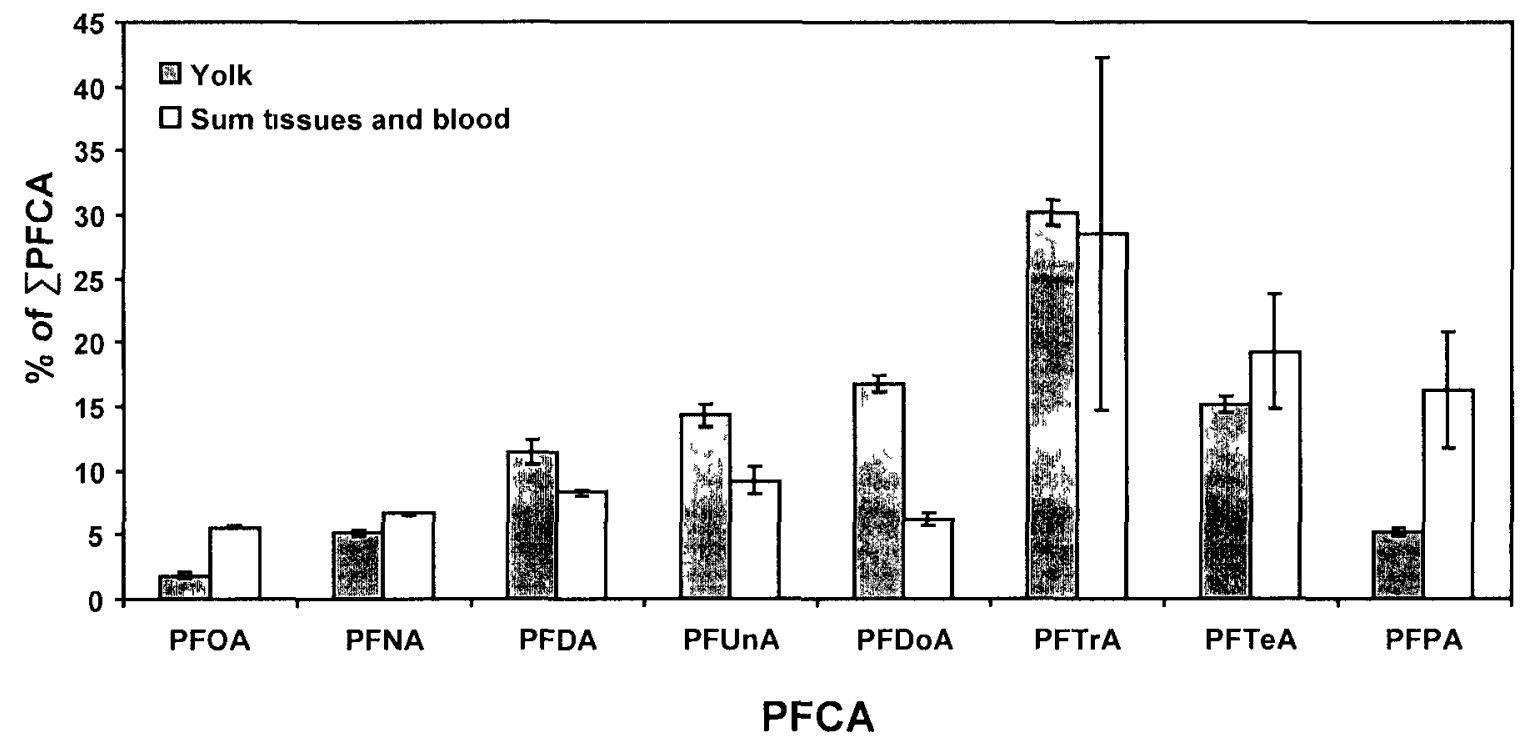

Figure 3.2 Arithmetic mean percent ( $\pm \mathrm{SE}$ ) of $\mathrm{C}_{8}$ to $\mathrm{C}_{15}$ PFCAs to $\sum \mathrm{PFCA}$ in the yolk and combined herring gull tissues and blood. 
$8: 2,10: 2)]$, all these compounds were not quantifiable. Chapter 4 reported low concentrations $(0.03 \mathrm{ng} / \mathrm{g}$ ww) of PFOSA in herring gull eggs collected from Chantry Island in 2007. The absence of PFOSA in the present eggs (collected in 2010) could be related to the phase out of $\mathrm{C}_{8}$ PFOSF chemistry in North America by the $3 \mathrm{M}$ Company in 2002, which could have resulted in decreasing "PreFOS" environmental concentrations (8). PFOSA has been detected in herring gull prey fish collected from Lake Ontario (23). The absence of PFOSA in herring gull tissues and eggs could also be an indication that PFOSA is degraded in gulls to PFOS if obtained through their diet. Degradation of PFOSA has been shown in in vitro experiments using rat microsomes (11). FTOHs and FTUCAs have not been reported in the herring gull diet; however, FTUCAs have been found in lake trout from the Great Lakes, indicating their presence in the aquatic environment (24). If exposed through their diet, it is hypothesized that gulls metabolize these precursors to PFCAs, similar to what has been shown in in vitro experiments using rats $(15)$.

\subsubsection{Tissue Distribution Based on Concentrations and Burdens}

In birds, as well as other species, in limited tissue distribution studies the liver is often the body compartment or tissue with the highest PFSA and PFCA concentrations $(34,35,30)$, although this was not the case for the present herring gull livers (Table 3.1). Regardless, protein binding/association of PFAAs likely plays a key role in the accumulation of these classes of PFAAs in the liver. Luebker et al. (27) reported on the binding of PFOS and PFOA to the liver fatty acid binding protein (L-FABP) isolated from rats. Chain lengthdependant binding to such proteins might also explain the selective accumulation of 
PFOA, PFNA, PFDA, and PFUnA in the present herring gull livers. From a PFOS exposure and toxicological standpoint in liver, in relation to protein-associated control of PFOS deposition into and out of the liver, Yu et al. (68) very recently reported that in PFOS exposed female Wistar rats that exposure to $3.0 \mathrm{mg} / \mathrm{kg}$ of PFOS significantly enhanced hepatic mRNA expression of the organic anion transport (OAT) protein OATP2, and increased hepatic expression of multidrug resistance-assisted protein MRP2. They concluded that PFOS increased hepatic expression of OAPT2 and MRP2, which could possibly enhance hepatic uptake, efflux and metabolism of thyroxine (T4) in rats. Unconjugated T4 has to interact with OATP1, OATP2 and MRP2 in order to gain access into and get out of liver cells.

In plasma, $\sum$ PFSA and $\sum$ PFCA concentrations were significantly higher compared to concentrations in RBCs (Table 3.1). To our knowledge, there has been no reported examination of the comparative compartmental accumulation of any PFC in blood, e.g, plasma versus RBCs, from any wildlife species. However, Ehresman et al. (69) suggested that PFHxS, PFOS, and PFOA are present in human plasma or serum and not in RBCs, which was based on plasma and whole blood measurements with no specific measurement in the RBC component. PFAAs have been found to bind to proteins such as albumin and sex-hormone binding globulins in birds, fish and humans $(28,29)$. The fact that these proteins are found in the plasma and not in the $\mathrm{RBC}$ might explain the observed preferred accumulation in the plasma. In the gull RBCs, PFCA/PFSA patterns were skewed toward PFOS, PFOA, PFNA, and PFUnA, although concentrations were lower. However, the PFCA/PFSAs patterns are basically the same as significant positive correlations were found between the plasma and RBC for the dominant PFOS, PFOA, 

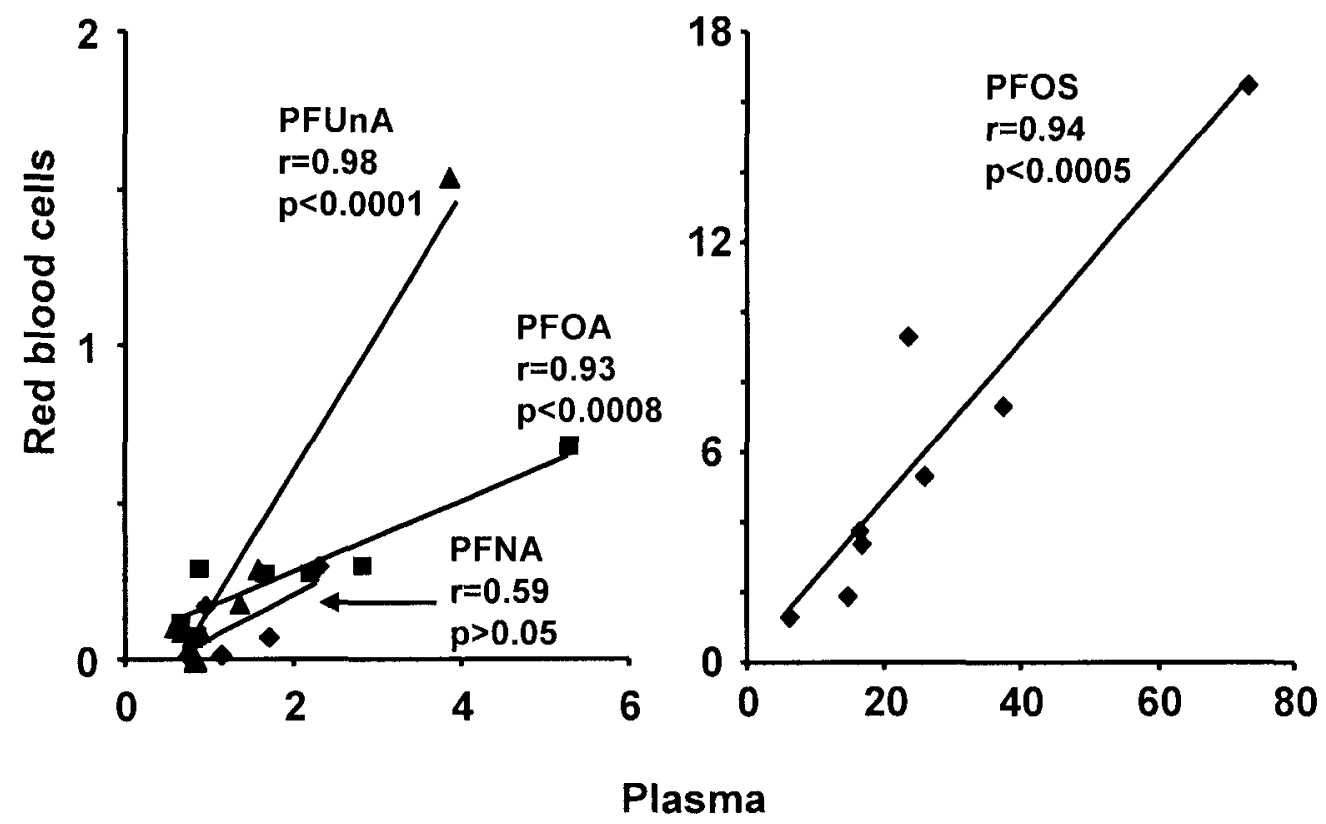

Figure 3.3 Linear correlations between the plasma and red blood cell concentrations (ng/g ww) for PFOS, PFOA, PFNA and PFUnA. Detection of other individual PFSAs and PFCAs was $<60 \%$ in plasma and/or red blood cells and were not included. 
and PFUnA concentrations (Figure 3.3). Relative abundances of individual PFSAs or PFCAs were all within $1 \%$ when comparing the plasma and the estimated whole blood patterns (combined plasma and $\mathrm{RBC}$ patterns). Thus, plasma patterns are reflective of the patterns in whole blood.

¿PFSA concentrations in herring gull brains were one order of magnitude lower compared to the liver concentrations; which was consistent with other limited bird studies $(33,35)$. Contrastingly, the $\sum$ PFCA concentrations in the brain were higher compared to the liver, and brain was the most contaminated tissue or body compartment studied (Table 3.1). This preferential accumulation of PFCAs in the brain has not been observed in any species. Furthermore, the brain PFCA and PFSA pattern relative to all other tissues and blood components was heavily skewed to the longer chain PFTrA, PFTeA and PFPA, and favoured PFDS (Table 3.1, Figure 3.1). Given that the whole brain was sampled, there is evidence of selective transfer of longer chain PFCAs and PFSAs through the blood brain barrier and into the brain. The mechanism of this longer chain PFCA passage into and retention in the brain is unclear. The presence of these PFAAs in the gull brain could be of concern from a toxicological standpoint. Vongphachan et al. (47) reported variable transcriptional changes in herring gull embryonic neuronal cells exposed to shorter chain length PFSAs (PFBS, PFHxS) and PFCAs (PFHxA, PFHpA), but PFTrA, PFTeA and PFPA were not studied. It has been shown in several toxicological studies on monkeys, rats and mice that serum thyroid hormone (TH) deficiency, especially for total thyroxine (T4), is induced by PFOS exposure (27). In mammals TH deficiency is known to be associated with structural brain damage, neurological defects, developmental delay, and behavioral problems (70). 
In limited reports for birds as well as other species, muscle and adipose tissue have been reported to be the less contaminated with PFCA and PFSA than liver $(34,35,30)$. In the present herring gulls, muscle generally had the lowest PFSA and PFCA concentrations among other tissues and blood components (Table 3.1). However, adipose tissue contained the highest $\sum$ PFSA (99.9\% PFOS) concentration, approximately 2 -fold higher than liver. In contrast, the adipose 2 PFCA concentrations were very low at 0.3 ng/g ww and comparable to muscle. However, the mean PFOS concentration in adipose tissue was highly variable among individuals, ranging from 3 to $577 \mathrm{ng} / \mathrm{g} w w$. Although PFAAs have been found to bind to proteins (28) and have low accumulation potential in fatty tissues (30), the present results show that the accumulation of PFOS in adipose tissue could be driven by other, unknown factors. No correlations were observed between $\sum$ PFSA concentrations in adipose and any other tissues.

The burdens of $\sum$ PFSA in liver, blood and brain were estimated at 2.2, 1.1, and 0.03 $\mu \mathrm{g}$, respectively, totaling $3.4 \mu \mathrm{g}$ (Figure 3.4). In liver, blood and brain, $\sum$ PFCA burdens were estimated at $0.13,0.32$, and $0.13 \mu \mathrm{g}$, respectively, and totalling $0.6 \mu \mathrm{g}$. As PFC burden estimates in the muscle and adipose were not generated, and PFCs have been reported in other avian tissues such as kidney, lung, heart, and feathers $(34,35,7 I)$, the combined burdens (liver, blood, and brain) underestimate whole body burdens in gulls. However, the combined burdens in liver, blood, and brain in harbor seals (German Bight) were reported to represent the majority (75\%) of the $\sum$ PFAA body burden (30). 


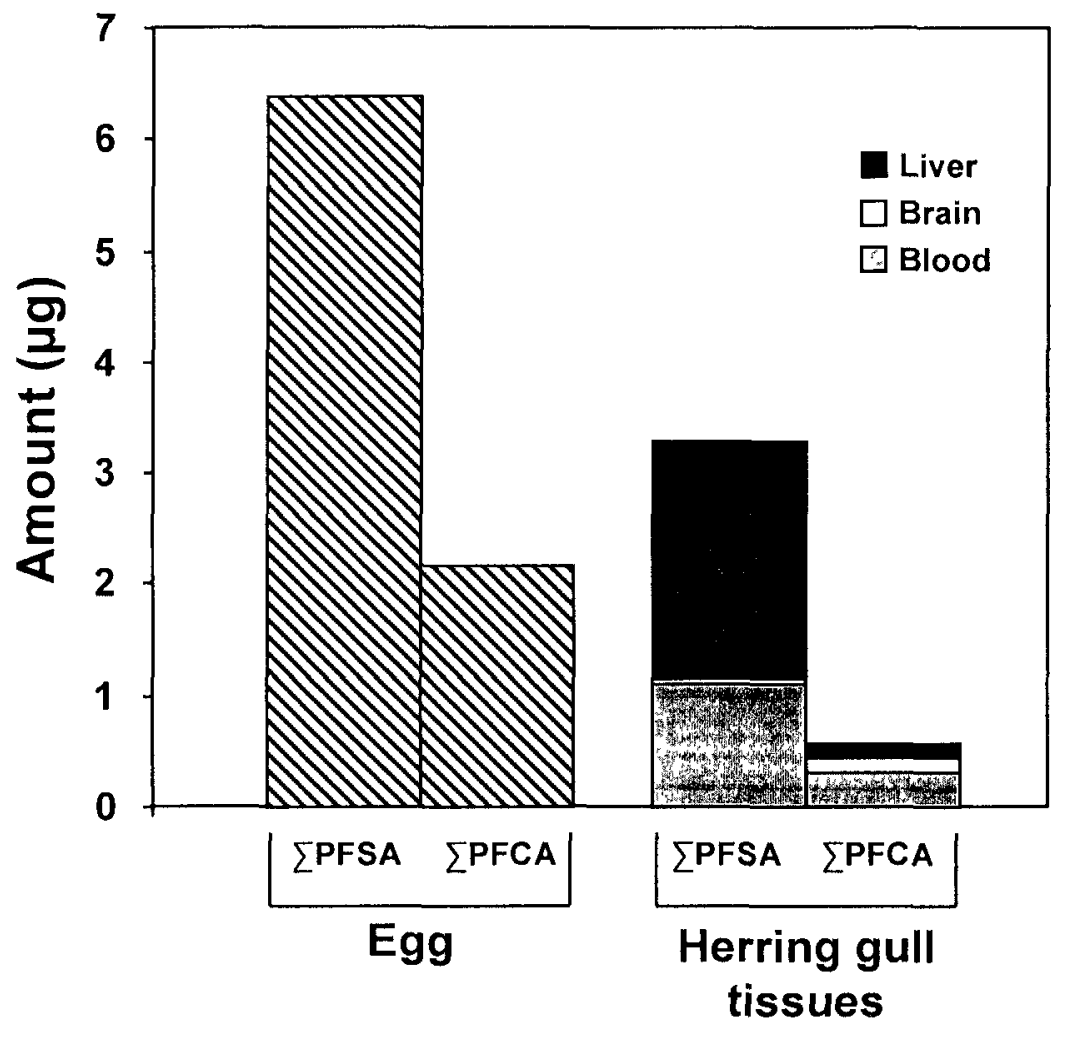

Figure 3.4 Tissue burden amount of $\sum$ PFSA and $\sum$ PFCA $(\mu \mathrm{g})$ in herring gull egg, liver, brain, and blood collectẹd from Chantry Island in 2010. 


\subsubsection{Maternal Transfer of PFCAs and PFSAs to Eggs}

The egg yolk contained $258 \mathrm{ng} / \mathrm{g}$ ww $\sum$ PFSA (PFHxS, PFOS, PFDS) and $88 \mathrm{ng} / \mathrm{g}$ ww $\sum$ PFCA $\left(\mathrm{C}_{6}\right.$ to $\left.\mathrm{C}_{15}\right)$, while in the albumen, PFSAs and PFCAs were below detection limits. See Appendix A for individual PFSA and PFCA concetrations in the yolk. Information on the order that the present eggs were laid within a clutch was not available. Concentrations of $\sum$ PFSA and $\sum$ PFCA in the yolk were higher (3-fold and 17-fold higher, respectively) than any body compartment or tissue examined including liver, (Table 3.1). This is consistent with results for Norwegian glaucous gulls although whole eggs were analyzed in that study (33). In the yolk, $\mathrm{C}_{6}$ to $\mathrm{C}_{15}$ PFCAs were detected and the pattern was dominated by PFTrA $>$ PFDoA $>$ PFTeA $>$ PFUnA, making up $76 \%$ of ¿PFCA. This PFCA pattern, as well as the PFSA pattern, was comparable to the patterns found in gull eggs collected in 2007 from Chantry Island (Chapter 4). The present gull eggs were consistently comprised of $\sim 30 \%$ yolk and $\sim 70 \%$ albumen, thus if concentrations were adjusted for yolk only, the $\sum$ PFSA in the whole egg would be about half the concentration of $\sum$ PFSA in eggs collected in 2007, while $\sum$ PFCA concentrations would be comparable (Chapter 4). When using whole egg homogenates to monitor for PFSAs and PFCAs, the albumen dilutes what is the absolute localization of these PFAAs in the yolk. Although both the yolk and the albumen contain proteins, absolute accumulation of PFCAs and PFSAs in the yolk is most likely a function of specific proteins transferred in ovo and into the yolk. Newsted et al. (36) found that PFOS was associated with very low density lipoproteins (VLDL) and to a lesser extent phosvitin and lipovitellin in the yolk of quails and mallards. 
Not only were the sum PFAA concentrations different between the yolk and liver, but the PFCA pattern in the yolk and liver differed as well, showing preferential accumulation depending of longer chain length PFCAs in the yolk (this was not observed for the PFSA pattern) (Table 3.1, Figure 3.1). Holmström et al. (34) reported on the maternal transfer of PFAAs in common guillemots and related it to the transfer of proteins produced in the liver to the egg. Yolk proteins, such as vitellogenin and VLDL, are produced in the liver and transported from the liver to the ovaries via the blood. The PFCA pattern in the liver was dominated by $\mathrm{C}_{8}$ to $\mathrm{C}_{11}$ PFCAs (95\% of the total), whereas the pattern in yolk was dominated by $\mathrm{C}_{10}$ and longer chain length PFCAs $(93 \%$ of the total). As has been shown for PFOS (36), binding of PFCAs to these proteins could serve as a transport mechanism from the liver to the eggs. The preferential accumulation of the longer chain length PFCAs in the egg relative to the liver was also seen for the guillemot; however, not for glaucous gulls (Figure 3.5) (34,33).

Eggs from wild bird species have been used for PFC monitoring purposes. Spatial and temporal trends of PFSAs and PFCAs (including PFOS isomers) have been determined in gull (herring, ring-billed, California, glaucous-winged) and guillemot eggs collected from the Canadian, Swedish and Norwegian environments (Chapters 4, 5, and 7) $(72,19)$. As the present data show, the PFAA profile, and especially the PFCA pattern in the egg does not reflect the PFCA pattern in other herring gull tissues. Using the PFCA pattern in the yolk as a reference point, the PFCA pattern in the liver (source of PFAAs to the egg), blood (transport of PFAA-protein from the liver to the egg) and whole body (combined pattern in all the tissues and blood) were compared (Figure 3.6). Higher proportions of $\mathrm{C}_{8}$ to $\mathrm{C}_{11}$ PFCAs in the liver were observed compared to the yolk. As 


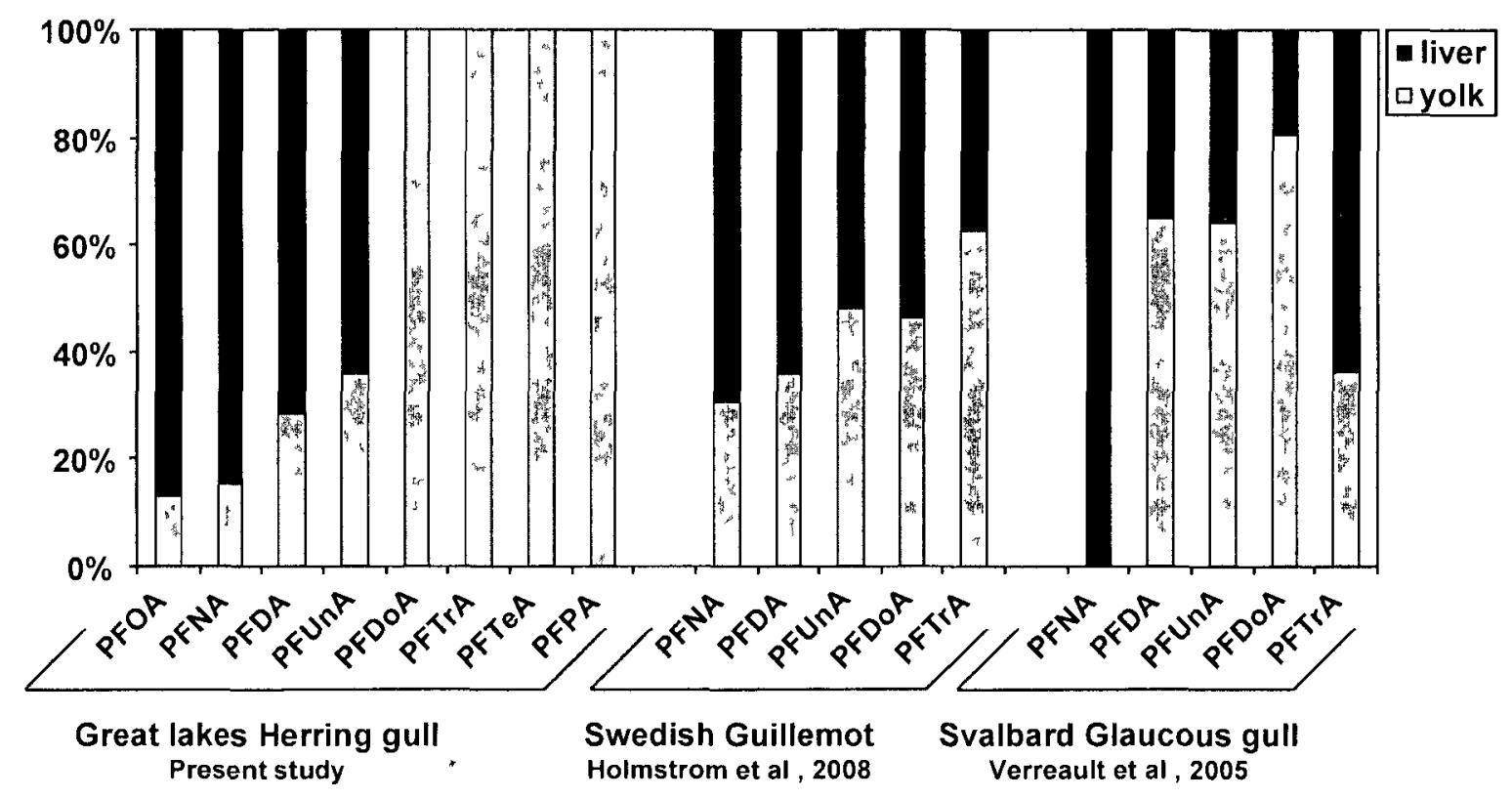

Figure 3.5 Relative percent composition of individual PFCA concentrations in liver versus egg yolk in female herring gulls and eggs, respectively, collected in 2010 from the Chantry Island (Lake Huron) colony site. Detection of PFDoA, PFTrA, and PFTeA in the liver was $<60 \%$ in individual samples and a comparison was not possible. Guillemot and glaucous gull liver and egg data were adapted from Holmström et al. (34) and Verreault et al (33). 


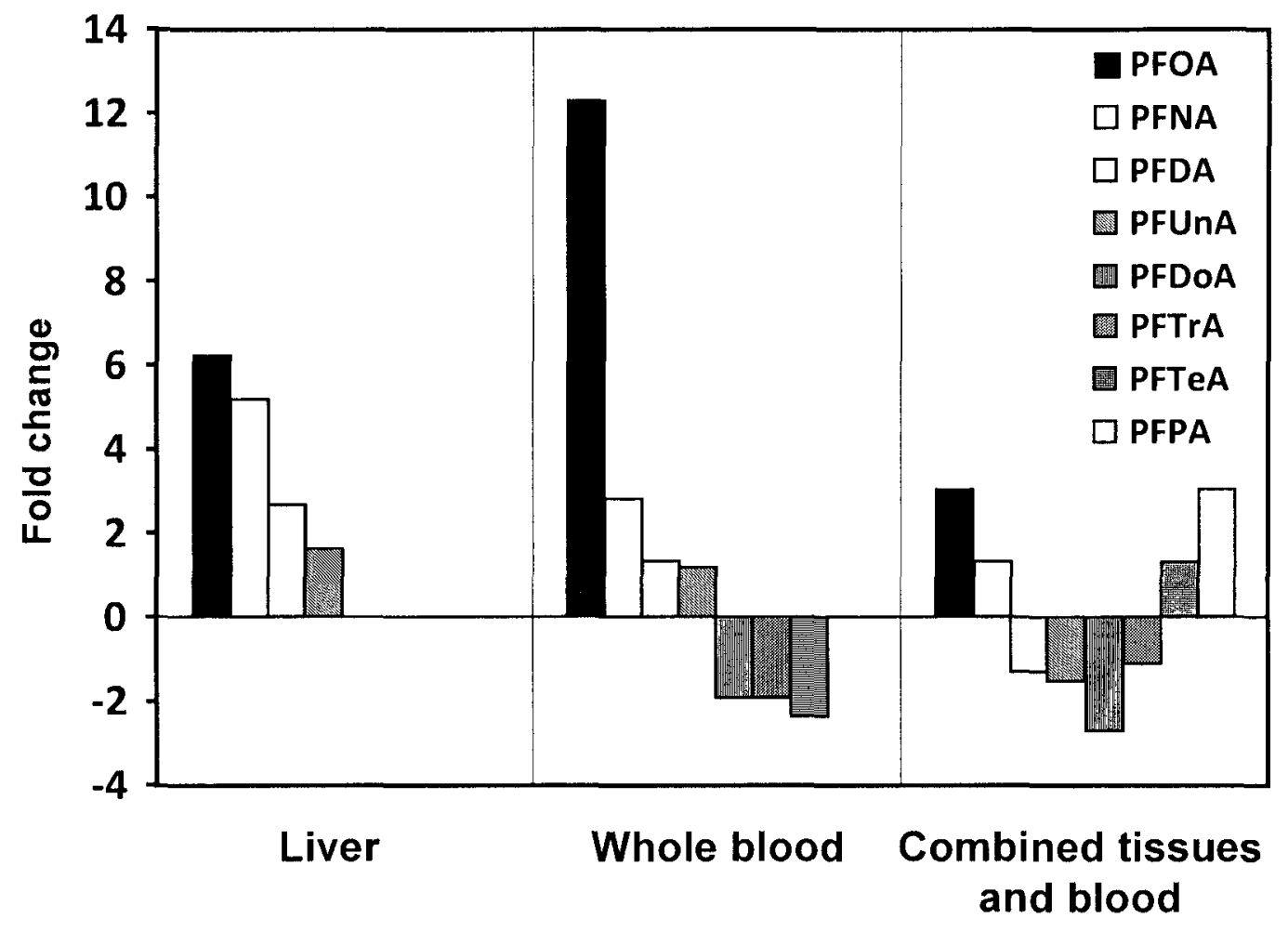

Figure 3.6 Fold change of PFCA to $\sum$ PFCA concentration ratio in herring gull liver, whole blood, and combined tissues and blood compared to the yolk. Only PFCAs with $>60 \%$ detection are included. 
mentioned earlier, selective binding of the longer chain length PFAAs to proteins and subsequent transfer to the egg might explain this. In the blood, PFCA pattern increases were seen for $\mathrm{C}_{8}-\mathrm{C}_{11}$ and decreases for $\mathrm{C}_{12}-\mathrm{C}_{14}$ compared to the yolk pattern. The blood transports PFAA-protein complexes from the liver to the egg. The observed pattern change might be related to binding to blood proteins (e.g., albumin) in addition to the binding to liver protein (e.g. OAT and MRP (68)). Although the PFCA pattern in individual tissues showed differences in the pattern compared to the yolk due to tissue specific accumulation, the combined PFCA pattern in all the tissues and blood showed a greater resemblance to the yolk pattern (Figure 3.2). The enrichment of PFTeA and PFPA in the whole body pattern is due to the high abundance of these two PFCAs in the brain. Declines of PFDoA in the PFCA pattern in the whole body compared to the yolk might be due to selective transfer to the yolk.

An important aspect of our study was to understand the extent of the maternal transfer of bioaccumulative PFCAs and PFSAs and overall burden in the egg. As female herring gulls usually lay three eggs in a clutch, a clutch of three eggs would contain $19.2 \mu \mathrm{g}$ of $\sum$ PFSA and $6.6 \mu \mathrm{g}$ of $\sum$ PFCA (6.4 $\mu \mathrm{g}$ of $\sum$ PFSA and $2.2 \mu \mathrm{g}$ of $\sum$ PFCA per egg) (Figure 3.4). Compared to the combined tissue burden (liver, blood, brain; $3.4 \mu \mathrm{g}$ of $\sum$ PFSA and $0.6 \mu \mathrm{g}$ of $\sum \mathrm{PFCA}$ ), female herring gulls are clearly transferring a considerable proportion of the estimated $\sum$ PFSA and $\sum$ PFCA body burden to their eggs. Although these combined liver, blood, and brain burdens are an underestimate of the whole gull PFAA burdens, as PFAAs have been reported in other avian tissues, the in ovo transfer is an elimination route for PFAAs for female herring gulls. Although Holmström et al. (34) did not compare PFAA burdens between Swedish guillemot eggs and tissues, the higher liver 
concentrations of PFCAs/SAs in chicks compared to adult birds was suggested to be the result of the transfer of high amounts to eggs.

Female herring gulls transfer a substantial proportion of their PFAAs body burden to their egg during breeding, however, O'Brien et al. $(45,47)$ showed that chicken eggs injected with comparable amounts of PFOS showed no effect on the expression of PPAR $\alpha$-regulated genes. Only after exposure to two orders of magnitude higher PFOS concentrations was decreased chick pippability observed. In the present study, regardless of this maternal transfer, PFSAs and PFCAs were detected in the liver, plasma, RBC, brain, muscle, and adipose, and tissue-specific accumulation appears to be related to protein-associated factors, which might be chain length dependent. Although the PFCA pattern was highly variable among tissues, the PFCA pattern in combined tissues and blood resembled the yolk pattern. For monitoring purposes, this is important as the egg PFCA pattern represents the PFCA pattern in the female herring gull. However, when investigating tissue specific effects of PFAAs, information on tissue PFAA pattern and concentrations is essential. 
Chapter 4: Perfluorinated Carboxylates and Sulfonates and Precursor Compounds in Herring Gull Eggs from Colonies Spanning the Laurentian Great Lakes of North

\section{America *}

\subsection{Introduction}

Recent studies of spatial trends, mainly of PFOS and PFCAs, have shown differences in concentrations in environmental samples collected from urban versus more nonurbanized areas. For example, guillemot eggs collected in north-west Europe (73), skipjack tuna collected off-shore and in open-ocean in eastern Asia (39) and bottlenose dolphins collected in South Carolina (38) all showed higher concentrations of PFCs in the samples that were collected closer to industrialized/urban areas.

To our knowledge, there is only one study that has investigated the spatial trend of any PFC in biota from the Laurentian Great Lakes of North America. Furdui et al. (24) determined the spatial trend of PFSAs, PFCAs and precursors (PFOSA and 8:2 and 10:2 FTUCAs) in lake trout collected in all five Great Lakes. Overall, the highest concentrations of $\Sigma$ PFCA $\left(\mathrm{C}_{8}-\mathrm{C}_{15}\right)$, $\Sigma$ PFSA $\left(\mathrm{C}_{6}, \mathrm{C}_{8}, \mathrm{C}_{10}\right)$ and PFOSA were found in trout collected from Lake Erie, followed by Lake Ontario and Lake Huron.

These areas represent some of the more populated and industrialized parts of the Great Lakes. The lowest concentrations of $\Sigma$ PFCA and $\Sigma$ PFSA were found in trout from Lake Superior and Lake Michigan, especially Lake Superior is more geographically remote with respect to urban areas and PFC and precursor sources. The pattern of PFCA

* Reproduced with permission from Gebbink, W.A., Hebert, C.E., Letcher, R.J. Environ. Sci Technol. 2009, 43, 7443-7449. Copyright 2009 American Chemical Society. 
$\left(\mathrm{C}_{8}-\mathrm{C}_{15}\right)$ in lake trout from Lake Michigan was dominated by PFOA when compared to fish from the other lakes. It was suggested that this was related to 8:2 FTUCA, which was detected in the trout and is a possible precursor of PFOA.

The herring gull, an avian top predator, is exposed to environmental contaminants via its diet. Herring gull eggs have been used to monitor (spatial and/or temporal trends) environmental contaminants such as PCBs, OC pesticides and PBDEs $(51,53)$. In Chapter 3, it was shown that the PFC profile in the egg reflects the PFC profile in the female herring gull body. For this reason, herring gull eggs are ideal to monitor for PFCs as there appears to be minimal selective transfer of individual PFCs from the female gull to the eggs. The objective was to characterize PFSAs, PFCAs, PFOSAs, FTUCAs and FTOHs in herring gull eggs (collected in 2007) from the Laurentian Great Lakes, and examine the fate, sources and trends of detected PFCs among eggs from 15 colonies spanning all 5 Great Lakes. The hypothesis was tested that the herring gull eggs collected from colonies near urbanized areas were more contaminated with PFSAs, PFCAs, and precursors compared to colonies near remote areas.

\subsection{Results and Discussion}

\subsubsection{PFSAs and Spatial Distribution}

The $\mathrm{C}_{6}, \mathrm{C}_{8}$, and $\mathrm{C}_{10}$ PFSAs were detected but dominated by PFOS $\left(\mathrm{C}_{8}\right)$, which comprised $91 \%$ to $99 \%$ of the $\Sigma$ PFSA concentrations depending on the colony. See Appendix B for individual PFSA concentrations in eggs from all colonies. This finding is consistent with a recent report for Lake Ontario fish including major aquatic prey fish of herring gulls such as alewife and rainbow smelt, where the PFSA pattern was also shown to be 
dominated by PFOS (>83\%) $(24,23)$. A similar result was reported for the contribution of PFOS to $\Sigma$ PFSA concentrations in the eggs and liver of glaucous gulls from the Norwegian Arctic and herring gull eggs from northern Norway $(>97 \%)(33,72)$.

The proportion of PFOS in $\mathrm{PPFSA}$ in gull eggs collected at Channel-Shelter Island was significantly lower $(p<0.0001)$ when compared to the other colonies. The contribution of PFOS to $\Sigma$ PFSA was significantly greater $(p<0.05)$ in eggs from Granite, Double, Chantry, and Snake Islands and Port Colborne compared to the Channel-Shelter, Fighting, and Strachan Islands and Hamilton Harbour. The proportion of PFHxS at the Toronto Harbour colony was significantly $(p<0.02)$ higher compared to Gull, Big Sister, Channel-Shelter, Middle Island, Port Colborne and Niagara River colonies (Figure 4.1). Channel-Shelter Island had a significantly $(p<0.0001)$ higher proportion of PFDS relative to the other colonies. Degradation of precursors could be one of the factors influencing the observed PFSA patterns among the colonies (as discussed later).

A northwest to southeast spatial trend was observed for arithmetic mean $\Sigma$ PFSA concentrations in eggs, where concentrations were lower for the more remote colonies on Lakes Superior, Michigan and Huron compared to colonies on the populated Lakes Erie and Ontario, indicating that local sources play a key role in the spatial distribution of PFSAs in herring gull eggs (Table 4.1, Figure 4.2). Arithmetic mean concentrations of ¿PFSA for Middle Island, Toronto Harbour and Strachan Island were significantly $(p<0.03)$ higher compared to colonies on Lakes Superior, Michigan and Huron and also the Fighting Island colony in the Detroit River. Gauthier et al. recently reported that for ¿PBDE concentrations in herring gull egg pools (collected in 2006) from seven Great Lakes sites, the highest concentrations were from Gull Is. (northern Lake Michigan) (54). 

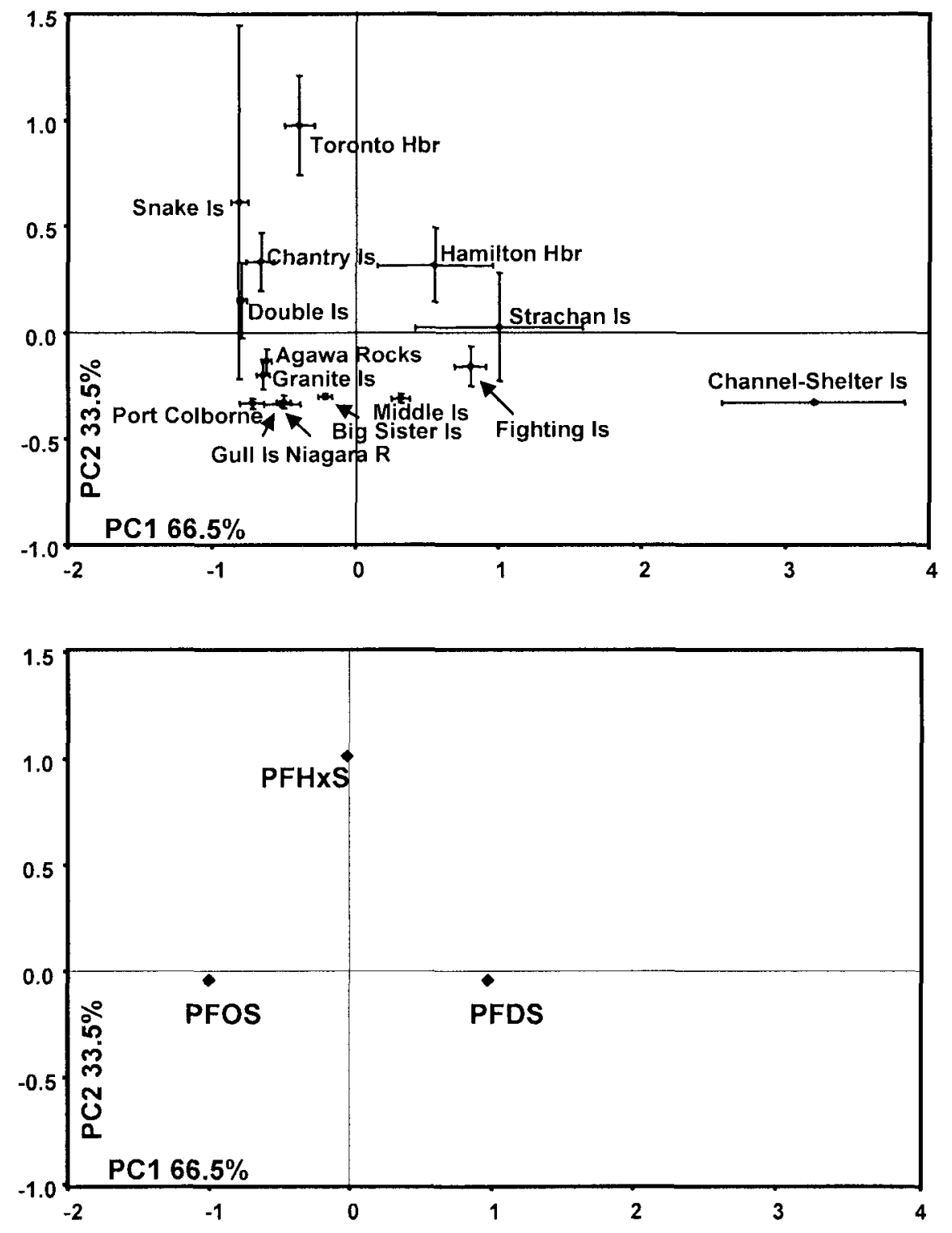

Figure 4.1 Proportions of PFHxS, PFOS and PFDS to 2 PFSA concentrations plotted using the first two principal components (PCs), $\mathrm{PCl}$ and $\mathrm{PC} 2$. Mean ( $\pm \mathrm{SE}$ ) factor scores (top biplot) are shown for the 15 colonies. The percent variability explained by $\mathrm{PCl}$ and PC2 is provided. 
Table 4.1 Arithmetic mean concentrations of $\Sigma$ PFSA and $\Sigma$ PFCA (ng/g wet weight) in individual herring gull eggs collected from 15 colonies in the Great Lakes in 2007 ( $n=13$ per colony).

\begin{tabular}{|c|c|c|c|c|c|c|}
\hline \multirow[t]{2}{*}{ Colony } & \multirow[t]{2}{*}{ Lake/River } & \multirow{2}{*}{$\begin{array}{l}\begin{array}{l}\text { EPFSA }{ }^{\mathrm{a}} \\
( \pm \mathrm{SE})\end{array} \\
\end{array}$} & \multirow{2}{*}{$\begin{array}{c}\mathrm{PFCA}^{\mathrm{b}} \\
( \pm \mathrm{SE})\end{array}$} & \multicolumn{3}{|c|}{ Correlations of $\Sigma$ PFCA versus $\Sigma P F S A^{\circ}$} \\
\hline & & & & slope & $r$ & $p$ \\
\hline Granite Is. & L. Superior & $127 \pm 20$ & $46 \pm 6$ & 2.47 & 0.744 & 0.001 \\
\hline Agawa Rocks & L. Superior & $91 \pm 13$ & $72 \pm 5$ & 0.89 & 0.335 & 0.22 \\
\hline Big Sister Is. & L. Michigan & $212 \pm 26$ & $63 \pm 9$ & 2.52 & 0.834 & $<0.0001$ \\
\hline Gull Is. & L. Michigan & $178 \pm 18$ & $30 \pm 5$ & 2.86 & 0.845 & $<0.0001$ \\
\hline Channel-Shelter Is. & L. Huron & $227 \pm 16$ & $41 \pm 4$ & 3.06 & 0.808 & 0.0003 \\
\hline Double Is. & L. Huron & $227 \pm 24$ & $113 \pm 12$ & 0.40 & 0.197 & 0.48 \\
\hline Chantry Is. & L. Huron & $160 \pm 37$ & $32 \pm 7$ & 5.07 & 0.959 & $<0.0001$ \\
\hline Fighting Is. & Detroit River & $264 \pm 47$ & $58 \pm 9$ & 5.06 & 0.972 & $<0.0001$ \\
\hline Middle Is. & L. Erie & $507 \pm 47$ & $94 \pm 9$ & 5.30 & 0.959 & $<0.0001$ \\
\hline Port Colborne & L. Erie & $328 \pm 32$ & $51 \pm 6$ & 5.47 & 0.949 & $<0.0001$ \\
\hline Niagara River & Niagara River & $301 \pm 40$ & $64 \pm 8$ & 4.94 & 0.965 & $<0.0001$ \\
\hline Hamilton Harbour & L. Ontario & $319 \pm 32$ & $56 \pm 8$ & 3.43 & 0.832 & $<0.0001$ \\
\hline Toronto Harbour & L. Ontario & $484 \pm 49$ & $70 \pm 6$ & 6.71 & 0.849 & $<0.0001$ \\
\hline Snake Is. & L. Ontario & $427 \pm 67$ & $73 \pm 12$ & 5.32 & 0.985 & $<0.0001$ \\
\hline Strachan Is. & St. Lawrence River & $486 \pm 59$ & $66 \pm 9$ & 6.12 & 0.956 & $<0.0001$ \\
\hline
\end{tabular}

${ }^{\mathrm{a}} \mathrm{\Sigma PFSA}=\mathrm{PFHxS}, \mathrm{PFOS}, \mathrm{PFDS}$

${ }^{b} \Sigma$ PFCA $=$ PFOA, PFNA, PFDA, PFUnA, PFDoA, PFTrA, PFTeA, PFPA.

${ }^{\mathrm{c}}$ See Figures 4.5 for the correlative plots and linear regression lines for colonies in each of the lakes. 


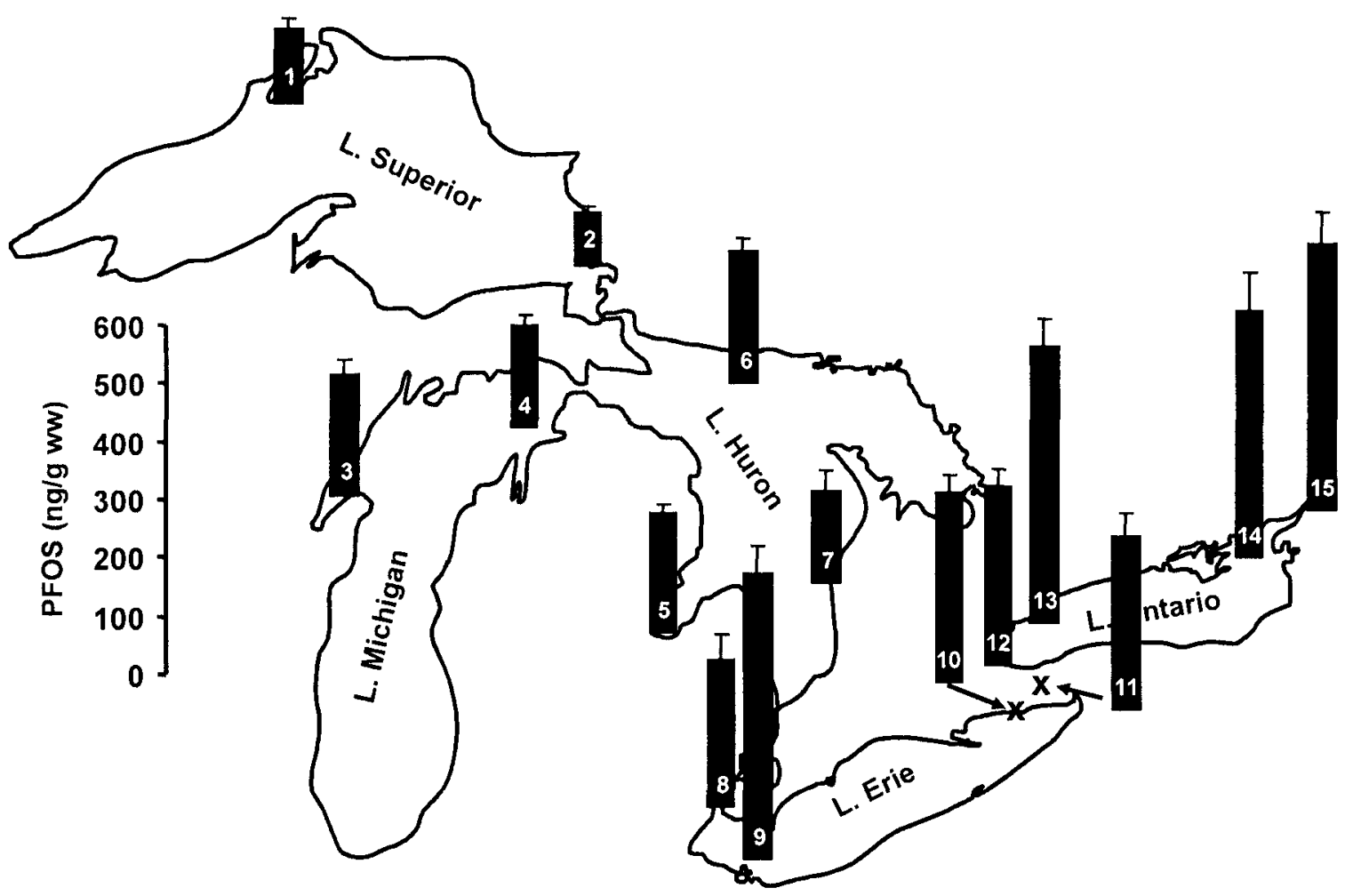

Figure 4.2 Arithmetic mean PFOS concentrations ( $\mathrm{ng} / \mathrm{g} \mathrm{ww} \pm \mathrm{SE}$ ) in individual herring gull eggs $(n=13)$ collected in 2007 from 15 colonies in the Laurentian Great Lakes: (1) Granite Island, (2) Agawa Rocks, (3) Big Sister Island, (4) Gull Island, (5) ChannelShelter Island, (6) Double Island, (7) Chantry Island, (8) Fighting Island, (9) Middle Island, (10) Port Colborne, (11) Niagara River, (12) Hamilton Harbour, (13) Toronto Harbour, (14) Snake Island, (15) Strachan Island. 
It was argued that this was likely due to higher PBDE exposures, at least from some eggs making up this pool, as a result of post-breeding migration to southern Lake Michigan, which is not known to freeze over in the winter and thus gulls have access to aquatic foods year-round (74). Southerly migration has been shown for gulls from colonies on Lakes Superior, Michigan, and northern Lake Huron (74), the ice coverage of these lakes was even greater during the $2006 / 07$ winter compared to the $2005 / 06$ winter (75), this does not appear to be a substantial explanatory factor for PFOS or mean LPFSA concentrations in the 2007 gull eggs analyzed here. Mean concentrations at northern colonies were significantly lower compared to those in eggs from colonies on Lake Erie and Lake Ontario (Figure 4.2).

\subsubsection{PFOSA in Relation to PFOS}

PFOSA is a known precursor to PFOS and was measurable in all herring gull eggs except some from the Granite Is. colony (Table 4.2). On average, the concentrations of PFOSA were $<1 \mathrm{ng} / \mathrm{g} \mathrm{ww}$, with the highest concentrations at Port Colborne and Hamilton Harbour, although only the Hamilton Harbour colony was significantly $(p<0.05)$ higher compared to Agawa Rocks, Gull Island, Channel-Shelter Island, Chantry Island, Fighting Island and Strachan Island The degradation of PFOSA to PFOS has been observed in in vitro studies using rainbow trout hepatocytes (10). Whether metabolic degradation of PFOSA to PFOS by the gulls could affect the observed spatial distribution of PFOS is unclear. In herring gull livers (collected in 2010) PFOSA was below detection limit, however, the eggs from those female gulls also contained no PFOSA (Chapter 3). The presence of PFOSA in herring gull fish prey has been studied in Lake Ontario (23), the 
PFOS to PFOSA ratios in alewife and rainbow smelt were found to be at least two orders of magnitude lower compared to the ratio in the present herring gull eggs (Table 4.2). A significant $(r=0.42 ; p<0.0001)$ positive correlation between PFOSA and PFOS concentration in individual eggs was also found (Figure 4.3). Collectively, these findings suggest that herring gulls are able to biotransform PFOSA to PFOS, although further study is warranted.

The PFOS to PFOSA ratio in the eggs from Hamilton Harbour were significantly $(p<0.03)$ lower compared to the other colonies except at the Agawa Rocks, Big Sister Island and Double Island colonies (Table 4.2). The highest ratio was found at the Strachan Island colony, which was significantly $(p<0.04)$ higher than the other colonies except the Channel-Shelter, Chantry, Middle and Snake Island colonies. To our knowledge, there are no available data on the spatial distribution of PFOSA (and thus PFOSA to PFOS ratios) in herring gull prey fish in the Great Lakes. Furdui et al. (24) showed inter-lake variation of the ratio of PFOS to PFOSA in lake trout, with ratios in fish from Lake Erie and Lake Ontario being higher compared to the other lakes, whether this could affect the spatial trend of PFOS was not mentioned. However, the ratios in lake trout were greater overall compared to those in alewife and smelt. The presence of PFOSA in herring gulls and possible subsequent biotransformation appears to be an additional source of PFOS. 
Table 4.2 Arithmetic mean concentrations of PFOSA (ng/g wet weight) and PFOS/PFOSA ratıo in individual herrıng gull eggs collected from 15 colonies in the Great Lakes in $2007(n=13$ per colony).

\begin{tabular}{llcc}
\hline Colony & Lake/River & PFOSA $( \pm \mathrm{SE})$ & $\begin{array}{c}\text { PFOS to PFOSA } \\
\text { Conc Ratıo }\end{array}$ \\
\hline Granite Is & L Superior & $<0005-014^{\mathrm{a}}$ & \\
Agawa Rocks & L Superior & $006 \pm 001$ & $1752 \pm 229$ \\
Big Sister Is & L Michigan & $028 \pm 005$ & $954 \pm 106$ \\
Gull Is & L Michigan & $010 \pm 001$ & $2063 \pm 258$ \\
Channel-Shelter Is & L Huron & $008 \pm 002$ & $5020 \pm 1723$ \\
Double Is & L Huron & $019 \pm 003$ & $1395 \pm 207$ \\
Chantry Is & L Huron & $003 \pm 001$ & $5035 \pm 1223$ \\
Fighting Is & Detroit River & $012 \pm 002$ & $2664 \pm 506$ \\
Middle Is & L Erie & $021 \pm 002$ & $2624 \pm 288$ \\
Port Colborne & L Erie & $043 \pm 030$ & $2923 \pm 400$ \\
Niagara River & Niagara River & $017 \pm 003$ & $3116 \pm 827$ \\
Hamilton Harbour & L Ontario & $054 \pm 013$ & $741 \pm 85$ \\
Toronto Harbour & L Ontario & $026 \pm 003$ & $2191 \pm 323$ \\
Snake Is & L Ontario & $013 \pm 002$ & $3811 \pm 620$ \\
Strachan Is & St Lawrence River & $009 \pm 001$ & $7664 \pm 2677$ \\
\hline
\end{tabular}

${ }^{\mathrm{d}}$ Detection of PFOSA was $<60 \%$ in individual eggs, range is given 


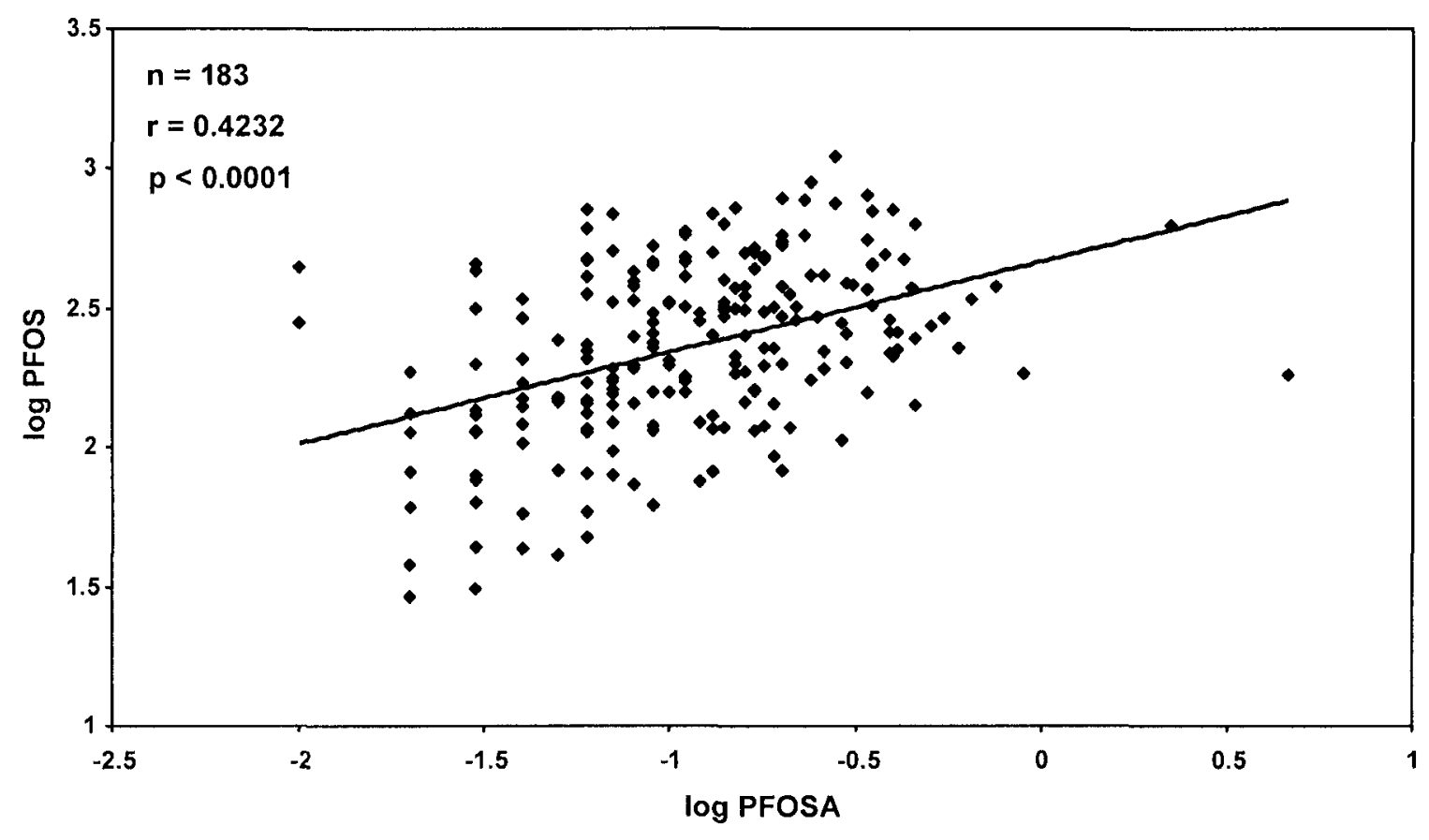

Figure 4.3 Correlation between PFOS and its precursor PFOSA (ng/g wet weight) in individual eggs from all colonies. 


\subsubsection{PFCAs and Spatial Distribution}

PFCAs of chain length $\mathrm{C}_{8}-\mathrm{C}_{15}$ were measurable in the herring gull eggs, and PFUnA and PFTrA dominated $\Sigma$ PFCA, at $26 \%$ and $28 \%$, respectively for eggs from all 15 colonies (Tables 4.1 and 4.3). See Appendix B for individual PFCA concentrations in eggs from all colonies. Studies investigating the PFCA pattern in birds North America are limited to the northern fulmar and the thick-billed murre from the Canadian Arctic where the $\mathrm{C}_{9}$, $\mathrm{C}_{11}$, and $\mathrm{C}_{12}$ PFCA dominated the pattern $(20,76)$. This is likely an indication of differences in PFCA exposure in the Arctic versus the Great Lakes. Norwegian herring gull and glaucous gull egg PFCA patterns were comparable to the present egg PFCA patterns suggesting similar exposure to PFCAs of various chain lengths $(33,72)$. The PFCA pattern in water birds from different locations in Asia were dominated by PFUnA, although the concentrations of PFCA $>\mathrm{C}_{13}$ were not reported $(77,78)$.

The PFCA pattern for various fish species from the Great Lakes, including prey species for the herring gulls such as alewife and rainbow smelt, have been reported $(23,24)$. Relative to alewife and rainbow smelt, the shorter chain length PFCAs, i.e., PFOA, PFNA, and PFDA, were less abundant in herring gull eggs. This suggests that pharmacokinetics of the $\mathrm{C}_{8}-\mathrm{C}_{15}$ PFCA differ in these fish relative to herring gulls; and/or there is selective PFCA transfer from female gulls to their eggs. As was shown in Chapter 3, the egg PFCA pattern was enriched with longer chain $\mathrm{C}_{11}-\mathrm{C}_{15}$ PFCAs compared to the liver PFCA pattern, this was also observed in the common guillemot (34). This would suggest that the PFCA pattern in adult gulls is similar to their fish prey (i.e, the greater proportion of shorter chain length PFCAs). Furthermore, enrichment on longer chain PFCAs in the gull eggs may be related to the binding of selective PFCAs to 
proteins that are part of in ovo transport, which is consistent with findings that PFCAs are known to bind to fatty acid binding proteins (FABPs), lipoproteins and albumin in the liver $(28,27)$.

On closer examination by PCA of the PFCA pattern in the herring gull eggs among colonies, there were small but significant differences. The proportion of PFOA and PFNA in the LPFCA from eggs collected from the colonies on Lake Superior, Lake Michigan and Lake Huron were greater compared to the eggs collected on Lake Erie and Lake Ontario (Figure 4.4). The amount of PFOA in the eggs from Granite Island, Big Sister Island, Double Island and Chantry Island was significantly greater $(p<0.005)$ compared to the other colonies. PFNA was more abundant in the eggs collected on Granite Island, Agawa Rocks and Double Island $(p<0.02)$. For the longer chain length PFCAs, the amount of PFUnA in the eggs collected from Snake Island and Strachan Island was significantly higher $(p<0.03)$ when compared to the other colonies except for the Channel-Shelter Island colony (Figure 4.4). For PFDoA and PFTeA, significantly higher $(p<0.04)$ contributions to the $\Sigma$ PFCA concentration were found at Fighting Island, and Hamilton and Toronto Harbours relative to the other colonies, with the exception of Big Sister and Middle Islands for PFDoA. At Chantry Island the amount of PFTrA was significantly higher $(p<0.001)$ compared to the other 14 colonies among the lakes. These differences in the PFCA patterns could be related to several factors, e.g., differences in the diet among the colonies, accumulation of precursors, and subsequent biotransformation. The greater abundance of the shorter chain length PFCAs in the northern lakes and the greater abundance of the longer chain PFCAs around Lake Erie 
Table 4.3 Arithmetic mean concentration ( \pm SE ng/g wet weight) of detectable PFCAs with carbon chain length varying from $\mathrm{C}_{8}$ to $\mathrm{C}_{15}$ in herring gull eggs $(\mathrm{n}=13)$ collected from 15 colonies in the Great Lakes in 2007.

\begin{tabular}{|c|c|c|c|c|c|c|c|c|}
\hline Colony & PFOA & PFNA & PFDA & PFUnA & PFDoA & PFTrA & PFTeA & PFPA \\
\hline Granite Is. & $0.98 \pm 0.20$ & $9.0 \pm 1.9$ & $7.7 \pm 1.1$ & $13 \pm 2$ & $3.9 \pm 0.5$ & $10 \pm 1$ & $1.1 \pm 0.2$ & $<0.05-0.79$ \\
\hline Agawa Rocks & $0.51 \pm 0.03$ & $9.6 \pm 0.6$ & $8.6 \pm 0.7$ & $20 \pm 2$ & $6.5 \pm 0.5$ & $23 \pm 2$ & $2.9 \pm 0.2$ & $1.3 \pm 0.2$ \\
\hline Big Sister Is. & $1.2 \pm 0.4$ & $3.1 \pm 0.3$ & $12 \pm 2$ & $14 \pm 2$ & $12 \pm 2$ & $15 \pm 2$ & $5.4 \pm 1.0$ & $0.51 \pm 0.19$ \\
\hline Gull Is. & $<0.10$ & $2.1 \pm 0.3$ & $4.1 \pm 0.6$ & $7.9 \pm 1.6$ & $3.2 \pm 0.6$ & $10 \pm 2$ & $1.5 \pm 0.4$ & $<0.05-4.9$ \\
\hline Channel-Shelter Is. & $<0.10$ & $0.71 \pm 0.16$ & $6.5 \pm 0.6$ & $13 \pm 1$ & $4.7 \pm 0.5$ & $12 \pm 1$ & $2.8 \pm 0.4$ & $1.2 \pm 0.3$ \\
\hline Double Is. & $2.6 \pm 0.4$ & $16 \pm 2$ & $20 \pm 2$ & $28 \pm 3$ & $12 \pm 1$ & $29 \pm 4$ & $4.6 \pm 0.7$ & $2.0 \pm 0.4$ \\
\hline Chantry Is. & $0.45 \pm 0.08$ & $2.1 \pm 0.4$ & $4.0 \pm 0.9$ & $6.1 \pm 1.6$ & $3.5 \pm 0.8$ & $13 \pm 3$ & $2.6 \pm 0.7$ & $<0.05-3.3$ \\
\hline Fighting Is. & $<0.10$ & $0.64 \pm 0.23$ & $7.8 \pm 1.2$ & $12 \pm 2$ & $11 \pm 2$ & $17 \pm 3$ & $7.4 \pm 1.1$ & $2.7 \pm 0.7$ \\
\hline Middle Is. & $<0.10$ & $1.6 \pm 0.3$ & $22 \pm 2$ & $25 \pm 2$ & $16 \pm 2$ & $20 \pm 2$ & $6.5 \pm 0.7$ & $1.7 \pm 0.3$ \\
\hline Port Colborne & $<0.10$ & $1.3 \pm 0.3$ & $10 \pm 1$ & $15 \pm 2$ & $6.1 \pm 0.8$ & $13 \pm 2$ & $3.6 \pm 0.6$ & $1.8 \pm 0.5$ \\
\hline Niagara River & $<0.10-0.64$ & $2.6 \pm 0.5$ & $13 \pm 2$ & $18 \pm 2$ & $7.5 \pm 1.0$ & $19 \pm 2$ & $3.7 \pm 0.6$ & $1.1 \pm 0.3$ \\
\hline Hamilton Harbour & $<0.10$ & $1.1 \pm 0.5$ & $7.6 \pm 1.8$ & $11 \pm 2$ & $12 \pm 2$ & $15 \pm 2$ & $7.2 \pm 1.1$ & $1.3 \pm 0.3$ \\
\hline Toronto Harbour & $0.40 \pm 0.09$ & $4.4 \pm 0.8$ & $11 \pm 1$ & $16 \pm 1$ & $13 \pm 2$ & $16 \pm 1$ & $7.9 \pm 1.1$ & $1.8 \pm 0.2$ \\
\hline Snake Is. & $<0.10$ & $1.4 \pm 0.5$ & $14 \pm 3$ & $24 \pm 4$ & $11 \pm 2$ & $19 \pm 3$ & $3.9 \pm 0.6$ & $<0.05-2.4$ \\
\hline Strachan Is. & $<0.10-0.46$ & $2.1 \pm 0.3$ & $12 \pm 2$ & $22 \pm 3$ & $8.9 \pm 1.3$ & $17 \pm 3$ & $2.9 \pm 0.6$ & $0.98 \pm 0.34$ \\
\hline
\end{tabular}



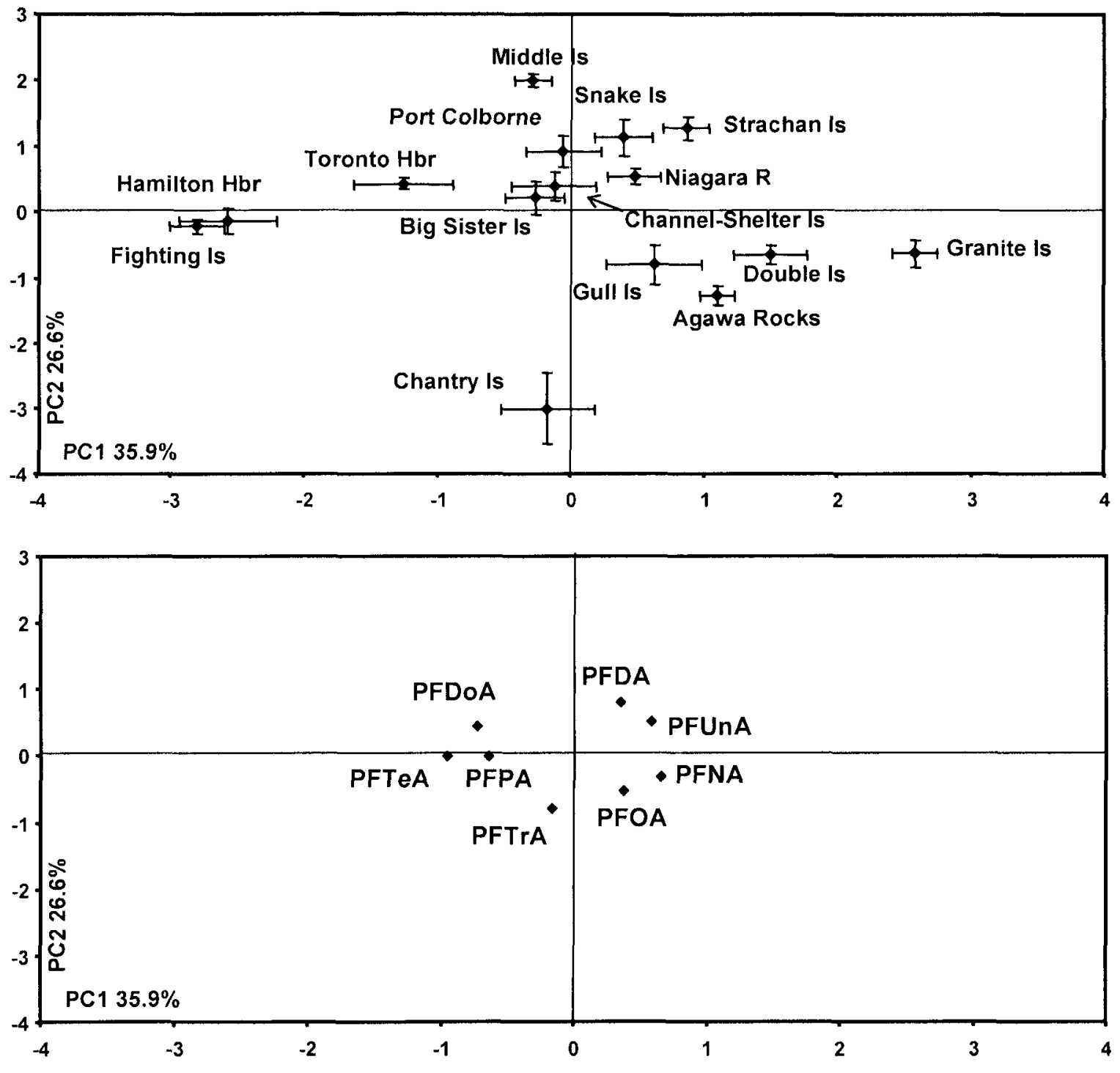

Figure 4.4 Proportions of $\mathrm{C}_{8}$ to $\mathrm{C}_{15}$ to $\Sigma \mathrm{PFCA}$ concentrations plotted using the first two principal components ( $\mathrm{PCs}), \mathrm{PC} 1$ and $\mathrm{PC} 2$. Mean ( $\pm \mathrm{SE}$ ) factor scores (top biplot) are shown for the 15 colonies. The percent variability explained by $\mathrm{PC} 1$ and $\mathrm{PC} 2$ is provided. 
and Ontario has also been reported in the spatial trend study of PFCAs in lake trout (24). For example, high amounts of PFOA were detected in lake trout from Lake Michigan, which the authors linked to the presence of the 8:2 FTUCA, a precursor to PFOA. Thus, differences in the observed PFCA pattern in herring gull eggs could be related to the degradation of more volatile precursors; although the FTUCAs and FTOHs were below the detection limit in the eggs from all the colonies. Laying female gulls may have not been exposed to accumulated precursor FTUCAs and FTOHs and may have been rapidly metabolized rapidly by the gulls. If accumulated, rapid metabolism of FTUCAs and FTOHs would have had to occur (in the liver). In livers of herring gull, FTUCAs (LOD $0.01 \mathrm{ng} / \mathrm{g}$ ) and FTOHs (LOD $0.5 \mathrm{ng} / \mathrm{g}$ ) were below detection limit (Chapter 3).

The highest IPFCA concentrations were found in eggs from the Double Island colony followed by the Middle Island colony (Table 4.1). Double Island had significantly higher $(p<0.05)$ concentrations in the eggs compared to the Granite Island, Big Sister Island, Gull Island, Channel-Shelter Island, Chantry Island, Fighting Island, Port Colborne and the Hamilton Harbour colonies. The highest concentrations found at colonies on Lake Huron (Double Island) and Lake Erie (Middle Island) are consistent with results reported for lake trout by Furdui et al. (24), where they reported that the highest $\Sigma$ PFCA concentrations were found in fish from Lake Erie followed by Lake Huron. As discussed for PFSAs, post-breeding migration of herring gulls from Double Island to Lake Ontario (74) may affect exposure to environmental contaminants. Alternatively, there may be a unique (e.g., terrestrial) local source that could explain the high concentrations at Double Island This explanation appears to be plausible since gull egg pools from Double Island have been reported to have among the lowest 
concentrations of PCBs, organochlorine pesticides and PBDEs compared to other colony sites. $(52,51)$. Similarly, the arithmetic mean $\Sigma$ PFSA concentration for eggs from Double Island was not among the most highly contaminated colonies (Figure 4.2, Table 4.1).

\subsubsection{IPFSA versus IPFCA Accumulation}

The concentrations of $\Sigma$ PFCA and $\Sigma$ PFSA were positively and significantly correlated for individual eggs from each of the 15 colonies, with the exception of Agawa Rocks and Double Island (Table 4.1, Figures 4.5 and 4.6). However, the slopes of the linear regressions varied considerably, which suggested covariant but different dietary sources (aquatic and/or terrestrial) of PFCAs and PFSAs depending on the colony. The slopes of these linear relationships of $\Sigma$ PFCA and $\Sigma$ PFSA concentration were compared to those previously reported for lake trout for each lake (24), and in the case of Lake Ontario also for alewife and rainbow smelt (23). Slopes describing the relationship between concentrations of $\Sigma$ PFCA and $\Sigma$ PFSA were similar for lake trout and herring gulls from Lake Michigan, and to a lesser degree, Lake Superior (Figure 4.5). Slopes were also similar between lake trout and gulls from Channel-Shelter Island on Lake Huron but less so between trout and gulls at Chantry Island (Figure 4.5). Even more different were the slopes for lake trout and herring gull eggs from the Double Island colony on Lake Huron (Figure 4.5). As has been discussed, this further suggests the contrasting sources for PFSAs and PFCAs for Double Island, which was reflected in lack of a statistically significant relationship between $\Sigma$ PFSAs and $\Sigma$ PFCAs $(p=0.40)$ unlike all other colonies except Agawa Rocks (Table 4.1). This may be a function of contrasting terrestrial and aquatic PFCA and PFSA dietary exposure among the Double Island birds. For all the gull 

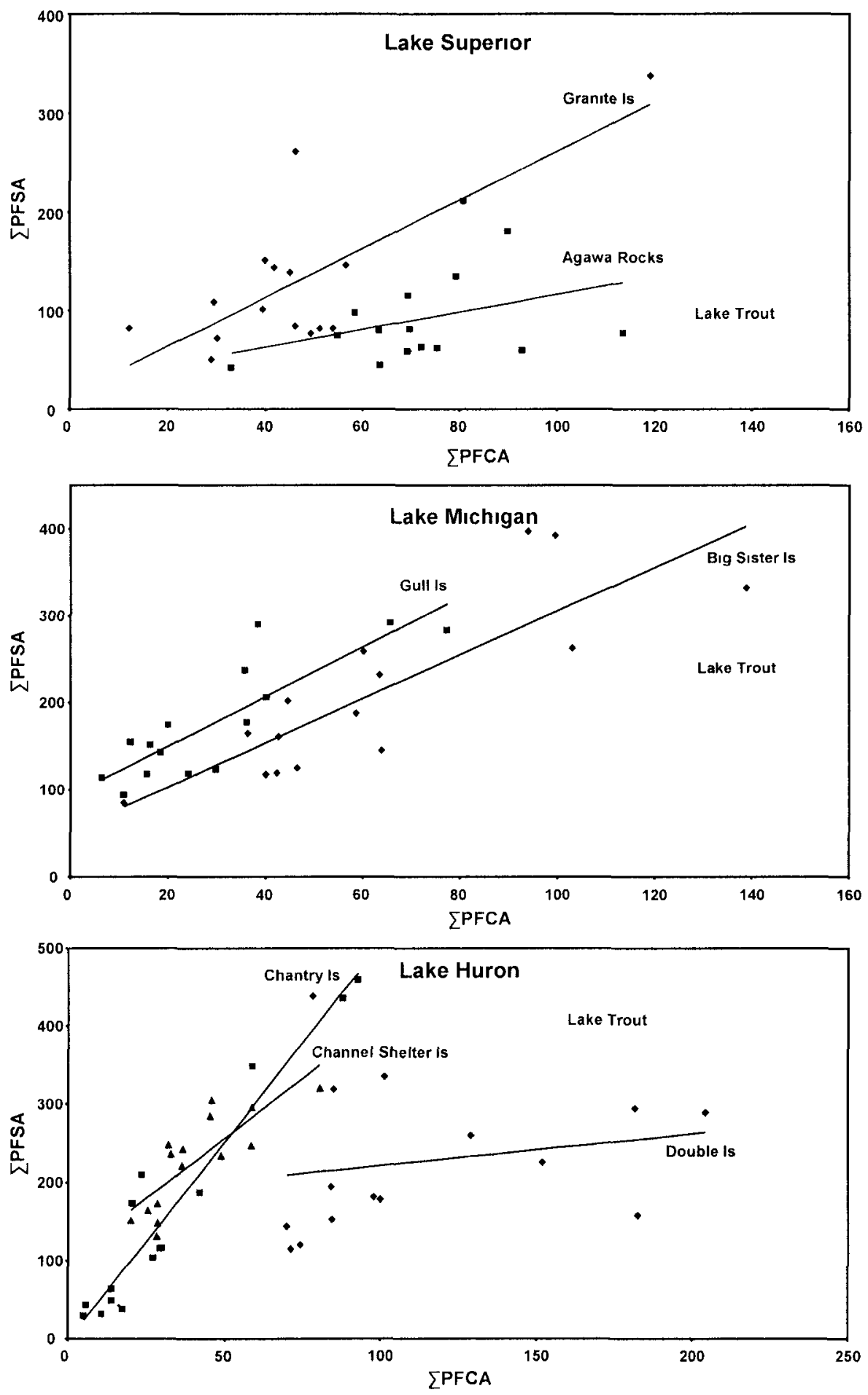

Figure 4.5 Plots of $\sum$ PFSA and $\sum$ PFCA concentration (ng/g wet weight) in individual herring gulls eggs from Lakes Superior, Michigan, and Huron, colonies were grouped per lake The dotted line indicates the $\sum$ PFSA/ $\sum$ PFCA ratio in lake trout per lake (adapted from Furdui et al (24) 

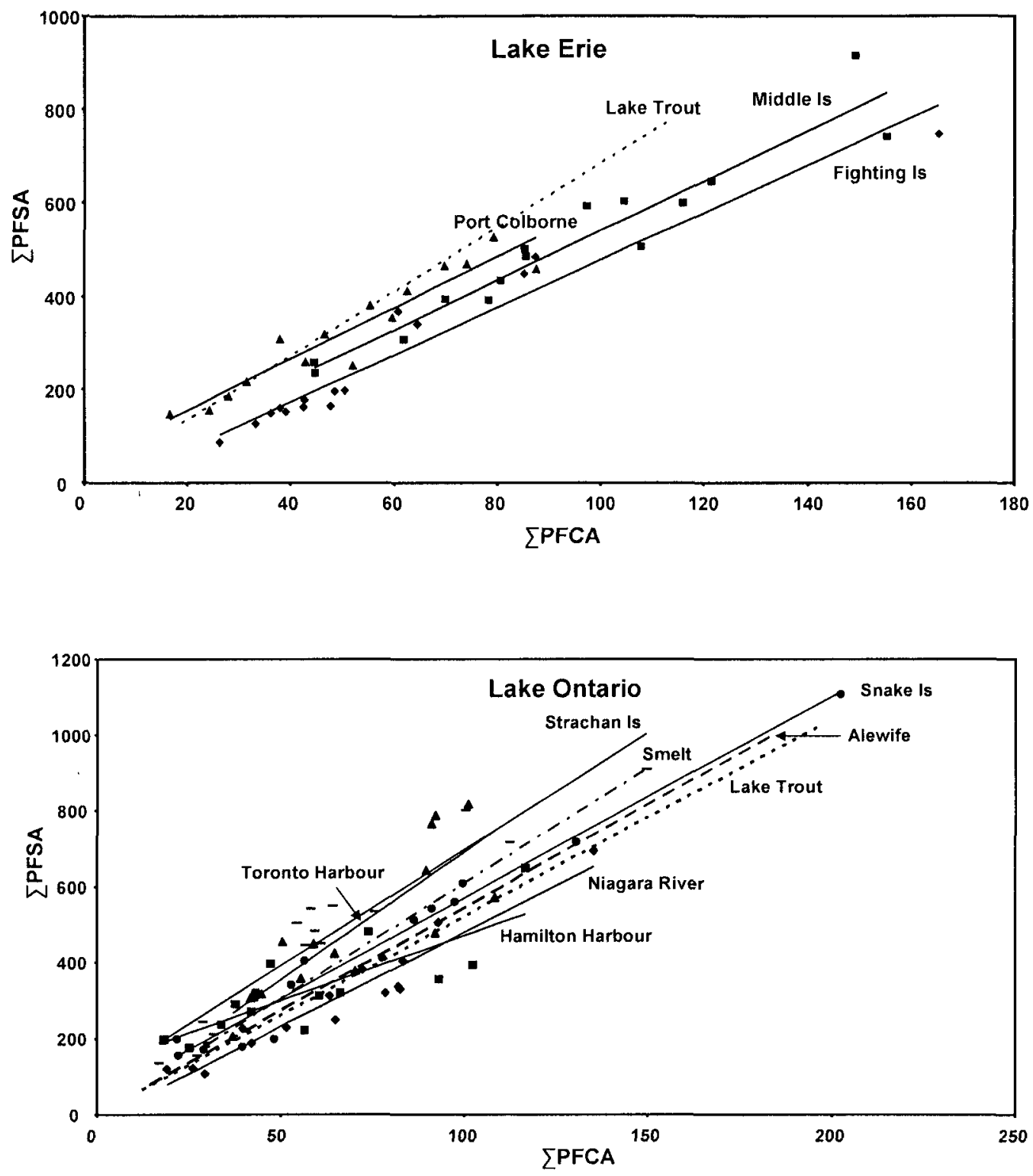

Figure 4.6 Plots of $\sum$ PFSA and $\sum$ PFCA concentration (ng/g wet weight) in individual herring gulls eggs from Lakes Erie and Ontario, colonies were grouped per lake. The dotted line indicates the $\sum$ PFSA/ $\sum$ PFCA ratio in lake trout per lake (adapted from Furdui et al.(24). The Lake Ontario plot includes the $\sum$ PFSA/ $\Sigma$ PFCA ratio in the alewife and smelt (adapted from Martin et al. (23). 
colonies on Lakes Erie and Ontario, the slope of the linear relationships between EPFCA and $\Sigma$ PFSA concentrations were similar to lake trout and/or alewife and rainbow smelt $(24,23)$ (Table 4.1, Figure 4.6). This suggests that the source of both PFCAs and PFSAs are mainly from aquatic food webs.

\subsubsection{Sources of PFC Exposure in Herring Gulls}

The differences observed in the patterns of PFCAs, PFSAs and PFOSA and sum concentrations among the breeding colonies are most likely due to differences in PFC patterns and concentrations in the gull diet. The gull diet consists mainly of prey fish, although a decline in trophic position in recent years indicates an increasing reliance on terrestrial food sources (61). For other POPs, i.e. PCBs, a decline in egg concentrations was linked to changes in trophic position. Greater proportions of terrestrial food in the gull diet result in lower exposure to PCBs highlighting the importance of aquatic food as the predominant source of these compounds (79). Whether this is the case for PFCAs, PFSAs, and PFOSA cannot be completely ascertained here. However, dietary source inputs are possible using tracers such as stable carbon and nitrogen isotope ratios and fatty acid profiles. Hebert et al. (6l) recently showed that there is a difference in trophic position of the gulls from the 15 different colonies in the Great Lakes basin based on stable carbon and nitrogen isotope data on egg pools from 2005. To illustrate the importance of diet in regulating concentrations of PFCs in gull eggs, individual herring eggs ( $\mathrm{n}=15$ ) collected (in 2001-2002) from Strachan Island (St. Lawrence River) were examined. Trophic position of individual female gulls was inferred from stable nitrogen isotope values in their eggs. $\mathrm{PPFCA}$ and LPFSA concentrations in eggs were 
significantly $(p<0.02$ for $\Sigma \mathrm{PFCA}$ and $p<0.009$ for $\Sigma \mathrm{PFSA})$ correlated with trophic position (Figure 4.7). A similar analysis conducted using eggs $(n=17)$ collected in 2005 from Scotch Bonnet Island (Lake Ontario) found a similar positive but non-significant relationship between trophic position and concentrations of $\Sigma$ PFCA $(r=0.408 ; p=0.10)$ and $\Sigma$ PFSA $(r=0.472 ; p=0.06)$. These data highlight the importance of diet as a major factor regulating the exposure of PFCs and further suggest that aquatic prey may be the main source of accumulation of PFCAs and PFSAs to herring gulls, and that any terrestrial inputs to the gull diet are not significant. In contrast, the observed spatial and temporal differences in 2 PBDEs in pools of gull egg from several (of the same) sites were attributed to differences or changes in PBDE exposure through the herring gull food web, which includes terrestrial (including human garbage, but also terrestrial invertebrates, small mammals, and passerine birds) as well as aquatic inputs (80). Hebert et al. (65) showed that the composition of the herring gull diet varies among the Great Lakes, including terrestrial foods.

Using the PFC data of the alewife and smelt from Martin et al. (23) as representative of the aquatic component of the gull's diet, estimated biomagnification factors (BMFs) were calculated for the herring gull eggs from Strachan Island (collected in 2001/02). Biomagnification of PFSAs and PFCAs was suggested as the BMFs of $\Sigma$ PFSA were estimated at 9.5 and 2.6 based on the alewife and smelt as prey fish, the $\Sigma$ PFCA BMF we estimated at 6.0 and 1.8 using these prey fish. Regardless of the diet, it is unlikely that there are inter-gull differences in PFC uptake and selectivity of in ovo transport during egg development. PFCAs and PFSAs are not lipophilic, but rather are protein-associated, and any PFC-protein complex formation and transfer to eggs would be PFC selective 

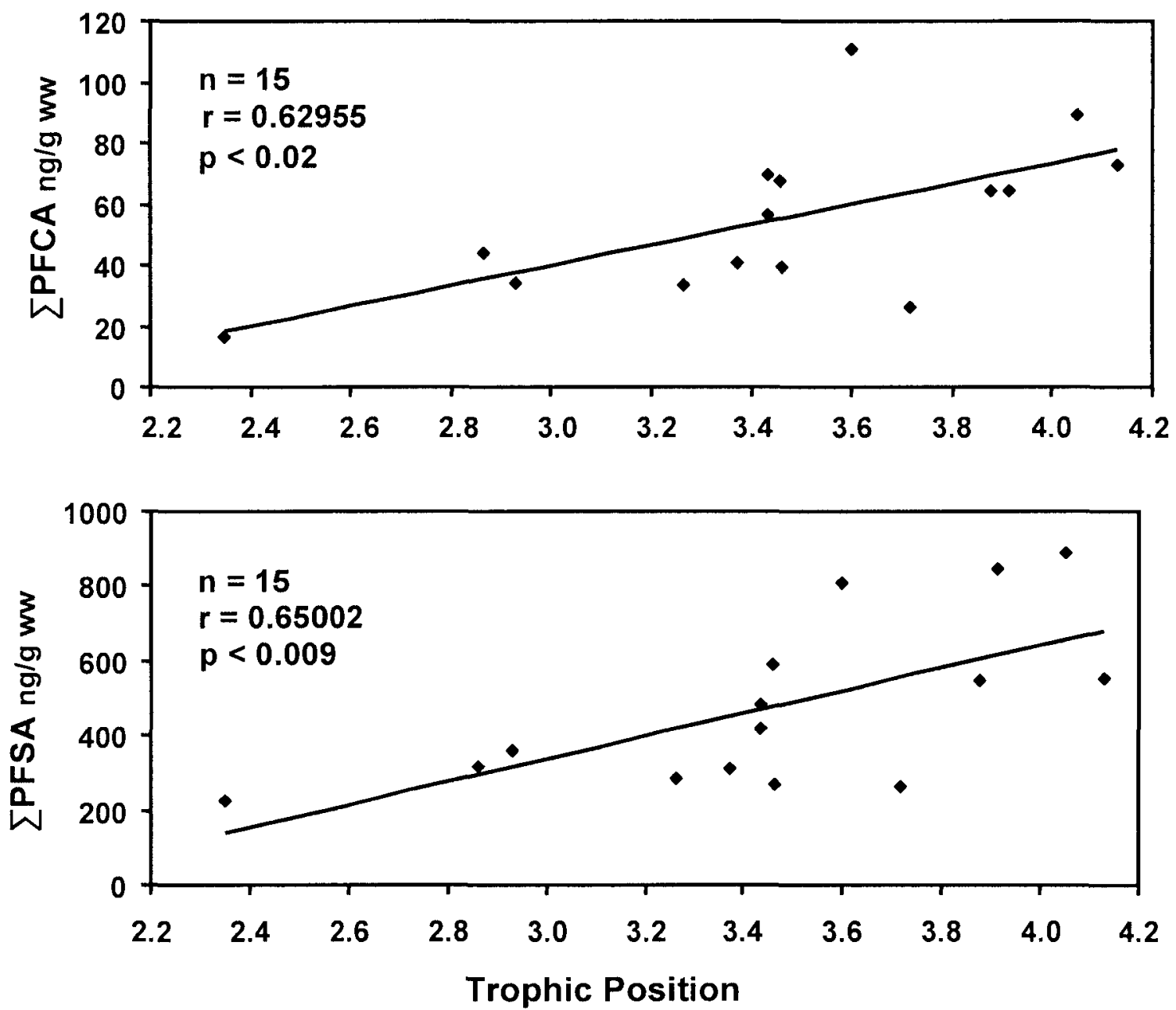

Figure 4.7 Plots of $\Sigma$ PFCA and $\Sigma$ PFSA concentrations (ng/g wet weight) versus trophic position based on individual herring gull eggs collected in 2001-2002 from Strachan Island, St. Lawrence River. 
rather than inter-bird selective.

The present findings suggest mainly aquatic sources of PFSA and PFCA accumulated in gulls and with subsequent transport to their eggs, either uptake from an aquatic (fish) diet and/or via metabolism of precursors. These dietary sources of accumulation were highly colony dependent, especially showing a northwest and southeast spatial trend and with higher concentrations in eggs from colonies in closer proximity to urban areas. To our knowledge, this is the first report on PFCAs and PFSAs and spatial trends in Great Lakes wildlife other than fish. The exposure and effects ramifications to herring gulls and perhaps other fish-eating bird species in the Great Lakes are unclear. There is extremely limited information on the effects of individual $\mathrm{C}_{8}$ $\mathrm{C}_{15}$ PFCAs and $\mathrm{C}_{4}-\mathrm{C}_{8}$ PFSAs or mixtures in any bird species. In a rare recent example, chicken eggs injected with PFOS showed a decline in hatchability and decreased embryo pippability at PFOS concentrations in the $\mu \mathrm{g} / \mathrm{g}$ range (measured in the liver) $(44,45)$. O'Brien et al. (45) showed that declines in embryo pippability of chicken eggs injected with PFOS were at concentrations comparable to what we presently report in the eggs of herring gulls from the highest contaminated colonies, i.e., in the $\mu \mathrm{g} / \mathrm{g} w \mathrm{w}$ concentration range. 


\section{Chapter 5: Linear and Branched Perfluorooctane Sulfonate Isomer Patterns in Herring Gull Eggs from Colonial Sites Across the Laurentian Great Lakes*}

\subsection{Introduction}

Many studies investigating PFCs as environmental contaminants in vertebrate biota have found that perfluorooctane sulfonate (PFOS) is the major persistent and bioaccumulative compound among the various perfluorosulfonates (PFSAs) and perfluorocarboxylates (PFCAs) (and their precursors) that have been monitored. Chapters $3 \& 4$ showed that the proportion of PFOS related to the sum of all PFCs measured was generally $>90 \%$ in herring gull eggs from 15 colonies across the Great Lakes. This is consistent with the dominance of PFOS in tissues in mammals, fish, and birds from higher trophic levels in (mainly) aquatic ecosystems in different parts of the world $(81,24,82)$. For example, the PFC profile in tissues of top predator species, including polar bears from across the Arctic, Norwegian herring gulls and lake trout from the Great Lakes is highly dominated by PFOS $(81,72,24)$.

PFOS is produced via the electrochemical fluorination (ECF) process, during which the hydrocarbon chain $\left(\mathrm{C}_{8}\right)$ is fragmented and rearranged resulting in the formation of a mixture of branched isomers in addition to linear PFOS (L-PFOS) (2). Typically, commercial PFOS contains between $2-20 \%$ of non-PFOS impurities, and of the remaining portion about $65-79 \%$ is L-PFOS and $21-35 \%$ is branched PFOS isomers

*Reproduced with permission from Gebbink, W.A. and Letcher, R.J. Environ. Sci Technol. 2010, 44, 3739-3745. Copyright 2010 American Chemical Society. 
$(3,4)$. Theoretically there are 89 geometric PFOS isomers that are branched $(5)$; however, only eleven isomers have been identified in technical PFOS products and/or environmental samples by either LC-MS or GC-MS-based methods $(3,4,6,26)$. For example, besides L-PFOS, six mono(trifluoromethyl) isomers have been reported in herring gull and double-crested cormorant eggs from Canada as well as in polar bear plasma and liver samples (3). In the Lake Ontario food web, di(trifluoromethyl) isomers were found in the smelt, sculpin and lake trout along with L-PFOS and the mono(trifluoromethyl) isomers (26). In all these studies, there was an enrichment of LPFOS in the PFOS isomer pattern compared to T-PFOS.

To our knowledge, published reports on PFOS structural isomers in any wildlife species from any population are extremely limited other than a recent report on fish of the Lake Ontario food web (26), and very limited herring gull, cormorant and polar bear samples (3). Furthermore, there are no reports on the spatial patterns of PFOS isomers among populations of a given wildlife species. The hypothesis was tested that the PFOS isomer pattern in herring gull egg was comprised of L-PFOS and several monomethyl and dimethyl branched isomers, and that an enrichment of L-PFOS will be seen in the eggs. Factors that could influence the site-specific concentrations and spatial patterns will be investigated.

\subsection{Results \& Discussion}

\subsubsection{Identification of PFOS Isomers in Herring Gulls}

The GC-MS method developed by Chu and Letcher (3), and used in this study, permitted the chromatographic and mass resolution of all eleven PFOS structural isomers shown to 
be present in technical PFOS mixtures (4) and in the present herring gull eggs. In the herring gull eggs, all six mono(trifluoromethyl) isomers (P1MHpS, P2MHpS, P3MHpS, P4MHpS, P5MHpS, P6MHpS) and two di(trifluoromethyl) isomers (P35DMHxS, P45DMHxS) were detected besides L-PFOS (Table 5.1, Figure 5.1). Consistent with present herring gull egg (collected in 2007) results were the findings of L-PFOS and mono(trifluoromethyl) isomers, although there were no detectable di(trifluoromethyl) isomers in a herring gull egg pool based on eggs collected in 1989 near Hamilton, ON, Canada, and in double-crested cormorant egg pool (based on egg collected in 2003) from the Great Lakes (3). Isomer-specific PFOS data for other wildlife and biota studies are extremely rare and therefore comparisons with the results of the present study are extremely limited. However, Houde et al. (26) detected several mono(trifluoromethyl) and di(trifluoromethyl) isomers along with the L-PFOS in water, sediment and several fish species collected from Lake Ontario. The P1MHpS, P6MHpS and P3MHpS, P4MHpS, P5MHpS (reported as a coelution) were detected in the Lake Ontario food web (including the alewife and smelt, which as major prey items of herring gulls) and water and sediment samples. The di(trifluoromethyl) isomers (reported as the sum of three isomers) were only found in water samples and fish species higher up in the food chain, including the smelt. Karrman et al. (83) reported on the isomer profile in human blood and detected the P1MHpS, P6MHpS, and P3MHpS, P4MHpS and P5MHpS as a coelution. Whereas L-PFOS was shown to be enriched in several Lake Ontario fish and food web samples (23), the isomer profile in the Swedish human blood samples were comparable to the isomer composition in T-PFOS, where the branched isomers comprised $>30 \%$ of $\sum$ PFOS. Thus, to our knowledge, with the exception of the Chu and 
Letcher (3) study this is the only other report for any environmental samples where complete resolution of all structural PFOS isomers has been achieved and thus isomerspecific quantification has been possible. PFOS isomer coelution issues reported in the Houde et al (26) and Karrman et al (83) studies, exemplifies the limitations of using liquid chromatography-based MS methods to separate the PFOS isomers, rather than the present GC-MS/in-port derivatization method (3).

\subsection{2 ¿PFOS Concentrations and Trends}

There was an increasing northwest to southeast spatial trend for the mean $\sum$ PFOS concentrations (sum of L-PFOS and mono(trifluoromethyl)- and di(trifluoromethyl)branched isomers), where the lowest concentrations were for eggs from colonies on Lakes Superior, Michigan, and Huron. See Appendix $\mathrm{C}$ for individual linear and branched PFOS isomer concentrations in eggs from all colonies. The highest $\Sigma$ PFOS concentrations were found for colonies on Lakes Erie and Ontario, the highly urbanized and industrialized lakes (Table 5.1). The $\sum$ PFOS concentrations were not significantly ( $p>0.05)$ different, as well as this spatial pattern, as compared to the $\sum$ (total)PFOS concentrations reported in Chapter 4 using an LC-ESI-MS/MS based method. A strong and significant correlation $(\mathrm{p}<0.0001, \mathrm{r}=0.971)$ was observed for $\mathrm{LC}-\mathrm{MS} / \mathrm{MS}$ versus GC-MS measured $\sum$ PFOS concentrations (Figure 5.2). The strong correlation indicated the robustness, reproducibility and comparability of $\sum$ PFOS concentrations determined by either analytical method. 
Table 5.1 Arithmetic mean percentage $( \pm \mathrm{SE})$ of detectable perfluorooctane sulfonate (PFOS) isomers and arithmetic mean concentration of $\sum$ PFOS $( \pm$ SE ng/g ww) in herring gull eggs $(n=13)$ collected in 2007 from 15 colonies in the Great Lakes.

\begin{tabular}{|c|c|c|c|c|c|c|c|c|c|c|}
\hline \multirow[t]{2}{*}{ Colony\# $^{a}$} & \multicolumn{9}{|c|}{ PFOS Isomer ${ }^{b}$} & \multirow[b]{2}{*}{$\sum$ PFOS } \\
\hline & L-PFOS & P1MHpS & P2MHpS & P3MHpS & P4MHpS & $\mathrm{P} 5 \mathrm{MHpS}$ & P6MHpS & P35DMHxS & P45DMHxS & \\
\hline Granite Is & $954 \pm 03$ & $026 \pm 002$ & $015 \pm 001$ & $063 \pm 006$ & $062 \pm 006$ & $079 \pm 005$ & $216 \pm 015$ & $0^{\mathrm{c}}$ & 0 & $148 \pm 22$ \\
\hline Agawa Rocks & $962 \pm 03$ & $016 \pm 002$ & $010 \pm 001$ & $059 \pm 006$ & $059 \pm 005$ & $105 \pm 009$ & $128 \pm 010$ & $0-004^{d}$ & 0 & $99 \pm 13$ \\
\hline Big Sister Is & $959 \pm 03$ & $040 \pm 003$ & $019 \pm 001$ & $068 \pm 005$ & $064 \pm 004$ & $091 \pm 006$ & $123 \pm 019$ & $0-005$ & 0 & $205 \pm 18$ \\
\hline Gull Is & $950 \pm 05$ & $042 \pm 005$ & $017 \pm 003$ & $074 \pm 005$ & $069 \pm 005$ & $118 \pm 007$ & $180 \pm 035$ & $0-004$ & $005 \pm 001$ & $193 \pm 13$ \\
\hline Channel-Shelter Is & $973 \pm 05$ & $026 \pm 001$ & $011 \pm 001$ & $073 \pm 016$ & $063 \pm 014$ & $097 \pm 021$ & 0 & $0-019$ & 0 & $186 \pm 13$ \\
\hline Double Is & $957 \pm 03$ & $020 \pm 001$ & $013 \pm 001$ & $074 \pm 006$ & $069 \pm 005$ & $113 \pm 007$ & $145 \pm 017$ & $0-008$ & 0 & $276 \pm 25$ \\
\hline Chantry Is & $975 \pm 02$ & $018 \pm 002$ & $012 \pm 001$ & $058 \pm 006$ & $047 \pm 008$ & $047 \pm 006$ & $066 \pm 017$ & $001 \pm 001$ & 0 & $169 \pm 38$ \\
\hline Fighting Is & $969 \pm 02$ & $026 \pm 002$ & $011 \pm 001$ & $046 \pm 003$ & $042 \pm 003$ & $057 \pm 005$ & $128 \pm 010$ & $001 \pm 001$ & 0 & $261 \pm 38$ \\
\hline Middle Is & $983 \pm 01$ & $023 \pm 001$ & $009 \pm 001$ & $032 \pm 003$ & $025 \pm 002$ & $043 \pm 003$ & $039 \pm 011$ & $0-003$ & 0 & $551 \pm 42$ \\
\hline Port Colborne & $971 \pm 02$ & $028 \pm 003$ & $010 \pm 001$ & $039 \pm 003$ & $031 \pm 002$ & $052 \pm 005$ & $128 \pm 011$ & 0 & $0-006$ & $350 \pm 31$ \\
\hline Niagara River & $965 \pm 03$ & $019 \pm 001$ & $010 \pm 001$ & $045 \pm 004$ & $044 \pm 004$ & $070 \pm 007$ & $158 \pm 020$ & $0-006$ & 0 & $317 \pm 39$ \\
\hline Hamilton Harbour & $951 \pm 04$ & $022 \pm 005$ & $011 \pm 002$ & $058 \pm 008$ & $050 \pm 005$ & $094 \pm 008$ & $250 \pm 015$ & $0-008$ & $0-013$ & $317 \pm 28$ \\
\hline Toronto Harbour & $955 \pm 02$ & $029 \pm 002$ & $014 \pm 001$ & $049 \pm 003$ & $045 \pm 003$ & $089 \pm 006$ & $221 \pm 013$ & $001 \pm 001$ & $001 \pm 001$ & $586 \pm 62$ \\
\hline Snake Is & $975 \pm 03$ & $023 \pm 002$ & $009 \pm 001$ & $035 \pm 006$ & $030 \pm 005$ & $055 \pm 008$ & $098 \pm 013$ & $0-006$ & 0 & $408 \pm 59$ \\
\hline Strachan Is & $956 \pm 08$ & $028 \pm 006$ & $014 \pm 004$ & $074 \pm 023$ & $060 \pm 014$ & $085 \pm 012$ & $177 \pm 021$ & $0-028$ & 0.016 & $422 \pm 40$ \\
\hline
\end{tabular}

${ }^{\text {a }}$ See Figure 1.3 for exact location of the 15 colonies.

${ }^{\mathrm{b}}$ See Table 2.3-Figure 1.2 for names, abbreviations and structures of the linear and branched PFOS isomers. See Figure 5.1 for a typical GC-MS(ECNI) mass chromatogram showing PFOS isomers in a typical herring gull egg sample. P55DMHxS and

P44DMHxS were below the detection limit in the eggs from all the 15 colonies.

${ }^{\mathrm{c}}$ Zero indicates that the isomer was below detection limit.

${ }^{d}$ Detection of the isomer was $<60 \%$ in individual eggs, a range of the percentage is given. 


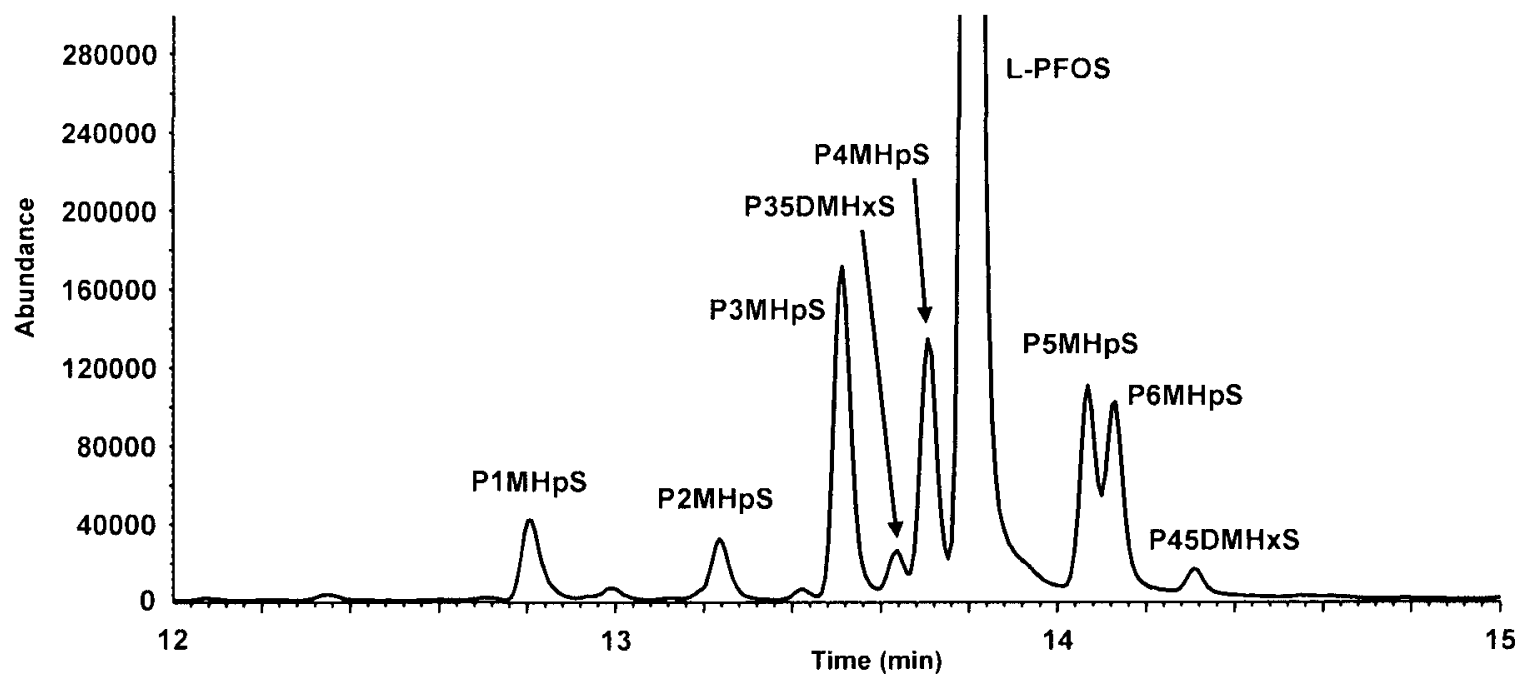

Figure 5.1 GC-MS(ECNI) mass chromatogram of linear and branched, geometric perfluorooctane sulfonate (PFOS) isomers in a representative herring gull egg from Strachan Island, Lake Ontario. 


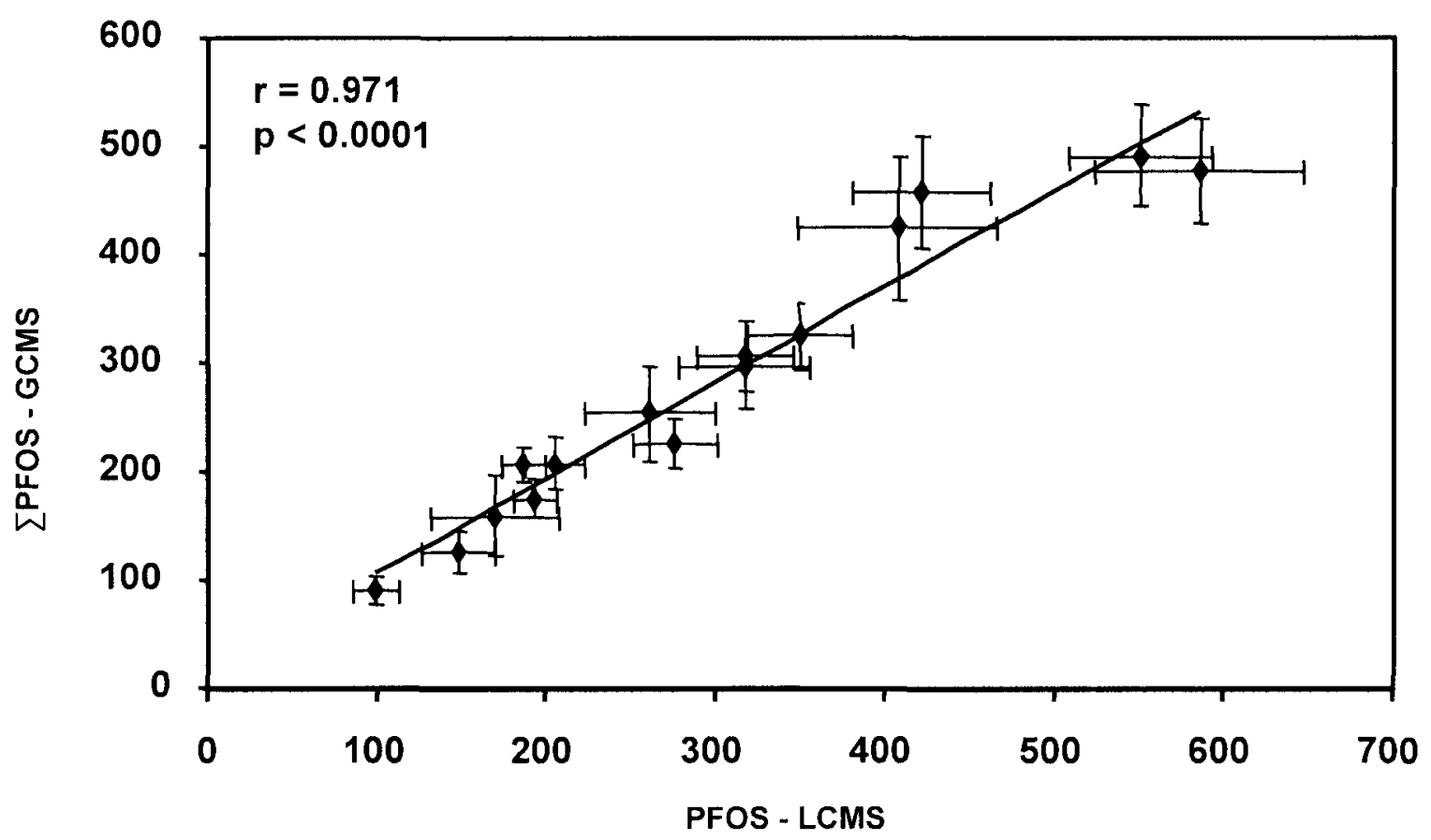

Figure 5.2 Plot of arithmetic mean PFOS concentration ( \pm SE ng/g ww) obtained by LCMS/MS analysis (Chapter 4) and arithmetic mean $\sum$ PFOS concentration ( $\pm \mathrm{SE} \mathrm{ng} / \mathrm{g} \mathrm{ww}$ ) obtained by the present GC-MS analysis of individual herring gull eggs $(n=13)$ from 15 colonies in the Great Lakes. 


\subsubsection{Spatial Patterns and Sources of PFOS Isomers}

Although the isomer pattern in the eggs was similar for all the 15 colonies, significant differences were observed. The L-PFOS made up between 95.0\% (Gull Island) and 98.3\% (Middle Island) of $\sum$ PFOS (Table 5.1). The amount of L-PFOS in the herring gull eggs from the Middle Island colony was significantly $(p<0.008)$ higher compared to the Gull, Strachan, Granite, Big Sister, and Chantry Island, Toronto and Hamilton Harbour and Agawa Rocks colonies (Figure 5.3).

Of the mono(trifluoromethyl) PFOS isomers, the mean proportion of the P1MHpS in the eggs from Gull Island $\left(0.42 \%\right.$ of $\sum$ PFOS $)$ was significantly $(\mathrm{p}<0.04)$ higher compared to the other colonies, except the Port Colborne, Big Sister Island and Strachan Island colonies. The P2MHpS isomer was found at highest mean proportion in the Big Sister Island eggs $\left(0.19 \%\right.$ of $\sum$ PFOS), and this was significantly $(\mathrm{p}<0.02)$ higher compared to the colonies on Channel-Shelter, Middle, Snake, and Fighting Islands, Port Colborne, Hamilton Harbour, Agawa Rocks, and Niagara River. The highest mean proportion of P3MHpS was found in eggs collected from Double Island, Gull Island and Strachan Island $\left(0.74 \%\right.$ of $\sum$ PFOS $)$; however, only Double Island was significantly $(\mathrm{p}<0.05)$ higher compared to Middle Island. At the colonies on Gull, Channel-Shelter, Strachan, Granite, Big Sister, and Double Islands and Agawa Rocks, the mean proportion of P4MHpS $\left(>0.59 \%\right.$ of $\sum$ PFOS $)$ was significantly higher $(\mathrm{p}<0.03)$ compared to the Middle Island colony, which had the lowest amount of P4MHpS in the eggs. The highest mean proportion of P5MHpS of the $\sum$ PFOS was found in the eggs collected from the Gull and Double Islands $\left(1.18 \%\right.$ and $1.13 \%$ of $\sum$ PFOS, respectively); this was significantly $(\mathrm{p}<0.01)$ higher compared to the Middle, Snake, Chantry, and Fighting Islands as well as 

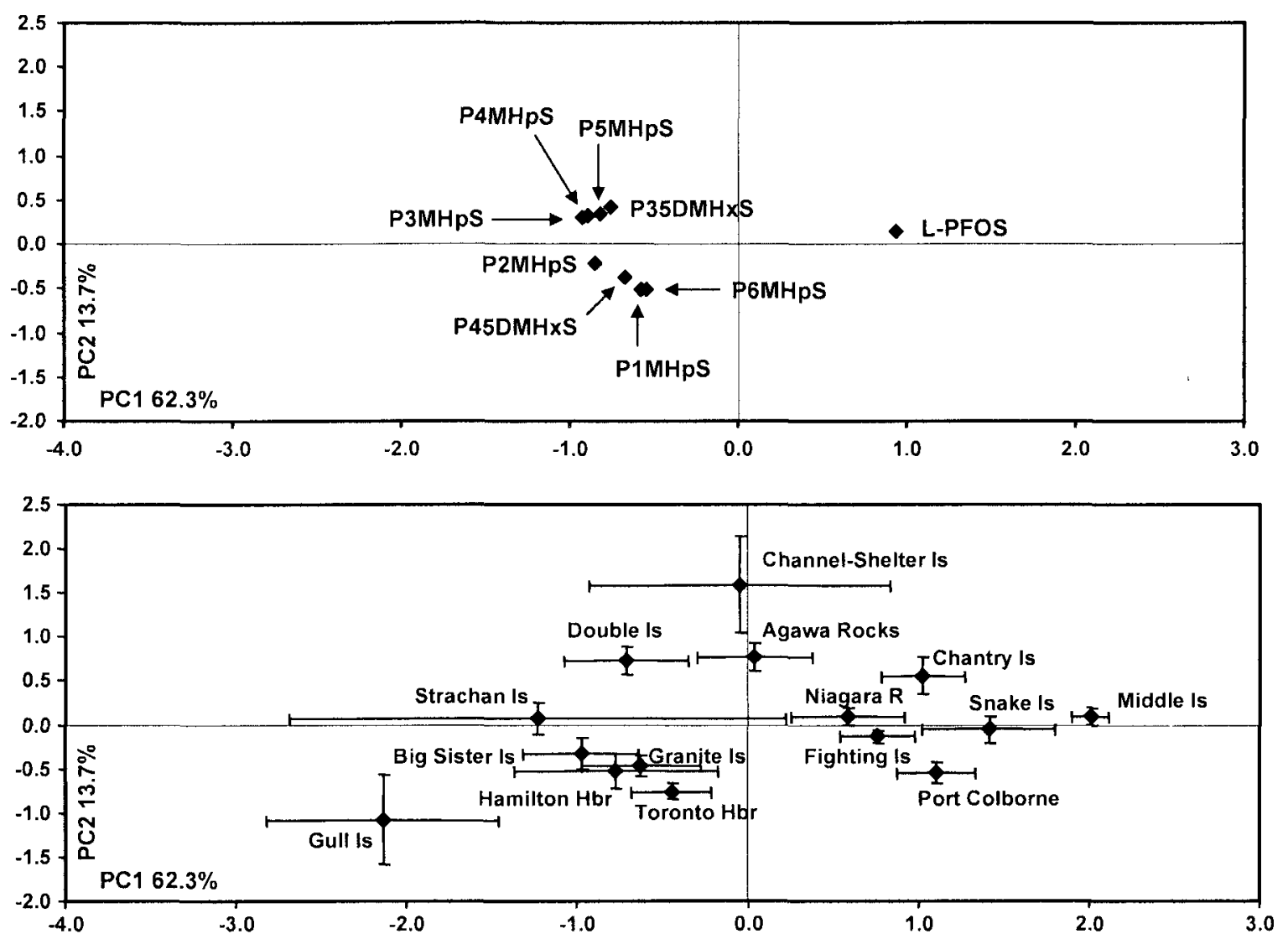

Figure 5.3 Proportions of individual perfluorooctane sulfonate (PFOS) isomers (linear PFOS (L-PFOS) and mono(triofluoromethyl)- and di(trifluoromethyl)-PFOS) to $\sum$ PFOS concentrations plotted using the first two principal components (PCs), PC1 and PC2. Mean $( \pm \mathrm{SE})$ factor scores (bottom biplot) are shown for the 15 colonies. The percent variability explained by $\mathrm{PC} 1$ and PC2 is provided. See Table 2.3 and Figure 1.2 for abbreviations and structures of the linear and branched PFOS isomers. 
Port Colborne and Niagara River colonies. For the proportion of P6MHpS, the eggs from the Hamilton and Toronto Harbour and Granite Island colonies ( $>2.16 \%$ of $\sum$ PFOS) was significantly higher $(\mathrm{p}<0.02)$ compared to the other colonies except the Gull, Strachan, and Double Island and Niagara River colonies.

Of the detected di(trifluoromethyl) PFOS isomers, there was no significant difference $(\mathrm{p}>0.05)$ of the proportion of P35DMHxS to $\sum$ PFOS in the eggs from Chantry Island, Fighting Island and Toronto harbour; these were the only colonies where detection was $>60 \%$ in the individual eggs. At Gull Island, the proportion of P45DMHxS was significantly $(\mathrm{p}<0.002)$ greater compared to Toronto Harbour, detection was only $>60 \%$ in the individual eggs collected from these two colonies.

T-PFOS contained between $65 \%$ and $79 \%$ L-PFOS depending on the provider; for the monomethyl isomers, the percentage of $\mathrm{P} 6 \mathrm{MHpS}>\mathrm{P} 5 \mathrm{MHpS}>\mathrm{P} 4 \mathrm{MHpS} \approx \mathrm{P} 3 \mathrm{MHpS}>$ $\mathrm{P} 2 \mathrm{MHpS} \approx \mathrm{P} 1 \mathrm{MHpS}$. The four dimethyl isomers (P35DMHxS, P44DMHxS, P45DMHxS, P55DMHxS) each comprised $<1 \%$ in T-PFOS and similar to that reported elsewhere in PFO technical mixtures $(3,4)$. Compared to T-PFOS, L-PFOS was highly enriched in the herring gull eggs (Table 5.1). Although the percentages of the monomethyl isomers as a group in the herring gull eggs were lower compared to TPFOS, the relative proportions of the individual monomethyl isomers were comparable to T-PFOS, i.e., P6MHpS $>$ P5MHpS $>$ P4MHpS $\approx \mathrm{P} 3 \mathrm{MHpS}>\mathrm{P} 2 \mathrm{MHpS} \approx \mathrm{P} 1 \mathrm{MHpS}$ (Table 5.1). The L-PFOS enrichment in herring gull eggs is further illustrated by $\sum$ branched/linear isomer ratios. In the T-PFOS the $\sum$ branched/linear isomer ratio varies between 0.267 and 0.537 depending on the source of the T-PFOS mixture $(4,3)$. The $\sum$ branched/linear isomer ratio in the herring gull eggs ranged from 0.018 (Middle Island) 
to 0.053 (Gull Island) (Figure 5.4). In the eggs from colonies on Lake Erie and southern Lake Huron the ratio was lower compared to the ratio in the eggs from colonies on Lake Superior, Michigan and Ontario. The Gull Island and Hamilton Harbour colony ratio was significantly $(\mathrm{p}<0.05)$ higher compared to Channel-Shelter, Chantry, Fighting, and Middle Island and Port Colborne. The $\sum$ branched/linear isomer ratio in the eggs from Middle Island were significantly $(\mathrm{p}<0.02)$ lower compared to all the colonies outside the Lake Erie and southern Lake Huron region with the exception of Snake Island. Overall, regardless of the hydrocarbon substitution of the mono(fluoromethyl) group, the proportion of the these branched isomers remained the same in herring gull eggs relative to T-PFOS. This suggests that the apparent dilution of the mono(fluoromethyl) isomers from environmental processes may have occurred prior to final accumulation in herring gull eggs and was independent of the mono(fluoromethyl) isomer structure.

The possible factors/processes influencing the PFOS isomer patterns and colonial site dependence in the present herring gull eggs are likely complex but are currently undefined. Possible factors may include sources, environmental release and transport, the abiotic processes, aquatic and/or terrestrial food web pathways, and/or pharmacokinetic processes within the gull and/or its prey and food web. Houde et al. (26) demonstrated that in the Lake Ontario food web the $\sum$ branched/linear isomer ratio in species, ranging from plankton to lake trout, was $\leq 0.1$. Although in water samples the ratio was $\sim$, sediment samples from Lake Ontario contained a similar ratio as the food web species. Houde et al. (26) suggested that there was greater sorption of L-PFOS to the sediment and that the sediment and the invertebrates are close to a chemical equilibrium 


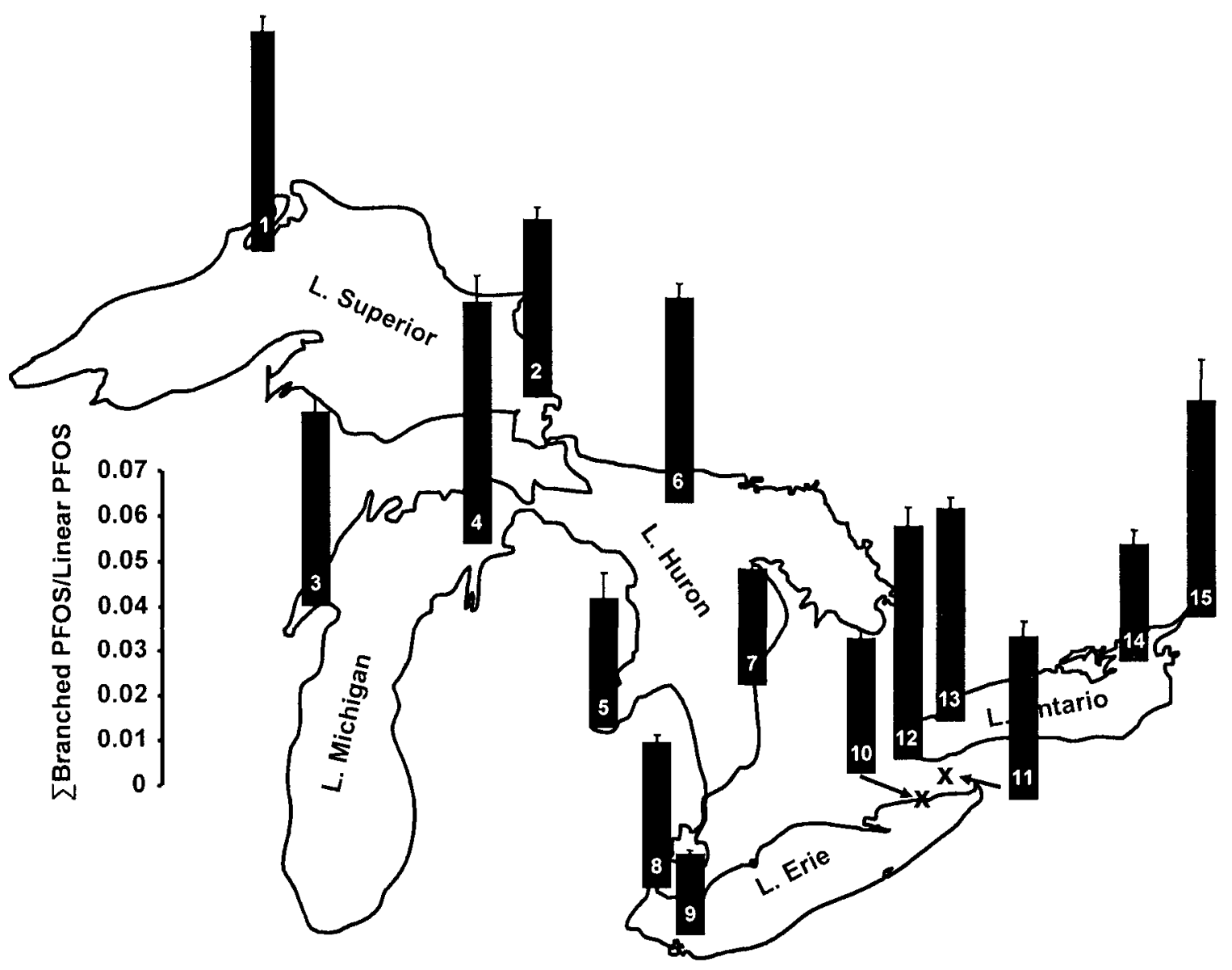

Figure 5.4 Arithmetic mean Ebranched perfluorooctane sulfonate (PFOS) isomer (mono(triofluoromethyl) and di(trifluoromethyl)) to linear PFOS isomer concentration ratios $( \pm \mathrm{SE})$ for herring gull eggs $(\mathrm{n}=13$ eggs per site) collected in 2007 from 15 colonies in the Laurentian Great Lakes: (1) Granite Island, (2) Agawa Rocks, (3) Big Sister Island, (4) Gull Island, (5) Channel-Shelter Island, (6) Double Island, (7) Chantry Island, (8) Fighting Island, (9) Middle Island, (10) Port Colborne, (11) Niagara River, (12) Hamilton Harbour, (13) Toronto Harbour, (14) Snake Island, (15) Strachan Island. 
partitioning with the ambient water. The L-PFOS enriched isomer pattern was subsequently transferred from prey to predator in the food web.

The PFOS isomer patterns in the present Great Lakes herring gull eggs could be influenced by the source and subsequent degradation of, e.g. perfluorosulfonamide precursors, e.g., NEtFOSA and PFOSA. Source differences could stem from colonial location-specific inputs to the precursor exposure in the herring gull food web (aquatic and terrestrial) and subsequent gull-specific difference in precursor metabolism and subsequent maternal egg transfer. In vitro studies with hepatic microsomes of rats, fish and humans have demonstrated differences in degradation, and in the case of humans isomer-specific degradation, NEtFOSA and PFOSA, which could be an additional source of (isomer-specific) PFOS $(10,11,16)$. Technical N-EtFOSA and PFOSA consists of linear and branched isomers, and Benskin et al. (16) showed the isomer-specific NEtFOSA to PFOSA degradation. Whether the PFOSA detected in the herring gulls diet (alewife and smelt) is linear or branched PFOSA has not been studied or confirmed (23). However, in herring gulls from the Great Lakes, the PFOS/PFOSA ratio in the eggs was at least two orders of magnitude higher compared to the alewife and smelt (Chapter 4) suggesting that the PFOSA (linear and/or branched) is metabolized to PFOS by the herring gull, although a selective transfer of PFOS and/or PFOSA from the female gull to the eggs cannot be ruled out. Although not reported for typical fish prey of herring gulls, inter-lake differences in PFOSA concentration in the top aquatic predator, lake trout, showed spatial variation among the Great Lakes (24). Whether this is the same as in the alewife and smelt and to what degree this could influence the spatial PFOS isomer pattern 
in gulls remains unclear as presently there is no information on the PFOS isomers in the aquatic food web from all the Great Lakes.

Differences in PFOS isomer pharmacokinetics among species might also influence the isomer pattern when comparing prey to predator patterns. In the western Arctic food web for example, the isomer pattern in Arctic cod contained about 50\% branched isomer while in ringed and bearded seals the percentage was drastically reduced to $4 \%$ (84). As seen in rats exposed to T-PFOS, the uptake and elimination rates varied among the linear and branched isomers $(85,86)$. In humans, the PFOS isomer pattern reflects the technical mixtures, i.e., $\sim 60-70 \%$ is L-PFOS (83), thus it appears that humans are exposed directly to T-PFOS. It is likely that human exposure to T-PFOS present in consumer products would result in a different isomer profile compared to e.g. consumption of fish (with predominantly L-PFOS) (26). Furthermore, PFOS isomer-specific biotransformation studies with human liver microsomes have recently shown that with POSF-based precursor compounds that branched NEtFOSA is more rapidly converted to PFOS compared to its linear analogue (16).

By comparing the isomer pattern of the main prey species (alewife and smelt) from the Lake Ontario food web to the present herring gull egg isomer pattern from Lake Ontario colonies, a further enrichment of L-PFOS appears to take place (Figure 5.5). Generally the L-PFOS was found 5\% higher in proportion in the $\sum$ PFOS in the eggs from the Hamilton and Toronto Harbour and Snake Island colonies compared to these two (typical) gull prey species (49). However, P1MHpS, P3/4/5MHpS (reported as a coelution by Houde et al. (26)) and P6MHpS showed a decrease regardless of the prey species. Different pharmacokinetics of the PFOS isomers (e.g., uptake and egg 


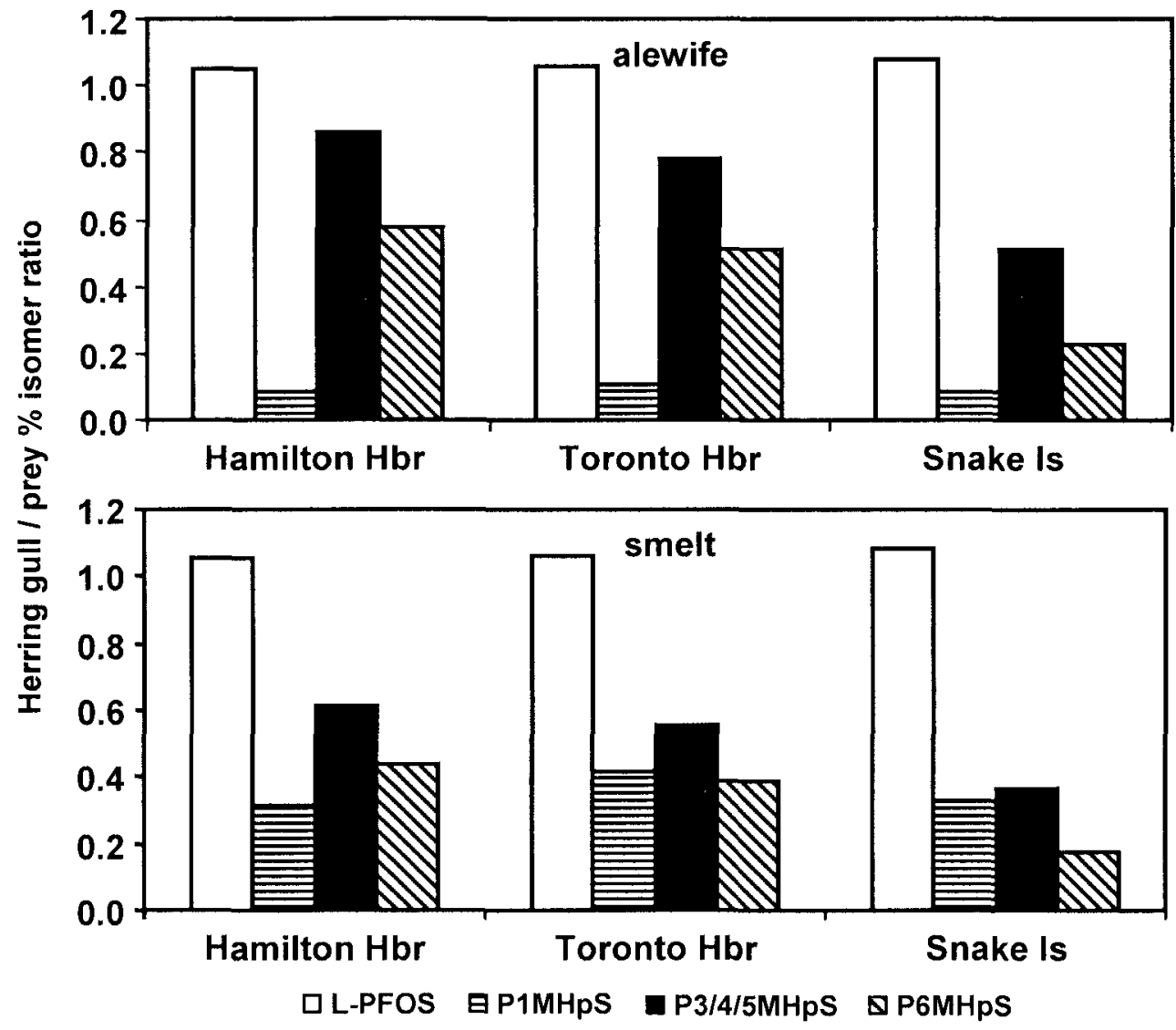

Figure 5.5 Herring gull egg to prey (top) alewife and (bottom) rainbow smelt ratio of \% individual perfluorooctane sulfonate (PFOS) isomers from Lake Ontario colonies. Alewife and smelt data is taken from Houde et al.(26). See Table 2.3 and Figure 1.2 for abbreviations and structures of the linear and branched PFOS isomers. 
deposition) or as previously indicated that isomer-specific biotransformation of branched POSF- based precursor compounds (16), could have resulted in a change in the PFOS isomer pattern. O'Brien et al. (87) very recently reported an enrichment of L-PFOS in the liver of embryonic chickens after direct injection of the undeveloped eggs to T-PFOS. Compared to their prey/diet, isomer-specific elimination rates in the maternal herring gulls in the present study may have contributed to a shift in the PFOS isomer pattern in the present eggs. In rats, Benskin et al. (85) showed that branched isomers generally had lower half-lives compared to L-PFOS, with the exception of P1MHpS, which had a longer half-life. For mono(trifluoromethyl) isomers, a relationship was observed between the position of the trifluoromethyl-group and the half-life whereby longer half-lives were observed when the trifluoromethyl-group was closer toward the sulfonate end of the carbon chain. Among the mono(trifluoromethyl) isomers detected in the typical prey species of Great Lakes herring gulls, the greatest decline was found for the P1MHpS, which, according to Benskin et al. (85) has a greater half-life than L-PFOS in rats. Different isomer specific elimination rates and/or biotransformation of P1MHpS by herring gulls could similarly explain the PFOS isomer patterns in eggs.

Another factor that could influence the PFOS isomer patterns (isomer-specific exposure to PFOS or PFOS precursors) in herring gulls is the colony-specific migration (during or around the breeding period) from Granite Island, Agawa Rocks, Big Sister Island, Gull Island, and Double Island during the winter months, when the lakes are covered with ice (74). As mentioned, the PFOS isomer concentrations and patterns in the gull's diet have not been studied for every lake. Regardless, the migration of the gulls from these northern colonies to more southern location might result to exposure of 
different isomers by consuming prey with different isomer patterns. One last factor, although speculative, with respect to branched to linear concentration ratios among colony-specific gulls may be PFOS isomer-specific in ovo transfer, as a function of protein binding, from mother to developing egg. Present studies investigating protein binding of PFOS are very limited. Luebker et al. (27) reported on the binding of L-PFOS to fatty acid binding proteins and Jones et al. (28) used T-PFOS to investigate the binding to serum proteins. However, no PFOS isomer specific analysis were performed, although it was stated differential binding of linear and branched PFOS isomers could occur.

Regardless of the possible source and exposure factors, there are variations in branched to linear PFOS concentration ratios among herring gulls (eggs) from across the Great Lakes (Figure 5.4). However, L-PFOS constituted $95-98 \%$ of the $\Sigma$ PFOS in all the sampled colonies. Thus, the branched isomer component of the apparent L-PFOS concentration (by a LC-MS based method) that is reported for herring gulls (eggs) in Chapter 4, is relatively minor and does not affect the observed spatial trends in eggs among Great Lakes colonies. The apparent spatial and temporal trends of L-PFOS concentrations and patterns in other biota, which have all been measured by LC-MS based methods, may not be entirely accurate since the PFOS isomer pattern is not known. However, this would be a function of the proportion of the apparent L-PFOS that is actually branched PFOS isomers.

Food web factors are noteworthy if further discussing influences on the present PFOS isomer patterns in Great Lakes herring gull eggs. Conclusions in Chapter 4 state that herring gulls are exposed to PFSAs and PFCAs primarily through the aquatic (and food web) as compared to a terrestrial component in the diet. Significant positive correlations 
were observed between the $\angle$ PFSA and $\sum$ PFCA and stable nitrogen isotope ratios (dietary tracers) for individual eggs from Strachan Island. For the individual mono(trifluoromethyl) isomers, positive, and in many cases significant $(\mathrm{p}<0.05)$, correlations were found between the individual mono(trifluoromethyl) isomers and ¿PFOS (Table 5.2). This suggests that the aquatic diet is the primary source of the individual mono(trifluoromethyl) isomers in herring gull eggs. For Channel-Shelter Island though, negative non-significant $(\mathrm{p}>0.05)$ correlations were observed between P3MHpS, P4MHpS, and P5MHpS, and P6MHpS was below detection in the eggs. Based on $\delta^{15} \mathrm{~N}$ values in eggs published by Hebert et al. (6I), the trophic position of herring gulls from Channel-Shelter Island are among the lowest of the 15 colonies indicating a greater terrestrial input in the diet. This terrestrial input in the diet might have resulted in the observed negative correlations due to a different isomer pattern in the terrestrial diet. For the Port Colborne colony, which had the lowest $\delta^{15} \mathrm{~N}$ values in the eggs among the 15 colonies (61), the even greater terrestrial input in the diet did not result in negative correlations between the mono(trifluoromethyl) isomers and $\sum$ PFOS (Table 5.2). Clearly, at Channel-Shelter Island, other (local) factor(s) influenced the isomer pattern in the diet of the herring gulls resulting in the negative correlations.

The present findings show that the PFOS present in the herring gull eggs is not just LPFOS but a mixture of linear and branched PFOS. To our knowledge, this is the first study investigating the spatial patterns of linear and branched PFOS isomers in biota in the environment. As the dietary PFOS isomer pattern of herring gulls has only been studied in Lake Ontario, it remains unclear what the gulls from colonies on the other Great Lakes are exposed to; this could possibly explain the spatial pattern of specific 
Table 5.2 Correlations between concentrations ( $\mathrm{ng} / \mathrm{g} \quad \mathrm{ww})$ of individual mono(trifluoromethyl) perfluorooctane sulfonate (PFOS) isomers and $\sum$ PFOS in individual herring gull eggs $(\mathrm{n}=13)$ from 15 colonies in the Great Lakes collected in 2007.

\begin{tabular}{llcccccc}
\hline Colony\# $^{\mathrm{a}}$ & & & \multicolumn{5}{c}{ PFOS Isomer } \\
& & P1MHpS & $\mathrm{P} 2 \mathrm{MHpS}$ & $\mathrm{P} 3 \mathrm{MHpS}$ & $\mathrm{P} 4 \mathrm{MHpS}$ & $\mathrm{P} 5 \mathrm{MHpS}$ & $\mathrm{P} 6 \mathrm{MHpS}$ \\
\hline Granite Is. & $\mathrm{r}$ & 0.871 & 0.770 & 0.847 & 0.838 & 0.926 & 0.942 \\
& $\mathrm{p}$ & $<\mathbf{0 . 0 0 0 1}$ & $<\mathbf{0 . 0 0 0 1}$ & $<\mathbf{0 . 0 0 0 1}$ & $<\mathbf{0 . 0 0 0 1}$ & $<\mathbf{0 . 0 0 0 1}$ & $<\mathbf{0 . 0 0 0 1}$ \\
Agawa Rocks & $\mathrm{r}$ & 0.744 & 0.602 & 0.281 & 0.392 & 0.222 & 0.774 \\
& $\mathrm{p}$ & $\mathbf{0 . 0 0 1}$ & $\mathbf{0 . 0 2}$ & 0.31 & 0.15 & 0.43 & $\mathbf{0 . 0 0 0 7}$ \\
Big Sister Is. & $\mathrm{r}$ & 0.639 & 0.779 & 0.631 & 0.778 & 0.813 & 0.804 \\
& $\mathrm{p}$ & $\mathbf{0 . 0 1}$ & $\mathbf{0 . 0 0 0 6}$ & $\mathbf{0 . 0 1}$ & $\mathbf{0 . 0 0 0 6}$ & $\mathbf{0 . 0 0 0 2}$ & $\mathbf{0 . 0 0 0 3}$ \\
Gull Is. & $\mathrm{r}$ & 0.364 & 0.337 & 0.376 & 0.487 & 0.612 & 0.435 \\
& $\mathrm{p}$ & 0.18 & 0.22 & 0.17 & 0.07 & $\mathbf{0 . 0 2}$ & 0.10 \\
Channel- & $\mathrm{r}$ & 0.845 & 0.253 & -0.368 & -0.360 & -0.330 & - \\
Shelter Is. & $\mathrm{p}$ & $<\mathbf{0 . 0 0 0 1}$ & 0.36 & 0.18 & 0.19 & 0.23 & - \\
Double Is. & $\mathrm{r}$ & 0.879 & 0.767 & 0.653 & 0.733 & 0.820 & 0.863 \\
& $\mathrm{p}$ & $<\mathbf{0 . 0 0 0 1}$ & $\mathbf{0 . 0 0 0 8}$ & $\mathbf{0 . 0 0 8}$ & $\mathbf{0 . 0 0 2}$ & $\mathbf{0 . 0 0 0 2}$ & $<\mathbf{0 . 0 0 0 1}$ \\
Chantry Is. & $\mathrm{r}$ & 0.945 & 0.843 & 0.670 & 0.384 & 0.766 & 0.947 \\
& $\mathrm{p}$ & $<\mathbf{0 . 0 0 0 1}$ & $<\mathbf{0 . 0 0 0 1}$ & $\mathbf{0 . 0 0 6}$ & 0.16 & $\mathbf{0 . 0 0 0 9}$ & $<\mathbf{0 . 0 0 0 1}$ \\
Fighting Is. & $\mathrm{r}$ & 0.919 & 0.962 & 0.857 & 0.855 & 0.853 & 0.919 \\
& $\mathrm{p}$ & $<\mathbf{0 . 0 0 0 1}$ & $<\mathbf{0 . 0 0 0 1}$ & $<\mathbf{0 . 0 0 0 1}$ & $<\mathbf{0 . 0 0 0 1}$ & $<\mathbf{0 . 0 0 0 1}$ & $<\mathbf{0 . 0 0 0 1}$ \\
Middle Is. & $\mathrm{r}$ & 0.819 & 0.848 & 0.684 & 0.877 & 0.819 & 0.358 \\
& $\mathrm{p}$ & $\mathbf{0 . 0 0 0 2}$ & $<\mathbf{0 . 0 0 0 1}$ & $\mathbf{0 . 0 0 5}$ & $<\mathbf{0 . 0 0 0 1}$ & $\mathbf{0 . 0 0 0 2}$ & 0.19 \\
Port Colborne & $\mathrm{r}$ & 0.862 & 0.867 & 0.815 & 0.845 & 0.783 & 0.759 \\
& $\mathrm{p}$ & $<\mathbf{0 . 0 0 0 1}$ & $<\mathbf{0 . 0 0 0 1}$ & $\mathbf{0 . 0 0 0 2}$ & $<\mathbf{0 . 0 0 0 1}$ & $\mathbf{0 . 0 0 0 6}$ & $\mathbf{0 . 0 0 1}$ \\
Niagara River & $\mathrm{r}$ & 0.924 & 0.950 & 0.796 & 0.798 & 0.743 & 0.895 \\
& $\mathrm{p}$ & $<\mathbf{0 . 0 0 0 1}$ & $<\mathbf{0 . 0 0 0 1}$ & $\mathbf{0 . 0 0 0 4}$ & $\mathbf{0 . 0 0 0 4}$ & $\mathbf{0 . 0 0 1}$ & $<\mathbf{0 . 0 0 0 1}$ \\
Hamilton & $\mathrm{r}$ & 0.561 & 0.590 & 0.451 & 0.694 & 0.824 & 0.913 \\
Harbour & $\mathrm{p}$ & $\mathbf{0 . 0 3}$ & $\mathbf{0 . 0 2}$ & 0.09 & $\mathbf{0 . 0 0 4}$ & $\mathbf{0 . 0 0 0 2}$ & $<\mathbf{0 . 0 0 0 1}$ \\
Toronto & $\mathrm{r}$ & 0.856 & 0.908 & 0.828 & 0.834 & 0.738 & 0.899 \\
Harbour & $\mathrm{p}$ & $<\mathbf{0 . 0 0 0 1}$ & $<\mathbf{0 . 0 0 0 1}$ & $\mathbf{0 . 0 0 0 2}$ & $\mathbf{0 . 0 0 0 1}$ & $\mathbf{0 . 0 0 2}$ & $<\mathbf{0 . 0 0 0 1}$ \\
Snake Is. & $\mathrm{r}$ & 0.718 & 0.711 & 0.633 & 0.673 & 0.747 & 0.908 \\
& $\mathrm{p}$ & $\mathbf{0 . 0 0 3}$ & $\mathbf{0 . 0 0 3}$ & $\mathbf{0 . 0 1}$ & $\mathbf{0 . 0 0 6}$ & $\mathbf{0 . 0 0 1}$ & $<\mathbf{0 . 0 0 0 1}$ \\
Strachan Is. & $\mathrm{r}$ & 0.533 & 0.213 & 0.107 & 0.190 & 0.300 & 0.565 \\
& $\mathrm{p}$ & $\mathbf{0 . 0 4}$ & 0.45 & 0.70 & 0.50 & 0.28 & $\mathbf{0 . 0 3}$ \\
\hline & & & & & & & \\
\hline
\end{tabular}

${ }^{a}$ See Figure 1.3 for exact location of the 15 colonies

${ }^{\mathrm{b}}$ See Table 2.3 and Figure 1.2 for names, abbreviations and structures of the linear and branched PFOS isomers. See Figure 5.1 for a typical GC-MS(ECNI) mass chromatogram showing PFOS isomers in a typical herring gull egg sample 
isomers in addition to possibly, e.g., feeding and foraging ecology and PFOS precursor exposure and degradation. Further research on the behaviour of individual PFOS isomers in the environment is needed to fully understand patterns and trends. PFOS isomerspecific studies and effects in wildlife need to be considered and are warranted. O'Brien et al. (45) recently reported a decrease in embryonic chicken pippability relative to increased exposure to T-PFOS. Whether this is caused by L-PFOS and/or branched isomers remains unclear as no isomer specific measurements were made. 


\section{Chapter 6: Twenty Years of Temporal Changes in Perfluoroalkyl Sulfonates and Carboxylates in Herring Gull Eggs from the Laurentian Great Lakes*}

\subsection{Introduction}

Perfluorinated compounds (PFCs) such as perfluorosulfonates (PFSAs) and carboxylates (PFCAs) and their various precursor compounds are man-made chemicals that have been produced since the 1950 s either by electrochemical fluorination (ECF; producing linear and branched PFCs) or telomerization (producing linear PFCs) $(1,8)$. While the $\mathrm{C}_{8} \mathrm{PFC}$ chemistry (PFOS and precursors), produced by ECF, was phased out in 2002 by the major producer in North America, 3M Company, PFOS is still produced in smaller volumes in Europe and Asia (8). In biota, temporal trends of PFSAs and PFCAs have been determined in birds, fish and mammals in various parts of the world $(20,21)$, with the earliest reports of PFOS in archived wildlife samples (guillemot eggs from Sweden) dating back to 1968 (19). In North America, and in particular in the Arctic, increasing concentrations of PFSAs and PFCAs were seen in polar bears, ringed seals, thick-billed murres, and northern fulmars between 1972 and $2005(20,21)$.

In the Great lakes, temporal trend studies of PFCs are limited to lake trout collected from Lake Ontario (7,23). While Martin et al. (23) only determined the temporal trend of PFOS, and found an increasing trend between 1980 and 2001; Furdui et al. (7) determined the temporal trends of a range of PFCs. Between 1979 and 2004, overall

* Gebbink, W.A., Letcher, R.J., Hebert, C.E., Weseloh, D.V.C., J. Environ. Monit., Accepted, Sept 14, 2011. 
increasing trends in lake trout were seen for PFOS, PFDS and $\mathrm{C}_{9}$ to $\mathrm{C}_{15}$ PFCAs, while no temporal changes were seen for PFOSA and PFOA. Based on linear and branched isomer analysis, Furdui et al. (7) implied that the source of PFCAs (PFUnA and PFTrA) in recent years was almost exclusively from linear products manufactured using the telomerization process.

In Chapters 3 and 4 it was shown that herring gull eggs could be used to monitor for PFCs and determine spatial trend, however, there are no studies that have examined possible temporal changes of PFCs in any bird species in the Great Lakes. The Canadian Wildlife Service has collected herring gull eggs since the 1970s from 15 colonies across the Great Lakes and stored at the EC-NWSB. Using the archived herring gull eggs, temporal changes of various environmental contaminants have been determined; in addition to changes in the herring gull diet, shown using stable isotopes and fatty acids $(62,54)$. To what extent this temporal diet change for the herring gull influences the temporal trend of PFCs is unknown.

In order to examine possible temporal changes or trends of PFCs, herring gull egg pools from various Great Lakes colony sites (Agawa Rocks, Gull Island, Channel-Shelter Island, Chantry Island, Fighting Island, Niagara River, and Toronto Harbour) were collected between 1990 and 2010. These PFCs include various PFSAs, PFCAs and several PFOSA, FTUCA and FTOH precursors. The hypothesis was tested that the egg PFSA concentrations decreased in recent years as a result from the 2002 phase-out, while PFCA concentrations increased during the examined time period. Colony location and dietary shifts of the gulls were investigated as factors that could influence any observed temporal trends. 


\subsection{Results and Discussion}

Chapters 3 and 4 reported on spatial trends and maternal transfer of PFSAs, PFCAs and precursors, and by using individual eggs in those studies inter-egg variation of PFC concentrations within a given colony were determined. An average relative standard error of $13 \%$ for both $\sum$ PFSA and $\sum$ PFCA concentrations was found among individual eggs $(n=13)$ collected in 2007 from 15 colonies throughout the Great Lakes, while the relative standard errors for $\sum$ PFSA and $\sum$ PFCA were $15 \%$ and $10 \%$, respectively, in 17 individual eggs collected in 2010 from Chantry Island. These inter-egg variations are in a comparable range as the analytical variation in PFC concentrations. For example, for $\mathrm{n}=60$ replicate analysis of a DCCO-RM egg homogenate, the mean $\mathrm{PFSA}\left(\mathrm{C}_{6}, \mathrm{C}_{8}, \mathrm{C}_{10}\right)$ and $\Sigma \mathrm{PFCA}\left(\mathrm{C}_{8}-\mathrm{C}_{15}\right)$ concentrations had a RSD of $13 \%$ and $10 \%$, respectively. Therefore, in the present study, using pooled egg homogenate samples ( $\mathrm{n}=13$ individual eggs) rather than individual eggs is an accurate measure of the mean concentrations in eggs from a given colony site.

\subsubsection{Perfluorinated Carboxylate and Sulfonate and Precursor Profiles and}

\section{Concentrations}

The herring gull egg pools collected from the seven colonies contained three PFSAs, i.e., PFHxS, PFOS, and PFDS. PFOS was the dominant compound with concentrations ranging between 83 and $933 \mathrm{ng} / \mathrm{g} \mathrm{ww}$, depending on the colony and year, comprising between 79.8 to $99.4 \%$ of $\sum$ PFSA concentrations (Table 6.1). PFDS was detected in all the eggs at concentrations ranging from 0.7 to $69 \mathrm{ng} / \mathrm{g} \mathrm{ww}$, which equates to 0.52 to $20.0 \%$ of $\sum$ PFSAs. PFHxS was detected in eggs from all years and colonies with the 
Table 6.1 Average percent (range) of individual PFSAs to $\sum$ PFSA and individual PFCAs to $\sum$ PFCA in herring gull eggs and temporal changes of percent PFSA and PFCA between 1990 and $2010^{\mathrm{a}}$.

\begin{tabular}{|c|c|c|c|c|c|c|c|c|}
\hline \multirow[t]{2}{*}{ PFC } & & \multicolumn{7}{|c|}{ Colony } \\
\hline & & Agawa Rocks & Gull Is & Channel-Shelter Is & Chantry Is & Fighting Is & Niagara $R$ & Toronto $\mathrm{Hbr}$ \\
\hline \multirow[t]{3}{*}{ PFHxS } & Average & $023(0-16)$ & $022\left(\begin{array}{lll}0 & 01-0 & 73)\end{array}\right.$ & $0-025^{b}$ & $015(0-039)$ & $017(0-056)$ & $011(0-032)$ & $034(015-079)$ \\
\hline & I & 0070 & 0094 & & -0136 & -0172 & -0321 & -0086 \\
\hline & $\mathrm{p}$ & 080 & 074 & & 063 & 056 & 024 & 076 \\
\hline \multirow[t]{3}{*}{ PFOS } & Average & $981(943-991)$ & $984(968-992)$ & $940(883-972)$ & $972(925-986)$ & $901(798-971)$ & $982(959-994)$ & $962(882-992)$ \\
\hline & t & 0279 & 0220 & 0.643 & 0407 & 0.600 & 0466 & 0.928 \\
\hline & $\mathrm{p}$ & 031 & 043 & 0.001 & 013 & 0.02 & 008 & 0.0001 \\
\hline \multirow[t]{3}{*}{ PFDS } & Average & $17(077-41)$ & $14(065-25)$ & $60(28-116)$ & $27(12-71)$ & $97(29-202)$ & $17(053-40)$ & $34(068-117)$ \\
\hline & $r$ & -0382 & -0275 & -0.634 & -0410 & -0.597 & -0445 & -0.921 \\
\hline & $\mathrm{p}$ & 016 & 032 & 0.01 & 013 & 0.02 & 010 & 0.0001 \\
\hline \multirow[t]{3}{*}{ PFOA } & Average & $062(0-16)$ & $13(0-37)$ & $0-053$ & $13(007-32)$ & $0-18$ & $0-072$ & $12(027-22)$ \\
\hline & $r$ & -0269 & -0464 & & -0483 & & & -0.632 \\
\hline & $\mathrm{p}$ & 033 & 008 & & 007 & & & 0.01 \\
\hline \multirow[t]{3}{*}{ PFNA } & Average & $142(97-187)$ & $90(25-148)$ & $54(21-110)$ & $108(57-203)$ & $17(047-46)$ & $72(37-116)$ & $77(44-116)$ \\
\hline & $r$ & 0320 & 0110 & 0106 & -0.715 & 0002 & 0015 & -0446 \\
\hline & $\mathrm{p}$ & 024 & 070 & 071 & 0.003 & 099 & 096 & 010 \\
\hline \multirow{3}{*}{ PFDA } & Average & $129(103-173)$ & $155(72-255)$ & $156(86-194)$ & $122(92-157)$ & $133(99-170)$ & $209(161-293)$ & $171(142-216)$ \\
\hline & r & -0350 & -0443 & 0.568 & 0137 & 0.739 & 0419 & -0.557 \\
\hline & $\mathrm{p}$ & 020 & 010 & 0.03 & 063 & 0.003 & 012 & 0.03 \\
\hline \multirow[t]{3}{*}{ PFUnA } & Average & $280(220-330)$ & $228(170-279)$ & $370(275-522)$ & $209(178-294)$ & $220(174-291)$ & $276(228-345)$ & $220(183-300)$ \\
\hline & r & 0282 & 0163 & -0456 & -0.644 & -0372 & -0504 & -0152 \\
\hline & $p$ & 031 & 056 & 009 & 0.001 & 019 & 006 & 059 \\
\hline \multirow[t]{3}{*}{ PFDOA } & Average & $104(81-122)$ & $115(75-153)$ & $111(81-144)$ & $113(84-190)$ & $197(137-268)$ & $116(92-134)$ & $188(147-270)$ \\
\hline & r & -0001 & 0118 & 0.544 & 0.680 & 0.542 & -0005 & -0291 \\
\hline & $\mathrm{p}$ & 099 & 067 & 0.04 & 0.005 & 0.05 & 099 & 029 \\
\hline \multirow[t]{3}{*}{ PFTrA } & Average & $264(134-329)$ & $289(195-451)$ & $227(145-293)$ & $308(18-9-399)$ & $273(169-376)$ & $250(201-308)$ & $202(147-264)$ \\
\hline & $\mathrm{r}$ & -0169 & 0315 & -0186 & 0141 & -0.79 & -0153 & 0331 \\
\hline & $\mathrm{p}$ & 055 & 025 & 051 & 062 & 0.0009 & 059 & 023 \\
\hline \multirow[t]{3}{*}{ PFTeA } & Average & $49(33-81)$ & $72(32-105)$ & $54(0-84)$ & $86(31-142)$ & $113(38-162)$ & $51(27-80)$ & $107(62-192)$ \\
\hline & r & -0188 & -0081 & 0.445 & 0.574 & 0361 & 0011 & 0452 \\
\hline & $\mathrm{p}$ & 050 & 078 & 0.01 & 0.03 & 020 & 097 & 009 \\
\hline \multirow[t]{3}{*}{ PFPA • } & Average & $26(0-54)$ & $35(0-89)$ & $28(040-50)$ & $42(0-81)$ & $44(0-83)$ & $25\left(\begin{array}{lll}0 & 13-67)\end{array}\right.$ & $25(0-57)$ \\
\hline & $r$ & 0008 & -0055 & -0007 & 0229 & 0262 & 0247 & 0.754 \\
\hline & $p$ & 098 & 085 & 098 & 041 & 036 & 037 & 0.001 \\
\hline
\end{tabular}

${ }^{\text {a }}$ Pearson's coefficient and significance are given for each percent of PFSA/CA to $\sum$ PFSA/CA as a function of year.

${ }^{b}$ Detection of individual PFSA or PFCA was in $<60 \%$ of the analyzed years, range of percent to the sum concentrations are given. Note. The bold values indicate that the linear correlations were strong and significant $(\mathrm{p}<0.05)$. 
the exception of Channel-Shelter Island, where detection was $<60 \%$ of the years. The highest PFHxS concentration was $3.8 \mathrm{ng} / \mathrm{g}$ ww, representing between 0 and $1.6 \%$ of $\sum$ PFSAs. PFOSA, the immediate and essential PFOS precursor, was detected in the egg pools from all the colonies and all year between 1990 and 2006; however, only at low concentrations $(<1.7 \mathrm{ng} / \mathrm{g}$ ww). After 2006, PFOSA egg concentrations were below the detection limit. The PFHxS, PFOS, PFDS, and PFOSA concentrations and patterns in egg pools were consistent with the findings in Chapters 3,4 , and 7 on these PFSAs in herring gull eggs from the Great Lakes. See Appendix D for individual PFSA concentrations in the egg pools collected between 1990 and 2010 from seven colonies.

Of the detected PFCAs $\left(\mathrm{C}_{8}-\mathrm{C}_{15}\right)$ the patterns in egg pools were mostly dominated by $\mathrm{C}_{10}-\mathrm{C}_{13}$ chain lengths (i.e., PFDA, PFUnA, PFDoA, and PFTrA, respectively) (Table 6.1). Concentrations of these four PFCAs in the egg pools ranged from $0.99-22.1,2.2-$ 39.3, 1.3-17.5, and 2.7-29.6 ng/g ww for PFDA, PFUnA, PFDoA, and PFTrA, respectively. These concentrations averaged into $15.3 \%, 25.8 \%, 13.5 \%$, and $25.9 \%$ of the SPFCA concentrations for PFDA, PFUnA, PFDoA, and PFTrA, respectively. The monitored PFCA precursors, FTOHs and FTUCAs, were below detection limits in all of the egg pools from any year and colony. The PFCA concentrations and patterns, and the absence of the FTOHs and FTUCAs, in the egg pools were consistent with the findings in Chapters 3, 4, and 7 on PFCAs in herring gull eggs from the Great Lakes. See Appendix D for individual PFCA concentrations in the egg pools collected between 1990 and 2010 from seven colonies. 


\subsubsection{Temporal Trend of Perfluorinated Sulfonates}

With the exception of the Toronto Harbour colony, declining $\sum$ PFSA concentrations were observed in the eggs from the monitored colonies, with two colonies (Agawa Rocks and Channel-Shelter Island) showing statistically significant $(\mathrm{p}<0.05)$ declines between 1990 and 2010 (Table 6.2, Figure 6.1). PFHxS and PFOS showed similar temporal trends, i.e., declines at all the colonies with the exception of the Toronto Harbour colony; however, PFDS concentrations declined in eggs collected from all colonies. Although PFOS concentrations declined at most colonies, the percent of PFOS comprising $\sum$ PFSA increased in the eggs from all seven colonies over time, which was significant $(p<0.05)$ for the Channel-Shelter Island, Fighting Island and Toronto Harbour colonies (Table 6.1). This might be linked to the declining proportion of PFDS that was seen at all the colonies that was again statistically significant at Channel-Shelter Island, Fighting Island and Toronto Harbour. No significant $(p>0.05)$ change was seen in the percent of PFHxS to ¿PFSA in the eggs collected from any colony.

Although the production of PFOS was mostly phased out by 2002, the proportion of PFOS to EPFSA increased significantly at three colonies (Table 6.1). A possible explanation could be the environmental degradation of PFOS precursors, such as PFOSA. PFOSA was detected in egg pools from all the colonies; however, only at low concentrations $(<1.7 \mathrm{ng} / \mathrm{g} \mathrm{ww})$ between 1990 and 2006. Post 2006, PFOSA was below the detection limit. The non-detects of PFOSA in recent years could be related to the phase-out of the $C_{8}$ chemistry and/or environmental degradation. The 1990 to 2006 declines in PFOSA concentrations were statistically significant $(r>0.57, p<0.05)$ at Gull Island, Chantry Island, Fighting Island, and Toronto Harbour. At Niagara River 
Table 6.2 Temporal trend of PFSA and PFCA concentrations (ng/g ww) and $\sum$ PFSA/ $\sum$ PFCA correlation in herring gull egg pools collected between 1990 and 2010 at seven colonies. ${ }^{d}$

\begin{tabular}{|c|c|c|c|c|c|c|c|c|}
\hline \multirow[t]{2}{*}{ PГAA } & & \multirow{2}{*}{\multicolumn{7}{|c|}{ Colony }} \\
\hline & & & & & & & & \\
\hline \multirow{2}{*}{ PFHxS } & $\mathrm{r}$ & -0197 & -0259 & & -0073 & -0196 & -0364 & 0148 \\
\hline & p & 048 & 035 & & 079 & 050 & 018 & 060 \\
\hline \multirow[t]{2}{*}{ PFOS } & $\mathrm{r}$ & -0.516 & -0464 & -0.577 & -0233 & -0043 & -0249 & 0489 \\
\hline & $\mathrm{p}$ & 0.05 & 008 & 0.02 & 040 & 088 & 037 & 006 \\
\hline \multirow[t]{2}{*}{ PFDS } & $r$ & -0.717 & -0.650 & -0.725 & -0.652 & -0.609 & -0501 & -0.937 \\
\hline & $\mathrm{p}$ & 0.003 & 0.009 & 0.002 & 0.008 & 0.02 & 006 & 0.0001 \\
\hline \multirow[t]{2}{*}{$\sum$ PFSA } & $r$ & -0.528 & -0472 & -0.604 & -0254 & -0181 & -0261 & 0413 \\
\hline & $\mathrm{p}$ & 0.04 & 008 & 0.02 & 036 & 054 & 035 & 013 \\
\hline \multirow[t]{2}{*}{ PFOA } & $r$ & -0080 & -0.652 & & -0139 & & & -0316 \\
\hline & p & 078 & 0.008 & & 062 & & & 025 \\
\hline \multirow[t]{2}{*}{ PFNA } & $r$ & 0.727 & -0078 & 0035 & -0329 & 0.551 & 0410 & 0161 \\
\hline & $\mathrm{p}$ & 0.002 & 078 & 090 & 023 & 0.04 & 013 & 057 \\
\hline \multirow[t]{2}{*}{ PFDA } & $r$ & 0.687 & -0480 & 0491 & 0209 & 0.902 & 0.706 & 0449 \\
\hline & $\mathrm{p}$ & 0.005 & 007 & 006 & 045 & 0.0001 & 0.003 & 009 \\
\hline \multirow[t]{2}{*}{ PFUnA } & $r$ & 0.721 & -0161 & -0162 & -0073 & 0.853 & 0421 & 0.516 \\
\hline & $\mathrm{p}$ & 0.002 & 057 & 056 & 080 & 0.0001 & 012 & 0.05 \\
\hline \multirow[t]{2}{*}{ PFDoA } & $r$ & 0.704 & -0205 & 0433 & 0.532 & 0.913 & 0.514 & 0.575 \\
\hline & $\mathrm{p}$ & 0.003 & 046 & 010 & 0.04 & 0.0001 & 0.05 & 0.02 \\
\hline \multirow[t]{2}{*}{ PFTrA } & $r$ & 0.630 & 0012 & -0041 & 0183 & 0.612 & 0468 & 0.654 \\
\hline & $\mathrm{p}$ & 0.01 & 097 & 088 & 051 & 0.02 & 008 & 0.008 \\
\hline \multirow[t]{2}{*}{ PFTeA } & $r$ & 0.514 & -0204 & 0346 & 0443 & 0.759 & 0374 & 0.748 \\
\hline & $\mathrm{p}$ & 0.05 & 047 & 021 & 010 & 0.002 & 017 & 0.001 \\
\hline \multirow[t]{2}{*}{ PFPA } & $r$ & 0.531 & $\begin{array}{lll}-0184 \\
\end{array}$ & $002 \overline{4}$ & 0407 & 0519 & 0304 & 0.824 \\
\hline & $\mathrm{p}$ & 0.04 & 051 & 093 & 013 & 006 & 027 & 0.0001 \\
\hline \multirow[t]{2}{*}{$\sum \mathrm{PFCA}$} & $r$ & 0.700 & -0224 & 0116 & 0147 & 0.823 & 0.591 & 0.623 \\
\hline & $p$ & 0.004 & 042 & 068 & 060 & 0.0003 & 0.02 & 0.01 \\
\hline$\sum \mathrm{PFSA}$ & $r$ & -0287 & 0.536 & 0447 & 0.777 & 0114 & 0448 & 0.710 \\
\hline ¿PFCA & $\mathrm{p}$ & 030 & 0.04 & 009 & 0.0007 & 070 & 009 & 0.003 \\
\hline
\end{tabular}

a Pearson's coefficient and significance are given for each concentration as a function of year.

Note. The bold values indicate that the linear correlations were strong and significant $(p<0.05)$. When detection of individual PFSA or PFCA was $<60 \%$ in analyzed samples, no temporal trends were determined. 


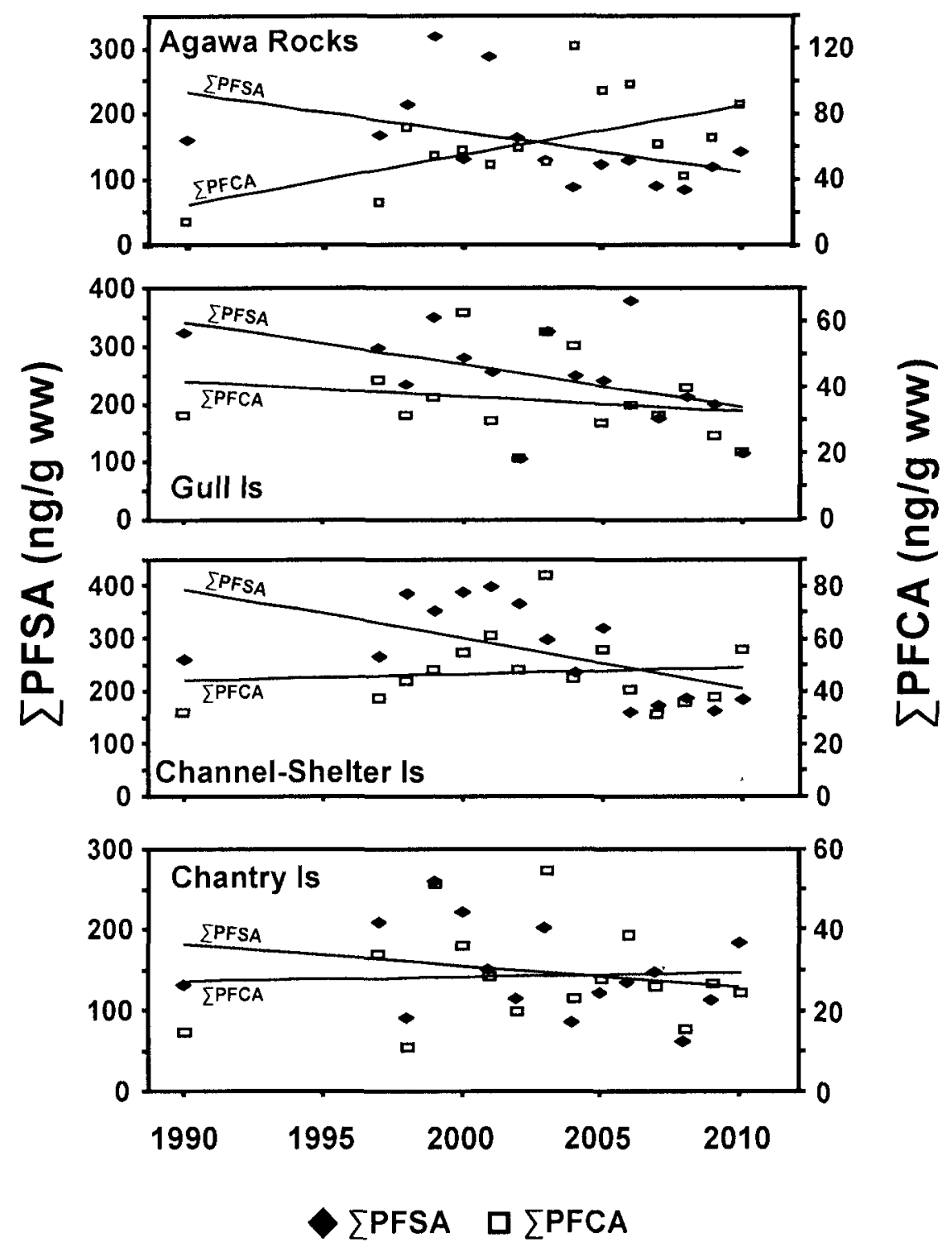

Figure 6.1 Temporal trends of $\sum$ PFSA and $\sum$ PFCA (ng/g wet weight) in herring gull egg pools collected between 1990 and 2010 from Agawa Rocks, Gull Island, Channel-Shelter Island, and Chantry Island. See Figure 1.3 for colony locations. 


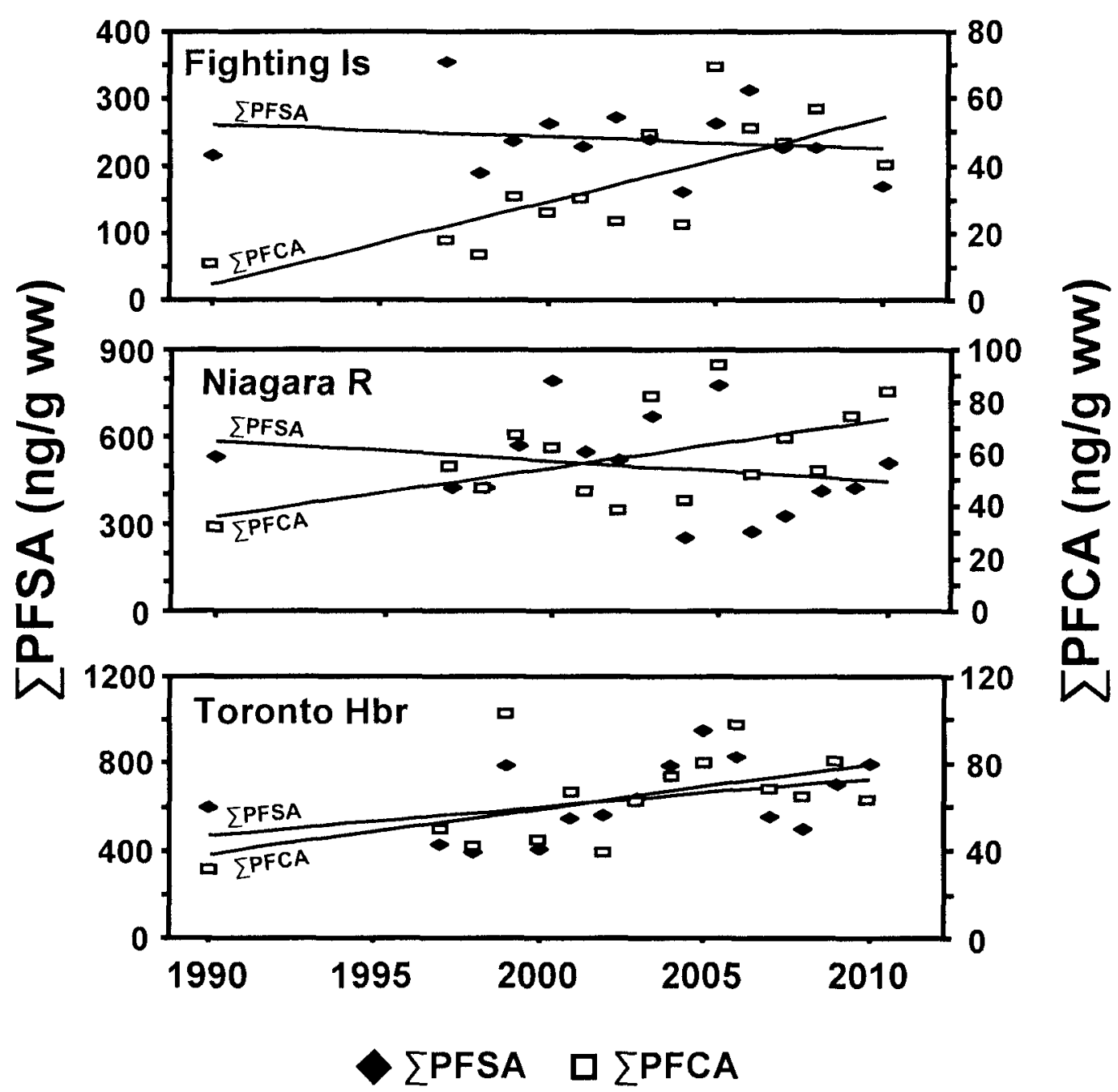

Figure 6.2 Temporal trends of $\sum$ PFSA and $\sum$ PFCA (ng/g wet weight) in herring gull egg pools collected between 1990 and 2010 from Fighting Island, Niagara River, and Toronto Harbour. See Figure 1.3 for colony locations. 
colony a marginally significant decline was observed $(\mathrm{r}=0.53, \mathrm{p}=0.08)$, while no changes were seen at the Agawa Rocks and Channel-Shelter Island colonies. When comparing the PFOS/PFOSA ratio in the eggs to the ratio in prey fish from Lake Ontario (23), the ratio in herring gull eggs was at least two orders of magnitude higher. This would suggest that herring gulls may be metabolizing a portion of PFOSA, which contributes to the higher PFOS levels in their eggs. However, whether herring gulls or prey fish are able to metabolize PFOSA to PFOS has not been studied. Although the rate was slow, $\mathrm{Xu}$ et al. (1I) demonstrated PFOSA to PFOS metabolism using an in vitro approach based on enzymatically viable, rat liver slices, whereas in other studies no such transformation has been reported using rat hepatocytes or microsomal fractions (8).

Information on temporal trends of PFSA concentrations in any species from the Great Lakes is limited. Martin et al. (23) and Furdui et al. (7) reported on the temporal trends of PFSAs in lake trout from Lake Ontario. In both studies, PFOS concentrations increased in lake trout between 1979 and 2004. This is consistent with the observed increase in PFOS concentrations in gull eggs from the only colony on Lake Ontario, i.e., the Toronto Harbour colony. However, where Furdui et al. (7) found an increasing trend for PFDS between 1979 and 2004, we found mostly significant ( $p=0.06$ to 0.0001$)$ declining trends in eggs from all colonies, particularly at Toronto Harbour (Table 6.2). Comparing temporal trends of the PFSAs to those in fish is not possible for the other Great Lakes because of the lack of fish data. The decline of PFOS concentrations observed for six of the seven monitored colonies (significant for only two colonies) appears to be associated with the phase out of the PFOS in 2002. In contrast, the apparently increasing concentrations of PFOS (Table 6.2; $\mathrm{r}=0.489, \mathrm{p}<0.06$ ) at the Toronto Harbour colony 
might be a consequence of the release of PFOS into the Great lakes environment from the technosphere of this highly urbanized region. The Toronto Harbour colony was among the mostly contaminated in a previous spatial assessment of PFCs in herring gull eggs throughout the Great Lakes (Chapter 4).

For some colonies, rates of temporal change in PFSA concentrations could be estimated. Where significant declines in gull eggs from colonies were observed (Table 6.2), the estimated half-lives of PFOS were 18.0 and 19.6 years in eggs from Agawa Rocks and Channel-Shelter Island, respectively. The temporal changes of the PFOS concentrations for the remaining colonies were weak and not significant and half lives or doubling times were not calculated (Table 6.2). The half-lives for PFDS were estimated to range from 6.2 (Toronto Harbour) to 12 years (Gull Island) depending on the colony. In the literature, there are inconsistent reports on the rates of temporal change of PFSAS in wildlife. In the Canadian Arctic, doubling times for PFOS concentrations in thickbilled murre and northern fulmar livers was reported to be $\sim 10$ years between 1975 and 2004 (40). In northern Europe, PFOS concentrations doubled every 12 years in peregrine falcon eggs (1974-2007) (4I), while the half-life of PFOS concentration in tawny owl eggs was estimated to be 40 years (1986-2009) (42). Factors such as the time period studied and the sampling location influences temporal trends. For PFOS, as more recent time points are added since the 2002 phase out of PFOS chemistry production by the $3 \mathrm{M}$ Company, it is increasingly likely that declines in PFOS concentrations in the environment would become more probable and the rates of decline clearer. 


\subsubsection{Temporal Trends of Perfluorinated Carboxylates}

In contrast to PFSAs, significant $(\mathrm{p}<0.02)$ increases in $\sum$ PFCA concentrations were generally seen in the eggs collected between 1990 and 2010 from Agawa Rocks, Fighting Island, Niagara River and Toronto Harbour, whereas no significant $(\mathrm{p}>0.05)$ trends were observed at Gull, Channel-Shelter, or Chantry Islands (Table 6.2, Figure 6.1). At Agawa Rocks, Fighting Island, Niagara River and Toronto Harbour increases were also seen for all the individual PFCAs $\left(\mathrm{C}_{8}\right.$ to $\left.\mathrm{C}_{15}\right)$ concentrations, which were mostly significant, with the exception of PFOA. For the Gull, Channel-Shelter, and Chantry Island colonies, no significant changes in concentrations between 1990 and 2010 were seen for any of the individual PFCAs with the exception of a negative significant trend for PFOA at Gull Island and a positive significant trend for PFDoA at Chantry Is. (Table 6.2). At Agawa Rocks, Gull Island and the Niagara River colony, no significant ( $\mathrm{p}>0.05$ ) temporal changes in the percent of the individual $\mathrm{C}_{8}$ to $\mathrm{C}_{15}$ PFCA to the $\sum$ PFCA were observed; however, increases in one or more individual PFCAs were seen at the remaining colonies (Table 6.1)

With respect to temporal changes in PFCA patterns, the most pronounced relationship were the even numbered, carbon chain length PFCAs, as shown in Figure 6.3. While a significant decline in the percent of PFOA in the PFCA was seen at the Toronto Harbour colony, declines were also seen at the other colonies, although these were not significant. Increases of the $\mathrm{C}_{10}, \mathrm{C}_{12}$, and $\mathrm{C}_{14}$ PFCAs in the PFCA pattern were observed in the eggs collected from Channel-Shelter Island, Chantry Island, and Fighting Island colonies. Increasing concentrations of PFCAs could be related to the increasing production of fluorotelomer based compounds in recent years (9). Degradation of these 
- Channel-Shelter Is $\square$ Chantry Is $\square$ Fighting Is $\mathbf{D}$ Toronto Hbr
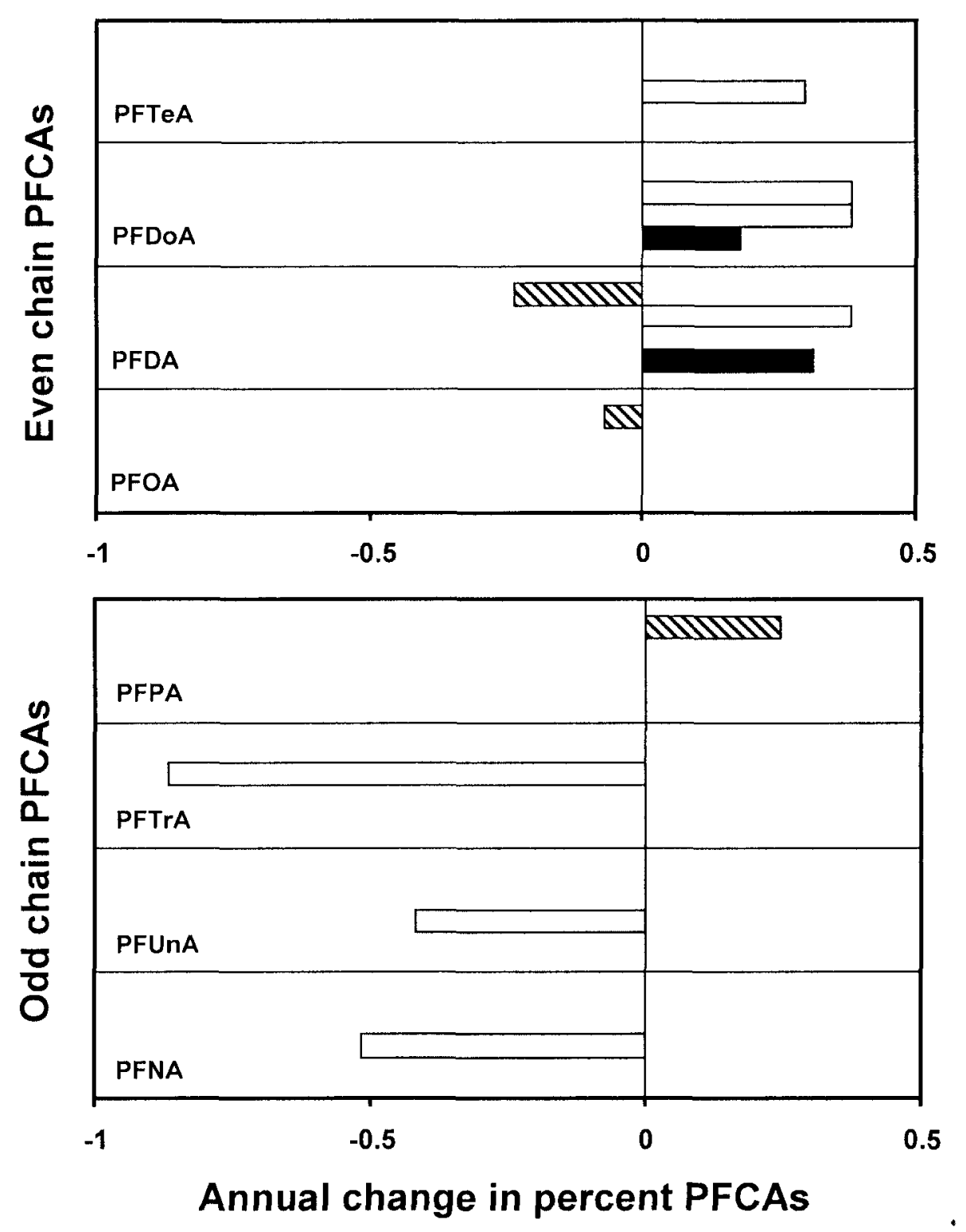

Figure 6.3 Annual increase or decrease in percent of individual PFCAs to the $\sum$ PFCA based on the slope of linear regression. Only PFCAs are included where significant $(p<0.05)$ temporal changes were observed (see Table 6.1). 
compounds, such as perfluoroalkyl phosphates (PAPS) or FTOHs, could be a source of PFCAs (9). For example, by using rat hepatocytes, Martin et al. (15) demonstrated the degradation of FTOHs and subsequent formation of PFCAs in vitro. The 8:2 FTOH was metabolized to PFOA and minor amounts of PFNA and shorter and longer even numbered chain FTOHs were metabolized to even number PFCAs. The preferential degradation of these precursors to even numbered chain length PFCAs could have resulted in the observed increasing trend of the $\mathrm{C}_{10}, \mathrm{C}_{12}$, and $\mathrm{C}_{14}$ PFCAs in the $\sum \mathrm{PFCA}$ compared to the odd numbered chain length PFCAs. Although FTOHs and FTUCAs were not detected in any of the egg pools from any year or colony, and there are no reports of FTOHs or PAPS in Great Lakes biota, FTUCAs were detected in lake trout collected from Lake Superior (24). The degradation of these fluorotelomer-based compounds in herring gull prey or by the gulls themselves could have influenced the PFCA pattern over time as these telomer based compounds are still being produced.

Increasing trends of $\mathrm{C}_{8}$ to $\mathrm{C}_{15}$ PFCA concentrations in the eggs from the Toronto Harbour were similar to those reported by Furdui et al. (7) for lake trout from Lake Ontario. Inter-taxa comparisons of trends are not possible for other lakes. Using our criteria to estimate doubling-times and half-lives, we were only able to generate estimates for multiple PFCAs at Agawa Rocks, Fighting Island and Toronto Habour. At Agawa Rocks, the estimated doubling-times ranged from 8.1 (PFNA) to 11.1 (PFTeA) years, while the average doubling-time for the $\mathrm{C}_{9}$ to $\mathrm{C}_{14}$ PFCA was estimated at 9.9 years. At Fighting Island, the estimated doubling-times ranged from 5.7 (PFTeA) to 12.2 (PFTrA) years, while the average doubling-time for the $\mathrm{C}_{9}$ to $\mathrm{C}_{14} \mathrm{PFCA}$ was estimated at 7.8 years. At Toronto Harbour, the estimated doubling-times ranged from 10.5 (PFTeA) to 
20.3 (PFDoA) years, while the average doubling-time for the $\mathrm{C}_{11}$ to $\mathrm{C}_{14}$ PFCA was estimated at 15.9 years. At Gull Island the PFOA half-life was estimated at 2.1 years; at Chantry Island the doubling-time of PFDoA was 16 years; at Niagara River the doublingtimes of PFDA and PFDoA were 14.6 and 20.3 years, respectively, while at ChannelShelter Island no doubling-times or half-lives were estimated for any of the individual PFCAs. In the literature, increases were seen in individual PFCA concentrations which were consistent with our results; average doubling-times of 9.7 years for $C_{10}$ to $C_{13}$ PFCAs were reported in tawny owl eggs between 1986 and 2009, while an average doubling-time of 7.4 years was reported for $\mathrm{C}_{9}$ to $\mathrm{C}_{14}$ PFCAs in peregrine falcon eggs between 1974 and $2007(41,42)$. However, in thick-billed murre and northern fulmars average half-lives were 4.9 and 5.7 years, respectively for $C_{10}$ to $C_{15}$ PFCAs between 1975 and $2004(40)$.

\subsubsection{Dietary Sources of Perfluoroalkyl Acids to Herring Gulls}

For the Gull Island, Chantry Island, and Toronto Harbour colonies, significant positive correlations $(\mathrm{p}<0.05)$ were observed between $\sum$ PFSA and $\sum$ PFCA concentrations, indicating a similar route of exposure (Table 6.2). For the Channel-Shelter Island and Niagara River colonies positive $\sum$ PFSA/ 2 PFCA correlations were seen $(p<0.1)$, while at Agawa Rocks and Fighting Island no correlations were observed. With the exception of the Agawa Rocks colony, Chapter 4 showed strong and significant, positive correlations between $\sum$ PFSA and $\sum$ PFCA in individual eggs ( $\left.n=13\right)$ collected in 2007 for the seven colonies, indicating similar routes of exposure to PFSAs and PFCAs for gulls. The lack of correlation seen between $\sum$ PFSA and $\sum$ PFCA in the egg pools from Agawa Rocks and 
Fighting Island over the 1990 and 2010 period could be a reflection of the dietary source of exposure of PFSAs and/or PFCAs to the maternal gulls changed over time for these colony sites. Similar routes of dietary exposure of PFSAs and PFCAs most likely occurred for gulls at the colonies where we found positive significant correlations between $\sum$ PFSA and $\sum$ PFCA in the egg pools (Gull Island, Chantry Island and Toronto Harbour).

Although significant positive and/or negative temporal trends were observed for PFSAs and PFCAs concentrations between 1990 and 2010 (Table 6.2, Figure 6.1), there were year-to-year variations in the concentrations among the colonies, which could have been a function of dietary changes over this time period. Using stable isotopes $\left(\delta^{15} \mathrm{~N}\right.$ and $\delta^{13} \mathrm{C}$ ) as dietary tracers, between 1981 and 2005 , Hebert et al. (6I) showed a decline in the amount of prey fish in the gull's diet across the Great Lakes and an increase in terrestrial food sources. Using this information on dietary changes, Hebert and Weseloh (62) reported that egg PCB concentrations adjusted for trophic position showed different temporal trends than unadjusted data. Using $\delta^{15} \mathrm{~N}$ and $\delta^{13} \mathrm{C}$ stable isotope data of the egg pools (1990 and 1997 to 2005 data from Hebert et al. (61); 2006-2008 data, Dr. Craig Hebert, unpublished data) significant correlations, positive and negative, were only observed between $\delta^{15} \mathrm{~N}$ and individual and/or sum PFSA/PFCA in eggs from the Agawa Rocks and Chantry Island. Since significant relationships were only seen in eggs from two of the seven colonies, no trophic position adjustments were made in egg concentrations of PFSAs and PFCAs. The lack of correlation between $\delta^{15} \mathrm{~N}$ and PFOS and PFCAs was also seen in lake trout from Lake Ontario, where it was concluded that 
exposure routes other than diet, i.e., aquatic exposure, are a more important source of exposure to the lake trout (7).

For herring gulls, PFSA and PFCA exposure may stem from consumption of both aquatic and terrestrial foods. Changes in egg stable isotope and fatty acid dietary markers are consistent with the possibility of increasing amounts of terrestrial food in the gull diet through time (61). Such changes could alter exposure to PFCs and could contribute to changes in egg PFC concentrations and compositional patterns. Only sporadic significant correlations were seen between $\delta^{13} \mathrm{C}$ and individual and/or sum PFSA/PFCA in the eggs from Channel-Shelter Island, which would indicate the terrestrial input in the diet as the main source for PFCs at this colony, for the other colonies no significant correlations were observed. The lack of significance in the correlations between $\delta^{15} \mathrm{~N}$ and $\delta^{13} \mathrm{C}$ and individual and/or sum PFSA/PFCA indicates the complexity of the PFC exposure to gulls. Most likely, both the aquatic and terrestrial foods are sources of PFCs. In the aquatic environment, Martin et al. (23) detected PFSAs and PFCAs in alewife and smelt, both are important prey fish for Great Lakes herring gulls. Although not demonstrated in the Great Lakes region, terrestrial top predator birds such as peregrine falcons (Sweden) and tawny owls (Norway) exibit exposure to PFSAs and PFCAs based upon concentrations in their eggs indicating the presence of PFCs in the terrestrial environment $(41,42)$.

The present retrospective (1990-2010) PFSA and PFCA data showed that herring gulls from seven colonies across the Great Lakes have continually and remain exposed. Other than apparently the Toronto Harbour colony, ¿PFSA concentrations decreased between 1990 and 2010, whereas EPFCA concentrations increased at most colonies. 
Declining concentrations of PFOS, PFOSA and PFOA could be related to the $\mathrm{C}_{8}$ chemistry phase-out, whereas increasing PFCA concentrations could be a result of ongoing fluorotelomer production and the subsequent degradation to PFCAs. 


\section{Chapter 7: Perfluoroalkyl Carboxylates and Sulfonates and Precursors in Relation to Dietary Source Tracers in the Eggs of Four Species of Gulls (Larids) from Breeding Sites Spanning Atlantic to Pacific Canada*}

\subsection{Introduction}

In Canada, the presence of PFCs in wildlife species has primarily been reported in the Great Lakes or Arctic regions. In the Great Lakes, the presence of PFSAs (including PFOS isomers), PFCAs, and PFOSA in herring gulls (tissues and eggs) was shown (Chapters 3-6), whereas PFSAs, PFCAs, PFOSA, and in some cases low levels of other PFC precursors such as fluorotelomer unsaturated carboxylic acids (FTUCAs), were detected in various fish species, e.g., lake trout, alewife, and smelt $(24,23)$. A spatial assessment in the Great Lakes of concentrations using lake trout and herring gull eggs showed higher concentrations in samples collected close to urbanized and/or industrialized areas, i.e., Lake Erie and Ontario (Chapter 4) (24). In the Canadian Arctic, PFCs were reported in (mainly liver) of marine mammals (including polar bears, ringed seals, and beluga whales), seabirds (liver and eggs) and several fish species (22). However, to our knowledge, the presence and/or concentrations and patterns of PFSAs, PFCAs and precursors have not been reported in any wildlife species in other regions across Canada, e.g., Atlantic and Pacific Canada.

\footnotetext{
*Reproduced with permission from Gebbink, W.A., Letcher, R.J, Burgess, N., Champoux, L., Elliot, J.E., Hebert, C.E., Martin, P., Wayland, M., Weseloh, D.V.C., Wilson, L. Environ. Int. 2011, 37, 1175-1182. Copyright 2011 Elsevier.
} 
Throughout Canada, herring gulls as well as other gull species are avian top predators in their respective ecosystems and are exposed to contaminants through their diet, which, depending on the species and location, can be via aquatic (marine or freshwater) or terrestrial prey. Nitrogen and carbon stable isotope $(\mathrm{SI})$ ratios $\left(\delta^{15} \mathrm{~N}, \delta^{13} \mathrm{C}\right)$ are increasingly used as chemical tracers of food web pathways and structure, for example for Great Lakes herring gulls $(60,88)$. Relative trophic positions of species within food webs have been estimated using $\delta^{15} \mathrm{~N}$, whereas $\delta^{13} \mathrm{C}$ differentiates feeding strategies e.g. nearshore/offshore, benthic/pelagic, freshwater/marine, terrestrial/freshwater and terrestrial $/$ marine.

The spatial distribution of PFSAs and PFCAs, and precursor compounds such as bioaccumulative PFOS precursors (PFOSA and NMeFOSA), as well as FTUCAs and fluorotelomer alcohols (FTOHs) were examined in individual eggs of four different gull species (glaucous-winged, California, ring-billed and herring) collected in 2008 from 15 colony sites across Canada (Figure 2.1). The hypothesis was tested that the gull eggs collected near urbanized areas are more contaminated by these compounds compared to colonies in remote areas. These gulls are avian top predators in their respective ecosystems and are exposed to contaminants through their diet, which, depending on the species and location can be via aquatic (marine or freshwater) or terrestrial prey. $\delta^{15} \mathrm{~N}$ and $\delta^{13} \mathrm{C}$ were also determined in all the gull eggs to examine how diet may regulate PFC exposure in gulls and to gain insights into routes of PFC transfer in the environment. 


\subsection{Results and Discussion}

\subsubsection{Stable Isotope Dietary Tracers among Gulls and Regions}

In the present study, inter-colony comparisons of gull trophic position using raw $\delta^{15} \mathrm{~N}$ values across vast geographic regions are not appropriate because possible regional differences in baseline $\delta^{15} \mathrm{~N}$ were not evaluated. The gull eggs used for this study came from colony locations in a variety of ecosystems, e.g., marine, freshwater, terrestrial; urbanized and remote areas; therefore, regional differences in baseline $\delta^{15} \mathrm{~N}$ values were expected. It is well established that baseline $\delta^{15} \mathrm{~N}$ values vary across systems and must be taken into account to compare $\delta^{15} \mathrm{~N}$ values in any meaningful way among different regions (88). In comparisons among ecosystems, the $\delta^{15} \mathrm{~N}$ and $\delta^{13} \mathrm{C}$ of an organism alone provides minimal information about its absolute trophic position or ultimate source of carbon. Considerable variation exists among ecosystems in the $\delta^{15} \mathrm{~N}$ and $\delta^{13} \mathrm{C}$ at the base of the food web from which organisms draw their nitrogen and carbon (89). Without suitable estimates of the base stable isotope value in each system, it is not possible to determine if the variation in an organism reflects changes in food web structure and carbon flow, or just a variation in the base stable isotope values.

The stage of embryo development can influence the $\delta^{15} \mathrm{~N}$ and $\delta^{13} \mathrm{C}$ stable isotope values in eggs as reported for chicken eggs by Sharp et al. (90). It was concluded that for wild avian eggs, collected eggs should be $<60 \%$ through the incubation period as this will result in minimal, development-associated influence of $\delta^{15} \mathrm{~N}$ and $\delta^{13} \mathrm{C}$ stable isotope values. Of all the gull eggs collected for the present study, only two individual eggs from the Kent Island colony were estimated to be beyond $60 \%$ of the incubation period. 
Therefore, any developmental-associated influence on stable isotope values was considered to be extremely minimal.

\subsubsection{1 $\delta^{15} N$}

Figure 7.1 illustrates mean $\delta^{15} \mathrm{~N}$ values among the various gull species and colony locations. Herring gull and ring-billed gull eggs were collected from a common location, Ile Deslaurier (near Montréal, Québec), and since and no winter migration has been reported for breeding-age birds it was deemed reasonable to compare their egg $\delta^{15} \mathrm{~N}$ values (Figure 7.1). In fact, it has been reported that breeding-age birds of the Great Lakes and East Coast populations winter within the breeding range, where adult birds $>3$ years old are virtually year-round within the Great lakes region, whereas birds in their first year have been reported throughout their winter range $(91,92)$. Herring gulls from Ile Deslaurier had significantly greater $(p<0.0001)$ egg $\delta^{15} \mathrm{~N}$ values compared to ring-billed gulls, i.e. $13.72 \pm 0.29 \%$ and $8.97 \pm 0.19 \%$, respectively. This indicated that herring gulls occupied higher trophic positions than the ring-billed gulls. This difference could be the result of greater proportions of aquatic food (occupying higher trophic levels) in the diets of herring gulls compared to ring-billed gulls. This is consistent with previous work that found that ring-billed gulls rely more on landfills as a primary source of food whereas herring gulls incorporate a greater proportion of aquatic food, primarily fish, in their diet (93). 


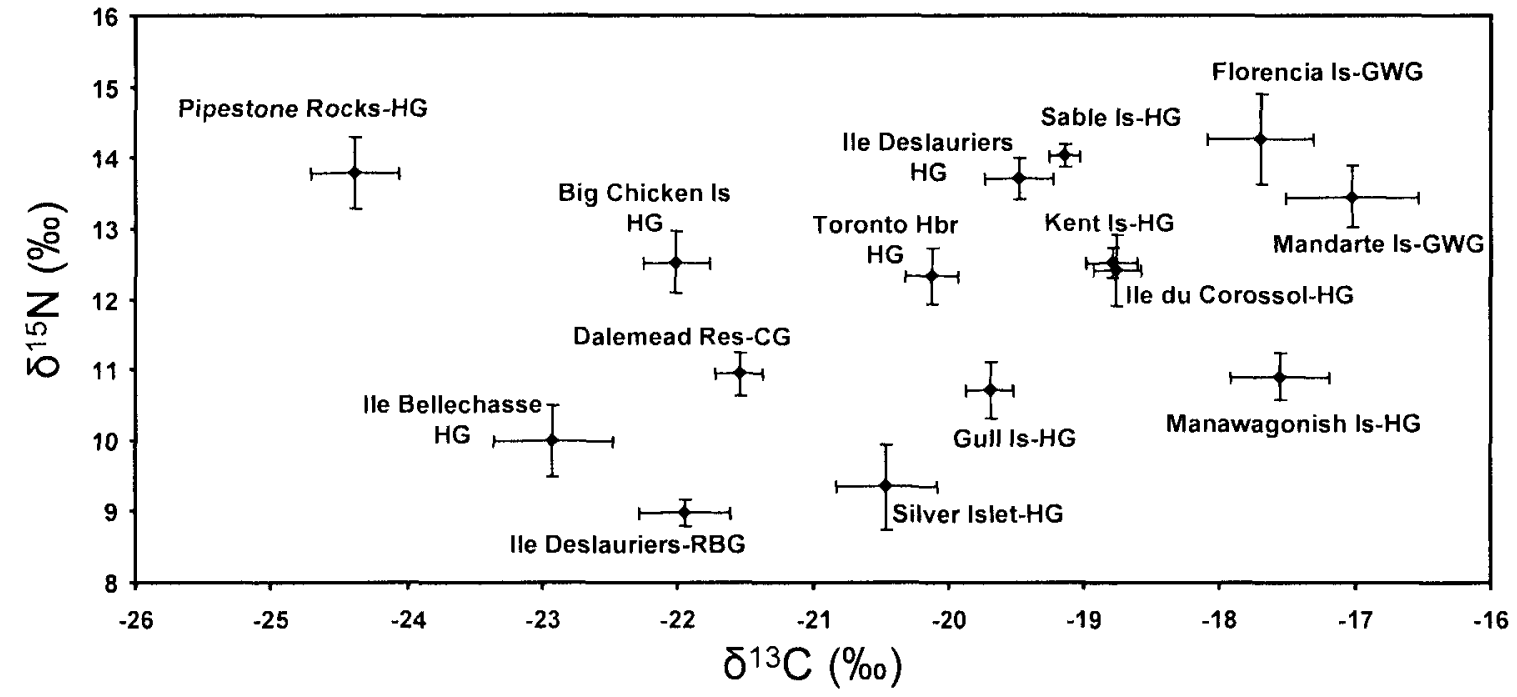

Figure 7.1 Arithmetic mean values of $\delta^{13} \mathrm{C}$ and $\delta^{15} \mathrm{~N}(\% \pm \pm \mathrm{SE})$ in individual eggs $(\mathrm{n}=10)$ collected from 15 gull colonies across Canada collected in 2008. HG - herring gull, CG California gull, RBG - ring-billed gull, GWG - glaucous-winged gull. 


\subsubsection{2 $\delta^{13} C$}

Figure 7.1 illustrates mean $\delta^{13} \mathrm{C}$ values among gull species and colony locations. $\delta^{13} \mathrm{C}$ values provide information regarding the source of dietary carbon, e.g. marine or freshwater; aquatic or terrestrial (94). In general, regardless of species, $\delta^{13} \mathrm{C}$ values in the present gull eggs from marine $\left(\delta^{13} \mathrm{C}>\sim-19\right)$ versus freshwater $\left(\delta^{13} \mathrm{C}<\sim-20\right)$ environments are distinct. Eggs from marine locations had less negative $\delta^{13} \mathrm{C}$ values than eggs from freshwater locations (Figure 7.1). This is consistent with the more negative $\delta^{13} \mathrm{C}$ values observed in freshwater versus marine dissolved inorganic carbon (see (95) for review).

The $\delta{ }^{13} \mathrm{C}$ values of glaucous-winged gulls from two Pacific coast colonies (Florencia and Mandarte Island) adjacent to Vancouver Island were among the least negative of the colonies studied. Although there was no significant difference $(p>0.05)$ observed between the $\delta^{13} \mathrm{C}$ values of the Florencia and Mandarte Island colonies, differences have been reported in the diet composition of the gulls from these two colonies. Vermeer (96) reported on the composition of regurgitated pellets by adult glaucous-winged gulls and found that there was a high occurrence of human refuse in pellets from gulls located on the Strait of Georgia (Mandarte Island); whereas, pellets from gulls located on the west coast of Vancouver Island (Florencia Island) contained a high occurrence of gooseneck barnacles.

The mean $\delta^{13} \mathrm{C}$ value for the Ile du Corossol herring gull eggs was $-18.76 \pm 0.17 \%$ o (Figure 7.1). As indicated by the $\delta^{13} \mathrm{C}$ value, the herring gulls from this colony were feeding on marine-based prey. Based on regurgitations, Rail and Chapdelaine (97) reported that capelin (Mallotus villosus) was the main prey species for gulls from Ile du 
Corossol. Chapdelaine and Rail (98) also reported the herring gulls from Ile du Corossol consume northern cod (Gadus morhua).

The $\delta^{13} \mathrm{C}$ values of herring gull eggs from the four Atlantic marine colonies ranged from $-17.56 \pm 0.36 \%$ for Kent Island (New Brunswick) to $-19.69 \pm 0.17 \%$ for Gull Island (Newfoundland) (Figure 7.1). Information on the diets of herring gulls from the four Atlantic colonies is very limited. Robertson et al. (99) reported that herring gulls from Gull Island fed on capelin but also alternative prey such as adult storm petrels (Oceanodroma leucorhoa). Hobson et al. (100) has linked the decline of northern cod in the northern Atlantic to a greater dependency of herring gulls from Gull Island on refuse as a dietary source. This might explain why the Gull Island colony had the most negative $\delta^{13} \mathrm{C}$ value among the four Atlantic colonies. For the Kent, Manawagonish and Sable Island colonies, there are, to our knowledge, no published reports describing the herring gull diet. Based on the $\delta^{13} \mathrm{C}$ values in eggs of herring gulls from these colonies, it is strongly indicated that their prey are mainly from the marine environment as the $\delta^{13} \mathrm{C}$ values are comparable to eggs of gulls from other marine locations (Figure 7.1).

California gull eggs from the Dalemead Reservoir (near Calgary, Alberta) had a mean $\delta^{13} \mathrm{C}$ value of $-21.55 \pm 0.18 \%$ (Figure 7.1 ). California gulls are known to have a mixed diet of both aquatic and terrestrial prey such as small mammals, fish, birds, garbage, and a variety of invertebrates (101). Herring gull eggs from the Pipestone Rocks colony on Lake Winnipeg had a mean $\delta^{13} \mathrm{C}$ value of $-24.39 \pm 0.32 \%$. Fox et al. (102) reported comparable $\delta^{13} \mathrm{C}$ values in herring gull breast muscle from Lake Winnipeg $(-24.8 \%$ ). Although not studied specifically for the Pipestone Rocks colony, herring gulls in the 
Lake Winnipeg area consume lake whitefish (Coregonus clupeaformis), suckers (Catostomidae) and perch (Percidae) $(102,103)$.

For herring gull eggs from the Great Lakes, i.e., Silver Islet (Lake Superior), Big Chicken Island (Lake Erie) and Toronto Harbour (Lake Ontario), $\delta^{13} \mathrm{C}$ values were -20.45 $\pm 0.37 \%,-22.01 \pm 0.24 \%$, and $-20.12 \pm 0.20 \%$, respectively (Figure 7.1 ). Alewife and rainbow smelt are the main fish prey of herring gulls on the Great Lakes; however, scavenging on terrestrial sources such as human refuse and garbage is also a source of food due to declines in prey fish abundance, resulting in less negative $\delta^{13} \mathrm{C}$ values over time (60). For example, in western Lake Superior, herring gull egg $\delta^{13} \mathrm{C}$ values increased between 1981 and 2005. $\delta^{13} \mathrm{C}$ values in eggs from Big Chicken Island and Toronto Harbour were consistent with previously reported values during the 1981-2005 period despite year to year variations (61).

On Ile Deslauriers (Montréal, QC), $\delta^{13} \mathrm{C}$ values in herring and ring-billed gulls eggs were $-19.47 \pm 0.25 \%$ and $-21.95 \pm 0.34 \%$, respectively (Figure 7.1 ). Although ringbilled gulls have been reported to incorporate a larger proportion of terrestrial foods in their diets compared to herring gulls, $\delta^{13} \mathrm{C}$ values indicate the opposite. Ring-billed gulls from another colony near Montréal have been shown to feed primarily on human refuse (including garbage) (104). Belant et al. (93) also showed that in another urban area, ringbilled gulls fed on a more terrestrial diet compared to herring gulls. Other factors might also explain the egg $\delta^{13} \mathrm{C}$ values from Ile Deslauriers. de Bruyn et al. (105) reported that sewage discharge of a wastewater treatment plant draining into the St. Lawrence River near Montréal could alter $\delta^{13} \mathrm{C}$ values of primary consumers (Amphipoda, Chironomidae, and Trichoptera), i.e., less negative were reported compared to reference sites. This less 
negative value of $\delta^{13} \mathrm{C}$ in primary consumers in the St. Lawrence River could subsequently be transferred into the aquatic food chain. The feeding of the herring gulls on aquatic prey from the St. Lawrence River, and thus accumulating the less negative $\delta^{13} \mathrm{C}$ values, could result in $\delta^{13} \mathrm{C}$ values that are enriched compared to the $\delta^{13} \mathrm{C}$ values in the ring-biled gull, which feed more on terrestrial prey. At the lle Bellechasse colony (Québec City, QC), mean $\delta^{13} \mathrm{C}$ value in herring gull eggs was $-22.92 \pm 0.44 \%$ (Figure 7.1). Information on the herring gull diet from this island is, to our knowledge, nonexistent; however, the prey species might originate from both freshwater and marine habitats since the island is located in an area of freshwater and saltwater convergence.

\subsubsection{Relationships between $\delta^{15} N$ and $\delta^{13} C$}

Gulls feeding on aquatic prey in a marine environment showed a positive relationship between $\delta^{13} \mathrm{C}$ and $\delta^{15} \mathrm{~N}$ values, as more fish is consumed (resulting in an increase in $\delta^{15} \mathrm{~N}$ values), $\delta{ }^{13} \mathrm{C}$ values become less negative. This positive, and significant, correlation was observed in the glaucous-winged gulls from the two British Columbia marine colonies (Table 7.1), which strongly suggested that these gulls were eating a high proportion of marine-based prey. For the Atlantic marine gull colonies, positive but non-significant correlations between $\delta^{13} \mathrm{C}$ and $\delta^{15} \mathrm{~N}$ values were observed in the eggs from the lle du Corossol, Manawagonish and Gull Island colonies (Table 7.1). For the Kent and Sable Island colonies, no correlation was found between the two stable isotope tracers.

For eggs collected from freshwater colonies, a negative $\delta^{15} \mathrm{~N} / \delta^{13} \mathrm{C}$ relationship would be expected. For freshwater colonies, in general, more negative $\delta^{13} \mathrm{C}$ values are indicative of consumption of aquatic prey whereas less negative values indicate a terrestrial input in 
Table 7.1 Correlations between $\delta^{15} \mathrm{~N}$ and $\delta^{13} \mathrm{C}, \delta^{15} \mathrm{~N}$ and $\sum$ PFSA and $\sum$ PFCA, $\delta^{13} \mathrm{C}$ and $\sum$ PFSA and $\sum$ PFCA in individual gull eggs from 15 colonies across Canada.

\begin{tabular}{|c|c|c|c|c|c|c|c|c|c|c|c|}
\hline \multirow[t]{2}{*}{ Ecosystem } & \multirow[t]{2}{*}{ Colony $^{\mathrm{a}}$} & \multicolumn{2}{|c|}{$\delta^{15} \mathrm{~N} / \delta^{13} \mathrm{C}$} & \multicolumn{2}{|c|}{$\delta^{15} \mathrm{~N}-\sum \mathrm{PFSA}$} & \multicolumn{2}{|c|}{$\delta^{15} \mathrm{~N}-\sum$ PFCA } & \multicolumn{2}{|c|}{$\delta^{13} \mathrm{C}-\sum$ PFSA } & \multicolumn{2}{|c|}{$\delta^{13} \mathrm{C}-\sum \mathrm{PFCA}$} \\
\hline & & $\mathrm{r}$ & $\mathrm{p}$ & $\mathrm{r}$ & $\mathrm{p}$ & $\mathrm{r}$ & $\mathrm{p}$ & $\mathrm{r}$ & $\mathrm{p}$ & $\mathrm{r}$ & $\mathrm{p}$ \\
\hline \multirow[t]{7}{*}{ Marine } & Florencia Is. & 0.976 & 0.0001 & 0.702 & 0.02 & -0.211 & 0.56 & 0.765 & 0.01 & -0.192 & 0.60 \\
\hline & Mandarte Is. & 0.748 & 0.01 & -0.580 & 0.08 & -0.641 & 0.05 & -0.251 & 0.48 & -0.361 & 0.31 \\
\hline & Ile du Corossol & 0.247 & 0.49 & 0.453 & 0.19 & 0.755 & 0.01 & -0.277 & 0.44 & 0.104 & 0.78 \\
\hline & Kent Is. & 0.009 & 0.98 & 0.293 & 0.41 & 0.385 & 0.27 & 0.304 & 0.39 & 0.045 & 0.90 \\
\hline & Manawagonish Is. & 0.241 & 0.50 & 0.842 & 0.002 & 0.882 & 0.0007 & -0.014 & 0.97 & -0.060 & 0.87 \\
\hline & Sable Is. & 0.018 & 0.96 & 0.213 & 0.56 & 0.343 & 0.33 & 0.664 & 0.04 & 0.583 & 0.08 \\
\hline & Gull Is. & 0.450 & 0.19 & 0.754 & 0.01 & 0.694 & 0.03 & 0.569 & 0.09 & 0.650 & 0.04 \\
\hline \multirow[t]{7}{*}{ Freshwater } & Dalemead Reservoir & -0.611 & 0.06 & -0.408 & 0.24 & -0.103 & 0.78 & 0.342 & 0.33 & -0.082 & 0.82 \\
\hline & Pipestone Rocks & -0.812 & 0.004 & -0.069 & 0.85 & -0.041 & 0.91 & -0.121 & 0.74 & -0.014 & 0.97 \\
\hline & Silver Islet & 0.856 & 0.002 & -0.386 & 0.27 & -0.501 & 0.14 & -0.650 & 0.04 & -0.426 & 0.22 \\
\hline & Big Chicken Is. & 0.004 & 0.99 & 0.508 & 0.14 & 0.493 & 0.15 & 0.400 & 0.25 & 0.416 & 0.23 \\
\hline & Toronto Harbour & -0.030 & 0.93 & 0.326 & 0.36 & 0.590 & 0.07 & 0.101 & 0.78 & -0.006 & 0.99 \\
\hline & Ile Deslauriers (HG) & 0.889 & 0.0006 & 0.739 & 0.01 & 0.691 & 0.03 & 0.538 & 0.11 & 0.519 & 0.12 \\
\hline & Ile Deslauriers (RBG) & 0.641 & 0.05 & 0.240 & 0.50 & -0.049 & 0.89 & 0.373 & 0.29 & 0.475 & 0.17 \\
\hline Mixed & Ile Bellechasse & 0.652 & 0.04 & 0.893 & 0.0005 & 0.940 & 0.0001 & 0.610 & 0.06 & 0.659 & 0.04 \\
\hline
\end{tabular}

${ }^{\mathrm{a}}$ See Figure 2.1 map for colony location

Note. The bold values indicate that the linear correlations were strong and significant $(\mathrm{p}<0.05)$. 
the diet. Negative and significant correlations between $\delta^{15} \mathrm{~N}$ and $\delta^{13} \mathrm{C}$ values were found for herring gulls from freshwater colonies at Pipestone Rocks and Dalemead Reservoir (Table 7.1). This indicated that an increase in tropic position was related to an increase in the proportion of freshwater aquatic food in the gull diet. The $\delta^{15} \mathrm{~N} / \delta^{13} \mathrm{C}$ relationship for individual eggs for Silver Islet (Lake Superior) had a significant positive correlation, whereas for Big Chicken Island (Lake Erie) and Toronto Harbour (Lake Ontario) colonies there were no correlations (Table 7.1). The Silver Islet result was unexpected and opposite of what Hebert et al. (60) reported, i.e., a significant negative correlation.

The lack of correlation between $\delta^{15} \mathrm{~N}$ and $\delta^{13} \mathrm{C}$ at the Big Chicken Island and Toronto Harbour colonies is consistent with the findings of Hebert et al. (60). The gulls from Ile Deslauriers and Ile Bellechasse showed significant positive correlations between $\delta^{15} \mathrm{~N}$ and $\delta^{13} \mathrm{C}$ (Table 7.1). Similar to the Silver Islet colony, these colonies are located in a freshwater environment, nevertheless positive correlations were observed instead of the negative correlations found by Hebert et al. (60) in freshwater environments. Factors such as changes in the stable isotope signatures at the base of the food web (as described above) in case of the Ile Deslauriers colony, or possible feeding on marine-based prey for the Ile Bellechasse colony (brackish water located downstream from Québec City) could have resulted in the unexpected $\delta^{15} \mathrm{~N} / \delta^{13} \mathrm{C}$ correlative relationships.

\subsubsection{PFCs and Precursors in Gull Eggs}

Of all the PFCs and precursors detected in the gull eggs from the 15 colony sites, PFOS was found to be the most concentrated. Of the $\sum$ PFSA $\left(\mathrm{C}_{6}, \mathrm{C}_{8}, \mathrm{C}_{10}\right.$, whereas $\mathrm{C}_{4}$ was below detection in all samples) concentrations, PFOS comprised between $89 \%$ 
- (Dalemead Reservoir) and 99\% (Silver Islet and Ile du Corossol) depending on the colony. PFDS was detected in the eggs from all the colonies although at much lower concentrations, i.e., 1 to $8 \%$ of $\sum$ PFSA. PFHxS was only present in the eggs from five colonies, Dalemead Reservoir (3\% of $\sum$ PFSA) and the Toronto Harbour, Ile DeslauriersHG, Sable Island and Gull Island colonies (all $<0.4 \%$ of $\sum$ PFSA). The PFSA pattern in the eggs was highly consistent with the pattern found in herring gull eggs from the Great Lakes collected in 2007 (Chapter 4).

Overall, the PFCA pattern in the gull eggs was similar but variable among the colonies. PFCAs with carbon chain length varying from $C_{6}$ to $C_{15}$ were detected, although PFHxA and PFHpA were only detected in four individual eggs from Ile du Corossol (Figures 7.2 and 7.3). Freshwater colonies close to urbanized areas had a greater proportion of PFDA, PFDoA, and PFTeA in $\sum$ PFCA pattern, which was significant $(p<0.05)$ in many cases compared to the other colonies (Figures 7.2, 7.3, and 7.4). The two Vancouver Island colonies had significantly $(p<0.05)$ higher portion of PFUnA in the EPFCA than any other colony, while the Kent Island colony had significantly $(p<0.05)$ higher amount of PFTrA in the $\sum$ PFCA than any other colony. The PFCA patterns in the eggs from the Silver Islet and Big Chicken Island were comparable to the pattern reported in Chapter 4 in eggs collected from Granite Island and Middle Island, respectively. The PFCA pattern in the eggs collected in Toronto Harbour showed changes compared to the 2007 samples (Chapter 4), in the present eggs PFTrA > PFDoA $>$ PFUnA $>$ PFDA, whereas in 2007 PFUnA $>$ PFTrA $>$ PFDoA > PFDA (Chapter 4). In other avian studies, the longer and odd carbon chain length PFCAs (PFUnA and PFTrA) were found to dominate the patterns in glaucous gull eggs from the Norwegian Arctic 

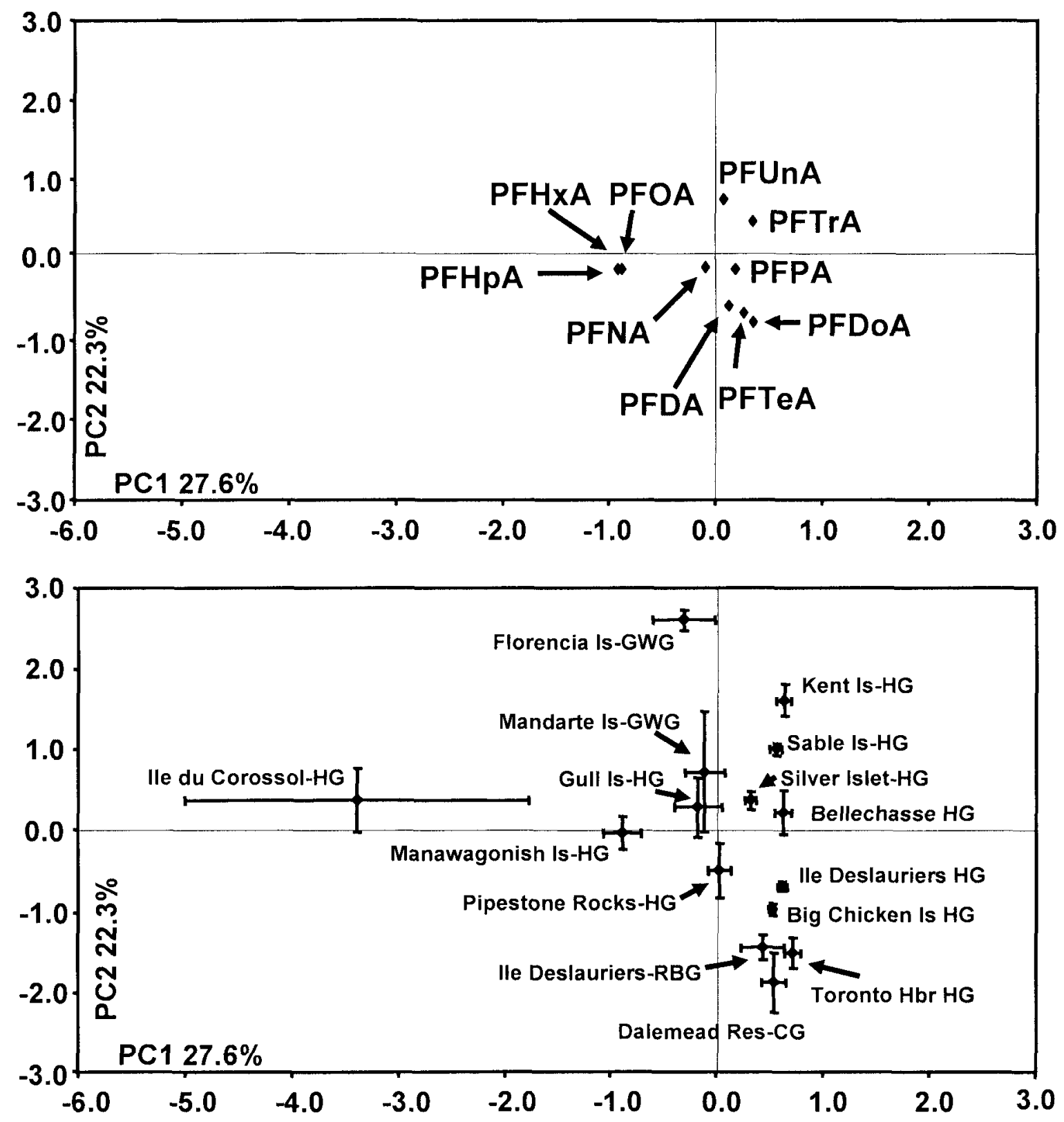

Figure 7.2 Proportions of $\mathrm{C}_{6}$ to $\mathrm{C}_{15}$ to $2 \mathrm{PFCA}$ concentrations plotted using the first two principal components (PCs), PCl and PC2. Mean ( \pm SE) factor scores (bottom biplot) are shown for the 15 colonies. The percent variability explained by $\mathrm{PC} 1$ and $\mathrm{PC} 2$ is provided. 

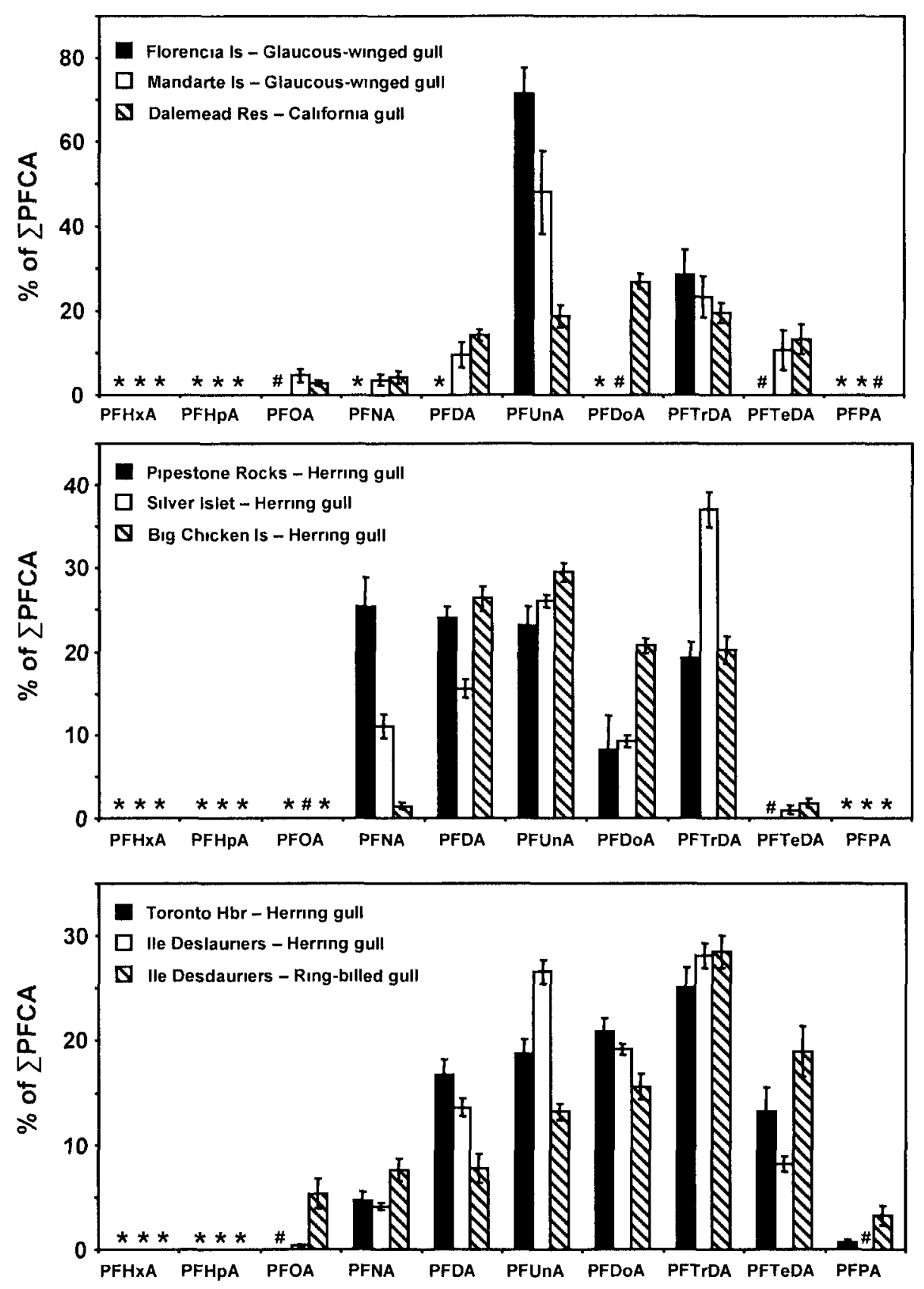

Figure 7.3 Arithmetic mean percent ( $\pm \mathrm{SE} \mathrm{ng/g} \mathrm{wet} \mathrm{weight)} \mathrm{of} \mathrm{detectable} \mathrm{PFCAs} \mathrm{to}$ $\sum$ PFCA with carbon chain length varying from $C_{6}$ to $C_{15}$ in gull eggs $(n=10)$ collected from nine colonies across Canada in 2008. " indicates compound being below detection limit $"$ indicates compound being detected only at $<60 \%$ in individual eggs. 

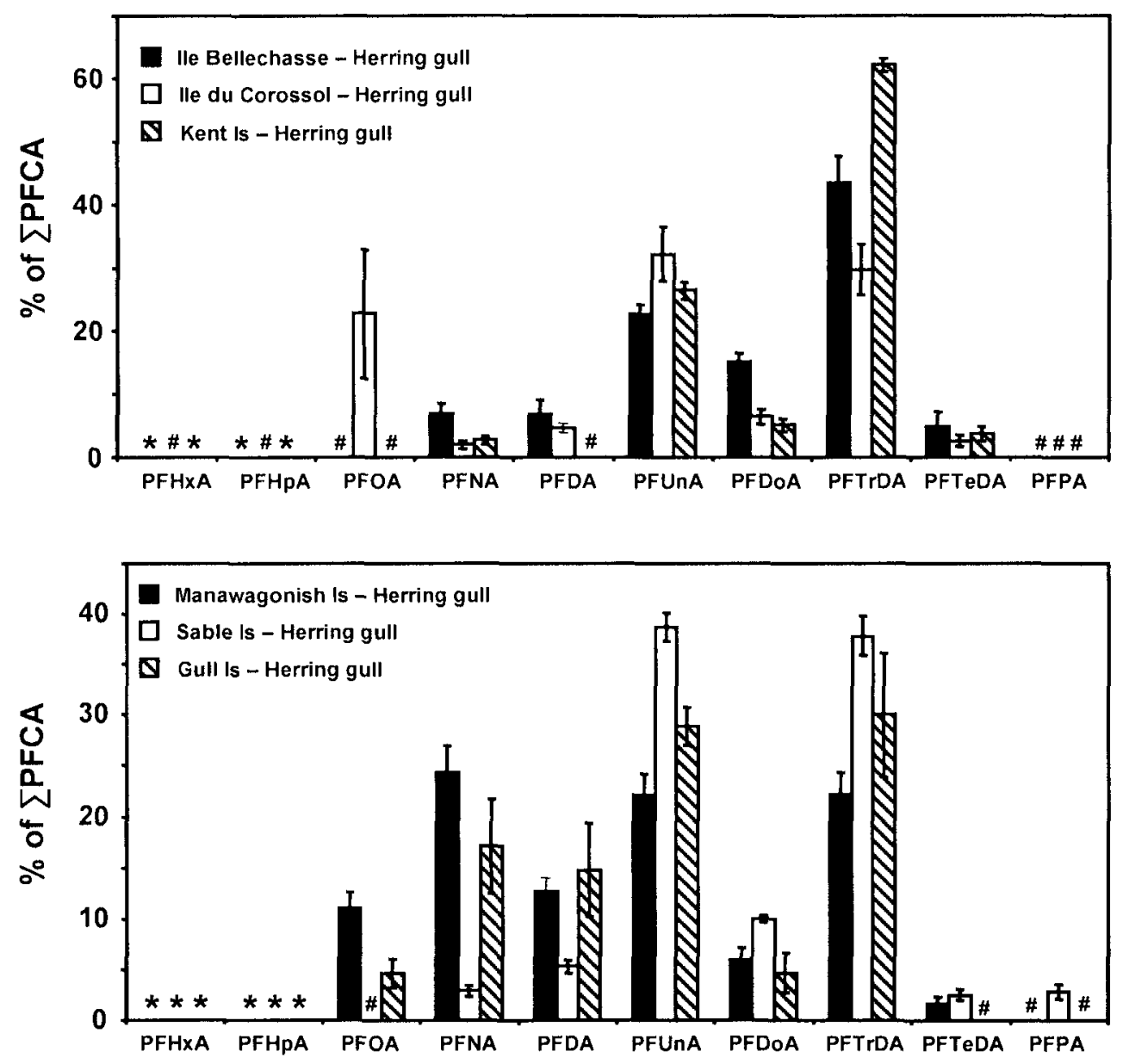

Figure 7.4 Arithmetic mean percent ( \pm SE ng/g wet weight) of detectable PFCAs to $\sum$ PFCA with carbon chain length varying from $\mathrm{C}_{6}$ to $\mathrm{C}_{15}$ in gull eggs $(\mathrm{n}=10)$ collected from six colonies across Canada in 2008. ${ }^{*}$ indicates compound being below detection limit. " indicates compound being detected only at $<60 \%$ in individual eggs. 
(33). However, Braune et al. (106) reported the dominance of PFDoA and PFTeA in the livers from northern fulmars from colonies in the Canadian high Arctic. The observed differences in PFCA patterns in the eggs of the present Pan-Canadian gulls from the various colonies were likely the result of a number of factors. The gull colonies are located in a range of environments, e.g. marine and freshwater, rural and urban, and birds in these environments likely consume different prey. Degradation of PFCA precursors such as FTOH and PAPS by the gulls or prey species could potentially influence the PFCA pattern (107). Other than in the Great Lakes (23), at present there is no information in the literature regarding PFCA patterns in any of the known prey species thus limiting our understanding of gull exposure scenarios.

Of all the monitored precursors for PFOS and PFCAs (PFOSA, NMeFOSA, 6:2, 8:2, 10:2 FTOH and 6:2, 8:2, 10:2 FTUCA) only PFOSA was detected in the gull eggs. PFOSA was only consistently detected in individual eggs from eight colonies with averages ranging from 0.05 to $0.29 \mathrm{ng} / \mathrm{g}$ wet weight (Table 7.2). The degradation of PFOSA to PFOS has been observed in in vitro studies using rainbow trout hepatocytes (15). Whether the present maternal gulls are able to metabolically degrade PFOSA to PFOS has not been studied. The PFOSA concentrations and PFOS/PFOSA ratios in the present eggs from the three Great Lakes colonies were comparable to those reported in Chapter 4. This suggests that by comparing the PFOS/PFOSA concentration ratio in Great Lakes herring gulls to their prey (the ratio in gull eggs was two orders of magnitude higher compared to the prey), it is possible that gulls are able to metabolize PFOSA to PFOS. However, maternal resource mobilization and transfer to eggs is a very selective process and one would have to assume that PFOS and PFOSA, which have slightly 
Table 7.2 Arithmetic mean concentrations of PFOSA (ng/g wet weight) and the PFOS to PFOSA concentration ratio in individual gull eggs from 15 colonies across Canada.

\begin{tabular}{lcc}
\hline Colony $^{\mathrm{a}}$ & PFOSA $( \pm \mathrm{SE})$ & $\begin{array}{c}\text { PFOS to PFOSA } \\
\text { conc. ratio }\end{array}$ \\
\hline Florencia Is. & $0.11 \pm 0.02$ & $65 \pm 8$ \\
Mandarte Is. & $0.09 \pm 0.03$ & $169 \pm 69$ \\
Dalemead Reservoir & $<0.005-0.25^{\mathrm{b}}$ & \\
Pipestone Rocks & $<0.005-0.11^{\mathrm{b}}$ & \\
Silver Islet & $0.05 \pm 0.01$ & $1258 \pm 159$ \\
Big Chicken Is. & $0.18 \pm 0.10$ & $2412 \pm 432$ \\
Toronto Harbour & $0.29 \pm 0.05$ & $2067 \pm 323$ \\
Ile Deslauriers (HG) & $<0.005-0.32^{\mathrm{b}}$ & \\
Ile Deslauriers (RBG) & $<0.005^{\mathrm{c}}$ & \\
Ile Bellechasse & $<0.005^{\mathrm{c}}$ & \\
Ile du Corossol & $0.11 \pm 0.04$ & $140 \pm 33$ \\
Kent Is. & $<0.005-0.09^{\mathrm{b}}$ & \\
Manawagonish Is. & $0.15 \pm 0.05$ & $153 \pm 22$ \\
Sable Is. & $0.09 \pm 0.03$ & $583 \pm 168$ \\
Gull Is. & $<0.005-0.09^{\mathrm{b}}$ & \\
\hline
\end{tabular}

\footnotetext{
a See Figure 2.1 map for colony location.

${ }^{b}$ Detection of PFOSA was $<60 \%$ in individual eggs, and thus the range of concentrations is given.

${ }^{c}$ PFOSA was below detection limit in all individual eggs.
} 
different physicochemical properties, are deposited in proportional amounts during the process of egg formation. See Appendix E for individual PFSA, PFCA and PFOSA concentrations in gull eggs collected in 2008 from 15 colonies across Canada.

\subsubsection{Geographical Distribution of PFSAs and PFCAs}

The highest concentrations of $\sum$ PFSA $\left(\mathrm{C}_{6}, \mathrm{C}_{8}\right.$, and $\left.\mathrm{C}_{10}\right)$ were found in the eggs collected from colonies close to urban areas in the Great Lakes and St. Lawrence River, i.e., Big Chicken Island, Toronto Harbour and Ile Deslauriers (HG) (Table 7.3). This is consistent with Chapter 4 where it was concluded that PPFSA concentrations in Great Lakes herring gull eggs (collected in 2007) from colonies on the more urbanized Lakes Erie and Ontario were higher compared to the more remote Lakes Superior, Michigan and Huron colonies. Overall, eggs from the freshwater colonies had higher $\sum$ PFSA concentrations than eggs from the marine gull colonies, which was significant $(p<0.05)$ in many cases. The Sable Island colony, however, had comparable $\sum$ PFSA concentrations to the more remote freshwater gull colonies (Dalemead Res, Pipestone Rocks, and Silver Islet). What factors caused these relatively high concentrations in the Sable Island eggs remain unclear. There is, to our knowledge, no information on what (marine) prey the gulls are feeding on this remote island and thus how they are exposed.

Concentrations of $\sum$ PFSA at two of the freshwater colonies (Ile Deslaurier-RBG and Ile Bellechasse) were not different from the marine colonies. The ring-billed gulls at the Ile Deslauriers colony appear to feed primarily on a terrestrial diet and that may have resulted in their lower egg concentrations. The herring gulls from Ile Bellechasse are 
Table 7.3 Arithmetic mean concentrations of $\Sigma$ PFSA and $\Sigma$ PFCA (ng/g wet weight) in individual gull eggs collected from 15 colonies across Canada in $2008(n=10$ per colony).

\begin{tabular}{lccccc}
\hline Colony $^{\mathrm{a}}$ & PPSA $^{\mathrm{b}}$ & $\Sigma \mathrm{PFCA}^{\mathrm{c}}$ & \multicolumn{3}{c}{$\Sigma \mathrm{PFSA} / \Sigma \mathrm{PFCA}$} \\
\cline { 5 - 6 } & $( \pm \mathrm{SE})$ & $( \pm \mathrm{SE})$ & slope & $\mathrm{r}$ & $\mathrm{p}$ \\
\hline Florencia Is. & $7.8 \pm 0.7$ & $1.4 \pm 0.3$ & 0.07 & 0.029 & 0.94 \\
Mandarte Is. & $23 \pm 4$ & $3.9 \pm 1.3$ & 2.77 & 0.967 & $<0.0001$ \\
Dalemead Reservoir & $74 \pm 18$ & $18 \pm 5$ & 3.26 & 0.863 & $<0.002$ \\
Pipestone Rocks & $131 \pm 19$ & $21 \pm 4$ & 2.25 & 0.513 & 0.13 \\
Silver Islet & $63 \pm 6$ & $19 \pm 2$ & 1.25 & 0.310 & 0.38 \\
Big Chicken Is. & $308 \pm 61$ & $53 \pm 15$ & 4.16 & 0.989 & $<0.0001$ \\
Toronto Harbour & $486 \pm 54$ & $74 \pm 8$ & 5.33 & 0.741 & $<0.02$ \\
Ile Deslauriers (HG) & $299 \pm 41$ & $82 \pm 13$ & 3.05 & 0.943 & $<0.0001$ \\
Ile Deslauriers (RBG) & $64 \pm 17$ & $29 \pm 7$ & 1.48 & 0.609 & 0.06 \\
Ile Bellechasse & $49 \pm 20$ & $16 \pm 7$ & 2.86 & 0.977 & $<0.0001$ \\
Ile du Corossol & $22 \pm 3$ & $61 \pm 19$ & 0.01 & 0.099 & 0.79 \\
Kent Is. & $13 \pm 1$ & $30 \pm 4$ & 0.08 & 0.329 & 0.35 \\
Manawagonish Is. & $29 \pm 5$ & $14 \pm 3$ & 1.45 & 0.937 & $<0.0001$ \\
Sable Is. & $103 \pm 38$ & $82 \pm 17$ & 2.20 & 0.973 & $<0.0001$ \\
Gull Is. & $30 \pm 8$ & $20 \pm 11$ & 0.56 & 0.785 & $<0.008$ \\
\hline
\end{tabular}

${ }^{a}$ See Figure 2.1 map for colony location.

${ }^{\mathrm{b}} \mathrm{SPFSA}=\mathrm{PFHxS}$, PFOS, PFDS.

${ }^{\circ} \Sigma$ PFCA $=$ PFHxA, PFHpA, PFOA, PFNA, PFDA, PFUnA, PFDoA, PFTrA, PFTeA, PFPA. 
close to the area in the St. Lawrence River where both fresh and salt water prey species are present. A greater proportion of marine prey with (possibly) lower PFSA concentrations might have resulted in the relatively low egg concentrations at that site. Based on the present data, it appears that the freshwater aquatic environment (i.e., freshwater prey species of the gulls) is more contaminated with PFSAs compared to the marine environment.

The highest $\sum$ PFCA concentrations $\left(\mathrm{C}_{6}-\mathrm{C}_{15}\right)$ were found in eggs collected from colonies close to urban areas [Big Chicken Island, Toronto harbour and Ile Deslauriers $(\mathrm{HG})]$ and Sable Island, although in many cases not significantly $(p<0.05)$ higher compared to other colonies (Table 7.3). On Sable Island, there must be a local, unknown, marine source of PFCAs that the gulls are feeding on leading to comparable concentrations relative to the colonies close to urbanized areas'. In contrast, the lowest $\sum$ PFCA concentrations were found in eggs from the two glaucous-winged gull colonies in Pacific Canada. These were significantly $(p<0.05)$ lower compared to all the other colonies. The only comparison of $\sum$ PFSA and/or $\sum$ PFCA concentrations to any of the 15 gull colonies was made in Chapter 4 where PFCs were determined in Great Lakes herring gull eggs. The three Great Lakes colonies in the present study had comparable $\Sigma$ PFSA and $\sum$ PFCA concentrations to the 2007 egg concentrations reported in Chapter 4 (using Granite Island to compare to Silver Islet and Middle Island to compare to Big Chicken Island). 


\subsubsection{Stable Isotopes as Dietary Tracers for PFC Exposure}

$\delta^{15} \mathrm{~N}$ and $\delta^{13} \mathrm{C}$ stable isotopes as dietary tracers provides some cautious insights into how the present gulls are exposed, e.g. marine versus freshwater prey, aquatic versus terrestrial prey, to PFCs. Colony eggs exhibiting significant relationships between concentrations of $\sum$ PFSA and $\sum$ PFCA could be an indication of a common exposure source of these two compound classes. The lack of correlation at some colonies could be an indication that there are several sources accounting for $\sum$ PFSA and $\sum$ PFCA exposure in the gulls, e.g., aquatic or terrestrial prey.

Among the seven marine colonies we found positive, significant correlations between ¿PFSA and ¿PFCA for four colonies (Table 7.3). At the Mandarte Island colony, negative relationships were found between both stable isotopes and $\sum$ PFSA and $\sum$ PFCA (Table 7.1), which suggests that the PFC exposure came from freshwater/terrestrial sources. Vermeer (96) reported that in the early 1980s glaucous-winged gulls from Mandarte Island relied heavily on human refuse, thus this possibly could be the primary source of $\sum$ PFSA and $\sum$ PFCA exposure for those gulls. However, a recent study (Davis, unpublished data) from 2009 and 2010 did not find evidence of significant garbage in the diet. A comparison of polybrominated diphenyl ethers (PBDEs) in another avian top predator, the bald eagle (Halieaeetus leucocephalus), in the some of the same systems, that unlike the legacy POPs, there was not significant relation between exposure and $\delta^{13} \mathrm{C}$ once the data were adjusted for $\delta^{15} \mathrm{~N}(108)$. At the Manawagonish, Sable and Gull Island colonies, positive, significant $(\mathrm{p}<0.05) \sum \mathrm{PFSA}$ to $\sum$ PFCA correlations were found, and positive (significant and non-significant) relationships were observed between stable isotope values and $\sum$ PFCs with the exception of the Manawagonish Island colony. For 
the Sable and Gull Island colonies, the positive relationships between the $\delta^{15} \mathrm{~N}$ and $\delta^{13} \mathrm{C}$ and the $\sum$ PFSA and $\sum$ PFCA suggest that marine aquatic prey may have been the primary source of exposure. Herring gulls from Gull Island feed on capelin and northern cod $(99,100)$, for Sable Island there is no information on gull prey. For the Manawagonish Island colony, the $\delta^{15} \mathrm{~N}$ to $\sum \mathrm{PFSA}$ and $\sum \mathrm{PFCA}$ correlation indicated that aquatic prey may have been the primary source for PFC exposure; however, there was no significant $(\mathrm{p}>0.05) \delta^{13} \mathrm{C}$ to $\sum \mathrm{PFSA}$ and $\sum \mathrm{PFCA}$ correlation. For the Florencia Island, Ile du Corossol and Kent Island colonies there was no correlation between $\sum$ PFSA and $\sum$ PFCA suggesting that there might be several sources for the two compound classes.

For the Pacific colonies, the glaucous-winged gull eggs from Florencia Island had positive, significant correlation between both stable isotopes and $\sum$ PFSA, suggesting that marine prey may be the primary source. The $\delta^{15} \mathrm{~N}$ and $\delta^{13} \mathrm{C}$ to $\sum \mathrm{PFCA}$ correlations were negative although not significant. Prey species other than marine prey might be the source of $\sum$ PFCA for these gulls. However, the recent study on glaucous winged gull dietary ecology, including colonies on the west coast of Vancouver Island, found that the diet is mostly marine (Davis, unpublished data). For both Ile du Corossol and Kent Island, positive correlations were observed between $\delta^{15} \mathrm{~N}$ and $\sum \mathrm{PFSA}$ and $\sum \mathrm{PFCA}$ in the eggs indicating that aquatic prey species are a likely source of PFC contamination at these colonies. The $\delta^{13} \mathrm{C}$ to $\sum$ PFSA and $\sum$ PFCA correlations were positive, negative or there was no correlation.

Among the freshwater colonies, positive significant correlations between 2 PFSA and ¿PFCA were observed for the Dalemead Reservoir, Big Chicken Island, Toronto Harbour, Ile Deslauriers (HG) and Ile Bellechasse colonies (Table 7.3). The negative 
correlations between $\delta^{15} \mathrm{~N}$ and the $\sum$ PFSA and $\sum$ PFCA and the positive correlation between $\delta^{13} \mathrm{C}$ and $\sum$ PFSA suggest that terrestrial inputs to the diet of California gulls from the Dalemead Reservoir colony was a possible source of PFCs. Based on correlations with $\delta^{15} \mathrm{~N}$, the aquatic diet may have been the primary source of $\sum$ PFSA and ¿PFCA at Big Chicken Island, Toronto Harbour, Ile Deslauriers (HG) and Ile Bellechasse; however, the mostly positive relationships between $\delta^{13} \mathrm{C}$ and $\sum$ PFSA and $\sum$ PFCA suggest that the concentrations were greater as a result of greater terrestrial input in the diet. In the eggs from the Pipestone Rocks, Silver Islet and Ile Deslauriers (RBG) colonies, there was no significant $\sum$ PFSA/ $\mathrm{PFCA}$ relationship (Table 7.3). At the Silver Islet colony, the $\delta^{15} \mathrm{~N} / \mathrm{PFC}$ correlations indicated that the terrestrial component of the herring gull diet was an important source of $\sum$ PFSA and $\sum$ PFCA; however, $\delta^{13} \mathrm{C} / \mathrm{PFC}$ relationships indicated that aquatic prey could have been the major route of exposure. In recent years, herring gulls on Lake Superior may be increasingly feeding on terrestrial prey as a result of declines in prey fish abundance (6I). This mixture of both aquatic and terrestrial prey might explain the observed stable isotope-PFC correlations. No stable isotope-PFC correlations were found in the individual eggs from the Pipestone Rocks colony. There is, to our knowledge, no information on the herring gull diet (aquatic and/or terrestrial) from this colony that might explain these results. Both stable isotopes to $\sum$ PFSA and $\sum$ PFCA correlations were positive in the eggs from Ile Bellechasse. The $\delta^{15} \mathrm{~N}$ correlations indicate that aquatic prey may have been the major source for $\sum$ PFSA and $\sum$ PFCA exposure. The presence of both freshwater and salt water prey downstream from the colony could explain the positive correlations between $\delta^{13} \mathrm{C}$ and $\sum$ PFSA and 
¿PFCA, most likely the herring gulls were exposed to PFCs by feeding on salt water prey.

The present findings document the presence of PFCs in gull eggs collected across Canada regardless of colony location. To our knowledge, this is the first report on PFSAs and PFCAs in any Canadian avian species in areas other than the Great Lakes and the Arctic. Both aquatic (marine and freshwater) and terrestrial prey are likely sources of PFC exposure to gulls but exposure scenarios are colony-specific. Clearly, further research needs to focus on understanding the complex, site-specific factors regulating PFC exposure and accumulation in wildlife. For example, more studies are required to understand relative sources, and the environmental transport and fate of these PFCs and precursors, as well as the diet and foraging ecology of the various monitored populations. 


\section{Chapter 8: Conclusions, Implications, and Future Directions}

\subsection{Conclusions and Implications}

The present study examined the presence of perfluorosulfonates, perfluorocarboxylates, and several precursor as well as PFOS isomer compounds in gulls throughout the Canadian environment, but in particular in the Great Lakes basin. The tissue distribution, maternal transfer, and spatial and temporal trends of PFCs (including PFOS isomers) were determined in herring gulls from colonies in the Great Lakes. In addition, a Canada wide spatial distribution of PFCs was determined using egg from multiple gull species and sources of exposure were investigated. Studies reporting on the presence of PFCs in the Canadian environment were limited to the Arctic and Great Lakes, and within those regions information on wild birds exposed to PFCs were even more limited. In regions like Atlantic and Pacific Canada there was no information on the presence of PFCs in birds. In this thesis, these knowledge gaps on PFCs in gulls in the Canadian environment were addressed and the following highlight conclusions were drawn from the individual results chapters:

- In breeding female herring gulls, sacrificed in the midst of active egg-laying, PFSAs and PFCAs were detected in several tissues and blood with the highest ¿PFSA and PFCA concentrations in the adipose and brain, respectively. Although there were tissue specific differences in the PFCA pattern, the combined PFCA pattern reflected the pattern in the eggs, which is crucial when using eggs for monitoring purposes. Results showed that a considerable amount of the PFSA and PFCA body burden is transferred to the eggs during development. 
- Spatial distribution studies showed that herring gull colonies located on/near the urbanized Lakes Erie and Ontario were more contaminated with $\sum$ PFSA compared to colonies located on/near the less urbanized Lakes Superior, Michigan, and Huron, while this was not the case for $\sum$ PFCA concentrations.

- The PFOS detected in herring gull eggs was comprised of linear and branched isomers. Besides L-PFOS, six monomethyl and two dimethyl branched isomers were detected, however, the isomer pattern was highly enriched with L-PFOS compared to T-PFOS.

- Herring gulls were continually and remained exposed to PFSAs and PFCA between 1990 and 2010. Other than the Toronto Harbour colony, ¿PFSA concentrations decreased between 1990 and 2010, whereas LPFCA concentrations increased at most colonies.

- Gull colonies spanning Atlantic to Pacific Canada were exposed to PFSAs and PFCAs and colonies located near the urbanized and industrialized lower Great Lakes (Lakes Erie and Ontario) and the St. Lawrence River (near Montreal) were generally more contaminated with $\sum$ PFSA and $\sum$ PFCA compared to other colonies. Both aquatic (marine and freshwater) and terrestrial prey are likely sources of PFC exposure to gulls but exposure scenarios are colony-specific.

Based on the results, herring gull eggs are useful to monitor PFSA and PFCA contamination to female gulls. Although there were tissue specific differences in the PFCA pattern, the combined tissue and blood PFCA pattern reflected the pattern in the eggs. Using the gull eggs for monitoring purposes, the results showed the importance of 
the colony location on the concentrations when spatial trends of PFSAs and PFCAs were determined in the Great Lakes and Canada wide. Gull colonies located in highly urbanized and/or industrialized areas in the lower Great Lakes and St. Lawrence River were more contaminated compared to colonies located in remote or less urbanized areas such as the northern Great Lakes, and Atlantic and Pacific Canada. Herring gull colonies in the highly urbanized areas have continually and remain to be exposed to increasing concentrations of PFSAs and PFCAs, as was seen at the Toronto Harbour colony. At some colonies located in the northern Great Lakes, declining $\sum$ PFSA concetrations were seen which could be a result of the $\mathrm{C}_{8}$ PFCs phase-out. Increasing $\sum$ PFCA concetrations were seen at several Great Lakes colonies regardless of location, this could be linked to the continuous production of fluorotelomer-based compound which are known precursors to PFCAs.

The exact routes of exposure of PFSAs, PFCAs, and PFOSA to gulls from colonies across Canada remain unclear. The diet of herring gulls from the Great Lakes has been well studied (6I), and the presence of PFSAs, PFCAs, and PFOSA in herring gull prey has been shown in prey fish from Lake Ontario (23). For gull colonies outside the Great Lakes there was limited or no information on the diet and/or presence of PFCs in prey species. The use of stable isotopes as dietary tracers revealed that there was no clear overall trend indicating that only marine prey, freshwater prey, or terrestrial prey was the primary source of PFCs to gulls among the colonies across Canada. Gulls are known to be scavangers and consume aquatic (marine and freshwater) as well as terrestrial prey. Given that at many colonies there was no relationship between PFCs and nitrogen and 
carbon stable isotopes, multiple prey species, whether aquatic or terrestrial, are likely a source of PFC contamination.

Besides direct accumulation of PFSAs and PFCAs from the prey (aquatic and/or terrestrial), biotransformation of precursors could be an alternative source for PFOS and PFCAs. PFOSA was the only detected precursor in eggs collected from colonies in the Great Lakes and Atlantic and Pacific Canada. It remains unclear whether gulls are able to metabolize PFOSA to PFOS. However, when comparing the PFOS/PFOSA ratio in prey fish from Lake Ontario (23), the ratio in the gull eggs from the Great Lakes was up to 2 orders of magnitude higher, which could be an indication of PFOSA biotransformation. Although, whether there is selective transfer of PFOS and/or PFOSA from the female herring gull to the eggs is unclear. PFOSA was below detection limit in the analyzed female herring gull tissues, blood and eggs collected in 2010. The absence of PFOSA in those samples could be a result that it was either metabolized to PFOS, or that in 2010 the Great Lakes herring gulls were not exposed to PFOSA anymore as it was not detected in eggs collected from several Great Lakes colonies since 2007. Although the PFCA precursors (FTOHs and FTUCAs) were below detection limit in herring gull tissues and eggs, their presence was seen in lake trout from the Great Lakes (24). It remains unclear whether herring gulls are exposed to these precursors and if so, to what extent this impacts the PFCAs (patterns and concentrations) in the herring gulls. With the continuous production of these PFCA precursors, including PAPS, degradation of these compounds by prey fish and/or gulls could ultimately lead to greater PFCA exposure.

Using the gull eggs as a monitor for PFC does not only provide information to what extent gull colonies are exposed to PFCs but it also provides information as to how 
contaminated the ecosystem in which the gulls reside. Not only gulls, but other species in ecosystems that are located near urbanized and/or industrialized areas are exposed to greater amounts of PFCs, as is likely the case for humans. The voluntary phase-out of the $\mathrm{C}_{8}$ PFCs by the $3 \mathrm{M}$ Company was a result of evidence of the persistence, bioaccumulative and toxic properties of PFOS, and subsequently the $\mathrm{C}_{8}$ PFCs were replaced by shorter chain length PFSAs (i.e., PFBS), which have a lower bioaccumulation potential. The production of fluorotelomer-based compounds, however, is still increasing and could be a major source of PFCAs in the environment. Replacing the longer chain length PFCAs (and their precursors) by shorter chain, and less bioaccumulative, PFCAs could ultimately reduce the increasing amount of PFCAs in the environment and would reduce the exposure to gulls and other wildlife.

Regardless of the sources, herring gulls located near highly urbanized areas have the greatest exposure of PFSAs and PFCAs among the studied colonies, however, what impact the PFC exposure has on the health of the gulls remains unclear. Avian (including herring gulls) toxicity studies of PFCs are mostly limited to liver and brain and generally effects were seen at concentrations higher than the environmental concentrations measured in the tissues $(47,45,46)$. However, the tested PFAAs in those studies did not always reflect the PFAAs that were detected in the target tissues. For example, the effects of $<\mathrm{C}_{11}$ PFCAs on changes in mRNA expression was tested in herring gull embryonic neural cells, however, as de,ostrated in the present study, $\mathrm{C}_{12}$ to $\mathrm{C}_{15}$ PFCAs dominated the PFCA pattern in the herring gull brains (47). Based solely on the endpoints mentioned in those toxicity studies, the concentrations of PFSAs and PFCAs detected in the tissues and eggs likely have little impact on the health of female gulls and developing chicks. 
However, gulls are not only exposed to PFCs but a variety of other persistent environmental contaminants suchs as PCBs, pesticides, and BFRs. There is little information on the toxicity of PFC mixtures (reflecting the PFCs detected in the tissues and eggs) and/or the toxicity of PFCs combined with other POPs. As a substantial amount of PFCs are transported from the female gulls to their eggs

\subsection{Future Directions}

Based on the results of this thesis, the following knowledge gaps and questions can be derived, and thus are the basis of future research directions.

Assessing the total mass balance of PFCs in female gulls. Knowing the full tissue and compartmental distribution, the use of non-destructive matrices other than eggs, such as feathers, could be investigated for future monitoring purposes of PFSAs, PFCAs, and potential precursors (including PAPs) in gulls throughout the Canadian environmnent.

FOSAs, FTOHs, and PAPS, have been shown to be precursors to PFOS and PFCAs. Of those compounds, only PFOSA has been detected in herring gull prey fish (23), while the presence of FTUCAs (degradation products of FTOHs) was shown in lake trout from the Great Lakes (24). There are no studies investigating PAPS in the birds or fish in the Great Lakes. Future work should investigate the presence of these precursors in herring gulls (PAPS, FOSAs and FOSEs) and in their food web (FOSAs, FOSEs, PAPS, FTOHs and FTUCAs). 
The presence of FOSAs, FOSEs, PAPS, FTOHs and FTUCAs precursors in the herring gulls or prey species could potentially lead to higher exposure to PFOS and PFCAs as biotransformation of these precursors has been shown $(11,15)$. However, it remains unclear whether herring gulls are able to metabolize these precursors. In this thesis, it was shown that the presence of the PFOS precursor (PFOSA) and the PFOS/PFOSA ratio in herring gull eggs was two orders of magnitude higher compare to the ratio reported in prey fish. This could be an indication that the herring gulls are able to degrade PFOSA to PFOS. Future work should investigate whether herring gulls are able to biotransform the precursors to PFOS and PFCAs and thus increasing the exposure of these compounds.

In Chapter 3, a chain length dependent distribution was observed in herring gull tissues, blood and eggs for $\mathrm{C}_{6}$ to $\mathrm{C}_{15}$ PFCAs. Information on the tissue diustribution of PFOS isomers and/or PFCA isomers in bird does not exist. Future work should investigate the distribution of PFOS and individual PFCA isomers in herring gull target tissues such as liver, blood, brain, and egg. 


\section{References}

(1) Prevedouros, K.; Cousins, I. T.; Buck, R. C.; Korzeniowski, S. H. Sources, fate and transport of perfluorocarboxylates. Environmental Science \& Technology 2006, 40, 32-44.

(2) Lehmler, H.-J. Synthesis of environmentally relevant fluorinated surfactants - a review. Chemosphere 2005, 58, 1471-1496.

(3) Chu, S. G.and Letcher, R. J. Linear and Branched Perfluorooctane Sulfonate Isomers in Technical Product and Environmental Samples by In-Port Derivatization-Gas Chromatography-Mass Spectrometry. Analytical Chemistry 2009, 81, 4256-4262.

(4) Arsenault, G.; Chittim, B.; McAlees, A.; McCrindle, R.; Riddell, N.; Yeo, B. Some issues relating to the use of perfluoro octane sulfonate (PFOS) samples as reference standards. Chemosphere 2008, 70, 616-625.

(5) Rayne, S.; Forest, K.; Friesen, K. J. Congener-specific numbering systems for the environmentally relevant $\mathrm{C}_{4}$ through $\mathrm{C}_{8}$ perfluorinated homologue groups of alkyl sulfonates, carboxylates, telomer alcohols, olefins, and acids, and their derivatives. Journal of Environmental Science and Health Part A 2008, 43, 1391 1401 .

(6) Vyas, S. M.; Kania-Korwel, I.; Lehmler, H. J. Differences in the isomer composition of perfluoroctanesulfonyl (PFOS) derivatives. Journal of Environmental Science and Health Part A-Toxic/Hazardous Substances \& Environmental Engineering 2007, 42, 249-255.

(7) Furdui, V. I.; Helm, P. A.; Crozier, P. W.; Lucaciu, C.; Reiner, E. J.; Marvin, C. H.; Whittle, D. M.; Mabury, S. A.; Tomy, G. T. Temporal Trends of Perfluoroalkyl Compounds with Isomer Analysis in Lake Trout from Lake Ontario (1979-2004). Environmental Science \& Technology 2008, 42, 4739-4744.

(8) Martin, J. W.; Asher, B. J.; Beesoon, S.; Benskin, J. P.; Ross, M. S. PFOS or PreFOS? Are perfluorooctane sulfonate precursors (PreFOS) important determinants of human and environmental perfluorooctane sulfonate (PFOS) exposure? Journal of Environmental Monitoring 2010, 12, 1979-2004.

(9) D'Eon, J. C.and Mabury, S. A. Exploring indirect sources of human exposure to perfluoroalkyl carboxylates (PFCAs): Evaluating uptake, elimination, and biotransformation of polyfluoroalkyl phosphate esters (PAPs) in the rat. Environmental Health Perspectives 2011, 119, 344-350.

(10) Tomy, G. T.; Tittlemier, S. A.; Palace, V. P.; Budakowski, W. R.; Braekevelt, E.; Brinkworth, L.; Friesen, K. Biotransformation of N-ethyl perfluorooctanesulfonamide by rainbow trout (Onchorhynchus mykiss) liver microsomes. Environmental Science \& Technology 2004, 38, 758-762. 
(11) Xu, L.; Krenitsky, D. M.; Seacat, A. M.; Butenhoff, J. L.; Anders, M. W. Biotransformation of N-ethyl-N-(2-hydroxyethyl)perfluorooetanesulfonamide by rat liver microsomes, cytosol, and slices and by expressed rat and human cytochromes P450. Chemical Research in Toxicology 2004, 17, 767-775.

(12) Ellis, D. A.; Martin, J. W.; De Silva, A. O.; Mabury, S. A.; Hurley, M. D.; Andersen, M. P. S.; Wallington, T. J. Degradation of fluorotelomer alcohols: A likely atmospheric source of perfluorinated carboxylic acids. Environmental Science \& Technology 2004, 38, 3316-3321.

(13) Dinglasan, M. J.; Ye, Y.; Edwards, E. A.; Mabury, S. A. Fluorotelomer alcohol biodegradation yields poly- and perfluorinated acids. Environmental Science \& Technology 2004, 38, 2857-2864.

(14) Wang, N.; Szostek, B.; Buck, R. C.; Folsom, P. W.; Sulecki, L. M.; Capka, V.; Berti, W. R.; Gannon, J. T. Fluorotelomer alcohol biodegradation - Direct evidence that perfluorinated carbon chains breakdown. Environmental Science \& Technology 2005, 39, 7516-7528.

(15) Martin, J. W.; Mabury, S. A.; O'Brien, P. J. Metabolic products and pathways of fluorotelomer alcohols in isolated rat hepatocytes. Chemico-Biological Interactions 2005, 155, 165-180.

(16) Benskin, J. P.; Holt, A.; Martin, J. W. Isomer-Specific Biotransformation Rates of a Perfluorooctane Sulfonate (PFOS)-Precursor by Cytochrome P450 Isozymes and Human Liver Microsomes. Environmental Science \& Technology 2009, 43, 8566-8572.

(17) Stock, N. L.; Lau, F. K.; Ellis, D. A.; Martin, J. W.; Muir, D. C. G.; Mabury, S. A. Polyfluorinated telomer alcohols and sulfonamides in the North American troposphere. Environmental Science \& Technology 2004, 38, 991-996.

(18) Giesy, J. P.and Kannan, K. Global distribution of perfluorooctane sulfonate in wildlife. Environmental Science \& Technology 2001, 35, 1339-1342.

(19) Holmstrom, K. E.; Jarnberg, U.; Bignert, A. Temporal trends of PFOS and PFOA in guillemot eggs from the Baltic Sea, 1968-2003. Environmental Science \& Technology 2005, 39, 80-84.

(20) Houde, M.; Martin, J. W.; Letcher, R. J.; Solomon, K. R.; Muir, D. C. G. Biological monitoring of polyfluoroalkyl substances: a review. Environmental Science and Technology 2006, 40, 3463-3473.

(21) Houde, M.; De Silva, A. O.; Muir, D. C. G.; Letcher, R. J, Monitoring of perfluorinated compounds in aquatic biota: An updated review. Environmental Science \& Technology 2011, doi: 10.1021/es104326w. 
(22) Butt, C. M.; Berger, U.; Bossi, R.; Tomy, G. T. Levels and trends of poly- and perfluorinated compounds in the arctic environment. Science of the Total Environment 2010, 408, 2936-2965.

(23) Martin, J. W.; Whittle, D. M.; Muir, D. C. G.; Mabury, S. A. Perfluoroalkyl contaminants in a food web from lake Ontario. Environmental Science \& Technology 2004, 38, 5379-5385.

(24) Furdui, V. I.; Stock, N. L.; Ellis, D. A.; Butt, C. M.; Whittle, D. M.; Crozier, P. W.; Reiner, E. J.; Muir, D. C. G.; Mabury, S. A. Spatial distribution of perfluoroalkyl contaminants in lake trout from the Great Lakes. Environmental Science \& Technology 2007, 41, 1554-1559.

(25) Kannan, K.; Franson, J. C.; Bowerman, W. W.; Hansen, K. J.; Jones, J. D.; Giesy, J. P. Perfluorooctane sulfonate in fish-eating water birds including bald eagles and albatrosses. Environmental Science \& Technology 2001, 35, 3065-3070.

(26) Houde, M.; Czub, G.; Small, J. M.; Backus, S. M.; Wang, X.; Alaee, M.; Muir, D. C. G. Fractionation and Bioaccumulation of Perfluorooctane Sulfonate (PFOS) Isomers in a Lake Ontario Food Web. Environmental Science \& Technology 2008, 42, 9397-9403.

(27) Luebker, D. J.; Hansen, K. J.; Bass, N. M.; Butenhoff, J. L.; Seacat, A. M. Interactions of flurochemicals with rat liver fatty acid-binding protein. Toxicology 2002, 176, 175-185.

(28) Jones, P. D.; Hu, W.; De Coen, W.; Newsted, J. L.; Giesy, J. P. Binding of perfluorinated fatty acids to serum proteins. Environmental Toxicology and Chemistry 2003, 22, 2639-2649.

(29) Chen, Y.-M.and Guo, L.-H. Fluorescence study on site-specific binding of perfluoroalkyl acids to human serum albumin. Archives of Toxicology 2009, 83, $255-261$.

(30) Ahrens, L.; Siebert, U.; Ebinghaus, R. Total body burden and tissue distribution of polyfluorinated compounds in harbor seals (Phoca vitulina) from the German Bight. Marine Pollution Bulletin 2009, 58, 520-525.

(31) Van de Vijver, K. I.; Hoff, P.; Das, K.; Brasseur, S.; Van Dongen, W.; Esmans, E.; Reijnders, P.; Blust, R.; De Coent, W. Tissue distribution of perfluorinated chemicals in harbor seals (Phoca vitulina) from the Dutch Wadden Sea. Environmental Science \& Technology 2005, 39, 6978-6984.

(32) Van de Vijver, K. I.; Holsbeek, L.; Das, K.; Blust, R.; Joiris, C.; De Coen, W. Occurrence of perfluorooctane sulfonate and other perfluorinated alkylated substances in Harbor Porpoises from the Black Sea. Environmental Science \& Technology 2007, 41, 315-320. 
(33) Verreault, J.; Houde, M.; Gabrielsen, G. W.; Berger, U.; Haukås, M.; Letcher, R. J.; Muir, D. C. G. Perfluorinated alkyl substances in plasma, liver, brain, and eggs of glaucous gulls (Larus hyperboreus) from the Norwegian Arctic. Environmental Science and Technology 2005, 39, 7439-7445.

(34) Holmström, K. E.and Berger, U. Tissue Distribution of Perfluorinated Surfactants in Common Guillemot (Uria aalge) from the Baltic Sea. Environmental Science \& Technology 2008, 42, 5879-5884.

(35) Olivero-Verbel, J.; Tao, L.; Johnston-Restrepo, B.; Guette-Fernandez, J.; BaldirisAvila, R.; O'byrne-Hoyos, I.; Kannan, K. Perfluorooctanesulfonate and related fluorochemicals in biological samples from the north coast of Colombia. Environmental Pollution 2006, 142, 367-372.

(36) Newsted, J. L.; Coady, K. K.; Beach, S. A.; Butenhoff, J. L.; Gallagher, S.; Giesy, J.P. Effects of perfluorooctane sulfonate on mallard and northern bobwhite quail exposed chronically via the diet. Environmental Toxicology and Pharmacology 2007, 23, 1-9.

(37) Tomy, G. T.; Budakowski, W.; Halldorson, T.; Helm, P. A.; Stern, G. A.; Friesen, K.; Pepper, K.; Tittlemier, S. A.; Fisk, A. T. Fluorinated organic compounds in an eastern Arctic marine food web. Environmental Science \& Technology 2004, 38, 6475-6481.

(38) Adams, J.; Houde, M.; Muir, D. C. G.; Speakman, T.; Bossart, G. D.; Fair, P. A. Land use and the spatial distribution of perfluoroalkyl compounds as measured in the plasma of bottlenose dolphins (Tursiops truncatus). Marine Environmental Research 2008, 66, 430-437.

(39) Hart, K.; Kannan, K.; Tao, L.; Takahashi, S.; Tanabe, S. Skipjack tuna as a bioindicator of contamination by perfluorinated compounds in the oceans. The Science of the Total Environment 2008, 403, 215-221.

(40) Butt, C. M.; Mabury, S. A.; Muir, D. C. G.; Braune, B. M. Prevalence of longchained perfluorinated carboxylates in seabirds from the canadian arctic between 1975 and 2004. Environmental Science \& Technology 2007, 41, 3521-3528.

(41) Holmström, K. E.; Johansson, A.-K.; Bignert, A.; Lindberg, P.; Berger, U. Temporal trends of perfluorinated surfactants in Swedish peregine falcon eggs (Falco peregrinus), 1974-2007. Environmental Science \& Technology 2010, 44, 4083-4088.

(42) Ahrens, L.; Herzke, D.; Huber, S.; Bustnes, J. O.; Bangjord, G.; Ebinghaus, R. Temporal trends and patterns of perfluoroalkyl compounds in tawny owl (Strix aluco) eggs from Norway, 1986-2009. Environmental Science \& Technology 2011, doi: $10.1021 /$ es $103473 \mathrm{v}$. 
(43) Newsted, J. L.; Beach, S. A.; Gallagher, S. P.; Giesy, J. P. Pharmacokinetics and acute lethality of perfluorooctanesulfonate (PFOS) to juvenile mallard and northern bobwhite. Archives of Environmental Contamination and Toxicology 2006, 50, 411-420.

(44) Molina, E. D.; Balander, R.; Fitzgerald, S. D.; Giesy, J. P.; Kannan, K.; Mitchell, R.; Bursian, S. J. Effects of Air Cell Injection of Perfluorooctane Sulfonate Before Incubation on DEvelopment of teh White Leghorn Chicken. (Gallus Domesticus) Embryo Environmental Toxicology and Chemistry 2006, 25, 227-232.

(45) O'Brien, J. M.; Carew, A. C.; Chu, S. G.; Letcher, R. J.; Kennedy, S. W. Perfluorooctane sulfonate (PFOS) toxicity in domestic chicken (Gallus domesticus) embryos in the absence of effects on peroxisome proliferator activated receptor alpha (PPARá)-regulated genes. Comparative Biochemistry and Physiology Part C 2009, 149, 524-530.

(46) O'Brien, J. M.; Crump, D.; Mundy, L. J.; Chu, S. G.; McLaren, K. K.; Vongphachan, V.; Letcher, R. J.; Kennedy, S. W. Pipping success and liver mRNA expression in chicken embryos exposed in ovo to $\mathrm{C}_{8}$ and $\mathrm{C}_{11}$ perfluorinated carboxylic acids and $\mathrm{C}_{10}$ perfluorinated sulfonate. Toxicology Letters 2009, 190, 134-139.

(47) Vongphachan, V.; Cassone, C. G.; Wu, D.; Chiu, S.; Crump, D.; Kennedy, S. W. Effects of Perfluoroalkyl Compounds on mRNA Expression Levels of Thyroid Hormone-Responsive Genes in Primary Cultures of Avian Neuronal Cells. Toxicological Sciences 2011, 120, 392-402.

(48) O'Brien, J. M.; Austin, A. J.; Williams, A.; Yauk, C. L.; Crump, D.; Kennedy, S. W. Technical grade PFOS alters the expression of more transcripts in cultured chicken embryonic hepatocytes than linear PFOS. Environmental Toxicology and Chemistry 2011, Submitted.

(49) Hebert, C. E.; Norstrom, R. J.; Weseloh, D. V. A quarter century of environmental surveillance: The Canadian Wildlife Service's Great Lakes Herring Gull Monitoring Program. Environmental Reviews 1999, 7, 147-166.

(50) Pekarik, C.and Weseloh, D. V. Organochlorine contaminants in herring gull eggs from the Great Lakes, 1974-1995: Change point regression analysis and shortterm regression. Environmental Monitoring and Assessment 1998, 53, 77-1 15.

(51) Weseloh, D. V. C.; Pekarik, C.; De Solla, S. R. Spatial patterns and rankings of contaminant concentrations in Herring Gull eggs from 15 sites in the Great Lakes and connecting channels, 1998-2002. Environmental Monitoring and Assessment 2006, 113, 265-284.

(52) Norstrom, R. J.; Simon, M.; Moisey, J.; Wakeford, B.; Weseloh, D. V. C. Geographical distribution (2000) and temporal trends (1981-2000) of brominated 
diphenyl ethers in Great Lakes herring gull eggs. Environmental Science and Technology 2002, 36, 4783-4789.

(53) Gauthier, L. T.; Hebert, C. E.; Weseloh, D. V.; Letcher, R. J. Current-use flame retardants in the eggs of herring gulls (Larua argentatus) from the Laurentian Great Lakes. Environmental Science \& Technology 2007, 41, 4561-4567.

(54) Gauthier, L. T.; Hebert, C. E.; Weseloh, D. V.; Letcher, R. J. Dramatic changes in the temporal trends of polybrominated diphenyl ethers (PBDEs) in herring gull eggs from the Laurentian Great Lakes: 1982-2006. Environmental Science \& Technology 2008, 42, 1524-1530.

(55) Gauthier, L. T.; Potter, D.; Hebert, C. E.; Letcher, R. J. Temporal Trends and Spatial Distribution of Non-polybrominated Diphenyl Ether Flame Retardants in the Eggs of Colonial Populations of Great Lakes Herring Gulls. Environmental Science \& Technology 2009, 43, 312-317.

(56) Fox, G. A.; Allan, L. J.; Weseloh, D. V.; Mineau, P. The diet of herring gulls during the nesting period in Canadian waters of the Great Lakes. Canadian Journal of Zoology 1990, 68, 1075-1085.

(57) Ewins, P. J.; Weseloh, D. V.; Groom, J. H.; Dobos, R. Z.; Mineau, P. The Diet of Herring-Gulls (Larus-Argentatus) During Winter and Early Spring on the Lower Great-Lakes. Hydrobiologia 1994, 280, 39-55.

(58) Kelly, J. F. Stable isotopes of carbon and nitrogen in the study of avian and mammalian trophic ecology. Canadian Journal of Zoology 2000, 78, 1-27.

(59) Bearhop, S.; Thompson, D. R.; Waldron, S.; Russell, I. C.; Alexander, G.; Furness, R. W. Stable isotopes indicate the extent of freshwater feeding by cormorants Phalacrocorax carbo shot at inland fisheries in England. Journal of Applied Ecology 1999, 36, 75-84.

(60) Hebert, C. E.; Shutt, J. L.; Hobson, K. A.; Weseloh, D. V. C. Spatial and temporal differences in the diet of Great Lakes herring gulls (Larus argentatus): evidence from stable isotope analysis. Canadian Journal Of Fisheries and Aquatic Sciences 1999, 56, 323-338.

(61) Hebert, C. E.; Weseloh, D. V. C.; Idrissi, A.; Arts, M. T.; O'Gorman, R.; Gorman, O. T.; Locke, B.; Madenjian, C. P.; Roseman, E. F. Restoring Piscivorous Fish Populations in the Laurentian Great Lakes Causes Seabird Dietary Change. Ecology 2008, 89, 891-897.

(62) Hebert, C. E. and Weseloh, D. V. C. Adjusting for temporal change in trophic position results in reduced rates of contaminant decline. Environmental Science \& Technology 2006, 40, 5624-5628. 
(63) Taniyasu, S.; Kannan, K.; So, M. K.; Gulkowska, A.; Sinclair, E.; Okazawa, T.; Yamashita, N. Analysis of fluorotelomer alcohols, fluorotelorner acids, and shortand long-chain perfluorinated acids in water and biota. Journal of Chromatography A 2005, 1093, 89-97.

(64) Chu, S. G.and Letcher, R. J. Analysis of fluorotelomer alcohols and perfluorinated sulfonamides in biotic samples by liquid chromatographyatmospheric pressure photoionization mass spectrometry. Journal of Chromatography A 2008, 1215, 92-99.

(65) Hebert, C. E.; Arts, M. T.; Weseloh, D. V. C. Ecological Tracers Can Quantify Food Web Structure and Change. Environmental Science \& Technology 2006, 40, $5618-5623$.

(66) Clark, T. P.; Norstrom, R. J.; Fox, G. A.; Won, H. T. Dynamics of organochlorine compounds in herring gulls (Larus argentatus): II A two-compartment model and data for ten compounds. Environmental Toxicology and Chemistry 1987, 6, 547559 .

(67) Hoysak, D. J.and Weatherhead, P. J. Sampling blood from birds: A technique and an assessment of its effect. The Condor 1991, 93, 746-752.

(68) Yu, W.-G.; Liu, W.; Liu, L.; Jin, Y.-H. Perfluorooctane sulfonate increased hepatic expression of OAPT2 and MRP2 in rats. Archives of Toxicology 2011, 85, 613-621.

(69) Ehresman, D. J.; Froehlich, J. W.; Olsen, G. W.; Chang, S.-C.; Butenhoff, J. L. Comparison of human whole blood, plasma, and serum matrices for the determination of perfluorooctanesulfonate (PFOS), perfluorooctanoate (PFOA), and other fluorochemicals. Environmental Research 2007, 103, 176-184.

(70) Zoeller, R. T.; Dowling, A. L. S.; Herzig, C. T. A.; lannacone, E. A.; Gauger, K. J.; Bansal, R. Thyroid Hormone, Brain Development, and the Environment. Environmental Health Perspectives 2002, 110, 355-361.

(71) Meyer, J.; Jaspers, V. L. B.; Eens, M.; De Coen, W. The relationship between perfluorinated chemical levels in the feathers and livers of birds from different trophic levels. Science of the Total Environment 2009, 407, 5894-5900.

(72) Verreault, J.; Berger, U.; Gabrielsen, G. W. Trends of perfluorinated alkyl substances in herring gull eggs from two coastal colonies in Nothern Norway: 1983-2003. Environmental Science \& Technology 2007, 41, 6671-6677.

(73) Löfstrand, K.; Jörundsdóttir, H.; Tomy, G. T.; Svavarsson, J.; Weihe, P.; Nygård, T.; Bergman, Å. Spatial trends of polyfluorinated compounds in guillemot (Uria aalge) eggs from North-Western Europe. Chemosphere 2009, 72, 1475-1480. 
(74) Hebert, C. E. Winter severity affects migration and contaminant accumulation in northern Great Lakes Herring Gulls. Ecological Applications 1998, 8, 669-679.

(75) Canadian Ice Service, E. C. Latest, Past \& Future Ice Conditions - Great Lakes http://ice-glaces. ec. gc. ca/App/WsvPageDsp. cfm? Lang=eng\&lnid $=37 \& S c n d L v l=n o \& I D=11890$

(76) Butt, C. M.; Stock, N. L.; Mabury, S. A.; Muir, D. C. G.; Braune, B. M. Spatial and temporal trends of perfluoroalkyl substances in ringed seals and seabirds (Northern flumar and thick-billed murre) from the Canadian Arctic. Presented at FLUOROS, Toronto, ON, Aug. 19-20 2004.

(77) Yoo, H.; Kannan, K.; Kim, S. K.; Lee, K. T.; Newsted, J. L.; Giesy, J. P. Perfluoroalkyl Acids in the Egg Yolk of Birds from Lake Shihwa, Korea. Environmental Science \& Technology 2008, 42, 5821-5827.

(78) Wang, Y.; Yeung, L. W. Y.; Taniyasu, S.; Yamashita, N.; Lam, J. C. W.; Lam, P. K. S. Perfluorooctane Sulfonate and Other Fluorochemicals in Waterbird Eggs from South China. Environmental Science \& Technology 2008, 42, 8146-8151.

(79) Hebert, C. E.; Shutt, J. L.; Norstrom, R. J. Dietary changes cause temporal fluctuations in polychlorinated biphenyl levels in herring gull eggs from Lake Ontario. Environmental Science \& Technology 1997, 31, 1012-1017.

(80) Hebert, C. E.; Weseloh, D. V. C.; Gauthier, L. T.; Arts, M. T.; Letcher, R. J. Biochemical tracers reveal intra-specific differences in the food webs utilized by individual seabirds. Oecologia 2009, 160, 15-23.

(81) Smithwick, M.; Mabury, S. A.; Solomon, K. R.; Sonne, C.; Martin, J. W.; Born, E. W.; Dietz, R.; Derocher, A. E.; Letcher, R. J.; Evans, T. J.; Gabrielsen, G. W.; Nagy, J.; Stirling, I.; Taylor, M. K.; Muir, D. C. G. Circumpolar study of perfluoroalkyl contaminants in polar bears (Ursus maritimus) Environmental Science and Technology 2005, 39, 5517-5523.

(82) Letcher, R. J.; Bustnes, J. O.; Dietz, R.; Jenssen, B. M.; Jørgensen, E. H.; Sonne, C.; Verreault, J.; Vijayan, M.; Gabrielsen, G. W. Exposure and effects assessment of persistent organic pollutants in Arctic wildlife and fish. Science of the Total Environment 2010, 408, 2995-3043.

(83) Karrman, A.; Langlois, I,; Van Bavel, B.; Lindstrom, G.; Oehme, M. Identification and pattern of perfluorooctane sulfonate (PFOS) isomers in human serum and plasma. Environment International 2007, 33, 782-788.

(84) Powley, C. R.; George, S. W.; Russell, M. H.; Hoke, R. A.; Buck, R. C. Polyfluorinated chemicals in a spatially and temporally integrated food web in the Western Arctic. Chemosphere 2008, 70, 664-672. 
(85) Benskin, J. P.; De Silva, A. O.; Martin, L. J.; Arsenault, G.; McCrindle, R.; Riddell, N.; Mabury, S. A.; Martin, J. W. Disposition of Perfluorinated Acid Isomers in Sprague-Dawley Rats; Part 1: Single Dose. Environmental Toxicology and Chemistry 2009, 28, 542-554.

(86) De Silva, A. O.; Benskin, J. P.; Martin, L. J.; Arsenault, G.; McCrindle, R.; Riddell, N.; Martin, J. W.; Mabury, S. A. Disposition of Perfluorinated Acid Isomers in Sprague-Dawley Rats; Part 2: Subchronic Dose. Environmental Toxicology and Chemistry 2009, 28, 555-567.

(87) O'Brien, J. M.; Kennedy, S. W.; Chu, S. G.; Letcher, R. J. Hepatic enrichment of the linear isomer in chicken embryos (Gallus gallus domesticus) exposed in ovo to a technical mixture of perfluorooctane sulfonate (PFOS). Environmental Toxicology and Chemistry $\mathbf{2 0 1 0 ,}$

(88) Post, D. M. Using Stable Isotopes to Estimate Trophic Position: Models, Methods, and Assumptions. Ecology 2002, 83, 703-718.

(89) Vander Zanden, M. J.and Rasmussen, J. B. Primary consumers $\delta 13 \mathrm{C}$ and $\delta 15 \mathrm{~N}$ and the trophic position of aquatic consumers. Ecology 1999, 80, 1395-1404.

(90) Sharp, C. M.; Abraham, K. F.; Burness, G. Embryo development influences the isotopic signatures of egg components in incubated eggs. The Condor 2009, 111, $361-365$.

(91) Pierotti, R. J.and Good, T. P. Herring gulls (Larus argentatus) In: Poole A., editor. The birds of North America online: 1996.

http://bna.birds.cornell.edu/bna/species/124 doi: 10.2173/bna.125.

(92) Ryder, J. P. Ring-billed gulls (Larus delawarensis) In: Poole A., editor. The birds of North America online: 1993. http://bna.birds.cornell.edu/bna/species/033 doi: 10.2173/bna.33.

(93) Belant, J. L.; Ickes, S. K.; Seamans, T. W. Importance of landfills to urbannesting herring and ring-billed gulls. Landscape and Urban Planning 1998, 43, 11-19.

(94) Jardine, T. D.; Kidd, K. A.; Fisk, A. T. Applications, Considerations, and Sources of Uncertainty When Using Stable Isotope Analysis in Ecotoxicology.

Environmental Science \& Technology 2006, 40, 7501-7511.

(95) Boutton, T. W. Stable carbon isotope ratios of natural materiala: II. atmospheric, terrestrial, marine, and freshwater environments. In: Coleman D.C., Fry B., editors Carbon isotope techniques. San Diego : Academic Press Inc., 1991. 173183.

(96) Vermeer, K. Comparison of the Diet of the Glaucous-Winged Gull on the East and West Coasts of Vancouver Island. The Murrelet 1982, 63, 80-85. 
(97) Rail, J.-F.and Chapdelaine, G. Diet of herring gull (Larus argentatus) chicks in the Gulf and Estuary of the St Lawrence River, Quebec. Atlantic Seabirds 2000, $2,19-34$.

(98) Chapdelaine, G.and Rail, J.-F. Relationship between cod fishery activities and the population of herring gulls on the North Shore of the Gulf of St Lawrence, Quebec, Canada. Journal of Marine Science 1997, 54, 708-713.

(99) Robertson, G. J.; Fifield, D.; Massaro, M.; Chardine, J. W. Changes in nestinghabitat use of large gulls breeding in Witless Bay, Newfoundland. Canadian Journal of Zoology 2001, 79, 2159-2167.

(100) Hobson, K. A.; Hughes, K. D.; Ewins, P. J. Using Stable-Isotope Analysis to Identify Endogenous and Exogenous Sources of Nutrients in Eggs of Migratory Birds: Applications to Great Lakes Contaminants Research. The Auk 1997, 114, 467-478.

(101) Winkler, D. W. California Gull (Larus californicus). In: Poole A., editor. The birds of North America online: 1996. http://bna.birds.cornell.edu/bna/species/259 doi: $10.2173 /$ bna.259.

(102) Fox, G. A.; Grasman, K. A.; Hobson, K. A.; Williams, K.; Jeffrey, D.; Hanbidge, $\mathrm{B}$. Contaminant residues in tissues of adult and prefledged herring gulls from the Great Lakes in relation to diet in the early 1990s. Journal of Great Lakes Research 2002, 28, 643-663.

(103) Vermeer, K. Food Habits and Breeding Range of Herring Gulls in the Canadian Prairie Provinces. The Condor 1973, 75, 478-480.

(104) Brousseau, P.; Lefebvre, J.; Giroux, J. F. Diet of Ring-Billed Gull Chicks in Urban and Non-urban Colonies in Quebec. Colonial Waterbirds 1996, 19, 22-30.

(105) deBruyn, A. M. H.; Marcogliese, D. J.; Rasmussen, J. B. The role of sewage in a large river food web. Canadian Journal Of Fisheries and Aquatic Sciences 2003, $60,1332-1344$.

(106) Braune, B. M.; Mallory, M. L.; Butt, C. M.; Mabury, S. A.; Muir, D. C. G. Persistent halogenated organic contaminants and mercury in northern fulmars (Fulmarus glacialis) from the Canadian Arctic. Environmental Pollution 2010, $158,3513-3519$.

(107) D'Eon, J. C.and Mabury, S. A. Production of perfluorinated carboxylic acids (PFCAs) from the biotransformation of polyfluoroalkyl phosphate surfactants (PAPS): exploring routes of human contamination. Environmental Science \& Technology 2007, 41, 4799-4805. 
(108) Elliot, K. H.; Cesh, L. S.; Dooley, J. A.; Letcher, R. J.; Elliot, J. E. PCBs and DDE, but not PBDEs, increase with trophic level and marine input in nestling bald eagles. Science of the Total Environment 2009, 407, 3867-3875. 


\section{Appendix A}

Arithmetic mean concentrations (ng/g ww $\pm \mathrm{SE}$ ), range of concentrations and detection frequency of detectable PFSAs and PFCAs in herring gull tissues, blood and eggs collected in 2010 from Chantry Island, Lake Huron.

\begin{tabular}{|c|c|c|c|c|c|c|c|c|c|c|c|c|c|c|}
\hline & & PFHXS & PFOS & PFDS & PFHXA & PFHpA & PFOA & PFNA & PFDA & PFUnA & PFDoA & PFTrA & PFTEA & PFPA \\
\hline \multirow[t]{3}{*}{ Yolk } & mean $\pm S E$ & $18 \pm 04$ & $251 \pm 29$ & $58 \pm 08$ & & & $16 \pm 01$ & $45 \pm 06$ & $100 \pm 13$ & $126 \pm 20$ & $148 \pm 14$ & $266 \pm 32$ & $134 \pm 10$ & $46 \pm 04$ \\
\hline & $\min -\max$ & $08-75$ & $82-745$ & $18-131$ & $<010-014$ & $<010-024$ & 097.29 & $21-93$ & $29-197$ & 47.324 & 63.240 & $138-630$ & $75-222$ & $26-92$ \\
\hline & Detection frequency & $17 / 17$ & $17 / 17$ & $17 / 17$ & $5 / 17$ & $5 / 17$ & $17 / 17$ & $17 / 17$ & $17 / 17$ & $17 / 17$ & $17 / 17$ & 17117 & 17117 & $17 / 17$ \\
\hline \multirow[t]{3}{*}{ Liver } & mean $\pm S E$ & $055 \pm 014$ & $845 \pm 159$ & $043 \pm 011$ & & & $06 \pm 02$ & $14 \pm 04$ & $16 \pm 05$ & $12 \pm 04$ & & & & \\
\hline & $\min -\max$ & $<005-16$ & $11-197$ & $005 \cdot 146$ & $<010$ & $<010$ & $<010-20$ & 015.32 & $01-40$ & $01-36$ & $<010-01$ & $<010-08$ & $<005-16$ & $<005$ \\
\hline & Detection frequency & $7 / 8$ & $8 / 8$ & $8 / 8$ & $0 / 8$ & $0 / 8$ & 718 & 818 & $8 / 8$ & $8 / 8$ & $1 / 8$ & $3 / 8$ & $3 / 8$ & $0 / 8$ \\
\hline \multirow[t]{3}{*}{ Plasma } & mean $\pm S E$ & $22 \pm 08$ & $266 \pm 74$ & & & $033 \pm 012$ & $19 \pm 06$ & $12 \pm 02$ & $13 \pm 05$ & $13 \pm 04$ & $08 \pm 03$ & $14 \pm 03$ & $05 \pm 03$ & \\
\hline & $\min -\max$ & $03-67$ & $62-729$ & $<005-12$ & $<010-012$ & $<010 \cdot 10$ & 06.53 & $04-23$ & $010-40$ & $06-38$ & $<010 \cdot 27$ & $05-30$ & $<005-21$ & $<005$ \\
\hline & Detection frequency & $8 / 8$ & $8 / 8$ & $3 / 8$ & $2 / 8$ & $6 / 8$ & $8 / 8$ & 818 & $8 / 8$ & $8 / 8$ & $7 / 8$ & 818 & 718 & $0 / 8$ \\
\hline \multirow[t]{3}{*}{$\mathrm{RBC}$} & mean $\pm S E$ & & $61 \pm 18$ & & & & $027 \pm 007$ & $007 \pm 004$ & & $03 \pm 02$ & & & & \\
\hline & $\min -\max$ & $<005-03$ & $14-165$ & $<005.01$ & $<010$ & $<010$ & $01-07$ & $<005-029$ & $<010-03$ & $<010 \cdot 15$ & $<010$ & $<010$ & $<005-04$ & $<005$ \\
\hline & Detection frequency & 218 & $8 / 8$ & $1 / 8$ & $0 / 8$ & $0 / 8$ & $8 / 8$ & $5 / 8$ & $1 / 8$ & $7 / 8$ & $0 / 8$ & $0 / 8$ & $1 / 8$ & $0 / 8$ \\
\hline \multirow[t]{3}{*}{ Brain } & mean $\pm S E$ & & $44 \pm 08$ & $06 \pm 01$ & & & & & $03 \pm 01$ & $09 \pm 03$ & $15 \pm 02$ & $84 \pm 12$ & $59 \pm 06$ & $53 \pm 07$ \\
\hline & $\min -\max$ & $<005.01$ & $14-83$ & $02-10$ & $<010$ & $<010$ & $<010.007$ & $<005$ & $01-06$ & $04-26$ & $08-24$ & $56-150$ & $32-86$ & 26.93 \\
\hline & Detection frequency & $1 / 8$ & $8 / 8$ & $8 / 8$ & $0 / 8$ & $0 / 8$ & $4 / 8$ & $0 / 8$ & $8 / 8$ & $8 / 8$ & $8 / 8$ & $8 / 8$ & $8 / 8$ & $8 / 8$ \\
\hline \multirow[t]{3}{*}{ Muscle } & mean $\pm S E$ & & $91 \pm 42$ & & & & & & & & & & & \\
\hline & $\min -\max$ & $<005-011$ & $12-375$ & $<005-014$ & $<010$ & $<010$ & $<010-025$ & $<005-011$ & $<010-018$ & $<010.051$ & $<010$ & $<010$ & $<005$ & $<005$ \\
\hline & Detection frequency & $4 / 8$ & 818 & $2 / 8$ & $0 / 8$ & $0 / 8$ & $4 / 8$ & $2 / 8$ & $3 / 8$ & $3 / 8$ & $0 / 8$ & $0 / 8$ & $0 / 8$ & $0 / 8$ \\
\hline \multirow[t]{3}{*}{ Adipose } & mean $\pm S E$ & & $179 \pm 83$ & & & & & & & & & & & \\
\hline & $\min -\max$ & $<005-096$ & $26-576$ & $<005$ & $<010$ & $<010$ & $<010$ & $<005-022$ & $<010$ & $<010-073$ & $<010$ & $<010$ & $<005$ & $<005$ \\
\hline & Detection frequency & $3 / 8$ & $8 / 8$ & $0 / 8$ & $0 / 8$ & $0 / 8$ & $0 / 8$ & $3 / 8$ & $0 / 8$ & $5 / 8$ & $0 / 8$ & $0 / 8$ & $0 / 8$ & $0 / 8$ \\
\hline
\end{tabular}




\section{Appendix B}

Arithmetic mean concentrations (ng/g ww \pm SE), range of concentrations and detection frequency of detectable PFSAs, PFCAs, and PFOSA in herring gull eggs collected in 2007 from 15 colonies in the Great Lakes.

\begin{tabular}{|c|c|c|c|c|c|c|c|c|c|c|c|c|c|}
\hline Colony & & PFHxS & PFOS & PFDS & PFOSA & PFOA & PFNA & PFDA & PFUnA & PFDoA & PFTrA & PFTeA & PFPA \\
\hline \multirow[t]{2}{*}{ Granite is } & mean $\pm \mathrm{SE}$ & & $126 \pm 20$ & $11 \pm 02$ & $008 \pm 001$ & $10 \pm 02$ & $90 \pm 19$ & $77 \pm 11$ & $130 \pm 16$ & $39 \pm 05$ & $101 \pm 09$ & $11 \pm 02$ & \\
\hline & $\begin{array}{l}\text { mın - max } \\
\text { Detection } \\
\text { frequency }\end{array}$ & $\begin{array}{c}<005-030 \\
3 / 13 \\
\end{array}$ & $\begin{array}{c}49-334 \\
13 / 13 \\
\end{array}$ & $\begin{array}{c}04-39 \\
13 / 13 \\
\end{array}$ & $\begin{array}{c}002 \cdot 014 \\
7 / 13 \\
\end{array}$ & $\begin{array}{c}036-33 \\
13 / 13 \\
\end{array}$ & $\begin{array}{c}18-341 \\
13 / 13 \\
\end{array}$ & $\begin{array}{c}23-218 \\
13 / 13 \\
\end{array}$ & $\begin{array}{c}34-310 \\
13 / 13 \\
\end{array}$ & $\begin{array}{c}05-92 \\
13 / 13 \\
\end{array}$ & $\begin{array}{c}37.168 \\
13 / 13 \\
\end{array}$ & $\begin{array}{c}<005-23 \\
12 / 13\end{array}$ & $\begin{array}{c}<005-079 \\
5 / 13\end{array}$ \\
\hline \multirow[t]{2}{*}{ Agawa Rocks } & mean $\pm S E$ & & $904 \pm 125$ & $10 \pm 02$ & $005 \pm 001$ & $051 \pm 003$ & $96 \pm 06$ & $86 \pm 07$ & $201 \pm 16$ & $65 \pm 05$ & $229 \pm 15$ & $29 \pm 02$ & $13 \pm 02$ \\
\hline & $\begin{array}{l}\min -\max \\
\text { Detection } \\
\text { frequency }\end{array}$ & $\begin{array}{c}<005-014 \\
6 / 13 \\
\end{array}$ & $\begin{array}{c}41-207 \\
13 / 13 \\
\end{array}$ & $\begin{array}{c}028-32 \\
13 / 13 \\
\end{array}$ & $\begin{array}{c}<00005-009 \\
12 / 13\end{array}$ & $\begin{array}{c}039-075 \\
13 / 13 \\
\end{array}$ & $\begin{array}{c}52-143 \\
13 / 13 \\
\end{array}$ & $\begin{array}{c}39-141 \\
13 / 13 \\
\end{array}$ & $\begin{array}{c}90-354 \\
13 / 13 \\
\end{array}$ & $\begin{array}{c}24-109 \\
13 / 13 \\
\end{array}$ & $\begin{array}{c}106-326 \\
13 / 13 \\
\end{array}$ & $\begin{array}{c}12-43 \\
13 / 13 \\
\end{array}$ & $\begin{array}{c}015-31 \\
13 / 13 \\
\end{array}$ \\
\hline \multirow[t]{2}{*}{ Big Sister Is } & mean $\pm \mathrm{SE}$ & & $208 \pm 25$ & $36 \pm 04$ & $028 \pm 005$ & $12 \pm 04$ & $31 \pm 03$ & $115 \pm 15$ & $136 \pm 19$ & $213 \pm 19$ & $154 \pm 22$ & $54 \pm 10$ & $051 \pm 019$ \\
\hline & $\begin{array}{l}\text { min - max } \\
\text { Detection } \\
\text { frequency }\end{array}$ & $\begin{array}{c}<005-010 \\
4 / 13\end{array}$ & $\begin{array}{c}83-390 \\
13 / 13 \\
\end{array}$ & $\begin{array}{c}19-67 \\
13 / 13 \\
\end{array}$ & $\begin{array}{c}005-090 \\
13 / 13 \\
\end{array}$ & $\begin{array}{c}05-74 \\
13 / 13 \\
\end{array}$ & $\begin{array}{c}09-56 \\
13 / 13 \\
\end{array}$ & $\begin{array}{c}20-240 \\
13 / 13 \\
\end{array}$ & $\begin{array}{c}26-326 \\
13 / 13 \\
\end{array}$ & $\begin{array}{c}16-324 \\
13 / 13 \\
\end{array}$ & $\begin{array}{c}31-311 \\
13 / 13 \\
\end{array}$ & $\begin{array}{c}04-138 \\
13 / 13 \\
\end{array}$ & $\begin{array}{c}<005-22 \\
7 / 13\end{array}$ \\
\hline \multirow[t]{2}{*}{ Gull Is } & mean $\pm S E$ & & $176 \pm 17$ & $22 \pm 05$ & $010 \pm 010$ & & $21 \pm 032$ & $41 \pm 06$ & $79 \pm 16$ & $32 \pm 06$ & $103 \pm 18$ & $15 \pm 04$ & \\
\hline & $\begin{array}{l}\text { min - max } \\
\text { Detection } \\
\text { frequency }\end{array}$ & $\begin{array}{c}<005-007 \\
3 / 13 \\
\end{array}$ & $\begin{array}{c}92-287 \\
13 / 13 \\
\end{array}$ & $\begin{array}{c}<005-57 \\
12 / 13\end{array}$ & $\begin{array}{c}<0005-022 \\
13 / 13 \\
\end{array}$ & $\begin{array}{l}<010 \\
0 / 13 \\
\end{array}$ & $\begin{array}{c}015-418 \\
13 / 13\end{array}$ & $\begin{array}{c}07-74 \\
13 / 13 \\
\end{array}$ & $\begin{array}{c}17-230 \\
13 / 13 \\
\end{array}$ & $\begin{array}{c}010.73 \\
13 / 13 \\
\end{array}$ & $\begin{array}{c}25-285 \\
13 / 13 \\
\end{array}$ & $\begin{array}{c}005-44 \\
13 / 13 \\
\end{array}$ & $\begin{array}{c}<005-49 \\
5 / 13\end{array}$ \\
\hline \multirow[t]{2}{*}{ Channel-Shelter is } & mean $\pm S E$ & & $206 \pm 15$ & $209 \pm 33$ & $008 \pm 001$ & & $071 \pm 016$ & $65 \pm 06$ & $125 \pm 13$ & $47 \pm 05$ & $120 \pm 12$ & $28 \pm 04$ & $12 \pm 03$ \\
\hline & $\begin{array}{l}\text { men - max } \\
\text { Detection } \\
\text { frequency }\end{array}$ & $\begin{array}{l}<005 \\
0 / 13 \\
\end{array}$ & $\begin{array}{c}128-304 \\
13 / 13 \\
\end{array}$ & $\begin{array}{c}35-478 \\
13 / 13 \\
\end{array}$ & $\begin{array}{c}001-019 \\
13 / 13\end{array}$ & $\begin{array}{l}<010 \\
0 / 13 \\
\end{array}$ & $\begin{array}{c}<010-227 \\
12 / 13\end{array}$ & $\begin{array}{c}30-104 \\
13 / 13 \\
\end{array}$ & $\begin{array}{c}65-258 \\
13 / 13 \\
\end{array}$ & $\begin{array}{c}18-104 \\
13 / 13 \\
\end{array}$ & $\begin{array}{c}72-228 \\
13 / 13 \\
\end{array}$ & $\begin{array}{c}05-65 \\
13 / 13 \\
\end{array}$ & $\begin{array}{c}<005-41 \\
10 / 13\end{array}$ \\
\hline \multirow[t]{2}{*}{ Double is } & mean $\pm S E$ & $035 \pm 011$ & $226 \pm 24$ & $11 \pm 01$ & $019 \pm 003$ & $26 \pm 04$ & $162 \pm 19$ & $196 \pm 23$ & $279 \pm 30$ & $117 \pm 13$ & $285 \pm 39$ & $46 \pm 07$ & $20 \pm 04$ \\
\hline & $\begin{array}{l}\text { min - max } \\
\text { Detection } \\
\text { frequency }\end{array}$ & $\begin{array}{c}<005-12 \\
9 / 13 \\
\end{array}$ & $\begin{array}{c}114-436 \\
13 / 13 \\
\end{array}$ & $\begin{array}{c}055-20 \\
13 / 13 \\
\end{array}$ & $\begin{array}{c}<0005-041 \\
9 / 13\end{array}$ & $\begin{array}{c}094-64 \\
13 / 13 \\
\end{array}$ & $\begin{array}{c}89-380 \\
13 / 13 \\
\end{array}$ & $\begin{array}{c}103 \cdot 454 \\
13 / 13 \\
\end{array}$ & $\begin{array}{c}170 \cdot 504 \\
13 / 13 \\
\end{array}$ & $\begin{array}{c}64-233 \\
13 / 13 \\
\end{array}$ & $\begin{array}{c}125-628 \\
13 / 13 \\
\end{array}$ & $\begin{array}{c}01.106 \\
13 / 13 \\
\end{array}$ & $\begin{array}{c}<005-63 \\
12 / 13\end{array}$ \\
\hline \multirow[t]{2}{*}{ Chantry is } & mean $\pm S E$ & $023 \pm 007$ & $158 \pm 37$ & $15 \pm 05$ & $003 \pm 001$ & $045 \pm 008$ & $21 \pm 04$ & $40 \pm 09$ & $61 \pm 16$ & $35 \pm 08$ & $128 \pm 27$ & $26 \pm 07$ & \\
\hline & $\begin{array}{l}\text { min - max } \\
\text { Detection } \\
\text { frequency }\end{array}$ & $\begin{array}{c}<005-10 \\
10 / 13\end{array}$ & $\begin{array}{c}29-456 \\
13 / 13 \\
\end{array}$ & $\begin{array}{c}<005-56 \\
10 / 13 \\
\end{array}$ & $\begin{array}{c}002-006 \\
13 / 13\end{array}$ & $\begin{array}{c}006-12 \\
13 / 13 \\
\end{array}$ & $\begin{array}{c}017-49 \\
13 / 13\end{array}$ & $\begin{array}{c}014-106 \\
13 / 13 \\
\end{array}$ & $\begin{array}{c}09-199 \\
13 / 13 \\
\end{array}$ & $\begin{array}{c}<010-92 \\
11 / 13\end{array}$ & $\begin{array}{c}32-376 \\
13 / 13 \\
\end{array}$ & $\begin{array}{c}<005-81 \\
11 / 13\end{array}$ & $\begin{array}{c}<005-33 \\
7 / 13\end{array}$ \\
\hline \multirow[t]{2}{*}{ Fighting is } & mean $\pm S E$ & & $253 \pm 45$ & $106 \pm 19$ & $012 \pm 002$ & & $064 \pm 023$ & $78 \pm 12$ & $117 \pm 19$ & $106 \pm 16$ & $172 \pm 26$ & $74 \pm 11$ & $27 \pm 07$ \\
\hline & $\begin{array}{l}\text { min - max } \\
\text { Detection } \\
\text { frequency }\end{array}$ & $\begin{array}{c}<005-15 \\
5 / 13\end{array}$ & $\begin{array}{c}82-720 \\
13 / 13 \\
\end{array}$ & $\begin{array}{c}38-249 \\
13 / 13 \\
\end{array}$ & $\begin{array}{c}004-026 \\
13 / 13 \\
\end{array}$ & $\begin{array}{l}<010 \\
0 / 13 \\
\end{array}$ & $\begin{array}{c}<010-37 \\
12 / 13\end{array}$ & $\begin{array}{c}37-224 \\
13 / 13 \\
\end{array}$ & $\begin{array}{c}52-342 \\
13 / 13 \\
\end{array}$ & $\begin{array}{c}38-283 \\
13 / 13 \\
\end{array}$ & $\begin{array}{c}84-487 \\
13 / 13 \\
\end{array}$ & $\begin{array}{c}29-177 \\
13 / 13 \\
\end{array}$ & $\begin{array}{c}010-103 \\
13 / 13 \\
\end{array}$ \\
\hline \multirow[t]{2}{*}{ Middle Is } & mean $\pm S E$ & $010 \pm 004$ & $491 \pm 46$ & $151 \pm 15$ & $020 \pm 002$ & & $16 \pm 03$ & $224 \pm 21$ & $250 \pm 23$ & $163 \pm 15$ & $201 \pm 17$ & $65 \pm 07$ & $17 \pm 03$ \\
\hline & $\begin{array}{l}\min -\max \\
\text { Detection } \\
\text { frequency }\end{array}$ & $\begin{array}{c}<005-046 \\
7 / 13\end{array}$ & $\begin{array}{c}227-892 \\
13 / 13\end{array}$ & $\begin{array}{c}67-289 \\
13 / 13\end{array}$ & $\begin{array}{c}009-038 \\
13 / 13\end{array}$ & $\begin{array}{l}<010 \\
0 / 13\end{array}$ & $\begin{array}{c}034-44 \\
13 / 13\end{array}$ & $\begin{array}{c}114-397 \\
13 / 13\end{array}$ & $\begin{array}{c}122-413 \\
13 / 13\end{array}$ & $\begin{array}{c}65-276 \\
13 / 13\end{array}$ & $\begin{array}{c}98-311 \\
13 / 13\end{array}$ & $\begin{array}{c}21-121 \\
13 / 13\end{array}$ & $\begin{array}{c}<005-37 \\
12113\end{array}$ \\
\hline
\end{tabular}




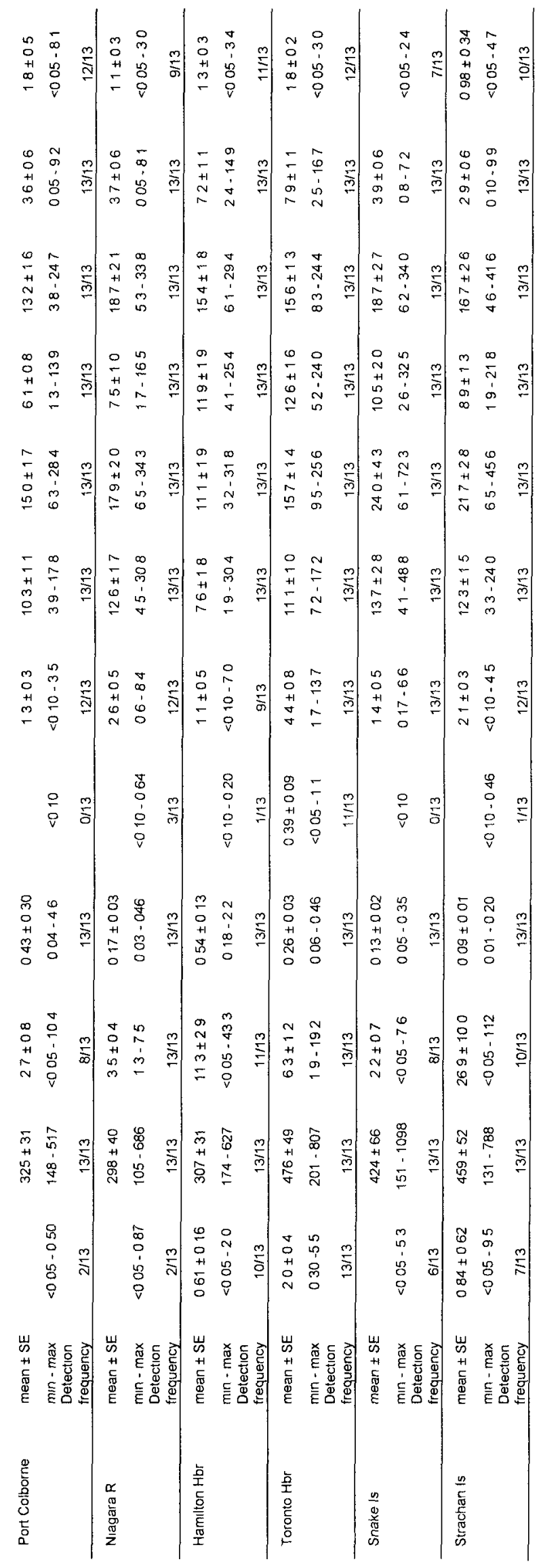




\section{Appendix C}

Arithmetic mean concentrations ( $\mathrm{ng} / \mathrm{g} \mathrm{ww} \pm \mathrm{SE}$ ), range of concentrations and detection frequency of detectable linear and branched PFOS isomers in herring gull eggs collected in 2007 from 15 colonies in the Great Lakes.

\begin{tabular}{|c|c|c|c|c|c|c|c|c|c|c|}
\hline Colony & & L-PFOS & P1MHpS & P2MHpS & P3MHpS & P4MHpS & P5MHpS & P6MHpS & P35DMHxS & P45DMHXS \\
\hline \multirow[t]{2}{*}{ Granite Is } & mean $\pm \mathrm{SE}$ & $141 \pm 21$ & $039 \pm 006$ & $021 \pm 002$ & $088 \pm 014$ & $086 \pm 014$ & $11 \pm 02$ & $33 \pm 06$ & & \\
\hline & $\begin{array}{l}\text { min - max } \\
\text { Detection } \\
\text { frequency }\end{array}$ & $\begin{array}{c}54-365 \\
13 / 13 \\
\end{array}$ & $\begin{array}{c}012-077 \\
13 / 13 \\
\end{array}$ & $\begin{array}{c}009-041 \\
13 / 13 \\
\end{array}$ & $\begin{array}{c}038-26 \\
13 / 13 \\
\end{array}$ & $\begin{array}{c}042-24 \\
13 / 13 \\
\end{array}$ & $\begin{array}{c}056-34 \\
13 / 13 \\
\end{array}$ & $\begin{array}{c}14-108 \\
13 / 13 \\
\end{array}$ & $\begin{array}{l}<005 \\
0 / 13 \\
\end{array}$ & $\begin{array}{l}<020 \\
0 / 13 \\
\end{array}$ \\
\hline \multirow[t]{2}{*}{ Agawa Rocks } & mean $\pm S E$ & $96 \pm 13$ & $016 \pm 002$ & $010 \pm 001$ & $050 \pm 003$ & $051 \pm 003$ & $090 \pm 006$ & $126 \pm 016$ & & \\
\hline & $\begin{array}{l}\min -\max \\
\text { Detection } \\
\text { frequency }\end{array}$ & $\begin{array}{c}38-216 \\
13 / 13 \\
\end{array}$ & $\begin{array}{c}004-035 \\
13 / 13 \\
\end{array}$ & $\begin{array}{c}005-016 \\
13 / 13 \\
\end{array}$ & $\begin{array}{c}036-075 \\
13 / 13 \\
\end{array}$ & $\begin{array}{c}035-076 \\
13 / 13 \\
\end{array}$ & $\begin{array}{c}055-14 \\
13 / 13 \\
\end{array}$ & $\begin{array}{c}035-21 \\
13 / 13 \\
\end{array}$ & $\begin{array}{c}<005-008 \\
2 / 13 \\
\end{array}$ & $\begin{array}{l}<010 \\
0 / 13 \\
\end{array}$ \\
\hline \multirow[t]{2}{*}{ Big Sister Is } & mean $\pm S E$ & $197 \pm 17$ & $082 \pm 009$ & $038 \pm 003$ & $13 \pm 01$ & $13 \pm 01$ & $18 \pm 02$ & $27 \pm 05$ & & \\
\hline & $\begin{array}{l}\text { mın - max } \\
\text { Detection } \\
\text { frequency }\end{array}$ & $\begin{array}{c}133-334 \\
13 / 13 \\
\end{array}$ & $\begin{array}{c}042-18 \\
13 / 13 \\
\end{array}$ & $\begin{array}{c}021-069 \\
13 / 13 \\
\end{array}$ & $\begin{array}{c}077-22 \\
13 / 13 \\
\end{array}$ & $\begin{array}{c}068-21 \\
13 / 13 \\
\end{array}$ & $\begin{array}{c}099-28 \\
13 / 13 \\
\end{array}$ & $\begin{array}{c}<010-69 \\
11 / 13 \\
\end{array}$ & $\begin{array}{c}<005-008 \\
2 / 13 \\
\end{array}$ & $\begin{array}{l}<010 \\
0 / 13 \\
\end{array}$ \\
\hline \multirow[t]{2}{*}{ Gull is } & mean $\pm S E$ & $183 \pm 12$ & $078 \pm 010$ & $031 \pm 005$ & $14 \pm 01$ & $13 \pm 01$ & $22 \pm 02$ & $35 \pm 07$ & & $009 \pm 002$ \\
\hline & $\begin{array}{l}\min -\max \\
\text { Detection } \\
\text { frequency }\end{array}$ & $\begin{array}{c}116-290 \\
13 / 13 \\
\end{array}$ & $\begin{array}{c}<010-12 \\
11 / 13 \\
\end{array}$ & $\begin{array}{c}<020-052 \\
10 / 13\end{array}$ & $\begin{array}{c}089-19 \\
13 / 13 \\
\end{array}$ & $\begin{array}{c}078-19 \\
13 / 13 \\
\end{array}$ & $\begin{array}{c}14-31 \\
13 / 13 \\
\end{array}$ & $\begin{array}{c}<010-017 \\
9 / 13\end{array}$ & $\begin{array}{c}<005-006 \\
3 / 13\end{array}$ & $\begin{array}{c}<010-017 \\
8 / 13\end{array}$ \\
\hline \multirow[t]{2}{*}{$\begin{array}{l}\text { Channel-Shelter } \\
\text { is }\end{array}$} & mean $\pm S E$ & $182 \pm 13$ & $049 \pm 004$ & $019 \pm 002$ & $12 \pm 01$ & $099 \pm 012$ & $15 \pm 02$ & & & \\
\hline & $\begin{array}{l}\min -\max \\
\text { Detection } \\
\text { frequency } \\
\end{array}$ & $\begin{array}{c}86-266 \\
13 / 13 \\
\end{array}$ & $\begin{array}{c}022-073 \\
13 / 13 \\
\end{array}$ & $\begin{array}{c}<010-029 \\
12 / 13 \\
\end{array}$ & $\begin{array}{c}046-25 \\
13 / 13 \\
\end{array}$ & $\begin{array}{c}036-21 \\
13 / 13 \\
\end{array}$ & $\begin{array}{c}045-33 \\
13 / 13 \\
\end{array}$ & $\begin{array}{l}<010 \\
0 / 13 \\
\end{array}$ & $\begin{array}{c}<005-020 \\
6 / 13 \\
\end{array}$ & $\begin{array}{l}<010 \\
0 / 13 \\
\end{array}$ \\
\hline \multirow[t]{2}{*}{ Double Is } & mean $\pm S E$ & $264 \pm 24$ & $055 \pm 006$ & $034 \pm 003$ & $19 \pm 01$ & $18 \pm 01$ & $30 \pm 03$ & $43 \pm 08$ & & \\
\hline & $\begin{array}{l}\min -\max \\
\text { Detection } \\
\text { frequency }\end{array}$ & $\begin{array}{c}145-437 \\
13 / 13 \\
\end{array}$ & $\begin{array}{c}027-11 \\
13 / 13 \\
\end{array}$ & $\begin{array}{c}016-057 \\
13 / 13 \\
\end{array}$ & $\begin{array}{c}11-26 \\
13 / 13 \\
\end{array}$ & $\begin{array}{c}091-24 \\
13 / 13 \\
\end{array}$ & $\begin{array}{r}17-55 \\
13 / 13 \\
\end{array}$ & $\begin{array}{c}008-120 \\
13 / 13 \\
\end{array}$ & $\begin{array}{c}<005-013 \\
4 / 13 \\
\end{array}$ & $\begin{array}{l}<010 \\
0 / 13 \\
\end{array}$ \\
\hline \multirow[t]{2}{*}{ Chantry is } & mean $\pm S E$ & $165 \pm 37$ & $033 \pm 010$ & $016 \pm 003$ & $071 \pm 010$ & $067 \pm 019$ & $062 \pm 011$ & $165 \pm 051$ & & \\
\hline & $\begin{array}{l}\text { min - max } \\
\text { Detectıon } \\
\text { frequency }\end{array}$ & $\begin{array}{c}28-485 \\
13 / 13\end{array}$ & $\begin{array}{c}<010-12 \\
12 / 13\end{array}$ & $\begin{array}{c}005-045 \\
13 / 13\end{array}$ & $\begin{array}{c}021-17 \\
13 / 13\end{array}$ & $\begin{array}{c}013-32 \\
13 / 13\end{array}$ & $\begin{array}{c}014-14 \\
13 / 13\end{array}$ & $\begin{array}{c}<010-54 \\
7 / 13\end{array}$ & $\begin{array}{c}<005-006 \\
6 / 13\end{array}$ & $\begin{array}{l}<010 \\
0 / 13\end{array}$ \\
\hline
\end{tabular}




\begin{tabular}{|c|c|c|c|c|c|c|c|c|c|c|}
\hline \multirow[t]{2}{*}{ Fighting Is } & mean $\pm \mathrm{SE}$ & $253 \pm 37$ & $064 \pm 010$ & $026 \pm 003$ & $11 \pm 01$ & $10 \pm 01$ & $14 \pm 01$ & $35 \pm 06$ & $002 \pm 001$ & \\
\hline & $\begin{array}{l}\text { mın - max } \\
\text { Detection } \\
\text { frequency }\end{array}$ & $\begin{array}{c}99-622 \\
13 / 13 \\
\end{array}$ & $\begin{array}{c}030-16 \\
13 / 13 \\
\end{array}$ & $\begin{array}{c}014-055 \\
13 / 13 \\
\end{array}$ & $\begin{array}{c}057-21 \\
13 / 13 \\
\end{array}$ & $\begin{array}{c}049-19 \\
13 / 13 \\
\end{array}$ & $\begin{array}{c}070-24 \\
13 / 13 \\
\end{array}$ & $\begin{array}{c}070-811 \\
13 / 13 \\
\end{array}$ & $\begin{array}{c}<005-006 \\
9 / 13\end{array}$ & $\begin{array}{l}<010 \\
0 / 13 \\
\end{array}$ \\
\hline \multirow[t]{2}{*}{ Middle is } & mean $\pm \mathrm{SE}$ & $542 \pm 42$ & $13 \pm 01$ & $049 \pm 004$ & $17 \pm 01$ & $13 \pm 01$ & $23 \pm 02$ & $23 \pm 07$ & & \\
\hline & $\begin{array}{l}\min -\max \\
\text { Detection } \\
\text { frequency }\end{array}$ & $\begin{array}{c}155-788 \\
13 / 13 \\
\end{array}$ & $\begin{array}{c}036-22 \\
13 / 13 \\
\end{array}$ & $\begin{array}{c}017.075 \\
12 / 13 \\
\end{array}$ & $\begin{array}{c}094 \cdot 26 \\
13 / 13 \\
\end{array}$ & $\begin{array}{c}069-19 \\
13 / 13 \\
\end{array}$ & $\begin{array}{c}11-36 \\
13 / 13 \\
\end{array}$ & $\begin{array}{c}<010-81 \\
9 / 13 \\
\end{array}$ & $\begin{array}{c}<005-006 \\
2 / 13 \\
\end{array}$ & $\begin{array}{l}<010 \\
0 / 13 \\
\end{array}$ \\
\hline \multirow[t]{2}{*}{ Port Colborne } & mean $\pm \mathrm{SE}$ & $340 \pm 30$ & $11 \pm 02$ & $038 \pm 006$ & $14 \pm 02$ & $11 \pm 01$ & $18 \pm 02$ & $44 \pm 05$ & & \\
\hline & $\begin{array}{l}\min -\max \\
\text { Detection } \\
\text { frequency }\end{array}$ & $\begin{array}{c}191-575 \\
13 / 13 \\
\end{array}$ & $\begin{array}{c}<010-20 \\
12 / 13 \\
\end{array}$ & $\begin{array}{c}<010-045 \\
12 / 13 \\
\end{array}$ & $\begin{array}{c}044-25 \\
13 / 13 \\
\end{array}$ & $\begin{array}{c}050-21 \\
13 / 13 \\
\end{array}$ & $\begin{array}{c}082-39 \\
13 / 13 \\
\end{array}$ & $\begin{array}{c}16-92 \\
13 / 13 \\
\end{array}$ & $\begin{array}{l}<005 \\
0 / 13\end{array}$ & $\begin{array}{c}<010-013 \\
1 / 13\end{array}$ \\
\hline \multirow[t]{2}{*}{ Niagara $R$} & mean $\pm S E$ & $306 \pm 37$ & $58 \pm 005$ & $030 \pm 003$ & $14 \pm 02$ & $14 \pm 02$ & $22 \pm 03$ & $55 \pm 10$ & & \\
\hline & $\begin{array}{l}\min -\max \\
\text { Detection } \\
\text { frequency }\end{array}$ & $\begin{array}{c}104-725 \\
13 / 13 \\
\end{array}$ & $\begin{array}{c}023-11 \\
13 / 13 \\
\end{array}$ & $\begin{array}{c}012.067 \\
13 / 13 \\
\end{array}$ & $\begin{array}{c}048-31 \\
13 / 13 \\
\end{array}$ & $\begin{array}{c}049-30 \\
13 / 13 \\
\end{array}$ & $\begin{array}{c}085-45 \\
13 / 13 \\
\end{array}$ & $\begin{array}{c}<010-161 \\
12 / 13 \\
\end{array}$ & $\begin{array}{c}<005-022 \\
6 / 13\end{array}$ & $\begin{array}{l}<010 \\
1 / 13 \\
\end{array}$ \\
\hline \multirow[t]{2}{*}{ Hamiton $\mathrm{Hbr}$} & mean $\pm S E$ & $301 \pm 27$ & $076 \pm 022$ & $036 \pm 008$ & $18 \pm 03$ & $16 \pm 02$ & $30 \pm 04$ & $81 \pm 10$ & & \\
\hline & $\begin{array}{l}\min -\max \\
\text { Detection } \\
\text { frequency }\end{array}$ & $\begin{array}{c}163-465 \\
13 / 13 \\
\end{array}$ & $\begin{array}{c}<010-35 \\
11 / 13 \\
\end{array}$ & $\begin{array}{c}<010-11 \\
11 / 13 \\
\end{array}$ & $\begin{array}{c}046 \cdot 43 \\
13 / 13 \\
\end{array}$ & $\begin{array}{c}045-34 \\
13 / 13 \\
\end{array}$ & $\begin{array}{c}12-54 \\
13 / 13 \\
\end{array}$ & $\begin{array}{c}31-156 \\
13 / 13 \\
\end{array}$ & $\begin{array}{l}<005 \\
7 / 13 \\
\end{array}$ & $\begin{array}{c}<010-037 \\
5 / 13\end{array}$ \\
\hline \multirow[t]{2}{*}{ Toronto $\mathrm{Hbr}$} & mean $\pm S E$ & $560 \pm 60$ & $18 \pm 03$ & $079 \pm 008$ & $28 \pm 02$ & $25 \pm 02$ & $49 \pm 04$ & $128 \pm 13$ & $003 \pm 001$ & $004 \pm 001$ \\
\hline & $\begin{array}{l}\min -\max \\
\text { Detection } \\
\text { frequency }\end{array}$ & $\begin{array}{c}328-992 \\
13 / 13 \\
\end{array}$ & $\begin{array}{c}059-49 \\
13 / 13 \\
\end{array}$ & $\begin{array}{c}045-14 \\
13 / 13 \\
\end{array}$ & $\begin{array}{c}15-44 \\
13 / 13 \\
\end{array}$ & $\begin{array}{r}15-37 \\
13 / 13 \\
\end{array}$ & $\begin{array}{c}27-72 \\
13 / 13 \\
\end{array}$ & $\begin{array}{c}59-212 \\
13 / 13 \\
\end{array}$ & $\begin{array}{c}<005-007 \\
8 / 13 \\
\end{array}$ & $\begin{array}{c}<010-013 \\
8 / 13\end{array}$ \\
\hline \multirow[t]{2}{*}{ Snake is } & mean $\pm \mathrm{SE}$ & $398 \pm 58$ & $091 \pm 017$ & $035 \pm 005$ & $13 \pm 02$ & $11 \pm 02$ & $21 \pm 03$ & $44 \pm 10$ & & \\
\hline & $\begin{array}{l}\min -\max \\
\text { Detection } \\
\text { frequency }\end{array}$ & $\begin{array}{c}196-950 \\
13 / 13 \\
\end{array}$ & $\begin{array}{c}<010-26 \\
12 / 13 \\
\end{array}$ & $\begin{array}{c}<010-093 \\
12 / 13\end{array}$ & $\begin{array}{c}042-33 \\
13 / 13 \\
\end{array}$ & $\begin{array}{c}034-28 \\
13 / 13 \\
\end{array}$ & $\begin{array}{c}061-53 \\
13 / 13 \\
\end{array}$ & $\begin{array}{c}085-154 \\
13 / 13 \\
\end{array}$ & $\begin{array}{c}<005-014 \\
1 / 13\end{array}$ & $\begin{array}{l}<010 \\
0 / 13 \\
\end{array}$ \\
\hline \multirow[t]{2}{*}{ Strachan Is } & mean $\pm \mathrm{SE}$ & $403 \pm 39$ & $12 \pm 03$ & $059 \pm 018$ & $31 \pm 10$ & $25 \pm 06$ & $35 \pm 06$ & $76 \pm 11$ & & 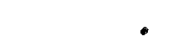 \\
\hline & $\begin{array}{l}\text { mın - max } \\
\text { Detection } \\
\text { frequency }\end{array}$ & $\begin{array}{c}195-762 \\
13 / 13\end{array}$ & $\begin{array}{c}<010-40 \\
12 / 13\end{array}$ & $\begin{array}{c}<010 \cdot 26 \\
12 / 13\end{array}$ & $\begin{array}{c}085-143 \\
13 / 13\end{array}$ & $080-98$ & $14-93$ & $16-162$ & $\begin{array}{c}<005-12 \\
6 / 13\end{array}$ & $\begin{array}{c}<010-069 \\
2 / 13\end{array}$ \\
\hline
\end{tabular}




\section{Appendix D}

Concentrations (ng/g ww) of detectable PFSAs, PFCAs and PFOSA in herring gull egg pools collected between 1990 and 2010 from 7 colonies in the Great Lakes.

Colony

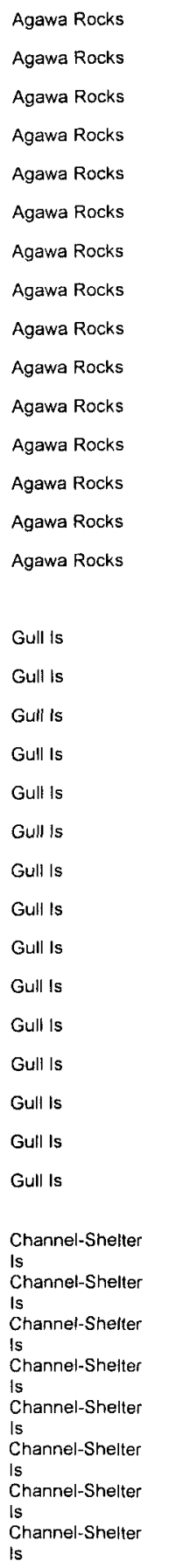

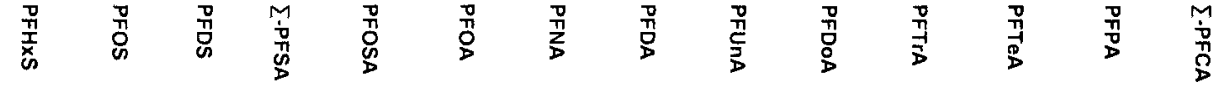

Year

$\begin{array}{lllllllllllllll}1990 & 005 & 1561 & 25 & 159 & <0005 & 009 & 17 & 24 & 42 & 15 & 34 & 045 & <005 & 137 \\ 1997 & 018 & 1611 & 67 & 168 & 020 & 013 & 42 & 34 & 59 & 21 & 76 & 132 & 057 & 252 \\ 1998 & 036 & 2103 & 36 & 214 & 046 & 044 & 73 & 94 & 196 & 83 & 207 & 335 & 171 & 709 \\ 1999 & 066 & 3150 & 35 & 319 & 056 & 036 & 52 & 55 & 118 & 66 & 177 & 432 & 228 & 538 \\ 2000 & 005 & 1275 & 30 & 131 & 021 & 061 & 87 & 66 & 152 & 55 & 167 & 231 & 132 & 570 \\ 2001 & 052 & 2823 & 44 & 287 & 031 & 042 & 53 & 64 & 118 & 54 & 129 & 390 & 234 & 484 \\ 2002 & 036 & 1601 & 31 & 164 & <0005 & 016 & 110 & 96 & 194 & 66 & 79 & 250 & 172 & 588 \\ 2003 & 033 & 1269 & 18 & 129 & 011 & 035 & 55 & 54 & 120 & 50 & 159 & 330 & 273 & 502 \\ 2004 & 144 & 829 & 36 & 88 & <0005 & 191 & 225 & 144 & 393 & 98 & 222 & 613 & 440 & 1206 \\ 2005 & 027 & 1213 & 13 & 123 & 013 & 059 & 153 & 104 & 273 & 87 & 253 & 376 & 252 & 937 \\ 2006 & 049 & 1263 & 14 & 128 & 006 & 085 & 125 & 114 & 247 & 100 & 296 & 509 & 303 & 972 \\ 2007 & <005 & 878 & 09 & 89 & <0005 & 002 & 84 & 79 & 186 & 62 & 170 & 237 & 071 & 611 \\ 2008 & <005 & 831 & 07 & 84 & <0005 & <005 & 66 & 53 & 132 & 47 & 102 & 140 & 046 & 419 \\ 2009 & 005 & 1183 & 12 & 120 & <0005 & 015 & 93 & 83 & 194 & 71 & 169 & 289 & 123 & 653 \\ 2010 & 010 & 1408 & 11 & 142 & <0005 & 046 & 141 & 123 & 248 & 93 & 202 & 289 & 100 & 850\end{array}$

$1990 \quad 034 \quad 3176 \quad 64 \quad 324$

$\begin{array}{lllll}1997 & 066 & 2933 & 29 & 297\end{array}$

$\begin{array}{lllll}1998 & 074 & 2289 & 51 & 235\end{array}$

$\begin{array}{llllllllll}048 & 044 & 218 & 579 & 693 & 366 & 725 & 278 & 128 & 311\end{array}$

$1999 \quad 078 \quad 3467 \quad 24 \quad 350$

$029 \quad 133 \quad 552$

877

$071 \quad 058 \quad 336$

800

$980 \quad 517$

$\begin{array}{lllll}2000 & 050 & 2742 & 46 & 279\end{array}$

$076 \quad 043 \quad 236$

$497 \quad 622 \quad 445$

$2001 \quad 035 \quad 2531 \quad 25 \quad 256$

$084 \quad 115$

$\begin{array}{lllll}2002 & 025 & 1014 & 26 & 104\end{array}$

059003

$\begin{array}{lllll}2003 & 067 & 3225 & 22 & 325\end{array}$

$<0005 \quad 0$

$\begin{array}{lllll}2004 & 182 & 2422 & 61 & 250\end{array}$

025015

$\begin{array}{lllll}2005 & 002 & 2355 & 39 & 239\end{array}$

$021 \quad 034 \quad 321$

$\begin{array}{lllll}2006 & 044 & 3746 & 24 & 377\end{array}$

$\begin{array}{lllll}2007 & 021 & 1705 & 31 & 174\end{array}$

$\begin{array}{lllll}2008 & 010 & 2087 & 23 & 211\end{array}$

$<0005$

$<0005<005$

$\begin{array}{lllll}2009 & 032 & 1977 & 15 & 199\end{array}$

$<0005$

$\begin{array}{lllll}2010 & 055 & 1121 & 13 & 114\end{array}$

$<0005$

$1990<005 \quad 2369$

$9 \quad 241 \quad 261$

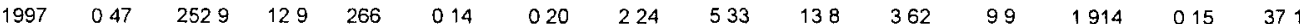

$\begin{array}{lllllllllllllll}1998 & 016 & 3509 & 330 & 384 & 015 & <005 & 196 & 814 & 190 & 485 & 92 & 0 & 044 & 437\end{array}$

$\begin{array}{lllllllllllllll}1999 & 088 & 3288 & 235 & 353 & <0005 & <005 & 230 & 681 & 168 & 549 & 117 & 3231 & 171 & 481\end{array}$

$\begin{array}{lllllllllllllll}2000 & 015 & 3423 & 451 & 387 & 015 & <005 & 234 & 764 & 197 & 538 & 137 & 3378 & 203 & 542\end{array}$

$\begin{array}{lllllllllllllll}2001 & 070 & 3766 & 199 & 397 & 052 & <005 & 249 & 992 & 231 & 669 & 128 & 3782 & 233 & 612\end{array}$

$\begin{array}{lllllllllllllll}2002 & <005 & 3475 & 184 & 366 & <0005 & 001 & 437 & 850 & 182 & 558 & 88 & 177 & 074 & 480\end{array}$

$\begin{array}{lllllllllllllll}2003 & 053 & 2812 & 162 & 298 & 049 & 028 & 919 & 982 & 248 & 843 & 219 & 4819 & 419 & 835\end{array}$ 


\begin{tabular}{|c|c|c|c|c|c|c|c|c|c|c|c|c|c|c|c|}
\hline $\begin{array}{l}\text { Channel-Shelter } \\
\text { Is }\end{array}$ & 2004 & 027 & 2255 & 109 & 237 & 021 & 016 & 274 & 845 & 157 & 534 & 86 & 2291 & 134 & 446 \\
\hline $\begin{array}{l}\text { Channel-Shelter } \\
\text { is } \\
\text { Channel-Shelter }\end{array}$ & 2005 & $<005$ & 2995 & 190 & 319 & 012 & $<005$ & 411 & 877 & 188 & 563 & 134 & 3121 & 181 & 556 \\
\hline Is & 2006 & 026 & 1483 & 103 & 159 & 006 & 006 & 086 & 614 & 111 & 507 & 119 & 3403 & 198 & 405 \\
\hline $\begin{array}{l}\text { Channel-Shelter } \\
\text { Is } \\
\text { Channel-Shelter }\end{array}$ & 2007 & $<005$ & 1694 & 54 & 175 & $<0005$ & $<005$ & 096 & 513 & 91 & 395 & 86 & 235 & 123 & 314 \\
\hline & 2008 & $<005$ & 1791 & 83 & 187 & $<0005$ & $<005$ & 086 & 666 & 124 & 516 & 70 & 26699 & 106 & 358 \\
\hline $\begin{array}{l}\text { Is } \\
\text { Channel-Shelter }\end{array}$ & 2009 & $<005$ & 1551 & 88 & 164 & $<0005$ & $<005$ & 095 & 732 & 134 & 507 & 80 & 24477 & 059 & 378 \\
\hline Is & 2010 & $<005$ & 1790 & 52 & 184 & $<0005$ & $<005$ & 565 & 795 & 270 & 472 & 80 & 17412 & 027 & 553 \\
\hline Chantry is & 1990 & $<005$ & 1264 & 46 & 131 & 039 & 047 & 295 & 228 & 427 & 137 & 274 & 045 & $<005$ & 145 \\
\hline Chantry is & 1997 & 059 & 2044 & 46 & 210 & 037 & 078 & 509 & 426 & 801 & 284 & 956 & 197 & 103 & 335 \\
\hline Chantry is & 1998 & 032 & 837 & 64 & 90 & 017 & 012 & 105 & 099 & 221 & 127 & 388 & 089 & 037 & 108 \\
\hline Chantry Is & 1999 & 061 & 2561 & 41 & 261 & 029 & 054 & 595 & 548 & 1015 & 469 & 1675 & 487 & 254 & 510 \\
\hline Chantry Is & 2000 & $<005$ & 2152 & 69 & 222 & 016 & 003 & 301 & 340 & 668 & 302 & 1292 & 397 & 273 & 358 \\
\hline Chantry is & 2001 & 016 & 1481 & 30 & 151 & 034 & 015 & 290 & 303 & 558 & 273 & 873 & 292 & 229 & 283 \\
\hline Chantry Is & 2002 & 015 & 1124 & 23 & 115 & $<0005$ & 028 & 245 & 254 & 538 & 193 & 600 & 084 & 006 & 195 \\
\hline Chantry is & 2003 & 078 & 1965 & 49 & 202 & 024 & 064 & 471 & 524 & 1029 & 480 & 2168 & 426 & 271 & 543 \\
\hline Chantry Is & 2004 & 021 & 800 & 43 & 85 & 010 & 047 & 204 & 229 & 411 & 273 & 741 & 235 & 147 & 229 \\
\hline Chantry is & 2005 & 037 & 1181 & 25 & 121 & 011 & 064 & 450 & 413 & 552 & 259 & 680 & 227 & 114 & 276 \\
\hline Chantry is & 2006 & 005 & 1316 & 32 & 135 & $<0005$ & 037 & 288 & 430 & 682 & 426 & 1327 & 413 & 235 & 384 \\
\hline Chantry is & 2007 & 004 & 1443 & 24 & 147 & $<0005$ & 019 & 205 & 358 & 511 & 355 & 832 & 220 & 072 & 257 \\
\hline Chantry is & 2008 & $<005$ & 606 & 10 & 62 & $<0005$ & 004 & 141 & 171 & 315 & 187 & 555 & 123 & 031 & 153 \\
\hline Chantry is & 2009 & 003 & 1105 & 25 & 113 & $<0005$ & 039 & 247 & 387 & 530 & 416 & 768 & 208 & 054 & 265 \\
\hline Chantry is & 2010 & 032 & 1806 & 23 & 183 & $<0005$ & 025 & 141 & 377 & 431 & 456 & 468 & 341 & 165 & 240 \\
\hline Fighting is & 1990 & 001 & 1906 & 250 & 216 & 063 & 015 & 039 & 116 & 317 & 150 & 410 & 042 & $<005$ & 109 \\
\hline Fightıng Is & 1997 & 153 & 3172 & 350 & 354 & 017 & $<005$ & 021 & 205 & 434 & 339 & 553 & 176 & 055 & 178 \\
\hline Fighting Is & 1998 & 035 & 1653 & 232 & 189 & 026 & $<005$ & 009 & 157 & 349 & 254 & 448 & 132 & $<005$ & 135 \\
\hline Fighting is & 1999 & 093 & $206 ?$ & 295 & 237 & 063 & 021 & 033 & 326 & 660 & 561 & 871 & 409 & 207 & 309 \\
\hline Fighting Is & 2000 & $<005$ & 2093 & 531 & 262 & 011 & $<005$ & 012 & 280 & 464 & 470 & 848 & 350 & 157 & 258 \\
\hline Fighting Is & 2001 & 053 & 2057 & 212 & 227 & 041 & $<005$ & 047 & 308 & 560 & 522 & 903 & 468 & 234 & 304 \\
\hline Fighting Is & 2002 & 030 & 2333 & 372 & 271 & $<0005$ & $<005$ & 024 & 373 & 569 & 625 & 568 & 177 & $<005$ & 234 \\
\hline Fightıng Is & 2003 & 029 & 2165 & 216 & 238 & 024 & $<005$ & 037 & 488 & 856 & 938 & 1584 & 598 & 409 & 491 \\
\hline Fightıng Is & 2004 & 044 & 1505 & 94 & 160 & 014 & $<005$ & 042 & 339 & 475 & 514 & 380 & 328 & 167 & 224 \\
\hline Fightıng Is & 2005 & 148 & 2328 & 287 & 263 & $<0005$ & 127 & 315 & 1041 & 1311 & 983 & 1492 & 1118 & 522 & 691 \\
\hline Fighting Is & 2006 & 004 & 2821 & 299 & 312 & 031 & 002 & 089 & 844 & 989 & 1149 & 1281 & 558 & 197 & 511 \\
\hline Fighting Is & 2007 & $<005$ & 2169 & 88 & 226 & $<0005$ & $<005$ & 064 & 694 & 1040 & 873 & 1184 & 562 & 243 & 466 \\
\hline Fighting Is & 2008 & $<005$ & 2174 & 90 & 226 & $<0005$ & $<005$ & 050 & 897 & 1185 & 1344 & 1231 & 666 & 280 & 565 \\
\hline Fighting is & 2010 & $<005$ & 1649 & 49 & 170 & $<0005$ & $<005$ & 118 & 683 & 1077 & 919 & 898 & 292 & 021 & 401 \\
\hline Niagara R & 1990 & 008 & 5259 & 61 & 532 & 034 & $<005$ & 265 & 685 & 972 & 319 & 822 & 103 & 022 & 319 \\
\hline Niagara R & 1997 & 092 & 4075 & 146 & 423 & 090 & 023 & 246 & 955 & 1892 & 726 & 1368 & 258 & 015 & 548 \\
\hline Niagara R & 1998 & 095 & 4126 & 120 & 426 & 084 & 006 & 303 & 928 & 1560 & 598 & 1025 & 219 & 062 & 470 \\
\hline Niagara R & 1999 & 183 & 5564 & 96 & 568 & 085 & 048 & 544 & 1392 & 1817 & 861 & 1467 & 417 & 141 & 669 \\
\hline Niagara R & 2000 & 020 & 7610 & 320 & 793 & 038 & $<005$ & 386 & 1049 & 1418 & 677 & 1910 & 495 & 272 & 621 \\
\hline Niagara R & 2001 & 143 & 5386 & 56 & 546 & 055 & 016 & 410 & 879 & 1252 & 516 & 1021 & 288 & 153 & 453 \\
\hline Niagara R & 2002 & 031 & 5140 & 69 & 521 & 068 & 005 & 369 & 892 & 1028 & 426 & 969 & 126 & 024 & 384 \\
\hline Niagara R & 2003 & 100 & 6616 & 93 & 672 & 038 & 012 & 466 & 1347 & 2304 & 1083 & 2356 & 431 & 193 & 819 \\
\hline Niagara R & 2004 & 035 & 2491 & 28 & 252 & 030 & 008 & 288 & 817 & 1114 & 415 & 1083 & 278 & 213 & 422 \\
\hline Niagara $R$ & 2005 & 016 & 7616 & 140 & 776 & 019 & $<005$ & 906 & 1800 & 2270 & 857 & 2675 & 479 & 333 & 932 \\
\hline Niagara R & 2006 & 047 & 2692 & 47 & 274 & 014 & 012 & 194 & 842 & 1237 & 702 & 1540 & 353 & 348 & 523 \\
\hline
\end{tabular}




\begin{tabular}{|c|c|c|c|c|c|c|c|c|c|c|c|c|c|c|c|}
\hline Niagara R & 2007 & $<005$ & 3249 & 40 & 329 & $<0005$ & $<005$ & 281 & 1363 & 1849 & 771 & 1638 & 387 & 256 & 654 \\
\hline Niagara R & 2008 & 008 & 4114 & 22 & 414 & $<0005$ & $<005$ & 612 & 1552 & 1311 & 528 & 1146 & 142 & 007 & 530 \\
\hline Niagara R & 2009 & $<005$ & 4184 & 35 & 422 & $<0005$ & $<005$ & 532 & 2117 & 2108 & 834 & 1491 & 249 & 094 & 742 \\
\hline Niagara R & 2010 & 037 & 5035 & 46 & 508 & $<0005$ & $<005$ & 597 & 2056 & 2245 & 1057 & 1873 & 413 & 130 & 837 \\
\hline Leslie St Spit & 1990 & 102 & 5241 & 693 & 594 & 132 & 038 & 182 & 641 & 660 & 832 & 451 & 273 & $<005$ & 308 \\
\hline Leslie St Spit & 1997 & 176 & 3934 & 297 & 425 & 048 & 111 & 488 & 779 & 1053 & 852 & 1120 & 529 & 003 & 493 \\
\hline Leslie St Spit & 1998 & 147 & 3588 & 269 & 387 & 084 & 048 & 318 & 726 & 774 & 852 & 744 & 609 & 070 & 414 \\
\hline Leshe St Spit & 1999 & 379 & 7591 & 244 & 787 & 170 & 164 & 1186 & 2214 & 2522 & 1602 & 1698 & 632 & 207 & 1023 \\
\hline Leslie St Spst & 2000 & 178 & 3897 & 160 & 407 & 094 & 075 & 507 & 802 & 1022 & 651 & 1020 & 307 & 034 & 442 \\
\hline Leslie St Spit & 2001 & 184 & 5249 & 211 & 548 & 113 & 136 & 570 & 1074 & 1475 & 1142 & 1380 & 613 & 267 & 666 \\
\hline Leslie St Spit & 2002 & 137 & 5484 & 106 & 560 & 076 & 043 & 344 & 730 & 953 & 691 & 720 & 370 & 049 & 390 \\
\hline Leslie St Spit & 2003 & 183 & 6172 & 166 & 636 & 047 & 082 & 419 & 966 & 1341 & 1269 & 1445 & 490 & 175 & 619 \\
\hline Leslie St Spt & 2004 & 620 & 7645 & 141 & 785 & 066 & 127 & 630 & 1091 & 2210 & 1196 & 1328 & 622 & 151 & 735 \\
\hline Lesle St Spt & 2005 & 161 & 9329 & 197 & 954 & 038 & 103 & 731 & 1451 & 1779 & 1474 & 1697 & 626 & 102 & 796 \\
\hline Leslie St Spt & 2006 & 234 & 8162 & 117 & 830 & 029 & 068 & 426 & 1379 & 1850 & 1719 & 2574 & 1258 & 465 & 974 \\
\hline Leslie St Spit & 2007 & 181 & 5456 & 89 & 556 & $<0005$ & 046 & 443 & 1131 & 1535 & 1294 & 1439 & 731 & 162 & 678 \\
\hline Lesilı St Spit & 2008 & 186 & 4842 & 76 & 494 & $<0005$ & 043 & 353 & 970 & 1249 & 1243 & 1383 & 928 & 256 & 642 \\
\hline Leslie St Spit & 2009 & 177 & 6885 & 95 & 700 & $<0005$ & 034 & 380 & 1176 & 1475 & 1754 & 1242 & 1552 & 464 & 808 \\
\hline Leslıe St Spıt & 2010 & 116 & 7894 & 54 & 796 & $<0005$ & 017 & 327 & 1140 & 1286 & 1174 & 1324 & 788 & 258 & 631 \\
\hline
\end{tabular}




\section{Appendix E}

Arithmetic mean concentrations (ng/g ww $\pm \mathrm{SE}$ ), range of concentrations and detection frequency of detectable PFSAs, PFCAs, and PFOSA in herring gull eggs collected in 2008 from 15 colonies across Canada.

\begin{tabular}{|c|c|c|c|c|c|c|c|c|c|c|c|c|c|c|c|}
\hline Colony & & PFHXS & PFOS & PFDS & PFOSA & PFH $\times A$ & PFHPA & PFOA & PFNA & PFDA & PFUnA & PFDOA & PFTIA & PFTEA & PFPA \\
\hline Florencia is & mean \pm SE & & $77 \pm 07$ & $013 \pm 001$ & $011 \pm 002$ & & & & & & $086 \pm 013$ & & $052 \pm 015$ & & \\
\hline & $\begin{array}{l}\min -\max \\
\text { Detection } \\
\text { frequency }\end{array}$ & $\begin{array}{l}<005 \\
0 / 40\end{array}$ & $\begin{array}{c}30-109 \\
\quad 10 / 10 \\
\end{array}$ & $\begin{array}{c}008.020 \\
10 / 10 \\
\end{array}$ & $\begin{array}{c}<0005-02 \\
8 / 100 \\
\end{array}$ & $\begin{array}{l}<010 \\
0 / 10 \\
\end{array}$ & $\begin{array}{l}<010 \\
0 \times 10 \\
\end{array}$ & $\begin{array}{c}<005-023 \\
3 / 10 \\
\end{array}$ & $\begin{array}{l}<010 \\
\quad 0110 \\
\end{array}$ & $\begin{array}{l}<010 \\
0 / 10 \\
\end{array}$ & $\begin{array}{c}02-15 \\
10 / 10 \\
\end{array}$ & $\begin{array}{l}<010 \\
0 / 10 \\
\end{array}$ & $\begin{array}{c}<010.15 \\
8 / 10\end{array}$ & $\begin{array}{c}<005-006 \\
\quad 1 / 10 \\
\end{array}$ & $\begin{array}{c}<005-012 \\
1 / 10\end{array}$ \\
\hline Mandarte is & mean $\pm \mathrm{SE}$ & & $228 \pm 36$ & $061 \pm 017$ & $009 \pm 003$ & & & $017 \pm 004$ & $014 \pm 005$ & $049 \pm 024$ & $095 \div 010$ & & $077 \pm 016$ & $067 \pm 037$ & \\
\hline & $\begin{array}{l}\min -\max \\
\text { Detection } \\
\text { frequency }\end{array}$ & $\begin{array}{c}<005-02 \\
2 / 110 \\
\end{array}$ & $\begin{array}{c}138-444 \\
10 / 10 \\
\end{array}$ & $\begin{array}{c}<005 \cdot 16 \\
7 / 10 \\
\end{array}$ & $\begin{array}{c}<0005-025 \\
7 / 10 \\
\end{array}$ & $\begin{array}{l}<010 \\
0 / 10 \\
\end{array}$ & $\begin{array}{l}<010 \\
0 / 10\end{array}$ & $\begin{array}{c}<005-037 \\
\quad 7 / 10 \\
\end{array}$ & $\begin{array}{c}<010-039 \\
\quad 7 / 10 \\
\end{array}$ & $\begin{array}{c}<010-24 \\
7 / 10 \\
\end{array}$ & $\begin{array}{c}047-132 \\
10 / 10 \\
\end{array}$ & $\begin{array}{c}<010-45 \\
2 / 10 \\
\end{array}$ & $\begin{array}{c}<010.13 \\
8 / 10 \\
\end{array}$ & $\begin{array}{c}<005-30 \\
6 / 10 \\
\end{array}$ & $\begin{array}{l}<005 \\
0,10 \\
\end{array}$ \\
\hline Dalemead & mean $\neq \mathrm{SE}$ & $19 \pm 10$ & $659 \pm 156$ & $67 \pm 19$ & & & & $041 \pm 010$ & $041 \pm 008$ & $24 \pm 059$ & $26 \pm 0.6$ & $53 \pm 15$ & $35 \pm 08$ & $38 \pm 03$ & \\
\hline Reservoir & $\begin{array}{l}\min -\max \\
\text { Detection } \\
\text { frequency }\end{array}$ & $\begin{array}{c}005 \cdot 108 \\
10 / 10 \\
\end{array}$ & $\begin{array}{c}152 \cdot 167 \\
10 / 10 \\
\end{array}$ & $\begin{array}{c}039-182 \\
10 / 10 \\
\end{array}$ & $\begin{array}{c}<0005-025 \\
4 / 10 \\
\end{array}$ & $\begin{array}{l}<010 \\
0 / 10 \\
\end{array}$ & $\begin{array}{l}<010 \\
0 / 10\end{array}$ & $\begin{array}{c}005-081 \\
10110 \\
\end{array}$ & $\begin{array}{c}014-090 \\
10 / 10 \\
\end{array}$ & $\begin{array}{c}019-56 \\
10110 \\
\end{array}$ & $\begin{array}{c}036-60 \\
10 / 10 \\
\end{array}$ & $\begin{array}{c}033.149 \\
10 / 10 \\
\end{array}$ & $\begin{array}{c}026-81 \\
10 / 10 \\
\end{array}$ & $\begin{array}{c}<005 \quad 105 \\
\quad 8 / 10 \\
\end{array}$ & $\begin{array}{c}<005-043 \\
1 / 10 \\
\end{array}$ \\
\hline Pipestone Rocks & mean $\pm \mathrm{SE}$ & & $124 \pm 17$ & $68 \pm 22$ & & & & & $45 \pm 09$ & $49 \pm 10$ & $44 \pm 07$ & $28 \pm 20$ & $36 \pm 05$ & & \\
\hline & $\begin{array}{l}\min -\max \\
\text { Detection } \\
\text { frequency }\end{array}$ & $\begin{array}{c}<005-006 \\
\quad 1 / 10 \\
\end{array}$ & $\begin{array}{c}75-223 \\
10 / 10 \\
\end{array}$ & $\begin{array}{c}12-201 \\
10 / 10 \\
\end{array}$ & $\begin{array}{c}<0005.011 \\
4 / 110 \\
\end{array}$ & $\begin{array}{l}<010 \\
0 / 10 \\
\end{array}$ & $\begin{array}{l}<010 \\
0 / 10 \\
\end{array}$ & $\begin{array}{l}<005 \\
0 / 10 \\
\end{array}$ & $\begin{array}{c}12.105 \\
\quad 80 / 10 \\
\end{array}$ & $\begin{array}{c}24-117 \\
10 / 10 \\
\end{array}$ & $\begin{array}{c}18-76 \\
10 / 10 \\
\end{array}$ & $\begin{array}{c}<010-205 \\
\quad 8 / 10 \\
\end{array}$ & $\begin{array}{c}10.65 \\
01110 \\
\end{array}$ & $\begin{array}{c}<005-63 \\
4 / 110 \\
\end{array}$ & $\begin{array}{l}<005 \\
0,10\end{array}$ \\
\hline Silver Islet & mean $\pm \mathrm{SE}$ & & $629 \pm 64$ & $048 \pm 008$ & $005 \pm 001$ & & & & $20 \pm 02$ & $29 \pm 02$ & $50 \pm 04$ & $18 \pm 02$ & $72 \pm 08$ & $022 \pm 013$ & \\
\hline & $\begin{array}{l}\min -\max \\
\text { Detection } \\
\text { frequency }\end{array}$ & $\begin{array}{l}<005 \\
0 / 10 \\
\end{array}$ & $\begin{array}{c}347-908 \\
10 / 10 \\
\end{array}$ & $\begin{array}{c}018-090 \\
10 / 10 \\
\end{array}$ & $\begin{array}{c}<0005-009 \\
8 / 10 \\
\end{array}$ & $\begin{array}{l}<010 \\
0 / 10\end{array}$ & $\begin{array}{l}<010 \\
0 / 10 \\
\end{array}$ & $\begin{array}{c}<005-007 \\
3 / 10\end{array}$ & $\begin{array}{c}093.26 \\
10 / 10 \\
\end{array}$ & $\begin{array}{c}16.37 \\
10 / 10 \\
\end{array}$ & $\begin{array}{c}24-66 \\
10110 \\
\end{array}$ & $\begin{array}{c}05 \cdot 27 \\
10 / 10 \\
\end{array}$ & $\begin{array}{c}18-98 \\
10 / 10 \\
\end{array}$ & $\begin{array}{c}<005-13 \\
6 / 10 \\
\end{array}$ & $\begin{array}{l}<005 \\
0 / 10 \\
\end{array}$ \\
\hline Big Chicken Is & mean $\pm \mathrm{SE}$ & & $299 \pm 61$ & $84 \pm 09$ & $018 \pm 010$ & & & & $12 \pm 08$ & $144 \pm 49$ & $151 \pm 40$ & $111 \pm 29$ & $101 \pm 18$ & $13 \pm 0.6$ & \\
\hline & $\begin{array}{l}\text { mir - max } \\
\text { Detection } \\
\text { frequency }\end{array}$ & $\begin{array}{c}<005-023 \\
1110 \\
\end{array}$ & $\begin{array}{c}129-811 \\
10 / 10 \\
\end{array}$ & $\begin{array}{c}39 \cdot 132 \\
10 / 10 \\
\end{array}$ & $\begin{array}{c}<0005-10 \\
\quad 9 / 10 \\
\end{array}$ & $\begin{array}{l}<010 \\
0 / 10 \\
\end{array}$ & $\begin{array}{l}<010 \\
0 / 10 \\
\end{array}$ & $\begin{array}{l}<005 \\
0 / 10 \\
\end{array}$ & $\begin{array}{c}<010-87 \\
9 / 10 \\
\end{array}$ & $\begin{array}{c}39-578 \\
10 / 10 \\
\end{array}$ & $\begin{array}{c}44-498 \\
\quad 10110 \\
\end{array}$ & $\begin{array}{c}18.350 \\
10 / 10 \\
\end{array}$ & $\begin{array}{c}13-215 \\
10 / 10 \\
\end{array}$ & $\begin{array}{c}<005-56 \\
6 / 110 \\
\end{array}$ & $\begin{array}{l}<005 \\
0 / 10 \\
\end{array}$ \\
\hline Toronto $\mathrm{Hbr}$ & mean $\pm \mathrm{SE}$ & $15 \pm 02$ & $477 \pm 53$ & $74 \pm 12$ & $029 \pm 005$ & & & & $31 \pm 05$ & $117 \pm 12$ & $135 \pm 16$ & $161 \pm 24$ & $181 \pm 18$ & $104 \pm 21$ & $052 \pm 016$ \\
\hline & $\begin{array}{l}\min -\max \\
\text { Detection } \\
\text { frequency }\end{array}$ & $\begin{array}{c}055-28 \\
10110 \\
\end{array}$ & $\begin{array}{c}274-712 \\
10 / 10 \\
\end{array}$ & $\begin{array}{c}18.154 \\
10110 \\
\end{array}$ & $\begin{array}{c}008-051 \\
10 / 10 \\
\end{array}$ & $\begin{array}{l}<010 \\
0 / 10\end{array}$ & $\begin{array}{l}<010 \\
0 / 10 \\
\end{array}$ & $\begin{array}{c}<005-050 \\
5 / 10 \\
\end{array}$ & $\begin{array}{c}092-61 \\
10 / 10 \\
\end{array}$ & $\begin{array}{c}68 \cdot 167 \\
10 / 10 \\
\end{array}$ & $\begin{array}{c}70-216 \\
10 / 10 \\
\end{array}$ & $\begin{array}{c}44-304 \\
10 / 10 \\
\end{array}$ & $\begin{array}{c}68-245 \\
10 / 10 \\
\end{array}$ & $\begin{array}{c}077-216 \\
10 / 10 \\
\end{array}$ & $\begin{array}{c}<005-12 \\
8 / 10 \\
\end{array}$ \\
\hline Ife Deslauniers & mean $\pm \mathrm{SE}$ & $035 \pm 011$ & $286 \pm 39$ & $126 \pm 22$ & & & & $027 \pm 007$ & $32 \pm 047$ & $113 \pm 22$ & $216 \pm 36$ & $157 \pm 25$ & $227 \pm 36$ & $65 \pm 11$ & \\
\hline HG & $\begin{array}{l}\min -\max \\
\text { Detection } \\
\text { Irequency } \\
\end{array}$ & $\begin{array}{c}<005-10 \\
7 / 10\end{array}$ & $\begin{array}{c}126-478 \\
10 / 10 \\
\end{array}$ & $\begin{array}{c}20-283 \\
10 / 10 \\
\end{array}$ & $\begin{array}{c}<0005-032 \\
5 / 10 \\
\end{array}$ & $\begin{array}{l}<10 \\
0 / 10 \\
\end{array}$ & $\begin{array}{l}<010 \\
0,10\end{array}$ & $\begin{array}{c}005-061 \\
10 / 10 \\
\end{array}$ & $\begin{array}{c}093-55 \\
10 / 10 \\
\end{array}$ & $\begin{array}{c}38-263 \\
\quad 10110 \\
\end{array}$ & $\begin{array}{c}72.446 \\
10 / 10 \\
\end{array}$ & $\begin{array}{c}46-278 \\
10 / 10 \\
\end{array}$ & $\begin{array}{c}64.438 \\
10 / 10 \\
\end{array}$ & $\begin{array}{c}13.132 \\
10110 \\
\end{array}$ & $\begin{array}{c}<005.29 \\
5 / 10 \\
\end{array}$ \\
\hline Me Deslauriers & mean $\neq \mathrm{SE}$ & & $619 \pm 162$ & $24 \pm 10$ & & & & $11 \pm 02$ & $17 \pm 01$ & $19 \pm 03$ & $35 \pm 06$ & $48 \pm 14$ & $84 \pm 20$ & $66 \pm 23$ & $14 \pm 06$ \\
\hline RBG & $\begin{array}{l}\min \text { - } \max \\
\text { Detection } \\
\text { frequency }\end{array}$ & $\begin{array}{c}<005-11 \\
3 / 10 \\
\end{array}$ & $\begin{array}{c}193-172 \\
10 / 10 \\
\end{array}$ & $\begin{array}{c}011.99 \\
10 / 10 \\
\end{array}$ & $<0005$ & $<010$ & $<010$ & $\begin{array}{c}047-25 \\
10 / 10 \\
\end{array}$ & 10.26 & 05.36 & $\begin{array}{c}14.85 \\
10 / 10 \\
\end{array}$ & $\begin{array}{c}14-168 \\
10 / 10 \\
\end{array}$ & $\begin{array}{c}25-250 \\
10110 \\
\end{array}$ & $\begin{array}{c}05-255 \\
10 / 10 \\
\end{array}$ & $\begin{array}{c}<005.63 \\
7110\end{array}$ \\
\hline
\end{tabular}




\begin{tabular}{|c|c|c|c|c|c|c|c|c|c|c|c|c|c|c|c|}
\hline \multirow[t]{2}{*}{ Ile Bellechasse } & \multicolumn{2}{|l|}{ mean $\pm \mathrm{SE}$} & \multirow{2}{*}{$\begin{array}{c}470 \pm 194 \\
73 \cdot 209 \\
10 / 10\end{array}$} & \multirow{2}{*}{$\begin{array}{c}21 \pm 12 \\
<005-118 \\
7 / 10\end{array}$} & \multirow[b]{2}{*}{$\begin{array}{c}<0005 \\
0 / 10\end{array}$} & \multirow[b]{2}{*}{$\begin{array}{l}<010 \\
0 / 10 \\
\end{array}$} & \multirow[b]{2}{*}{$\begin{array}{l}<010 \\
0 / 10 \\
\end{array}$} & \multirow[b]{2}{*}{$\begin{array}{c}<005.017 \\
1 / 10 \\
\end{array}$} & \multirow{2}{*}{$\begin{array}{c}11 \pm 05 \\
<010-486 \\
9 / 10\end{array}$} & \multirow{2}{*}{$\begin{array}{c}22 \pm 16 \\
<010-163 \\
8 / 10\end{array}$} & \multirow{2}{*}{$\begin{array}{c}39 \pm 20 \\
07-215 \\
10 / 10 \\
\end{array}$} & \multirow{2}{*}{$\begin{array}{c}23 \pm 10 \\
04-110 \\
10 / 10 \\
\end{array}$} & \multirow{2}{*}{$\begin{array}{c}49 \pm 15 \\
17 \cdot 176 \\
10 / 10 \\
\end{array}$} & \multirow{2}{*}{$\begin{array}{c}087 \pm 042 \\
<005 \cdot 38 \\
6 / 10\end{array}$} & \multirow[b]{2}{*}{$\begin{array}{c}<005-10 \\
3 / 10 \\
\end{array}$} \\
\hline & $\begin{array}{l}\min \max \\
\text { Detection } \\
\text { frequency }\end{array}$ & $\begin{array}{l}<005 \\
0 / 10\end{array}$ & & & & & & & & & & & & & \\
\hline \multirow[t]{2}{*}{ He du Corossol } & mean $\pm \mathrm{SE}$ & & $212 \pm 25$ & $034 \pm 011$ & $011 \pm 004$ & & & $116 \pm 94$ & $044 \pm 0.08$ & $14 \pm 02$ & $104 \pm 17$ & $24 \pm 05$ & $92 \pm 14$ & $13 \pm 06$ & \\
\hline & $\begin{array}{l}\min -\max \\
\text { Detection } \\
\text { frequency }\end{array}$ & $\begin{array}{l}<005 \\
0 / 10\end{array}$ & $\begin{array}{c}115.337 \\
10 / 10 \\
\end{array}$ & $\begin{array}{c}<005.091 \\
6 / 10\end{array}$ & $\begin{array}{c}<0005-032 \\
\quad 6 / 10 \\
\end{array}$ & $\begin{array}{c}<010-431 \\
\quad 4 / 10 \\
\end{array}$ & $\begin{array}{c}<010-303 \\
\quad 4 / 10 \\
\end{array}$ & $\begin{array}{c}<005-829 \\
\quad 6 / 10 \\
\end{array}$ & $\begin{array}{l}010-10 \\
10 / 10 \\
\end{array}$ & $\begin{array}{c}041-30 \\
10 / 10 \\
\end{array}$ & $\begin{array}{c}40.224 \\
10 / 10 \\
\end{array}$ & $\begin{array}{c}038-53 \\
10110 \\
\end{array}$ & $\begin{array}{c}40-167 \\
10 / 10 \\
\end{array}$ & $\begin{array}{c}<005-45 \\
7 / 10 \\
\end{array}$ & $\begin{array}{c}<005 \cdot 29 \\
3 / 10 \\
\end{array}$ \\
\hline \multirow[t]{2}{*}{ Kent is } & mean $\pm \mathrm{SE}$ & & $123 \pm 10$ & $021 \pm 007$ & & & & & $076 \pm 018$ & & $74 \pm 09$ & $18 \pm 05$ & $185 \pm 26$ & $13 \pm 04$ & \\
\hline & $\begin{array}{l}\min -\max \\
\text { Detection } \\
\text { frequency } \\
\end{array}$ & $\begin{array}{l}<005 \\
0 / 10 \\
\end{array}$ & $\begin{array}{c}74-179 \\
10 / 10 \\
\end{array}$ & $\begin{array}{c}<005-075 \\
9 / 10\end{array}$ & $\begin{array}{c}<0005.009 \\
3 / 10\end{array}$ & $\begin{array}{l}<010 \\
0 / 10\end{array}$ & $\begin{array}{l}<010 \\
0 / 10\end{array}$ & $\begin{array}{c}<005-020 \\
2 / 10\end{array}$ & $\begin{array}{r}010-18 \\
-10 / 10 \\
\end{array}$ & $\begin{array}{c}<010-047 \\
2 / 10 \\
\end{array}$ & $\begin{array}{c}44 \cdot 134 \\
10 / 10 \\
\end{array}$ & $\begin{array}{l}<-47 \\
9 / 10\end{array}$ & $\begin{array}{c}77-344 \\
10 / 10\end{array}$ & $\begin{array}{c}<005-33 \\
\quad 6 / 10 \\
\end{array}$ & $\begin{array}{c}<005-20 \\
5 / 10\end{array}$ \\
\hline \multirow[t]{2}{*}{ Manawagonish is } & mean $\pm \mathrm{SE}$ & & $279 \pm 52$ & $10 \pm 02$ & $015 \pm 005$ & & & $12 \pm 02$ & $29 \pm 04$ & $19 \pm 04$ & $33 \pm 12$ & $11 \pm 04$ & $34 \pm 12$ & $033 \pm 015$ & \\
\hline & $\begin{array}{l}\min -\max \\
\text { Detection } \\
\text { frequency } \\
\end{array}$ & $\begin{array}{c}<005-070 \\
5 / 10\end{array}$ & $\begin{array}{c}147-664 \\
10 / 10 \\
\end{array}$ & $\begin{array}{c}036-29 \\
10 / 10 \\
\end{array}$ & $\begin{array}{c}<0005-046 \\
6 / 10 \\
\end{array}$ & $\begin{array}{l}<010 \\
0 / 10 \\
\end{array}$ & $\begin{array}{l}<010 \\
0 / 10 \\
\end{array}$ & $\begin{array}{c}<005-21 \\
9 / 10 \\
\end{array}$ & $\begin{array}{c}062-51 \\
-10110 \\
\end{array}$ & $\begin{array}{c}009-50 \\
10 / 10 \\
\end{array}$ & $\begin{array}{c}12 \cdot 139 \\
10 / 10\end{array}$ & $\begin{array}{c}<010.46 \\
9 / 10 \\
\end{array}$ & $\begin{array}{r}10-134 \\
10 / 10 \\
\end{array}$ & $\begin{array}{c}<005-12 \\
7 / 10 \\
\end{array}$ & $\begin{array}{c}<005 \cdot 073 \\
2110 \\
\end{array}$ \\
\hline \multirow[t]{2}{*}{ Sable is } & mean $\pm \mathrm{SE}$ & $017 \pm 006$ & $101 \pm 38$ & $16 \pm 04$ & $009 \pm 003$ & & & & $31 \pm-12$ & $52 \pm-18$ & $333 \pm 81$ & $82 \pm 17$ & $279 \pm 39$ & $20 \pm 04$ & $18 \pm 03$ \\
\hline & $\begin{array}{l}\min -\max \\
\text { Detection } \\
\text { frequency }\end{array}$ & $\begin{array}{c}<005 \cdot 052 \\
8 / 10\end{array}$ & $\begin{array}{c}244-377 \\
10 / 10 \\
\end{array}$ & $\begin{array}{c}052.40 \\
10 / 10 \\
\end{array}$ & $\begin{array}{c}<0005-021 \\
6 / 10 \\
\end{array}$ & $\begin{array}{l}<010 \\
0 / 10\end{array}$ & $\begin{array}{l}<010 \\
0 / 110 \\
\end{array}$ & $\begin{array}{c}0005-009 \\
2110 \\
\end{array}$ & $\begin{array}{c}<010.119 \\
\quad 9 / 10 \\
\end{array}$ & $\begin{array}{c}095-187 \\
10 / 10 \\
\end{array}$ & $\begin{array}{c}94 \cdot 875 \\
10 / 10 \\
\end{array}$ & $\begin{array}{c}21-188 \\
-10 / 10 \\
\end{array}$ & $\begin{array}{c}120-484 \\
\quad 10 / 40 \\
\end{array}$ & $\begin{array}{c}005-38 \\
10410 \\
\end{array}$ & $\begin{array}{c}041-40 \\
10 / 10 \\
\end{array}$ \\
\hline \multirow[t]{2}{*}{ Gull Is } & mean $\pm \mathrm{SE}$ & $023 \pm 013$ & $297 \pm 78$ & $040 \pm 006$ & & & & $035 \pm 013$ & $18 \pm 06$ & $18 \pm 07$ & $54 \pm 38$ & $21 \pm 155$ & $70 \pm 51$ & & \\
\hline & $\begin{array}{l}\text { minr - max } \\
\text { Detection } \\
\text { frequency }\end{array}$ & $\begin{array}{c}<005-10 \\
6 / 10\end{array}$ & $\begin{array}{c}113.870 \\
10 / 10 \\
\end{array}$ & $\begin{array}{c}020-068 \\
10 / 10 \\
\end{array}$ & $\begin{array}{c}<0005-009 \\
2 / 10\end{array}$ & $\begin{array}{l}<010 \\
0 / 10 \\
\end{array}$ & $\begin{array}{l}<010 \\
0 / 10\end{array}$ & $\begin{array}{c}005-12 \\
10 / 10 \\
\end{array}$ & $\begin{array}{c}029-58 \\
10 / 10 \\
\end{array}$ & $\begin{array}{c}013-71 \\
10 / 10 \\
\end{array}$ & $\begin{array}{c}092 \cdot 337 \\
10110 \\
\end{array}$ & $\begin{array}{c}<010-156 \\
6 / 10 \\
\end{array}$ & $\begin{array}{c}026-526 \\
10 / 10 \\
\end{array}$ & $\begin{array}{c}<005-61 \\
4 / 10 \\
\end{array}$ & $\begin{array}{c}<005-34 \\
2 / 10 \\
\end{array}$ \\
\hline
\end{tabular}

